\title{
SEISMOTECTONICS OF A LOCKED SUBDUCTION PATCH: THE SOUTHERN HIKURANGI MARGIN
}

By

Dominic Alessandro David Evanzia

\author{
A Thesis Submitted to \\ Victoria University of Wellington \\ in Fulfillment of the Requirements \\ for the Degree of \\ Doctor of Philosophy in Geophysics
}

Victoria University of Wellington

2018 

"Reason is a choice. Wishes and whims are not facts, nor are they a means to discovering them. Reason is our only way of grasping reality - it's our basic tool of survival. We are free to evade the effort of thinking, to reject reason, but we are not free to avoid the penalty of the abyss we refuse to see.

-Terry Goodkind, Faith of the Fallen 



\begin{abstract}
Subduction zones produce the largest earthquakes on the planet, where rupture along the plate interface can result in the release of stress over large areas, with up to tens of meters of slip extending from below the surface to the trench. The regional stress field is a primary control on the faulting process, ergo understanding the regional stress field leads to a better understanding of the current and future faulting in the area.

Abundant new seismic and continuous Global Positioning System (cGPS) data in the southern North and northern South Island, New Zealand, make it possible to characterize stress and strain parameters throughout the southern Hikurangi subduction zone. Stress orientations calculated within the subducting plate, the overriding Australian plate, and due to gravitational forces reveal that stress throughout the subducting system varies across the southern North Island. Margin parallel motion is being accommodated by shear deformation west of the Wairarapa fault, whereas margin perpendicular motion is being accommodated east of the Wairarapa fault.

Stress parameters within the double Benioff zone (DBZ) were characterized in term of two bands of seismicity. In the deep region of the DBZ, inversion the upper band of seismicity shows down-dip tension, while the lower band shows compression. Tension in the upper band and compression in the lower band is consistent with bending stresses. In the shallow region of the DBZ, the inversion of both the upper and lower bands seismicity showed tension; this is indicative of slab pull.

Shear-wave splitting of stacked waveforms of local earthquakes recorded on 291 three-component stations showed an average fast azimuth of N-S to NNE-SSW, west of the Wairarapa fault. A fast azimuth orientation of N-S to NNE-SSW is sub-parallel to the local major faults. This indicates that the observed anisotropy west of the Wairarapa fault is structurally derived. East of the Wairarapa fault, within the Wairarapa Basin, the average fast azimuth orientation is NNW-SSE. Because the fast azimuth orientation showed no dependence on station-earthquake distance, depth, or back azimuth and is perpendicular to major local faults; it has been interpreted as being reflective of the SHmax orientation.

cGPS daily solutions for long-term and inter-slow slip events (inter-SSE) time periods show distinctly differing regions of shear strain rate in the southern North Island and northern South Island. Compression and positive (clockwise) rotation in the southern North and northern South Island was observed using both datasets. Inter-SSE time periods resulted in lower magnitude strain parameters than those calculated dur-
\end{abstract}


ing time periods including SSEs. These datasets shows that strain parameters change on time scales of SSEs ( $<10$ years). 


\section{Acknowledgments}

First, I'd like to thank my primary supervisor Martha Savage, for her support and guidance throughout my Ph.D. at Victoria University in Wellington. I'd also like to thank my two secondary advisors Tim Stern and Simon Lamb for providing excellent advice with research and writing.

I'd like to convey a special thanks to my office mates Calum Chamberlain, Emily Warren-Smith, Cecile Massiot, and Konstantinos Michailos, who were always more than willing to help me with a multitude of research activity ranging from coding to figure making. Thank you to past and present SGEES graduate students: Lauren Vargo, Chet Hopp, Kenny Graham, Laura-May Baratin, Jamey Stutz, Katelyn Johnson, Katie Jacobs, Hubert Zal, Steve Sewell, Dan Lowry, Laurine van Haastrecht, Hannah Chorley, Ross Whitmore, Jurgen Osterle, Marcel Mizera, Jesse-Lee Dimech, Konrad Weaver, Lucie Capova, Francesco Civilini, and all the others, for the good times that have been had over the past years. I am grateful for others within and external to the SGEES department such as John Townend, Richard Arnold, Rupert Sutherland, Huw Horgan, Euan Smith, Adrian Benson, Alec Beliaev, Miranda Voke, Monika Hanson, Emma Fisher, and Patricia Stein, for adding me with research, providing me with valuable insight and expertise in all matters pertaining to geophysics, and general help with my scholarship.

To my friends back home, Jake, Ashley, Erik, Jamie, Michael, Jill, Tejal, Sean, Brenna, and Sarah, I can not describe the joy that your letters and gifts brought me over the years. Last, but certainly not least, I'd like to thank all of my family for encouraging me to follow my passions and for always supporting me wherever life took me. 


\section{Contents}

1 Introduction $\quad 7$

1.1 Context and Reasoning . . . . . . . . . . . . . . . . 7

1.2 Thesis Format . . . . . . . . . . . . . . . . . . . . . 10

1.3 Tectonic Overview . . . . . . . . . . . . . . . . . . . . . . . 12

2 Theoretical Background $\quad 15$

2.1 Earthquake Location . . . . . . . . . . . . . . . . . . . . 15

2.1.1 Linearized Location _. . . . . . . . . . . . . . . . . . . 15

2.1.2 Non-Linear Location . . . . . . . . . . . . . . . . . . . . . . . 16

2.1.3 Double-Difference Location . . . . . . . . . . . . . . . . . 17

2.2 Focal Mechanisms and Stress Inversion $\ldots \ldots \ldots \ldots$

2.2.1 Focal Mechanisms . . . . . . . . . . . . . . . . 18

2.2 .2 Stress Inversion $\ldots \ldots \ldots$

2.3 Seismic Anisotropy . . . . . . . . . . . . . . . . . . . 21

2.4 Continuous Global Positioning System . . . . . . . . . . . . . . . . 21

2.4.1 GPS Reference Frame Transformation . . . . . . . . . . . . . . 22

3 Stress Orientations Throughout the Southern Hikurangi Margin 25

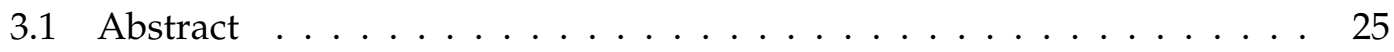

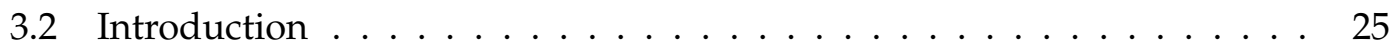

3.2 .1 Tectonic Setting . . . . . . . . . . . . . . . . . . 26

3.2.2 Previous Studies . . . . . . . . . . . . . . . . . . 28

3.3 Seismic Data . . . . . . . . . . . . . . . . . . . . . . . . . . . 29

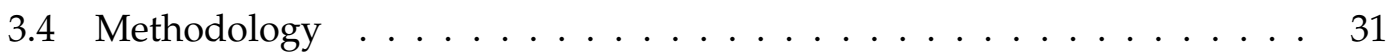

3.4.1 Shear Wave Splitting Measurements . . . . . . . . . . . . . . . 31

3.4.2 Focal Mechanism Inversion . . . . . . . . . . . . . . . . . . 34 
3.4.3 Gravitational Stresses . . . . . . . . . . . . . . 37

3.5 Results . . . . . . . . . . . . . . . . . 37

3.5.1 Shear Wave Splitting . . . . . . . . . . . . . . . . . . 37

3.5 .2 Focal Mechanisms . . . . . . . . . . . . . . . . 38

3.5 .3 Stress Inversions $\ldots \ldots \ldots$. . . . . . . . . . . . . 40

3.5.4 Gravitational Stress Field . . . . . . . . . . . . . . . . 41

3.5.5 Comparison of Methods . . . . . . . . . . . . . . . . . . 41

3.6 Discussion . . . . . . . . . . . . . . . . . . . . . . 44

3.6.1 Stresses in the Subducted Pacific Plate . . . . . . . . . . . . . . . 44

3.6.2 Seismic Anisotropy . . . . . . . . . . . . . . . . 46

3.6.3 Comparing Stress Orientations by Region . . . . . . . . . . . . . . 46

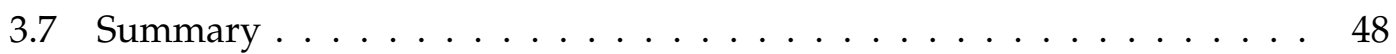

3.8 Acknowledgements . . . . . . . . . . . . . . . . . . . . . . . 49

4 Illumination of Deformation by Bending Stresses within the Southern Hikurangi Double Benioff Zone

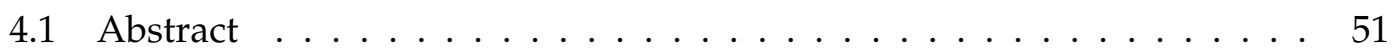

4.2 Introduction . . . . . . . . . . . . . . . . . . 51

4.3 Southern Hikurangi Margin . . . . . . . . . . . . . . . . . 52

4.4 Previous Studies . . . . . . . . . . . . . . . . . . . . . . 54

4.5 Seismic Data . . . . . . . . . . . . . . . . . . . . . . . . 56

4.6 Methods ............................ 56

4.6.1 Earthquake Relocation . . . . . . . . . . . . . . . 56

4.6.2 Bayesian Focal Mechanism and Stress Inversion . . . . . . . . 56

4.6.3 Focal Mechanism Clustering . . . . . . . . . . . . . . . 56

4.7 Results . . . . . . . . . . . . . . . . . 58

4.7 .1 Earthquake Locations . . . . . . . . . . . . . . 58

4.7.2 Focal Mechanism and Stress Inversion . . . . . . . . . . . . 58

4.8 Discussion . . . . . . . . . . . . . . . . . . . 60

4.8.1 Upper Band Stress Orientations . . . . . . . . . . . . . . . . . 60

4.8.2 Lower Band Stress Orientations ．. . . . . . . . . . . . 60

4.8.3 Stress Orientations in Double Benioff Zones _ . . . . . . . . . . 62

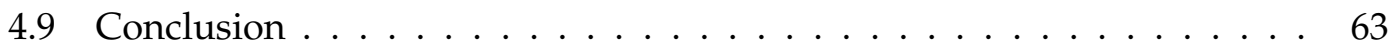


4.10 Acknowledgements . . . . . . . . . . . . . . . . . . . . . 64

5 Stress and Structure Controlled Anisotropy Revealed by a High-Density Seismic Transect Across Southern North Island, New Zealand 67

5.1 Abstract . . . . . . . . . . . . . . . . . . . 67

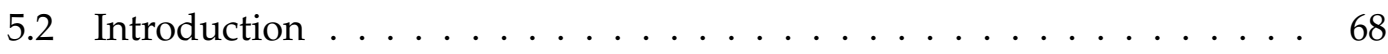

5.2 .1 SAHKE II Experiment . . . . . . . . . . . . . . . . . . . 68

5.2.2 Shear-wave Anisotropy . . . . . . . . . . . . . . . . 70

5.3 Tectonic and Geologic Setting . . . . . . . . . . . . . . . . . . 70

5.4 Previous Studies . . . . . . . . . . . . . . . . . . . . . . 71

5.5 Seismic Data . . . . . . . . . . . . . . . . . . . . 73

5.6 Shear-Wave Analysis Methods _ . . . . . . . . . . . . . . . 73

5.7 MFAST Splitting Results . . . . . . . . . . . . . . . . . . 76

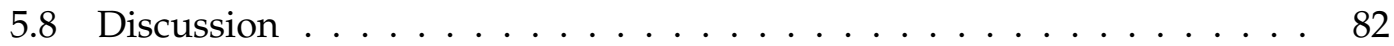

5.8 .1 West of Wairarapa Fault . . . . . . . . . . . . 83

5.8 .2 East of Wairarapa Fault $\ldots \ldots \ldots$. . . . . . . . 84

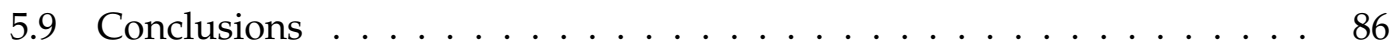

5.10 Acknowledgements . . . . . . . . . . . . . . . . 87

6 Preliminary Examination of Long-Term and Short-Term Strain Rates in Central New Zealand $\quad 89$

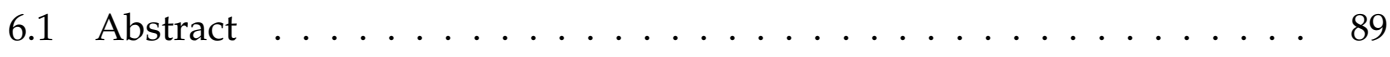

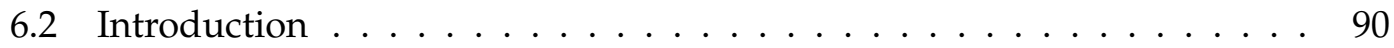

6.2 .1 Tectonic Setting . . . . . . . . . . . . . . . . . . . 90 90

6.2 .2 Previous GPS Studies _ . . . . . . . . . . . . . . . . . . 92

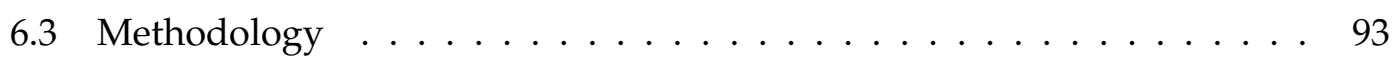

$6.3 .1 \quad$ cGPS Station Velocities . . . . . . . . . . . . . . . . . . . 93

6.3.2 Shear Strain Rate, Dilatation, Vorticity . . . . . . . . . . . . . . . . 95

6.4 Results . . . . . . . . . . . . . . . . . . . 95

6.4.1 cGPS Station Velocities . . . . . . . . . . . . . . . . . . . . . 95

6.4.2 Long-Term Strain Rate Parameters . . . . . . . . . . . . . . 96

6.4.3 Inter-SSE (Short-Term) Strain Rate Parameters . . . . . . . . . . 98

6.4.4 Co-Seismic 2016 Kaikōura Earthquake . . . . . . . . . . . . . . . . 98

6.5 Discussion . . . . . . . . . . . . . . . . . . . . . . 104 
6.5.1 Comparing Strain Parameters . . . . . . . . . . . . . . . . . . . . 104

6.5.2 Co-Seismic Strain Rates of 2016 Kaikōura Earthquake . . . . . . . 105

6.5.3 Preliminary Analysis Mega-thrust Locking Depths . . . . . . . 105

6.6 Conclusions . . . . . . . . . . . . . . . . . . . . . . . . . 109

6.7 Acknowledgements . . . . . . . . . . . . . . . . . . . . 110

$\begin{array}{lll}7 & \text { Conclusions } & 113\end{array}$

7.1 A Review of Stress Orientations and Strain Rates at the Southern Hikurangi Margin . . . . . . . . . . . . . . . . . . . . . . . . . 113

7.1.1 Subducting Pacific Plate . . . . . . . . . . . . . . . . . 113

7.1.2 Overriding Australian Plate . . . . . . . . . . . . . . . . . . . . . 114

7.2 Overriding and Subducting Plate Interaction . . . . . . . . . . . 117

7.3 Future Work . . . . . . . . . . . . . . . . . . . . . . . . . . 117

8 Appendix A: Stress Orientations Throughout the Southern Hikurangi Margin

9 Appendix B: Illumination of Deformation by Bending Stresses within the Southern Hikurangi Double Benioff Zone

10 Appendix C: Stress and Structure Controlled Anisotropy Revealed by a HighDensity Seismic Transect Across Southern North Island, New Zealand

11 Appendix D: Preliminary Examination of Long-Term and Short-Term Strain Rates in Central New Zealand 


\section{List of Figures}

1.12012 New Zealand Seismic Hazard Map . . . . . . . . . . . . . . . . . . 8

1.2 New Zealand Tectonics . . . . . . . . . . . . . . . . . . . . . . . . . . 13

2.1 Strike, Dip, Rake Example . . . . . . . . . . . . . . . . . . . . . . . . . . 19

2.2 Focal Mechanism Examples . . . . . . . . . . . . . . . . 20

2.3 Shear-Wave Splitting Example . . . . . . . . . . . . . . . . . . 21

3.1 Plate Boundary and Local Tectonics . . . . . . . . . . . . . . . 27

3.2 Earthquake Locations . . . . . . . . . . . . . . . . . . . . 30

3.3 Shear-Wave Splitting Fast Azimuths . . . . . . . . . . . . . . . . 32

3.4 Bayesian Focal Mechanisms and Focal Mechanism Clusters . . . . . . . . 36

3.5 Gravitational SHmax . . . . . . . . . . . . . . . . . . . . . . 43

3.6 Comparison of Fast Direction, Gravitational Stress and Focal Mechanism Inversion . . . . . . . . . . . . . . . . . . . . . 44

3.7 Extentional and Compressional Due to Stress . . . . . . . . . . . . . 47

4.1 New Zealand Plate Boundary and Station Locations . . . . . . . . . . . . 53

4.2 Previous DBZ Studies in Southern Hikurangi . . . . . . . . . . . . . 55

4.3 3D Earthquake Relocations . . . . . . . . . . . . . . . . 57

4.4 Focal Mechanism by Style . . . . . . . . . . . . . . . . . . . . . . . . 59

4.5 Clusters and Stress Inversions . . . . . . . . . . . . . . . . . . . 61

4.6 Cartoon Representation of Stress Distribution . . . . . . . . . . . . . . . 65

5.1 Southern North Island, New Zealand: Local Tectonics . . . . . . . . . . . 69

5.2 Geologic Terranes of the Southern North Island . . . . . . . . . . . . 72

5.3 Earthquake Recorded on SAHKE II Array . . . . . . . . . . . . . . . . 74

5.45 Trace Stacking . . . . . . . . . . . . . . . . . . . . . 75 
5.5 After Stacking: Earthquake Recorded on SAHKE II Array . . . . . . . . . 77

5.6 A-Quality Splitting Result ～. . . . . . . . . . . . . . . . . . . . 78

5.7 Density Plots Comparing Splitting Parameters . . . . . . . . . . . . . . 80

5.8 Density Plot of Fast Azimuth Along SAHKE II . . . . . . . . . . . . . . 81

5.9 Circular-mean of Fast Azimuths . . . . . . . . . . . . . . . . . . . . 83

5.10 Seismic Traces Rotated into Fast Azimuth . . . . . . . . . . . . . . . . 85

5.11 Average fast azimuth along the SAHKE II . . . . . . . . . . . . 86

6.1 Central New Zealand Tectonics . . . . . . . . . . . . . . . . . . . . . . . 91

6.2 Longterm cGPS Displacement at KAPT station . . . . . . . . . . . . . 93

6.3 Inter-SSE cGPS Displacement at KAPT station $\ldots \ldots \ldots$. . . . . . . . . 94

6.4 cGPS Delauney Network . . . . . . . . . . . . . . . . . . . . . . . . . . . . 94

6.5 cGPS Velocities: Long-term and Inter-SSE (ITRF2008) . . . . . . . . . 96

6.6 cGPS Velocities: Australian Plate Reference Frame . . . . . . . . . . . . . 97

6.7 cGPS Velocities: Co-Seismic $\mathrm{M}_{W} 7.8$ Kaikōura $\ldots \ldots \ldots$. . . . . . . . . . . 100

6.8 Strain Parameters: Long-term . . . . . . . . . . . . . . . . . . . . . . 101

6.9 Strain Parameters: Inter-SSE . . . . . . . . . . . . . . . . . . . . . 102

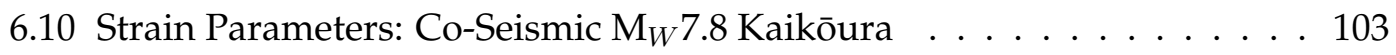

6.11 Strain Parameter Comparison: Central North Island . . . . . . . . . 106

6.12 Strain Parameter Comparison: Southern North Island . . . . . . . . . 106

6.13 Strain Parameter Comparison: Cook Strait . . . . . . . . . . . . . . . . . 107

6.14 Strain Parameter Comparison: Northern South Island . . . . . . . . . . 107

6.15 Dislocation Model: Long-Term Velocities ～. . . . . . . . . . . . . . 108

6.16 Dislocation Model: Inter-SSE Velocities ．. . . . . . . . . . . . . . 109

6.17 Dislocation Model: Inter-SSE Velocities (Multiple Slipping Patches) . . . 110

7.1 Seismotectonics of the Southern Hikurangi Margin . . . . . . . . . . . . 117

8.1 Appendix A: Shear-Wave Splitting by Depth . . . . . . . . . . . . . . 136

8.2 Appendix A: Enlarged Map of Shear-Wave Splitting . . . . . . . . . . 137

8.3 Appendix A: Bayesian Focal Mechanisms and 20 Focal Mechanism Clusters . . . . . . . . . . . . . . . . . . . . . 138

8.4 Appendix A: 20 Bayesian Stress Inversions . . . . . . . . . . . . . . 139

9.1 Appendix B: Study Area Comparison . . . . . . . . . . . . . . . . . 171 
9.2 Appendix B: Radius of Curvature Comparison . . . . . . . . . . . . 172

9.3 Appendix B: Stress Inversion Results for DBZ Clusters . . . . . . . . . 173

9.4 Appendix B: Comparison of HypoDD, NonLinLoc, and SEISAN Locations175

9.5 Appendix B: Stress Inversion Results for HypoDD and SEISAN Locations 176

9.6 Appendix B: 2 Clusters Using NonLinLoc Locations . . . . . . . . . . 177

9.7 Appendix B: Stress Inversion Results for 2 Clusters $\ldots \ldots$. . . . . . 178

10.1 Appendix C: Earthquakes Location . . . . . . . . . . . . . . . 180

10.2 Appendix C: Fast Azimuth (Density Plot) for All Earthquakes . . . . . . 181

10.3 Appendix C: Fast Azimuth for All Earthquakes . . . . . . . . . . . . . . 182

10.4 Appendix C: Shear-wave Anisotropy Parameters . . . . . . . . . . . . . 183

10.5 Appendix C: MFAST Filters All Earthquakes . . . . . . . . . . . . . . . 184

10.6 Appendix C: 4 Closest Earthquakes Location . . . . . . . . . . . . . 185

10.7 Appendix C: Fast Azimuth (Density Plot) for 4 Closest Earthquakes . . . 186

10.8 Appendix C: Fast Azimuth for 4 Closest Earthquakes . . . . . . . . . 187

10.9 Appendix C: Shear-wave Anisotropy Parameters . . . . . . . . . . . . . 188

10.10Appendix C: MFAST Filters 4 Closest Earthquakes . . . . . . . . . . . 189

10.11Appendix C: 5 Random Earthquakes Location ． . . . . . . . . . . 190

10.12Appendix C: Fast Azimuth (Density Plot) for 5 Random Earthquakes . . 191

10.13Appendix C: Fast Azimuth for 5 Random Earthquakes . . . . . . . . . . 192

10.14Appendix C: Shear-wave Anisotropy Parameters . . . . . . . . . . . . 193

10.15Appendix C: MFAST Filters 5 Random Earthquakes . . . . . . . . . . . 194

10.16Appendix C: 1 Earthquake Location ． . . . . . . . . . . . . 195

10.17Appendix C: Fast Azimuth (Density Plot) for 1 Earthquake . . . . . . . . 196

10.18Appendix C: Fast Azimuth for 1 Earthquake . . . . . . . . . . . . 197

10.19Appendix C: Shear-wave Anisotropy Parameters . . . . . . . . . . . . 198

10.20Appendix C: MFAST Filters 1 Earthquake . . . . . . . . . . . . . . . 199

10.21Appendix C: 2 Deep Earthquake Location . . . . . . . . . . . . . . . . 202

10.22Appendix C: Fast Azimuth (Density Plot) for 2 Deep Earthquakes . . . . 203

10.23 Appendix C: Shear-wave Anisotropy Parameters . . . . . . . . . . . . 204

10.24Appendix C: MFAST Filters 2 Deep Earthquake . . . . . . . . . . . 205

10.25Appendix C: Azimuth of Rakaia Bedding Planes . . . . . . . . . . . 206

10.26Appendix C: Azimuth of Rakaia Foliation Planes . . . . . . . . . . . 206 
10.27Appendix C: Azimuth of Rakaia Bedding Planes near SAHKE II . . . . . 207 10.28Appendix C: Azimuth of Pahau Bedding Planes . . . . . . . . . . . 207 10.29Appendix C: Azimuth of Pahau Bedding Planes near SAHKE II . . . . 208 


\section{List of Tables}

3.1 Average Splitting Measurements . . . . . . . . . . . . . . . . . . . . . . 39

3.2 Stress Inversion Results $\ldots \ldots \ldots$. . . . . . . . . . . . . . . . 40

3.3 SHmax due to Gravitational Stress . . . . . . . . . . . . . . . . . . . . 42

3.4 Regional Averages for Fast Direction, Gravitational Stresses, and Focal Mechanism Inversions . . . . . . . . . . . . . . . . . 46

4.1 Double Benioff Zone Parameters . . . . . . . . . . . . . . . . . . . 62

5.1 Average Fast Azimuth Across the SAHKE II . . . . . . . . . . . . . 82

8.1 Appendix A: 20 Stress Inversion Results . . . . . . . . . . . . . . . . 140

8.2 Appendix A: Focal Mechanism Parameters . . . . . . . . . . . . . . 143

8.3 Appendix A: Western Region Stress Inversion Parameters . . . . . . . . 151

8.4 Appendix A: Central Basin Region Stress Inversion Parameters . . . . 151

8.5 Appendix A: Eastern Region Stress Inversion Parameters . . . . . . . . . 151

9.1 Appendix B: Earthquake Magnitude Distribution . . . . . . . . . . . . 154

9.2 Appendix B: Focal Mechanism Parameters . . . . . . . . . . . . . . 155

9.3 Appendix B: Down-Dip Lower Plane Stress Inversion Parameters . . . 170

9.4 Appendix B: Up-Dip Lower Plane Stress Inversion Parameters . . . . . . 170

9.5 Appendix B: Upper Plane Stress Inversion Parameters . . . . . . . . . . 170

9.6 Appendix B: Down-Dip Lower Plane Stress Inversion Parameters (All) . 174

9.7 Appendix B: Up-Dip Lower Plane Stress Inversion Parameters (All) . . 174

9.8 Appendix B: Upper Plane Stress Inversion Parameters (All) . . . . . . . . 174

10.1 Average Splitting Parameters on Unstacked SAHKE II (All Earthquakes) 200

10.2 Average Splitting Parameters on Unstacked SAHKE II (4 Closest Earthquakes $\ldots \ldots \ldots \ldots \ldots$. . . . . . . . . . . . . . . 200 
10.3 Average Splitting Parameters on Unstacked SAHKE II (5 Random Earthquakes) . . . . . . . . . . . . . . . . . . 201

10.4 Average Splitting Parameters on Unstacked SAHKE II (1 Earthquake) . . 201

11.1 Appendix D: cGPS Longterm Time Periods . . . . . . . . . . . . . . . 210

11.2 Appendix D: cGPS Inter-SSE Time Periods . . . . . . . . . . . . . . . 213

11.3 Appendix D: cGPS Station Velocities (ITRF 2008) . . . . . . . . . . . 216

11.4 Appendix D: cGPS Station Velocities (AUS) … . . . . . . . . . . 217

11.5 Appendix D: Co-Seismic Kaikoura cGPS Velocities . . . . . . . . . . . . . 219 


\section{Chapter 1}

\section{Introduction}

\subsection{Context and Reasoning}

Earthquakes represent a clear and present danger to life and infrastructure throughout New Zealand. Thorough seismic hazard evaluation is contingent on an understanding of the past and present seismological dynamics of a region. The goal of this study is to add to the current understanding of stress and strain throughout the southern Hikurangi locked subduction patch, in order to provide background stress and strain information for future seismic hazard analysis of North Island, New Zealand. Characterization of stress and strain provides invaluable information when evaluating current and future deformation and seismic hazards in a region.

The analysis of stress and strain in this study will serve as background information in the evaluation of future seismic hazards in the southern North Island, specifically in the characterization of onshore deformation in the southern North Island and the seismotectonic dynamics of the southern Hikurangi subduction locked patch.

The most up-to-date seismic hazard model for New Zealand (Stirling et al., 2012, Figure 1.1) incorporates fault and seismicity distribution, including paleoseismological data, into a probabilistic seismic hazard analysis method developed by Cornell (1968). The most recent seismic hazard model includes 13 subduction interface sources, which incorporates observations of interface coupling (Wallace et al., 2009), in an effort to better account for seismic hazards associated with the Hikurangi subduction system. An expert panel (comprised of the co-authors of (Stirling et al., 2012)) was needed to develop a weighting system, based on subduction margin characteristics (e.g., seismicity, plate interface coupling, and slow-slip earthquakes, etc.), in order to quantify the 13 subduction interface source models. Though the 2012 seismic hazard model is reasonably up-to-date, future iterations can be improved upon by the addition of more seismic and tectonic characterization, which this thesis seeks to provide.

A large portion of the data used in this study was provided by a collaborative ef- 
(a)

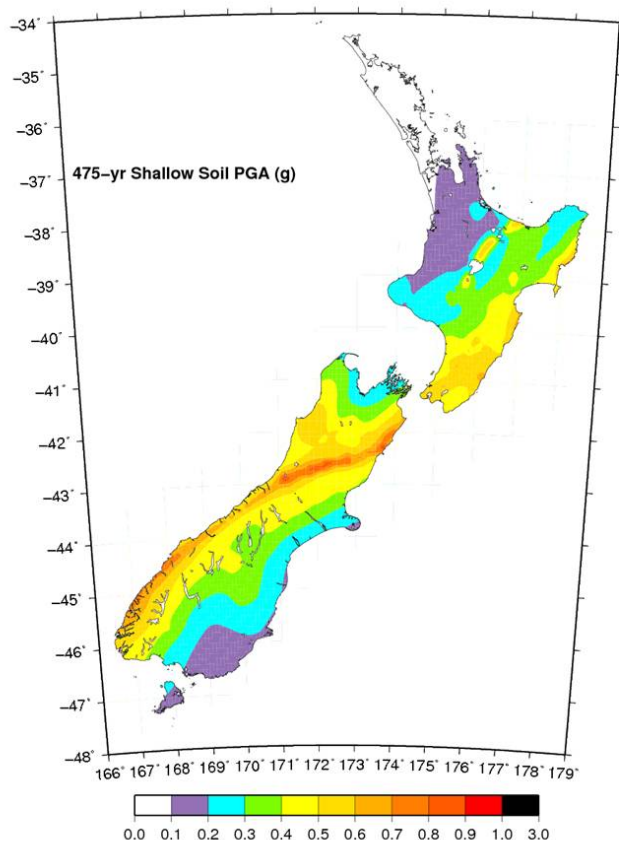

(c)

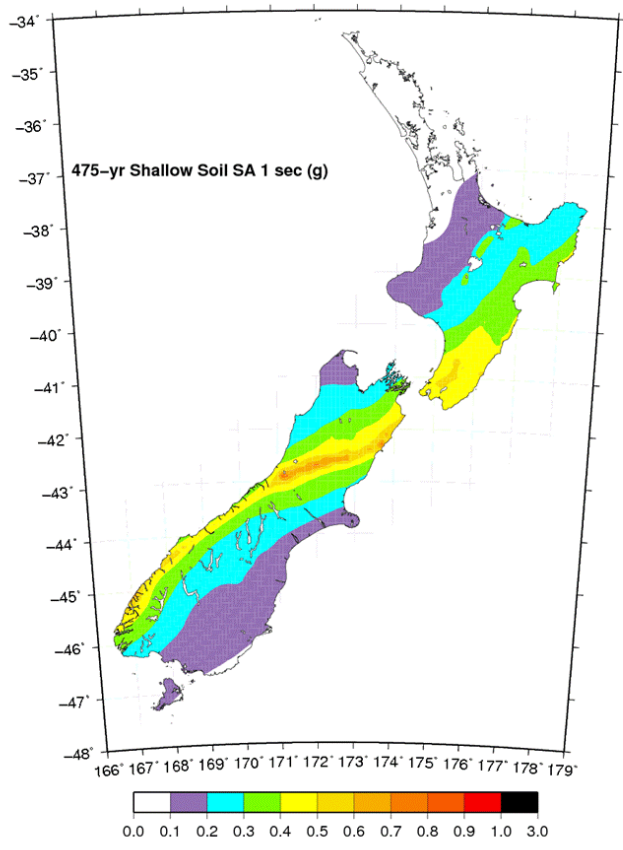

(b)

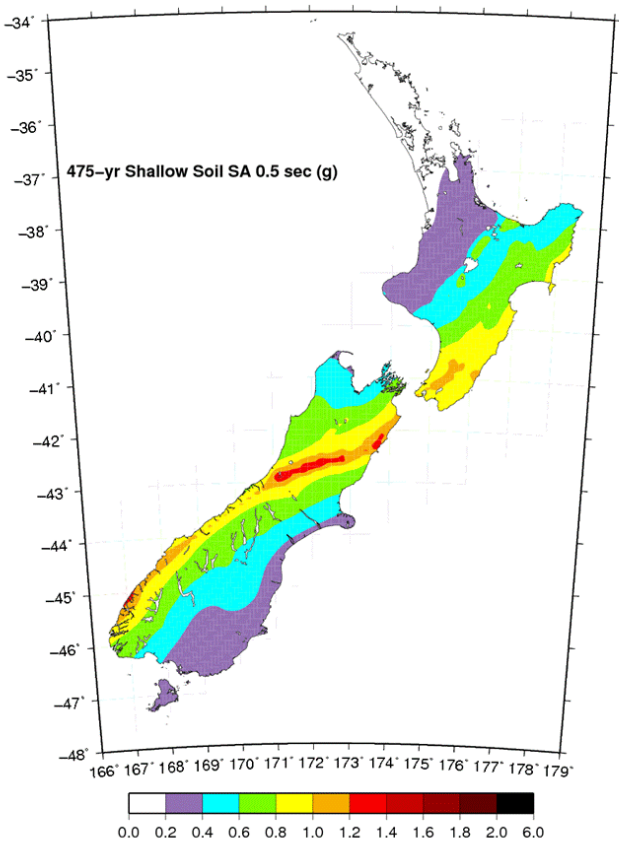

(d)

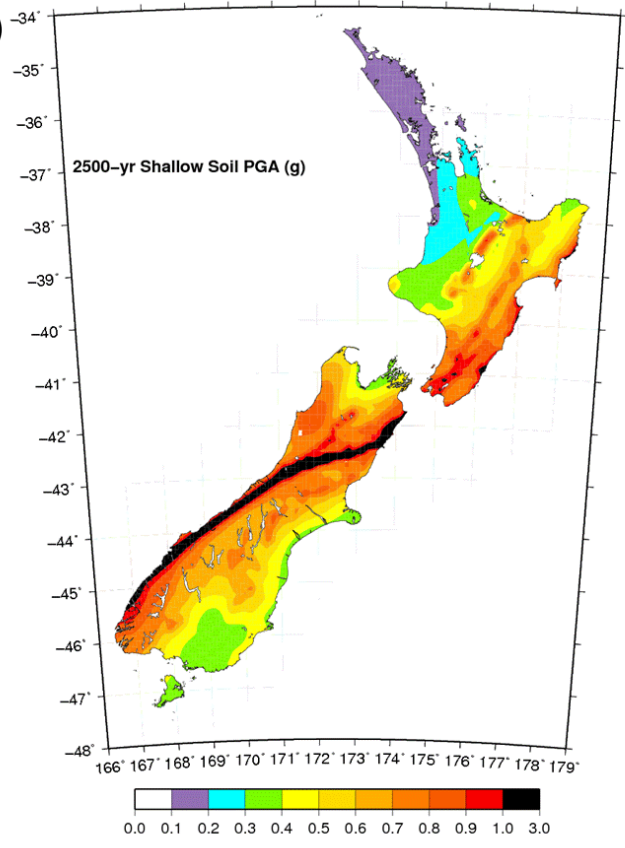

Figure 1.1: 2012 New Zealand Seismic Hazard Model from Stirling et al. (2012). Seismic hazard maps for 475 and 2500 year return periods for shallow soil site conditions (10\% and $2 \%$ probability of exceedance in 50 years, respectively). (a) peak ground acceleration (PGA) for 475 year return. (b) spectral acceleration (SA) $0.5 \mathrm{~s} 475$ year return. (c) SA $1.0 \mathrm{~s} 475$ year return. (d) PGA for 2500 year return. (e) SA $0.5 \mathrm{~s}$ SA 2500 year return. (f) SA 1.0 s 2500 year return. (g) 2002 Seismic Hazard model PGA 475 return. Continued 
(e)

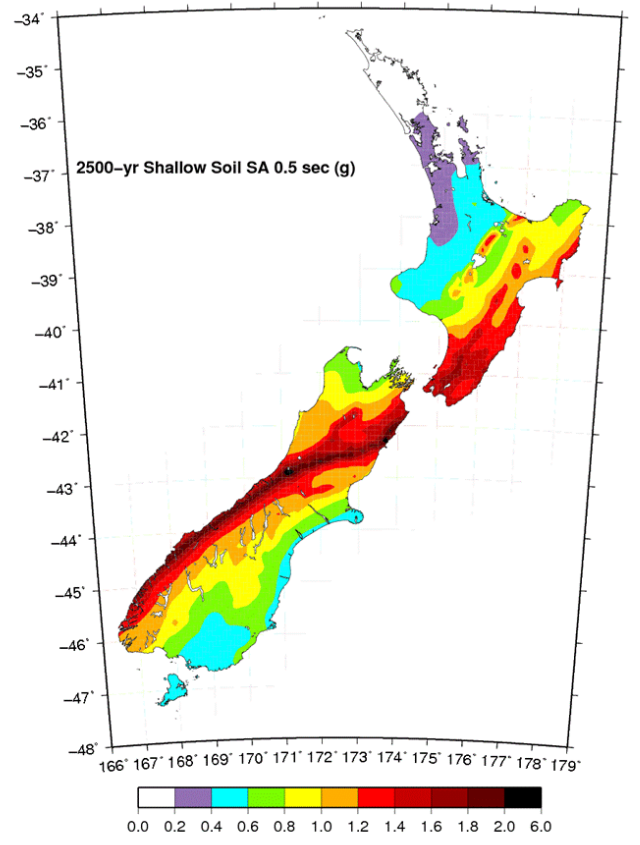

(f)

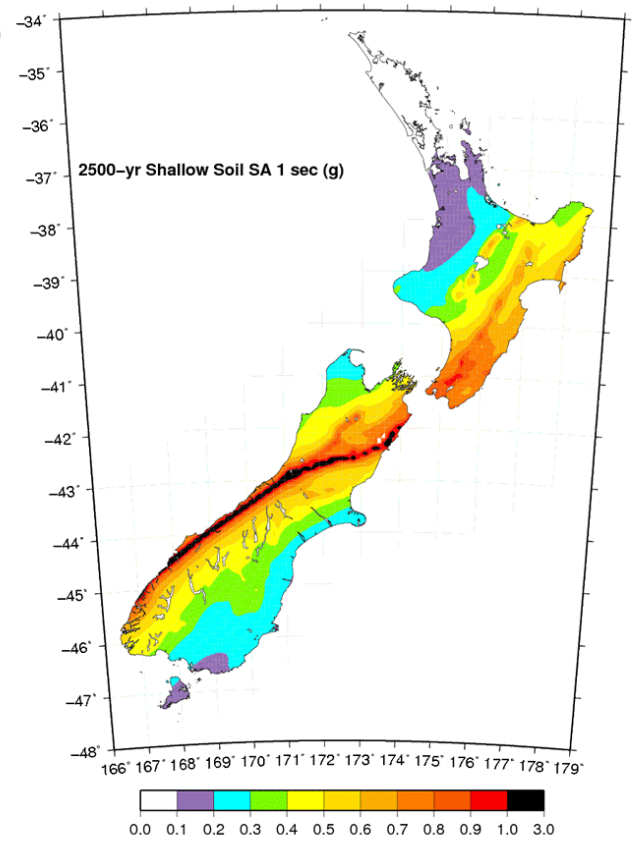

(g)

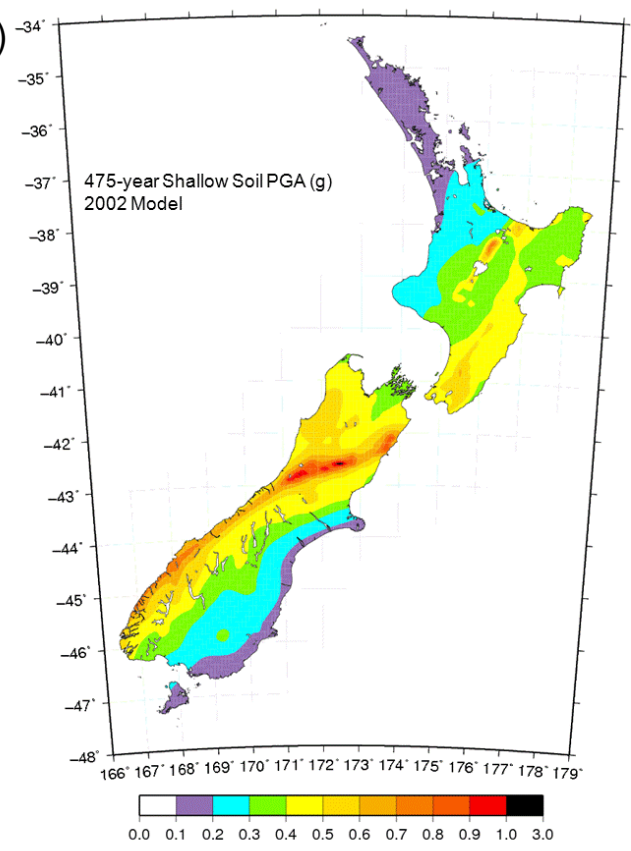

Figure 1.1: continued. Largest hazards are along the Alpine fault trace, and in the northern South and southern North Islands. 
fort among GNS Science, Victoria University of Wellington, and Earthquake Research Institute (University of Tokyo, Japan), in conjunction with Ministry of Economic Development and Crown Minerals. The data were part of the Seismic Array Hikurangi Experiment (SAHKE I and II), a controlled-source and passive seismic imaging experiment. The goal of the SAHKE projects were to investigate the physical parameters controlling locking on the plate interface and the characterization of slip processes beneath the southern North Island of New Zealand (GNS Science Report 2010/48 and 2011/50).

\subsection{Thesis Format}

Chapter 2 outlines the theoretical background of the methods utilized in the proceeding chapters. Location of microseismicity is calculated with several location algorithms and velocity models. The location algorithms used are Hypocenter (Lienert et al., 1986; Lienert and Havskov, 1995) and NonLinLoc (Lomax et al., 2000; Lomax, 2011), with additional relocation done with HypoDD (Waldhauser and Ellsworth, 2000). Within the various location algorithms a one dimensional velocity model from Henrys et al. (2013) and a three dimensional velocity model from Eberhart-Phillips et al. (2010) was used. Focal mechanisms and stress inversions were calculated using Bayesian methods from Walsh et al. (2009); Arnold and Townend (2007), respectively. Shear-wave splitting analysis is preformed in Chapter 5 using the Multiple Filter Automatic Splitting Technique (MFAST) from Savage et al. (2010). Strain parameters calculated in Chapter 6 are done using algorithms from Lamb and Smith (2013); Lamb (2015). Algorithm particulars are expanded upon in proceeding chapters.

The objective of Chapter 3 is to compare and contrast stress orientations within the subducting Pacific plate and the overriding Australian plate, in order to discern if stresses within the subducting plate are being transfered to the overriding plate at southern North Island, New Zealand. This is achieved by the inversion of focal mechanisms for stress orientations in the subducting Pacific plate, the calculation of the shear-wave fast azimuth (an approximation of SHmax) within the overriding Australian plate, and the determination of SHmax due to gravity based on crustal structure and topography of the Australian plate. Chapter 3 was published as: Stress Orientations in a Locked Subduction Zone at the Southern Hikurangi Margin, New Zealand in the Journal of Geophysical Research: Solid Earth, with myself (Dominic Evanzia) as lead author and Thomas Wilson, Martha Savage, Simon Lamb, and Hamish Hirschberg as co-authors. I was responsible for writing and submission of the manuscript, phase picking, the earthquake relocations, focal mechanism calculations, and stress inversions. I am also responsible for incorporating the stress inversions data, shear-wave splitting measurements from Wilson (2016), and gravitational stress data provided by Hamish Hirschberg. Guidance on the methods, interpretations, and editing was provided by Martha Savage and Simon Lamb. Supplemental materials are in Appendix 
A.

The objective of Chapter 4 is to characterize stress parameters within the Double Benioff Zone beneath the southern North Island, in an effort to better understand stress within and deformation of the subducting Pacific plate. This is accomplished by first clustering relocated focal mechanisms into the upper and lower bands of seismicity, and then by inverting those clusters for stress parameters (i.e., maximum, intermediate, minimum stress, and SHmax orientation). Chapter 4 is in the process of being submitted as: Illumination of Deformation by Bending Stresses within the Southern Hikurangi Double Benioff Zone in the New Zealand Journal of Geology and Geophysics, with myself (Dominic Evanzia) as lead author and Simon Lamb, Martha Savage, and Tim Stern, as co-authors. I am responsible for writing of the manuscript, phase picking, earthquake relocations, focal mechanism calculations, and stress inversions. Guidance with concepts, interpretations, and editing was provided by Tim Stern, Martha Savage, and Simon Lamb. Supplemental materials are in Appendix B.

The objective of Chapter 5 is to determine near surface seismic anisotropy and stress parameters (e.g., fast azimuth/SHmax and delay time) using earthquakes recorded on a high-density array, during the active source (Seismic Hikurangi Array Experiment) SHAKE II experiment. The density of the array allows for the unique opportunity to stack waveforms in order to attempt to increase signal to noise ratio. Seismic anisotropy is measured on hand-picked phases from 21 local earthquakes, using the Multiple Filter Automatic Splitting Technique (Savage et al., 2010). Chapter 5 is in the process of being submitted as: Stress-Controlled Anisotropy Revealed by a HighDensity Seismic Array Across Southern North Island, New Zealand in the Journal of Earth and Planetary Science Letters, with myself (Dominic Evanzia) as lead author and Martha Savage, Stuart Henrys, and David Okaya, as co-authors. I was responsible for writing of the manuscript, phase picking, and implementation of shear-wave analysis. Guidance with methods, interpretation, and editing was provided by Martha Savage, Stuart Henrys, and David Okaya. Supplemental materials are in Appendix C.

The objective of Chapter 6 is to calculate strain rate parameters, using continuous Global Position system (cGPS) data, to examine how stress relief via slow-slip events (SSEs) and large earthquakes, affect strain in the southern North and northern South Islands of New Zealand. This is achieved by using three cGPS datasets: (1) long-term cGPS velocity, which includes slow-slip events (SSEs); (2) inter-SSE cGPS velocity; (3) co-seismic cGPS velocity during the 2016 Kaikoura earthquake. Additionally in Chapter 6, preliminary dislocation modeling methods from Okada $(1985,1992)$ and Lamb and Smith (2013) are used to examine the degree to which SSEs affect the slip dynamics on the plate interface below the southern North Island. Supplemental materials are in Appendix D. 


\subsection{Tectonic Overview}

The New Zealand portion of the Pacific-Australian plate boundary consists of oblique subduction, back-arc rifting, transform motion, and continental collision (Beavan and Haines, 2001) (Figure 1.2). Relative to the Australian plate, the Pacific plate is converging $\sim 50 \mathrm{~mm} / \mathrm{yr}$ west in northern New Zealand, $\sim 40 \mathrm{~mm} / \mathrm{yr}$ south-west in central new Zealand, and $\sim 30 \mathrm{~mm} / \mathrm{yr}$ south-south west in southern New Zealand (DeMets et al., 1990, 1994). The tectonics of the North Island are dominated by subduction at the Hikurangi Margin, back-arc rifting in the Taupo Volcanic Zone (TVZ), and strike-slip faulting in the North Island Seismic Belt (NISB) (Beanland and Haines, 1998; Wallace et al., 2004). In the South Island, the dominating tectonic process is continental collision and strike-slip faulting along the Alpine Fault (Walcott, 1984, 1998) (Figure 1.2).

Slip on the Hikurangi subduction plate interface is not uniform (Walcott, 1984). Wallace et al. $(2004,2009,2012)$ show there to be a slip deficit of $\sim 20-30 \mathrm{~mm} / \mathrm{yr}$ on the slab interface below the southern North Island, indicating that the subducting Pacific and overriding Australian plates are partially 'locked' or 'coupled'. A locked or coupled subduction interface would have several impacts on the dynamics of the subduction zone. A locked subduction interface would imply the presence of increased amounts of stress on the interface. The accumulation of this stress could manifest in some combination of two end-members: (1) a mega-thrust subduction earthquake located in proximity to the locked portion of the subduction interface or (2) the allocation and transmission of stress to the overriding plate, leading to more numerous large earthquakes on crustal faults.

The transition from oblique subduction at the southern Hikurangi margin to oblique continental collision on the northernmost extent of the Alpine fault occurs at the northernmost South Island (Figure 1.2). Relative plate motion transitions from slip along the subduction mega-thrust to upper plate faults zones. The Marlborough fault zone dominate the northern South Island, it contains a number of strike-slip faults that are oblique to the underlying subducting slab (Langridge et al., 2005, 2016). Amount of displacement in the Marlborough fault zone decreases from northwest to the southeast, with the greatest amount occurring along the Wairau fault (the northernmost continuation of the Alpine fault), then the Awatere fault, with the Hope fault having the least of these three (Eberhart-Phillips et al., 2014).

The major surface structural features of the southern North Island are NE-SW striking faults (Litchfield et al., 2014) (Figure 1.2). The relative motion of the Pacific and Australian plates is associated with the occurrence of numerous magnitude $\geq 3$ earthquakes (>33000 in the last 10 years quakesearch.geo.org.nz). Since 1834 there have been 28 large $(M \geq 7)$ earthquakes and one great earthquake, the M8+ 1855 Wairarapa earthquake in New Zealand (Stirling et al., 1998). The most recent large earthquake was the $2016 \mathrm{M}_{W} 7.8$ Kaikoura earthquake, which occurred in the northeastern South 


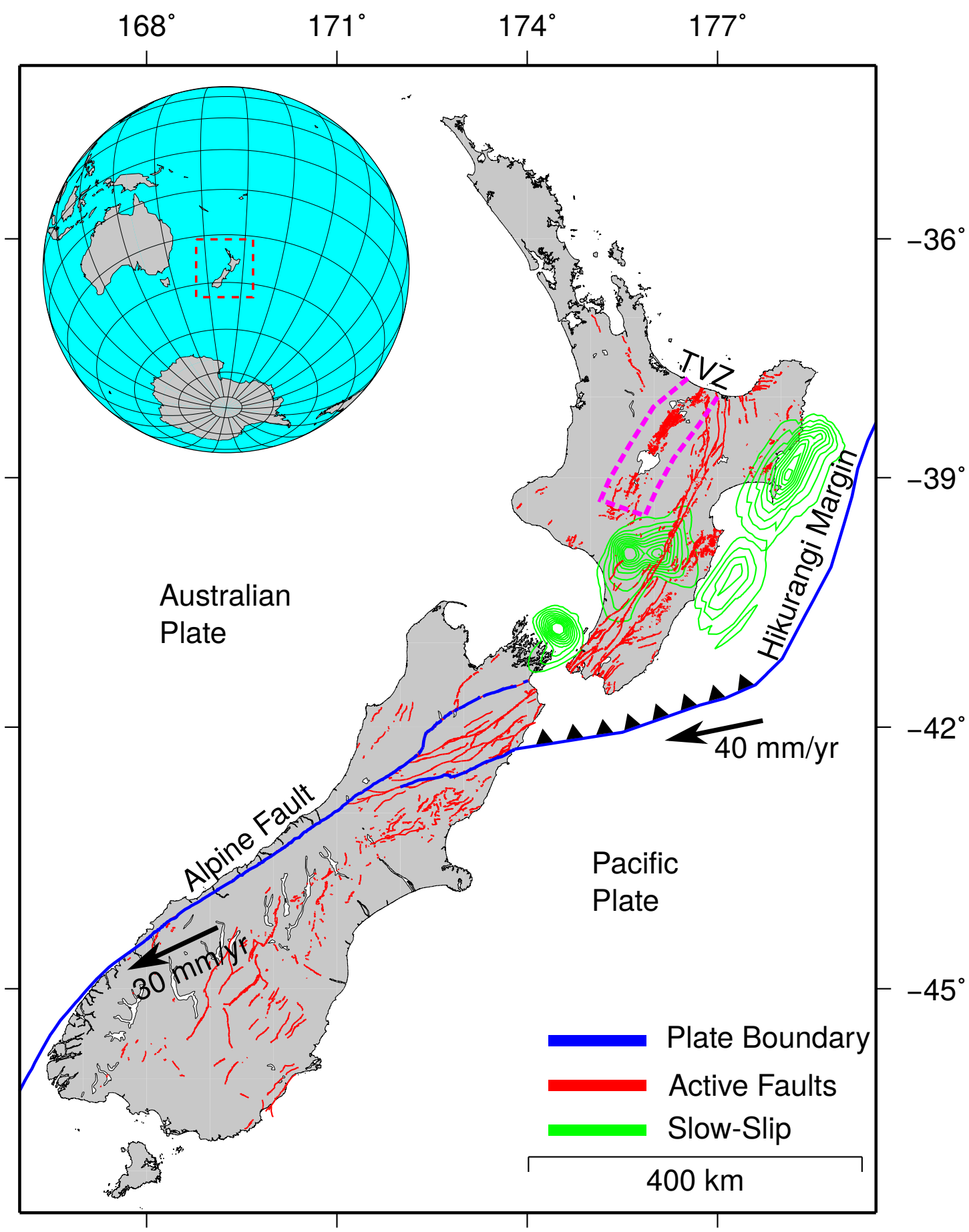

Figure 1.2: Overview of New Zealand tectonics. The New Zealand portion of the Australian and Pacific plate boundary is marked by the Hikurangi Margin (Blue), in the North Island, and the Alpine Fault (Blue) in the South Island (Coffin et al., 1998). Other major features of the North Island are the Taupo Volcanic Zone (TVZ), the extent of which is marked by the dashed-magenta lines and the Slow-Slip earthquakes (Green) (Wallace and Beavan, 2010), which originate on the plate interface of the subduction zone, and active faults (Red) throughout the North and South Island (https: / / data.gns.cri.nz/af /) 
Island.

For further characterization of study area specific tectonics, see individual chapters. 


\section{Chapter 2}

\section{Theoretical Background}

\subsection{Earthquake Location}

\subsubsection{Linearized Location}

The simplest earthquake location calculation is performed when considering an earthquake as a point source within a homogeneous half-space model (i.e., a single layer of material buttressed against a vacuum). The hypocenter position $(\mathrm{H})$ can be defined, in a Cartesian coordinate system:

$$
H=(X, Y, Z)
$$

The calculated arrival time at station $i\left(T_{i}^{c}\right)$ of a given seismic phase from a hypocenter is given by the following:

$$
T_{i}^{c}=\frac{\sqrt{\left(X-X_{i}\right)^{2}+\left(Y-Y_{i}\right)^{2}+\left(Z-Z_{i}\right)^{2}}}{V}+T_{0}
$$

where $\left(X_{i}, Y_{i}, Z_{i}\right)$ is the $i^{t h}$ station's position, $V$ is the velocity of the homogeneous half-space, and $T_{0}$ is the origin time of the earthquake (Stein and Wysession, 2009).

Equation 2.2 is non-linear and has four unknowns $\left(X, Y, Z\right.$, and $\left.T_{0}\right)$. The reliability of a hypocenter and origin time can be measured by a misfit factor, the residual $\left(R_{i}\right)$, at each station. Uncertainties in locations are directly related to imprecise phase arrival picks and uncertainties in the velocity model used. $R_{i}$ is the difference between the observed $\left(T_{i}^{o}\right)$ and calculated travel times $\left(T_{i}^{c}\right)$.

$$
R_{i}=T_{i}^{o}-T_{i}^{c}
$$

With increasing station coverage and knowledge of the velocity characteristics of the subsurface, the average travel-time residual from each station-earthquake pair would become more minimized, resulting in a more reliable hypocenter location. 
Geiger (1910) developed an iterative inversion method for locating local (within or near to the array of stations) earthquakes. Geiger's method solves for the location by linearizing the location equation in a least-squares manner, utilizing the Taylor series of the hypocenter coordinates. This method describes the residual $\left(R_{i}\right)$ by the following:

$$
R_{i}=\frac{\partial T_{i}}{\partial X} \Delta X+\frac{\partial T_{i}}{\partial Y} \Delta Y+\frac{\partial T_{i}}{\partial Z} \Delta Z+\Delta T_{0}
$$

where $\Delta$ describes variations made to hypocenter parameters (e.g. $X, Y, Z$, origin time) in order to minimize the residual. The partial derivatives above can be calculated (in a half-space) from Equation 2.2 describing arrival time $\left(T_{i}\right)$ in a homogeneous half-space:

$$
\begin{gathered}
\frac{\partial T_{i}}{\partial X}=\frac{X-X_{i}}{V} \times \frac{1}{\sqrt{\left(X-X_{i}\right)^{2}+\left(Y-Y_{i}\right)^{2}+\left(Z-Z_{i}\right)^{2}}} \\
\frac{\partial T_{i}}{\partial Y}=\frac{Y-Y_{i}}{V} \times \frac{1}{\sqrt{\left(X-X_{i}\right)^{2}+\left(Y-Y_{i}\right)^{2}+\left(Z-Z_{i}\right)^{2}}} \\
\frac{\partial T_{i}}{\partial Z}=\frac{Z-Z_{i}}{V} \times \frac{1}{\sqrt{\left(X-X_{i}\right)^{2}+\left(Y-Y_{i}\right)^{2}+\left(Z-Z_{i}\right)^{2}}} \\
\frac{\partial T_{i}}{\partial T_{0}}=1
\end{gathered}
$$

\subsubsection{Non-Linear Location}

In this study earthquake relocations were initially solved as a linearized problem using HYPOCENTER (Lienert et al., 1986; Lienert and Havskov, 1995) within the SEISAN package (Havskov and Ottemoller, 1999). Final locations were determined using NonLinLoc, a probability based non-linear location package (Lomax et al., 2000). Using NonLinLoc to obtain final earthquake locations is advantageous because of the program's ability to incorporate a 3D velocity model and because hypocenter solutions are described by a posterior probability density function (PDF), which incorporates uncertainties. Furthermore, the PDFs are used in later programs (focal mechanism and stress inversion), which allows for explicit use of location uncertainties to determine the uncertainties throughout the stress analysis process.

NonLinLoc implements the probabilistic formulation of inversion developed by Tarantola and Valette (1982) and Tarantola (1987). The probabilistic formulation uses normalized and non-normalized PDFs to characterize desired parameters:

$$
P(X \leq x \leq X+\Delta X)=\int_{X}^{X+\Delta X} f(x) d x
$$

where the probability $(P)$ of a parameter $(x)$ being between $X \leq x \leq X+\Delta X$ is described by a normalized density function $f(x)$. 
The goal is to constrain an unknown parameter $(p)$ (e.g., hypocenter location) given the observed data $(d)$ (e.g., station locations, travel time, initial hypocenter location). While integrating over the data $(d)$ space, a probabilistic solution can be characterized by a PDF $\left(\sigma_{p}(p)\right)$ if the density function of the model parameters $\rho_{p}(p)$ and observation $\rho_{d}(d)$ are each independent and there is a theoretical relationship $\theta(d, p)$ between the data and model parameters:

$$
\sigma_{p}(p)=\rho_{p}(p) \int \frac{\rho_{d}(d) \theta(d \mid p)}{\mu_{d}(d)} \delta(d)
$$

where $\theta(d \mid p) \mu_{p}(p)$ is the conditional density function of the data given the model parameter $(p)$ and $\delta(d)$ represents the differential of the variable $\mathrm{d}$. The functions $\mu_{p}(p)$ and $\mu_{d}(d)$ are null information probability density functions, where no prior knowledge exists. Tarantola and Valette (1982) showed that if you assume the observed arrival times and theoretical relationship have Gaussian uncertainties and the prior information on origin times is uniform, then it is possible to integrate over the observed data (Equation 2.10) to calculate a maximum likelihood estimation of the origin time and PDF for hypocenter coordinates.

This study utilizes the Oct-Tree grid search method (Lomax, 2011), within NonLinLoc. The Oct-Tree method employs an iterative grid search, where a course grid (defined by 8 corner nodes) is subdivided into eight cells (64 nodes). The cell with the highest location probability is then split into eight more cells. Cell division is repeated until a predetermined threshold of node-to-node length $(0.001 \mathrm{~km})$, maximum number of nodes (100000), or number of possible locations (1000) is achieved.

\subsubsection{Double-Difference Location}

Additional relocations of earthquakes were preform used HypoDD (Waldhauser and Ellsworth, 2000; Krischer, 2015), a double-difference location method, which simultaneously relocates sets of earthquakes. It combines P- and S-wave differential travel times derived from cross-spectral methods with travel-time differences from catalog data. It minimizes residual differences for pairs of earthquakes by adjusting the vector differences between hypocenters.

Equation 2.10 gives the travel-time residual $\left(r_{k}^{i}\right)$ for a single earthquake $(i)$-station $(k)$ pair, where $r_{k}^{i}=\left(t^{o b s}-t^{c a l}\right)_{k}^{i}, t^{o b s}$ and $t^{c a l}$ are the observed and theoretical travel time, and $\Delta m^{i}=\left(\Delta x^{i}, \Delta y^{i}, \Delta z^{i}, \Delta t^{i}\right)$ is the difference in hypocenter location and origin time for a given perturbation of parameters:

$$
\frac{\partial t_{k}^{i}}{\partial m} \Delta m^{i}=r_{k}^{i}
$$

where $\frac{\partial}{\partial m}$ represents the partial derivative with respect to the parameter $m$. Crosscorrelation at a single station is used to measure the travel-time difference between 
two earthquakes at that station. The residual $\left(d r_{k}^{i j}\right)$ from cross-correlation travel-time difference between two earthquakes $(i, j)$ was described by Frechet (1985) as:

$$
\frac{\partial t_{k}^{i j}}{\partial m} \Delta m^{i j}=d r_{k}^{i j}
$$

where $\frac{\partial}{\partial m}$ represents the partial derivative with respect to the parameter $m, \Delta m^{i j}=$ $\left(\Delta x^{i j}, \Delta y^{i j}, \Delta z^{i j}, \Delta t^{i j}\right)$ is the change of relative hypocenter locations, $t_{k}^{i j}$ equals the time difference between each earthquake $(i$ and $j)$, and $d r_{k}^{i j}=\left(t_{k}^{i}-t_{k}^{j}\right)^{o b s}-\left(t_{k}^{i}-t_{k}^{j}\right)^{c a l}$, where $d r_{k}^{i j}$ is the double-difference travel-time residual (the difference between the observed and calculated values of the difference in time between two earthquakes at the same station) (Waldhauser and Ellsworth, 2000).

The Waldhauser and Ellsworth (2000) double-difference location method assumes a constant slowness vector for earthquakes close together. The location method relies on a reasonably dense catalog with closely-spaced earthquakes.

\subsection{Focal Mechanisms and Stress Inversion}

\subsubsection{Focal Mechanisms}

A focal mechanism is a characterization of slip on a plain (a fault) at an earthquake hypocenter. Focal mechanisms provide a visual representation of the propagation of an earthquakes's seismic energy, displayed a projection of the southern hemisphere of a sphere 'a beach ball'. A focal mechanism displays regions of dilatation (tension and compression) that result from initial ground movement at the hypocenter. A negative dilation response is indicated by a 'down' seismic signal response, while an 'up' response is expressive of a positive dilation response. A focal mechanism $(\theta)$ is described by two nodal planes, the strike $(\xi)$, dip $(\delta)$, and rake $(\lambda)$ angles (Figure 2.2).

$$
\theta=(\xi, \delta, \lambda)
$$

Nodal planes define the boundaries between regions of "tension" and "compression". There are two nodal planes, one describes the geometry of the fault plane, the other is known as the auxiliary plane and is orthogonal to the fault plane. Movement on either nodal plane would be satisfactory to generate the displayed focal mechanism. The fault plane is chosen in concert with other geologic factors (e.g., known stress field orientations, fault orientatons, rock fabric orientations, aftershock patterns, etc.).

The strike $(\xi)$ of a fault describes the angle of clockwise rotation (right-hand rule: fault dips to the right), from true north, of the intersection of the fault plane to a horizontal surface. The angle of rotation is measured from $0^{\circ} \geq \xi \geq 360^{\circ}$ (Figure 2.1).

The dip $(\delta)$ is a measurement of the angle downwards to the fault plane from a horizontal plane. The dip is measured from the right of the strike orientation and is 


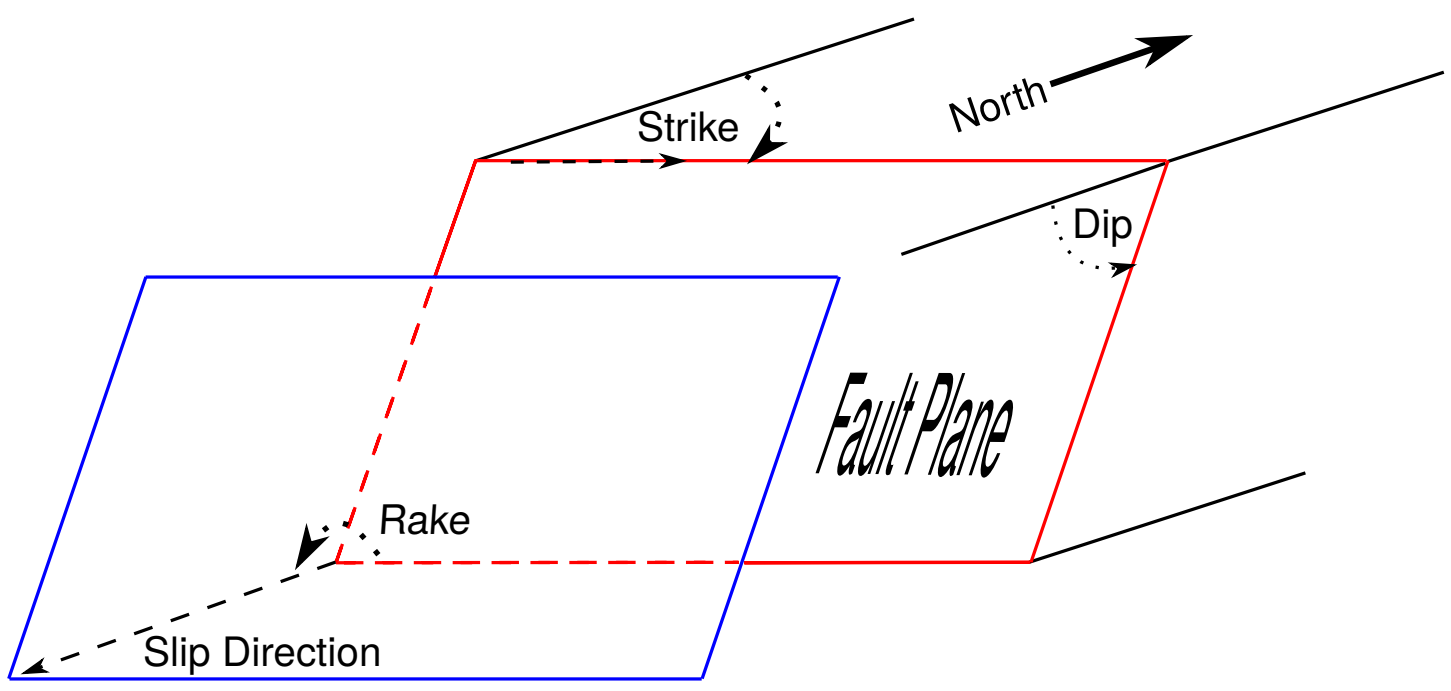

Figure 2.1: Example of the how a strike $(\xi)$, dip $(\delta)$, and rake $(\lambda)$ is measured on a fault. The red plane is the original location of blue plane pre faulting.

measured from $0^{\circ} \geq \delta \geq 90^{\circ}$ (Figure 2.1).

The rake $(\lambda)$ angle is measured on the fault plane and is a characterization of the motion of the hanging wall, counter-clockwise from the strike direction. Rake is measured from $0^{\circ}-360^{\circ}$ (Figure 2.1).

There are three end-member faulting styles: (1) normal; (2) reverse; (3) strike-slip. Focal mechanisms with styles reflective of more than one end member are classified as oblique (e.g., oblique-normal, oblique-reverse). The style of faulting is determined via rake $(\lambda)$ angle.

- $210^{\circ}>\operatorname{normal}($ red $)>330^{\circ}$

- $30^{\circ}<$ reverse (blue) $<150^{\circ}$

- $330^{\circ}>$ strike-slip sinistral (green) $<30^{\circ}$

- $210^{\circ}>$ strike-slip dextral (green) $>150^{\circ}$

According to the Andersonian faulting theory (Stein and Wysession, 2009), each of the three faulting styles are representative of a particular arrangement of the applied stresses (assuming one principal stress is vertical). Focal mechanisms display quadrants of the P- (white Figure 2.2) and T- axis (colored Figure 2.2). The quadrant with the P-axis in it will contain maximum compressive stress $(S 1)$ direction, while the quadrant with the T-axis in it will contain the the minimum compressive stress $(S 3)$ direction. Normal faulting (Figure 2.2 red) occurs in an extensional environment, resulting in a vertical S1-axis and a horizontal S2- and S3-axis. Reverse faulting (Figure 2.2 blue) is initiated in a compressive environment resulting in a horizontal S1- and S2- 


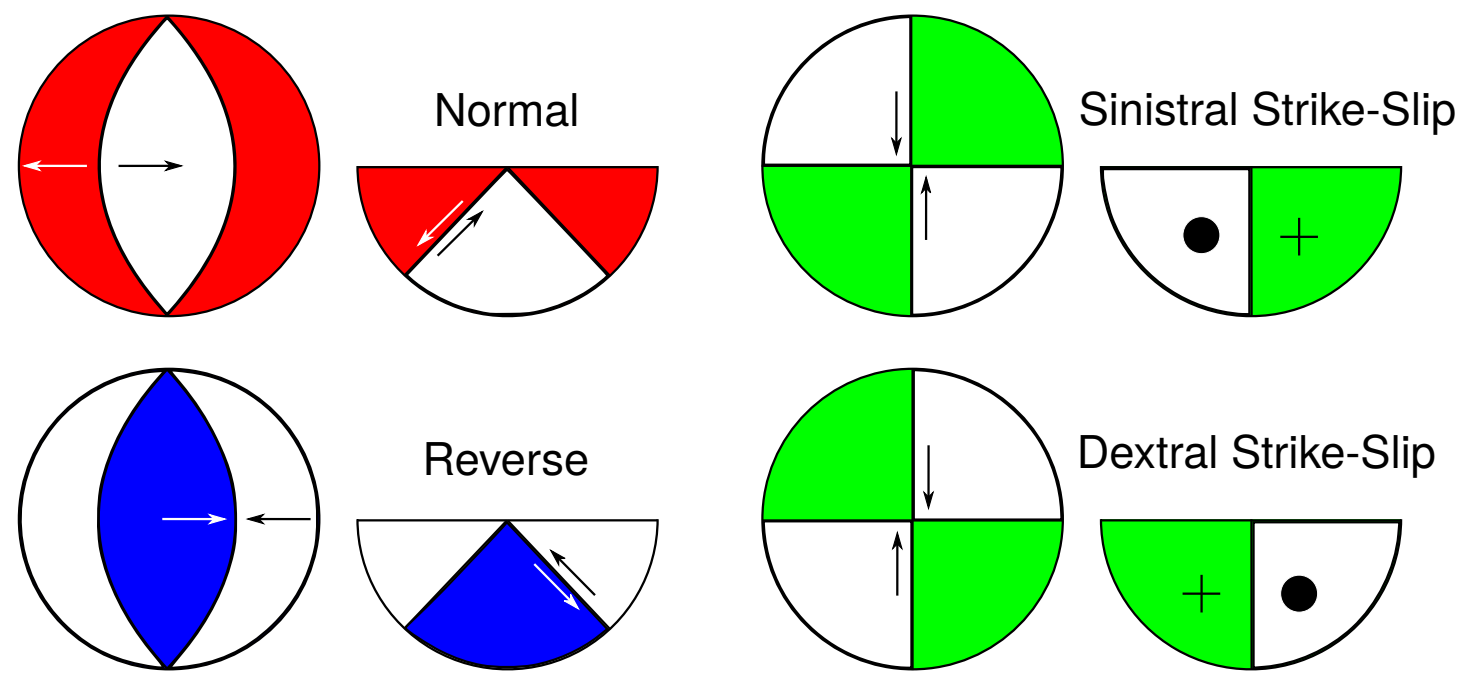

Figure 2.2: Example of normal, reverse, and strike-slip focal mechanisms. In map-view, focal mechanisms are displayed the lower hemisphere. Colored regions indicate first motion compression, white regions indicate first motion expansion. Arrows indicate relative motion across fault plane. On strike-slip focal mechanisms dots show slip towards, while pluses show slip away. In order to determine which nodal plane is the fault plane independent information in needed. Note, these are end member examples of focal mechanisms, oblique focal mechanisms are predominate in nature and would be a combination of either normal and strike-slip or reverse and strike-slip.

axis and a vertical S3-axis. Strike-slip faulting (Figure 2.2 green) results in horizontal S1- and S3-axes and a vertical S2-axis.

For the particulars on the focal mechanism package used see Chapter 3: Stress Orientations Throughout the Southern Hikurangi Margin.

\subsubsection{Stress Inversion}

An individual focal mechanism can only inform about which quadrants the stresses (maximum, intermediate, minimum compressive stress) acted on that particular medium, at that time. In order to characterize a regions entire stress field a study must incorporate a multitude of focal mechanisms located throughout the area of interest. The inversion of a cluster of focal mechanisms results in the calculation of that cluster's average stresses.

A synthetic $3 \times 3$ tensor is used to characterize stress acting on a given medium. Given the symmetry of the stress tensor, there are six independent variables describing the magnitude (in bold) and orientation of the maximum ( $S 1)$, intermediate $(S 2)$, and minimum $(S 3)$ compressional stresses. The inversion of focal mechanisms can provide sufficient information to calculate the orientations of $S 1, S 2$, and $S 3$, as well as the ratio of the relative magnitudes of the stresses. In this study, in order to easily compare with previous studies (e.g., Townend et al., 2012) in New Zealand, stress ratio $(R)$ is defined 


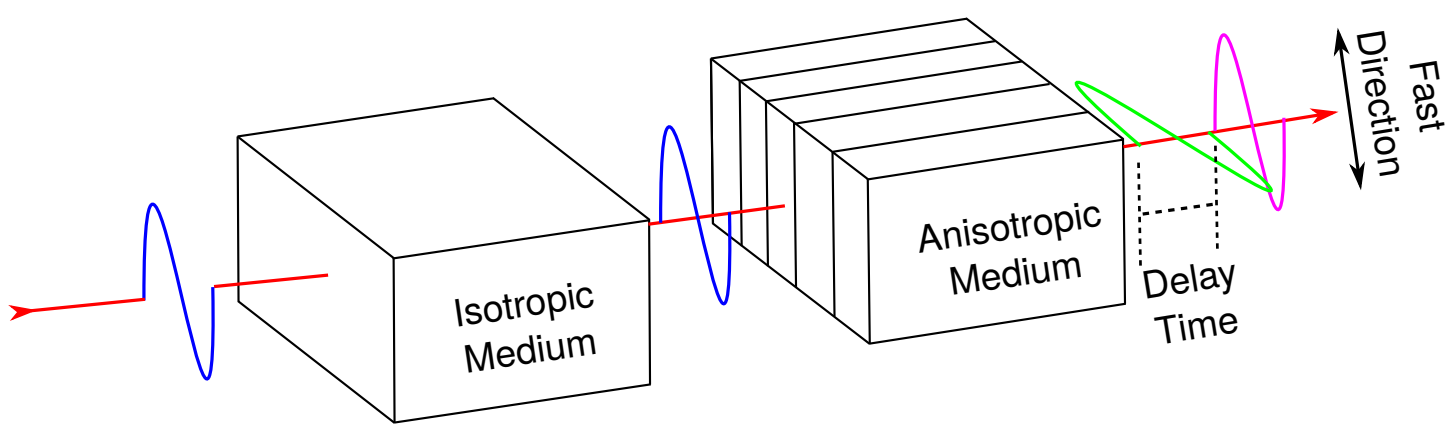

Figure 2.3: Shear-wave splitting example. As a polarized shear-wave (blue) enters an isotropic medium, the shear-wave is unsplit (blue), upon entering an anisotropic medium, the shear-wave becomes split (magenta \& green). Delay time describes the time difference between the arrival of the split waves. Fast azimuth is the orientation of the faster of the two split waves (magenta).

as:

$$
R=\frac{\mathbf{S} 1-\mathbf{S} 2}{\mathbf{S} 1-\mathbf{S} 3}
$$

where the bold characters indicate the stress magnitude. For particulars on the stress inversion estimation package used see Chapter 3: Stress Orientations Throughout the Southern Hikurangi Margin.

\subsection{Seismic Anisotropy}

Seismic anisotropy is a property of a medium that describes the phase velocity dependence on propagation direction or particle motion. Splitting of the shear-wave occurs when a polarized shear-wave encounters an anisotropic body, causing the polarized wave to split. One of split waves will propagate parallel along the fast azimuth (often cracks or crystalline fabric), whereas the other will propagate orthogonal to the fast azimuth or the azimuth of original polarized wave depending on the nature of the anisotropic medium (Figure 2.3).

Shear-wave splitting measurement parameters of interest in this thesis are: (1) fast azimuth of the two polarized waves and (2) delay time between the fast and slow polarized waves. The splitting parameters were calculated using the Multiple Filter Automatic shear-wave Splitting Technique (MFAST) (Savage et al., 2010). For the particulars of the MFAST splitting package see Chapter 6: Shear-wave Anisotropy Across the Southern North Island, New Zealand.

\subsection{Continuous Global Positioning System}

Continuous Global Positioning System (cGPS) datam measure the change in position relative to a designated reference point. Publicly available cGPS daily-solution 
data were downloaded from http://www . geonet.org.nz. The cGPS data are processed by GeoNet using the GAMIT and GLOBK software developed at Department of Earth Atmospheric and Planetary Sciences of the Massachusetts Institute of Technology (MIT). The following section summarizes the processing method (http://www . geonet.org.nz/data/supplementary/gnss_time_series_notes).

1. Solutions are calculated each day for data 1, 3, 30 and 90 days behind Coordinated Universal Time (UTC).

2. Orbits are held fixed and not solved for.

3. International GNSS Service (IGS) final orbits for data 30 and 90 days behind, rapid orbits for data 3 days behind, ultra-rapid orbits for data 1 day behind.

4. Earth orientation parameters from International Earth Rotation and Reference Systems Service (IERS) Bulletin A values (USNO and USND for most recent solutions).

5. Ambiguity resolution by wide-lane and narrow-lane L1 and L2 frequency (= LC, ionosphere free) combination.

6. Absolute IGS phase center corrections for satellite and receiver antennas from igs08-wwww.atx file, provided by MIT.

7. Ocean loading from FES2004 grid ocean tide model.

8. Atmospheric delay estimated using the "global mapping function" (GMF) (Böhm et al., 2006).

9. Atmospheric loading not applied.

10. Depending on the increasing size of the network in time, a loosely-constrained solution is done as increasing numbers of clusters, each of less than about 30 stations and 6 tie sites, that are then combined during the reference frame realization.

11. A final solution is aligned to International Terrestrial Reference Frame (ITRF) 2008, using a 6-parameter Helmert transformation (translation and rotation) onto available and good quality IGS sites in Australia, the south-west Pacific and the Antarctic.

\subsubsection{GPS Reference Frame Transformation}

The methods of Lamb and Smith (2013) were used to transform the cGPS station velocities from the International Terrestrial Reference Frame (ITRF2008) (Altamimi et al., 2012) to an Australian plate Reference Frame (AURF). In this method, the Australian 
plate Euler pole is calculated in the ITRF2008 reference frame, then the inverse of that Euler pole is applied to the New Zealand cGPS station velocity data.

For information on calculation of station velocity, strain parameters, and dislocation modeling, see Chapter 6: cGPS Strain Parameters in the Southern North and Northern South Island of New Zealand. 


\section{Chapter 3}

\section{Stress Orientations Throughout the Southern Hikurangi Margin}

\subsection{Abstract}

We analyze the orientation of the stress field in the southern Hikurangi subduction zone, New Zealand, using focal mechanism inversions, $\mathrm{S}$ wave splitting fast directions, and gravitational stresses. Here the oceanic Pacific plate is being obliquely subducted beneath the continental Australian plate in the New Zealand plate boundary zone. The study makes use of 399 earthquakes for focal mechanism inversion and 425 earthquakes for shear wave splitting analysis, located with a network of seismic stations spanning southern North Island. We distinguish between stresses in the Pacific plate (from focal mechanism inversion) and Australian plate (from $\mathrm{S}$ wave fast directions) and gravitational stresses, in three regions: Western, Central Basin, and Eastern. In the Western region, the principal axis of horizontal compression (SHmax) is oriented NE-SW, parallel to the margin, in the upper Australian and lower Pacific plate. In the Central Basin, SHmax in the Australian plate is oriented NW-SE, perpendicular to the margin; in the lower subducting Pacific plate SHmax is oriented NE-SW. In the Eastern region, SHmax is oriented NE-SW in the upper plate, while in the lower plate there is a change in orientation to NNW-SSE. We interpret the stress orientations of the lower plate in the Western and Central Basin regions as a consequence of bending of the subducting plate. Sources of upper Australian plate stresses are likely to be bending stresses, gravitational stresses, and tectonic loading, with differing relative magnitudes across the study area.

\subsection{Introduction}

Subduction zones are the sites of the largest earthquakes on the planet, where rupture of the plate interface results in the release of stress over large areas, with tens of meters of slip extending up to the surface in the trench. One of the primary controls 
on the faulting process is the regional stress field (Kusznir et al., 1991; Zoback, 1992; Townend et al., 2012). New Zealand, where the oceanic Pacific plate is being obliquely subducted beneath the continental Australian plate. Southern North Island is one of the few places in the world that allows for an on-land seismic deployment above the shallow part of a subduction zone, making it possible to study the subduction zone in greater detail using onshore seismic and geodetic networks.

\subsubsection{Tectonic Setting}

In New Zealand's southern North Island, the contemporary Pacific-Australian plate boundary consists of oblique subduction along the southern Hikurangi margin at $~ 38$ mm/yr (Figure 3.1) (Beavan and Haines, 2001; Beavan et al., 2002).

Surface structural features of the region are dominated by NE-SW striking reverse and dextral strike-slip faults (Figure 3.1, NZ active fault database, www . gn s.cri.nz). Partitioning of deformation results in predominantly dextral shear on the northwestern margin of the onshore part of the plate boundary, with a greater component of reverse faulting farther to the SE toward the trench, a pattern that is also seen in geologic and geodetic measurements (Lamb and Vella, 1987). The combined motion on the major onshore faults accommodates $60-90 \%$ of the margin-parallel motion (Langridge et al., 2005), whereas margin-perpendicular motion is mainly taken up by the subduction thrust (Wallace et al., 2012). This predominantly occurs through episodic earthquake slip on time scales of hundreds to thousands of years. However, the region is also subject to prolific microseismicity, with thousands of earthquakes of $M>3$ in the last 10 years (www. geonet. org.nz), as well as occasional large ( $\mathrm{M} \geq 7$ ) earthquakes and the M8+ 1855 Wairarapa event (Stirling et al., 1998). In addition, slow slip events on the megathrust, lasting weeks to months, occur offshore and farther west, at depths of $\sim 30$ to $60 \mathrm{~km}$, roughly every 6 years (Wallace and Beavan, 2010; Lamb and Smith, 2013; Wallace et al., 2014).

The distribution of interseismic slip on the plate interface varies along the length of the Hikurangi subduction zone, with the greatest proportion of free slip in the northern part (Walcott, 1984; Wallace et al., 2004, 2009, 2012). However, high-resolution decadal campaign GPS measurements of velocity (Beavan et al., 2016) and decadal continuous GPS time series (www . geonet . org. nz) show that the southern part of the plate interface in the vicinity of southern North Island is locked, with strain and stress build up due to slip on the plate interface at depths $>22 \mathrm{~km}$ (Darby and Beavan, 2001; Wallace et al., 2004; Lamb and Smith, 2013). Darby and Beavan (2001) note that if the coupling at the plate interface is variable then maximum coupling occurs between 16 and $24 \mathrm{~km}$ depth. Furthermore, Lamb and Smith (2013) determine the locking point on the interface, which ranges in depth from 5 to $15 \mathrm{~km}$ in the northernmost part of the Hikurangi margin beneath the northeast North Island, to $\sim 35 \mathrm{~km}$ in the southernmost section, south of the study area in the northeast South Island. The sudden release of 


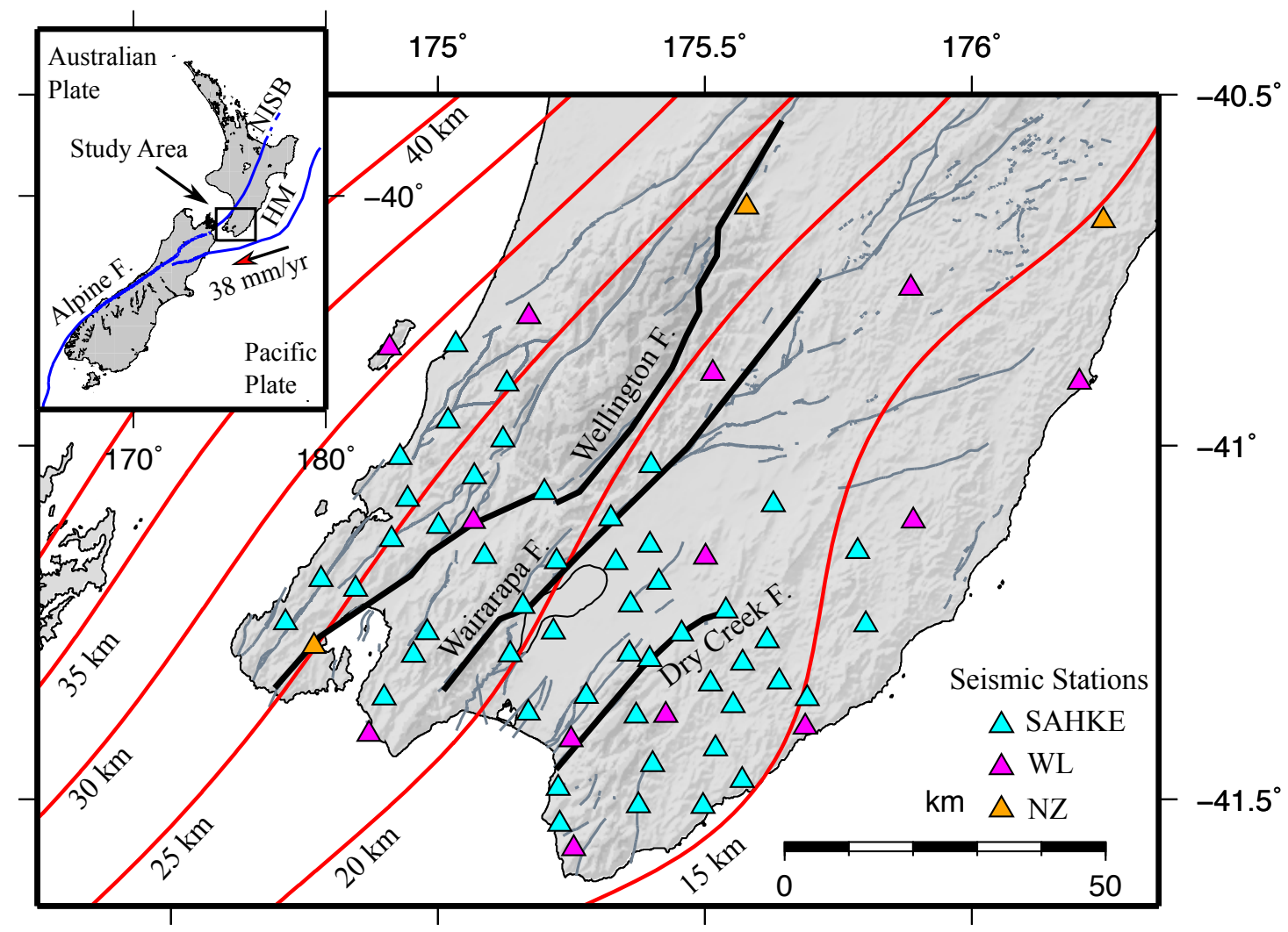

Figure 3.1: Southern Hikurangi subduction zone and seismic array map. Topography is in a gray scale. Red contours show subduction plate interface as modeled by Williams et al. (2013) and bold grey and black lines show traces of active faults; this is same for all relevant subsequent figures. Locations of seismic stations are shown by triangles: Seismic Array Hikurangi Experiment (cyan, November 2009 - March 2010), Wellington Regional Seismic Network (magenta, permanent), and New Zealand National Seismic Network (orange, permanent). Map inset: Study area (box) in context of overall New Zealand tectonics. Pacific plate (subducting) motion relative to Australian plate (overriding) shown by red arrow is $38 \mathrm{~mm} / \mathrm{yr}$. Blue lines are plate boundaries (e.g., location of Hikurangi Margin (HM), North Island Seismic Belt (NISB), and the Alpine Fault). 
the accumulated stress could result in a large megathrust earthquake, which would have far-reaching effects throughout North Island and South Island of New Zealand (Power et al., 2008).

Allen (1978) and Lamb and Vella (1987) used 100 years of retriangulation geodetic measurements to determine the pattern of horizontal strain rates between the Australian and Pacific plates in southern North Island, dividing the strain rates into two components: (1) a shortening rate normal to, and (2) a shear rate parallel to, the strike of the Wairarapa fault. East of the Wairarapa fault, the shorting rate is greater than the shear rate, meaning that compression is the principal deformation force in this region. However, west of the Wairarapa fault, the shear rate is greater than the shorting rate, demonstrating that in this region, deformation is primarily the result of dextral shear parallel to the strike of the Wairarapa fault (Lamb and Vella, 1987; Beanland and Haines, 1998).

\subsubsection{Previous Studies}

There have been few direct observations of the stress field in the southern Hikurangi margin. Lamb (2015) combined strain rates from neotectonic deformation with estimates of the variation in gravitational potential energy (in effect, stresses due to gravity) to infer total deviatoric stress magnitude for the New Zealand plate boundary zone, averaged over the whole thickness of the crust (top $\sim 25 \mathrm{~km}$ ) or lithosphere ( 100 $\mathrm{km}$ ). This showed that average deviatoric stresses are in the range $130 \mathrm{MPa}$, comparable to the gravitational stresses themselves.

Gledhill and Stuart (1996) used shear wave splitting from local earthquakes, recorded on the temporary Tararua array, to study crustal anisotropy in the southern North Island, New Zealand. They determined a fast direction in the Australian plate that was orientated $051^{\circ} \pm 18^{\circ}$ for earthquakes between 5 and $42 \mathrm{~km}$ depth. For earthquakes in the depth range 77-260 km, in the subducted Pacific plate beneath the Taranaki Basin, they determined a fast direction with an azimuth of $041^{\circ} \pm 15^{\circ}$. These orientations are subparallel to both the strike of the subduction zone and to dominant faults in the overlying Australian plate. Audoine et al. (2000) and Brisbourne et al. (1999) concluded that this orientation for the deeper earthquakes reflected trench-parallel flow of the mantle. SKS phases indicated anisotropy in the mantle beneath the lower plate to be oriented $028^{\circ}\left( \pm 11^{\circ}\right)$ (Gledhill and Stuart, 1996). Variation in frequency content for different phases suggested some variations despite a general NE-SW fast alignment (Marson-Pidgeon and Savage, 1997, 2004; Karalliyadda, 2014).

Previous earthquake focal mechanism studies in the southern North Island have focused on the kinematics of active deformation, and their implications for slip partitioning, plate coupling, and earthquake hazards (Reyners et al., 1997; Reyners, 1998; Webb and Anderson, 1998; McGinty et al., 2000). Strong coupling between the Aus- 
tralian and Pacific plates was inferred from slip vectors of intraplate thrust earthquakes (Webb and Anderson, 1998) and an absence of low-angle thrust events at the plate interface (Reyners et al., 1997). Reyners (1998) related the amount of plate coupling to the risk of a large subduction thrust earthquake in the southern North Island, inferring that the subduction zone here is capable of producing a $\mathrm{M}_{W} 8.0$ earthquake. Townend et al. (2012) analyzed the orientation of the stress field throughout the New Zealand plate boundary zone using earthquake focal mechanisms, but with only sparse data in the southern North Island. This showed that in the northernmost South Island and the southwest North Island, at a depth of $20 \mathrm{~km}$ to $50 \mathrm{~km}$, the maximum horizontal stress orientation (SHmax) is subparallel to the strike of the Hikurangi subduction trench. This is consistent with the finding of McGinty et al. (2000) for the northern South Island. Also in the northern South Island, Balfour et al. (2005) found that the average angle between SHmax and the strike of local major faults was $\sim 60^{\circ}$, indicating that the faults were poorly oriented for slipping and were thus weak.

In this study the stress field orientations in the lower plate are determined from stress inversions of focal mechanisms, while the stress field orientations of the upper plate are characterized by crustal anisotropy measurements. We compare these observations with both gravitational stress orientations averaged over the top $25 \mathrm{~km}$ of Australian plate and predicted bending stress orientations in the subducted Pacific plate. This approach may help improve our knowledge of the locked section of the Hikurangi subduction zone by distinguishing between the stress field in the overriding and subducting plates.

\subsection{Seismic Data}

We use earthquakes recorded at 50 stations (48 short period and 2 broadband) that form part of the Seismic Array Hikurangi Experiment (SAHKE) seismic array, deployed between November 2009 and March 2010 (Seward et al., 2010; Henrys et al., 2013). We supplement these stations with permanent GeoNet stations: 3 broadband and 16 short period seismic stations (Figure 3.1). The 2010 Seismic Array Hikurangi Experiment (SAHKE) was designed to investigate the physical parameters controlling a locked megathrust and to characterize slip processes on a segment of the Hikurangi system beneath the southern North Island, New Zealand, summarized in Seward et al. (2010) and Henrys et al. (2013). The experiment was a collaborative effort between GNS Science, Victoria University of Wellington, University of Tokyo, Japan (Earthquake Research Institute), and the Ministry of Economic Development, Crown Minerals.

During the $\sim 5$ month period of the SAHKE deployment, 425 earthquakes (M2+ to $\mathrm{M} 5+$ ) detected at depths $<50 \mathrm{~km}$ were used for crustal anisotropy measurements, and 399 (M2+ to M5+) earthquakes were used as an initial dataset for determining focal mechanisms (Figure 3.2). 


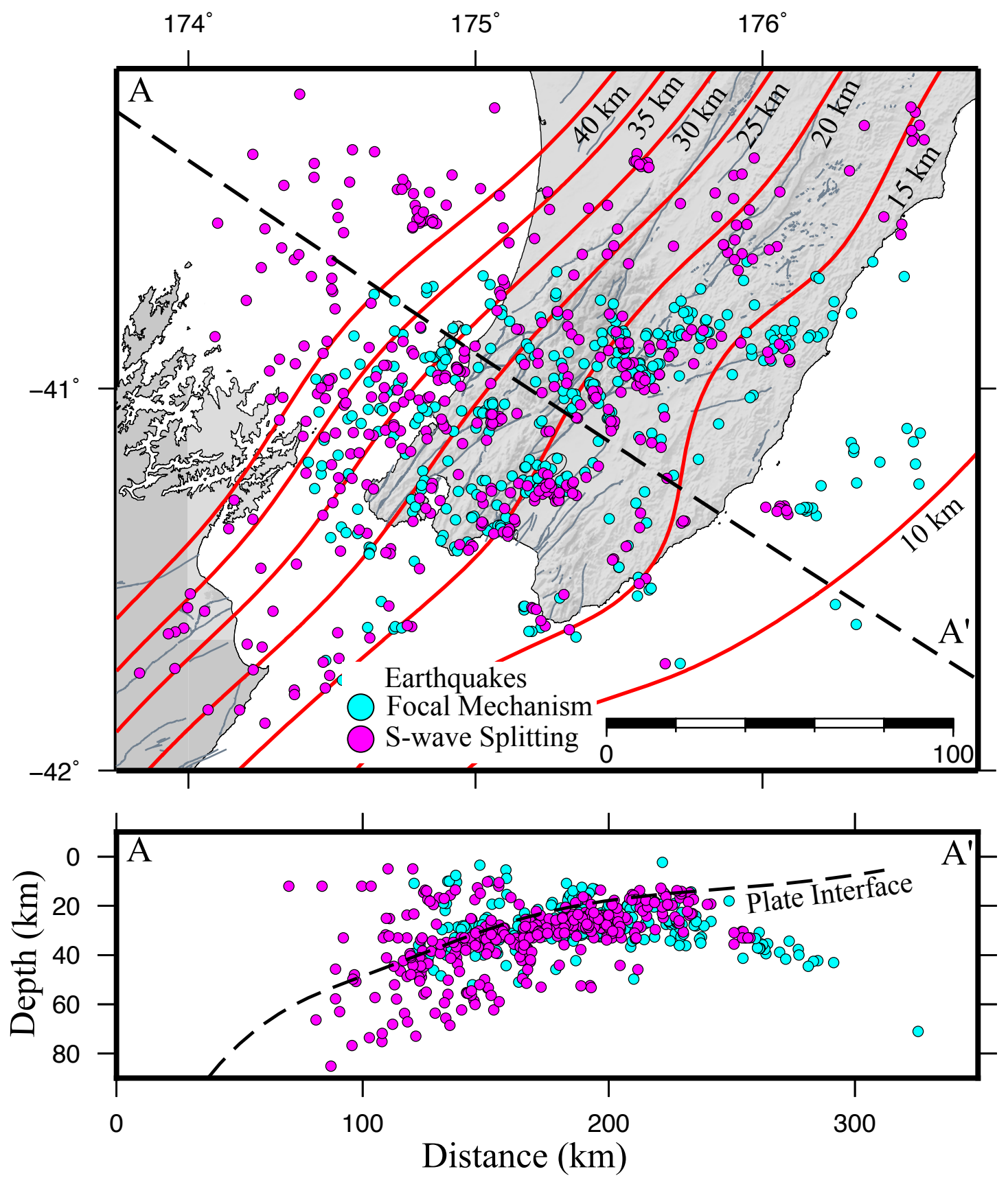

Figure 3.2: Location of 425 earthquakes for $S$ wave splitting (magenta) and 399 earthquakes, used as an initial data set for focal mechanism stress inversion (cyan) portions of this study. See Figure 3.1 for background description. Dashed line A to A' indicates strike of cross-section map. Cross section: Crosssectional view of earthquake location from A to $A^{\prime}$. Dashed line (black) is projected view of plate interface contours. Location differences between common earthquakes used in both data sets are due to the relocation of the focal mechanism data set. 


\subsection{Methodology}

To facilitate comparisons between our inferred stress directions from focal mechanisms, seismic anisotropy and gravitational stresses, we consider stress orientations in the upper (Australian plate) and lower (subducted Pacific plate) plates for three regions spanning southern North Island (Figure 3.3): (1) west of the Wairarapa fault (Western region), (2) between the Wairarapa and Dry Creek faults (Central Basin region), and (3) east of the Dry Creek fault (Eastern region). The boundary between the Western and Central regions is the Wairarapa fault, and the Central Basin region is at a lower average topographic level than the other two (Figure 3.3). Within each region, average SHmax orientations derived from shear wave splitting and gravitational stresses were calculated with the MATLAB Circular Statistics Toolbox (Directional Statistics) package (Berens et al., 2009).

\subsubsection{Shear Wave Splitting Measurements}

Anisotropy in the crust is generally modeled in terms of the effect of near-vertical fluid filled microcracks throughout the crust (Crampin, 1981; Savage, 1999). Differential stresses in the crust will preferentially close cracks that are aligned perpendicular to the maximum principal stress direction (Nur, 1971). Shear wave speed is decreased for waves traversing the cracks, and so cracks in the vertical plane cause a seismic anisotropy with the maximum shear wave speed (fast direction) parallel to the open cracks. Therefore, the maximum horizontal compressive stress (SHmax) orientation is roughly parallel to the shear wave fast directions (e.g. Crampin, 1994). The time between the first shear wave arrival and its orthogonal component is called the delay time. Most shear waves arrive at the surface with near-vertical paths, so cracks in the horizontal plane are not well sampled by shear wave splitting studies.

Shear wave splitting measurements from local earthquakes tend to be scattered (Zhang et al., 2007; Johnson et al., 2011; Karalliyadda and Savage, 2013; Savage et al., 2016). Often shear wave splitting fast orientations change rapidly in short distances, and there is little dependence between delay time and depth. In these cases, anisotropy is interpreted to be shallow. For example, the direction of shear wave splitting near Wellington varied rapidly even between stations spaced only a few kilometers apart (Gledhill, 1991). This is expected because cracks generally close rapidly with depth (Nur and Simmons, 1969) due to the pressure of the overburden. However, mineral and structural alignment can also cause anisotropy (Do Nascimento et al., 2004), so the results need to be examined in concert with other methods.

Often measurements at a single station may be consistent for the same earthquake location but vary for different earthquake locations (Zhang et al., 2007; Johnson et al., 2011). Yet when splitting measurements are averaged regionally, the measurements should align with the maximum horizontal stress (Savage et al., 2016), although some- 


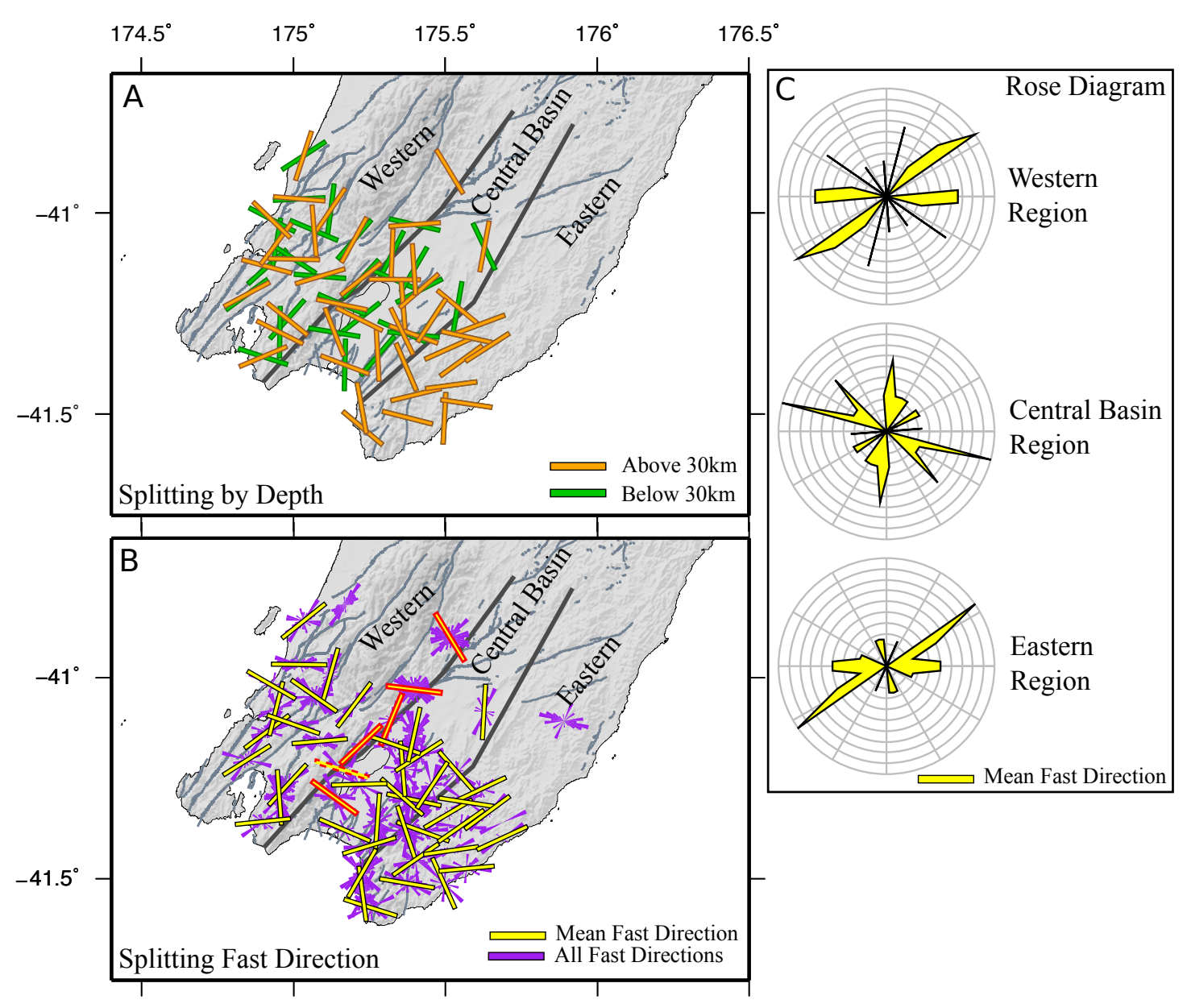

Figure 3.3: Map of splitting fast Azimuths. The study area is divided into three regions, used in subsequent sections of study: Western, Central Basin, and Eastern. (a) Mean fast direction splitting results for earthquakes recorded on the SAHKE array only by depth, above (orange) and below (green) $30 \mathrm{~km}$. Depth of earthquake does not have a great effect on fast direction results. (b) All (purple) and mean (yellow) fast direction measurements from earthquakes of all depths. Results show clear variation in splitting in the Western, Central Basin, and Eastern regions. Yellow bars with red outlines are specifically referred to in the text. (c) Rose diagrams displaying the orientations of the mean shear wave fast direction within the three regions (Western, Central Basin, and Eastern) of the study area. The rose diagram illustrates the spread of the orientations of the shear wave fast direction. Diagrams are scaled by maximum number of events per region. 
times they are more consistent with regional structures or with faulting (Zinke and Zoback, 2000; Balfour et al., 2005).

Multiple processing steps were used to obtain $S$ arrival times in the study area. Earthquakes located by GeoNet (www . geonet . org.nz) were used together with a 1D velocity model (Henrys et al., 2013) and the TauP traveltime routine (Crotwell et al., 1999) to calculate both the expected phase arrival times as well as the ray incidence angles. The expected phase arrival times were used as guides for both manual and automatic picks. Automatic P arrival times were made using Automatic Picking function (Allen, 1978), using Seismic Analysis Code (Goldstein et al., 2003; Goldstein and Snoke, 2005). These $P$ arrival times were used to determine a search window for automatic $S$ waves picks using SpickerC (Castellazzi et al., 2015), which is based on the Diehl et al. (2009) Spicker function. The SpickerC function combines three different phase picking methods: (1) STA/LTA, (2) Polarization filters, and (3) Autoregression modeling. A weighting scheme was applied to the results of the three picking processes to determine the final pick and obtain an error estimation on those picks (Diehl et al., 2009). No relocations were carried out for this part of the study, because measurements of delay time and fast direction are not strongly dependent on location.

For crustal anisotropy analysis, fast direction and delay time were calculated for individual earthquake-station pairs using the Multiple Filter Automatic Splitting Technique (MFAST) (Savage et al., 2010). MFAST uses the following steps: (1) a set of bandpass filters is applied to the $S$ arrival waveform to find the filter that yields the maximum product of the signal-to-noise ratio (SNR) and bandwidth; (2) using multiple measurement windows, a grid search over the fast azimuth and the delay time parameter space is performed on the waveforms filtered at the best bandpass filter. The search determines the fast direction and delay time that best corrects for splitting, as measured by the minimum of the smallest eigenvalue of the corrected particle motion (Silver and Chan, 1991); (3) an unsupervised cluster analysis (calculation of cluster's $\mathrm{R}^{2}$ value)(Teanby et al., 2004) is applied to the fast direction azimuth and delay times to determine the most stable solution; (4) MFAST automatically grades the earthquakestation pair measurements from A to D, based on the following four criteria: (I) SNR, (II) uncertainty, (III) distinctiveness of the cluster (cluster with smallest $\mathrm{R}^{2}$ value), and (IV) whether the measurement is null. Null measurements occur when either there is little anisotropy or when a wave arrives at an anisotropic medium with its polarization parallel or perpendicular to the fast direction in these cases, the wave is not split. Null measurements can be identified by U-shaped confidence intervals, which allow for any amount of splitting in two narrow bands of possible fast directions that are parallel to the calculated incoming polarization direction. The MFAST program considers null measurements to be measurements with delay times within $80 \%$ of the highest value allowed in the grid search (1.0 s here, local event delay times should be $<<1 \mathrm{sec}$ ), or with fast directions within $20^{\circ}$ of either in the incoming polarization or its 
perpendicular.

In this study we use the A and B quality measurements with incidence angles less than $35^{\circ}$ from the vertical, calculated using the earthquake locations and the 1-D velocity model of Henrys et al. (2013). A and B quality measurements meet the following criteria: (I) SNR $>3$, (II) error in fast direction $<25$ degrees, and (III) the measurement is not null.

As shown by Wilson (2016) in his Figure 3.5, scatter plots of the delay times versus raypath lengths show that the delay time is not cumulative along the path length of the ray. This suggests that the delay time does not result from a homogeneous region of anisotropy but is likely to be due to near-surface stress or structures. To further examine the anisotropy as a function of depth, we divide the earthquake measurements, recorded on the SAHKE array only, into two depth bins: (1) above (226 events) and (2) below $30 \mathrm{~km}$ (209 events) (Figure 3.3a). There was an attempt to further subdivide the data into a third depth bin of above $15 \mathrm{~km}$, but there were only 22 earthquakes, an insufficient amount to calculate reliable results. Plots of delay time versus the dominant frequency of the incoming waveforms for splitting measurements indicate that there is no dependency of delay time on the frequency of the incoming waves (i.e., splitting is frequency independent).

\subsubsection{Focal Mechanism Inversion}

Earthquake focal mechanisms can serve as in-situ gauges of stress because earthquakes occur when the ambient stress field exceeds the local strength of rocks or the frictional strength of a preexisting fault, and the kinematics of rupture of a random array of faults directly reflects the orientation of the stress field. Arnold and Townend (2007) developed a Bayesian method to invert clusters of earthquake focal mechanisms for the orientation of the stress field. They assumed that the stress field is homogeneous and faults are randomly oriented, with equal probability of either nodal plane being the fault plane, and that individual faults are blind to rupture on neighboring ones. Subject to these assumptions, and with sufficient unique earthquake clusters, it should be possible to determine the variation of the orientation of the stress field, within a given region.

Starting with initial locations by GeoNet (www . geonet . org . nz), 399 earthquakes arrivals and polarities were repicked by hand using the Seisan Earthquake Analysis Software (SEISAN) package (Havskov and Ottemoller, 1999). The handpicks were then used for hypocentral calculations, initially with a 1-D seismic velocity model (Henrys et al., 2013) and HYPOCENTER (Lienert et al., 1986; Lienert and Havskov, 1995), and then refined with a full 3-D velocity model (Eberhart-Phillips et al., 2010) and the nonlinear location package NonLinLoc (Lomax et al., 2000).

The stress inversions and focal mechanisms, using $\mathrm{P}$ wave polarities, were calcu- 
lated using the Bayesian method of Arnold and Townend (2007) and Walsh et al. (2009), respectively. The Walsh et al. (2009) method of calculating focal mechanisms models the entire data generation process and incorporates multiple observational errors (i.e., hypocenter location, seismic velocity structure, and P wave polarities). The Arnold and Townend (2007) stress inversion method incorporates fault plane ambiguity and observation errors. As in Walsh et al. (2009), focal mechanisms $(\theta)$ are expressed as a function of their strike $(\xi)$, dip $(\delta)$, and rake $(\lambda)$ :

$$
\theta=(\xi, \delta, \lambda)
$$

Computed focal mechanism were deemed reliable based on two quality control parameters: number of polarity picks $(\mathrm{P} \rho)$ and precision $(\tau)$. Arnold and Townend (2007) expressed by the following relationship:

$$
\sigma_{\theta}=e^{3.9155-0.5659 \log \tau}
$$

where $\sigma_{\theta}$ is the standard deviation of the uncertainties in the angles of $\xi, \delta$, and $\lambda$, of a given $\theta$. The minimum number of $\mathrm{P} \rho$ needed and the minimum value of $\tau$ for a focal mechanism to be considered reliable in this study were 5 and 2, respectively, where a precision of 2 is equivalent to approximately a $33^{\circ}$ standard deviation of the strike, dip, and rake directions. Although a minimum of 5 polarity picks for a focal mechanism is unusually low, the Walsh et al. (2009) Bayesian method allows for location of the polarity pick on a focal sphere to be taken into account, when assessing focal mechanism quality (i.e., error estimation). Thus, a focal mechanism with a low number of $\mathrm{P}$ wave polarity picks could return a low-error focal mechanism, given stations in ideal locations on the focal sphere.

Focal mechanisms, located only in the subducting plate with at least 5 polarity picks and an error less than $33^{\circ}$ are used in the stress inversions. We separated the earthquakes into clusters based on a visual analysis of which region they were located (i.e., Western, Central Basin, and Eastern) (Figure 3.4a).

The stress inversion routine returns the orientation of the three principal stresses and the stress ratio for each cluster of earthquakes (Arnold and Townend, 2007). The orientation of SHmax is calculated with the method of Lund and Townend (2007), making it possible to compare with SHmax derived from shear wave splitting and gravitational stresses. Stress ratio is defined here as $(\mathrm{S} 1-\mathrm{S} 2) /(\mathrm{S} 1-\mathrm{S} 3)$, where $\mathrm{S} 1$ = maximum compressive stress magnitude, $\mathrm{S} 2$ = intermediate compressive stress magnitude, and S3 = minimum compressive stress magnitude (e.g. Townend et al., 2012). 

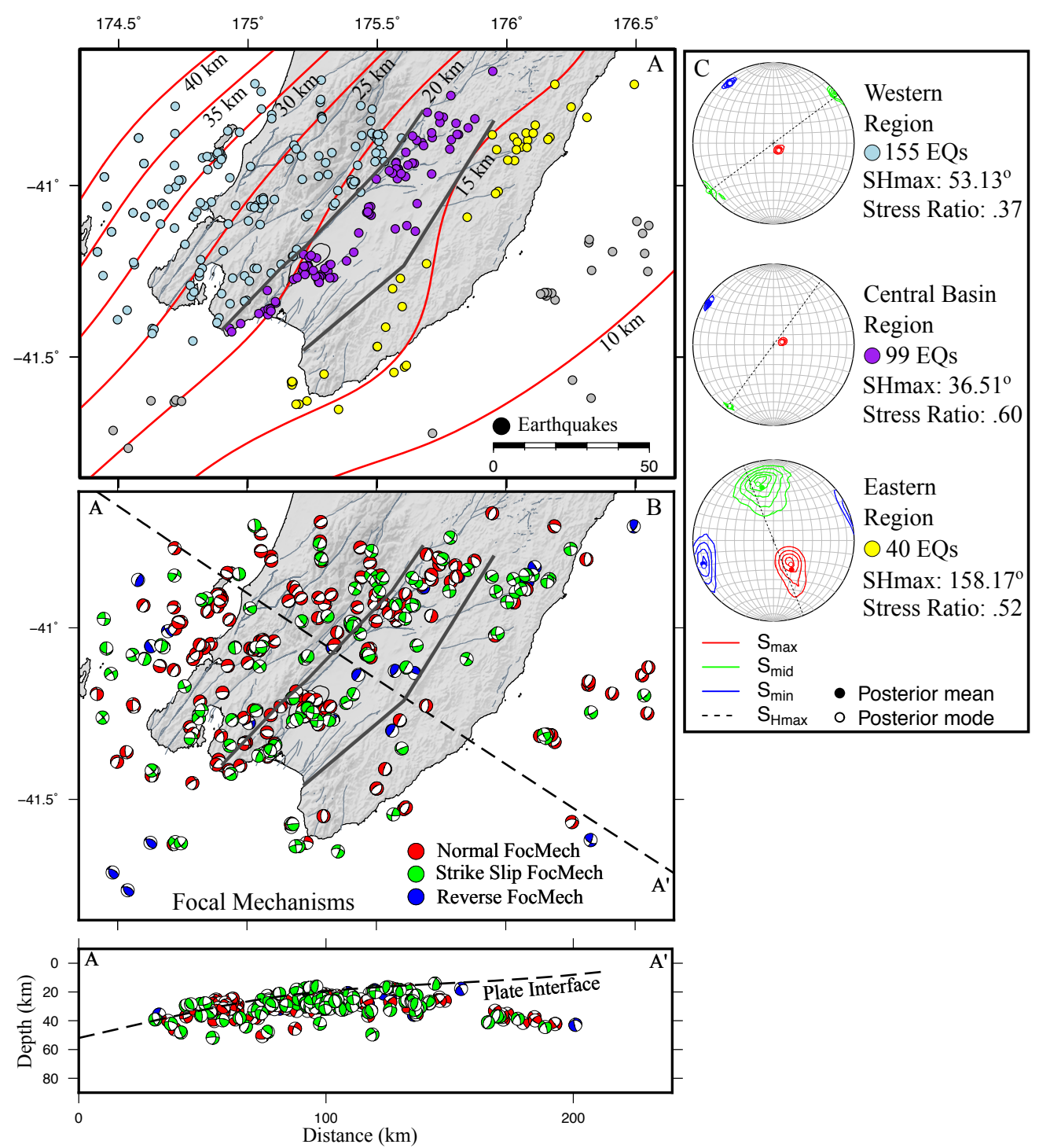

Figure 3.4: Map of Bayesian calculated focal mechanisms and clusters of focal mechanisms used to calculate stress parameters. Red contours and grey faults are as in Figure 3.1. (a) Three clusters used for stress inversion: Western (light blue), Central Basin (purple), and eastern (yellow). Grey earthquakes were not used in stress inversion. (b) Focal mechanisms calculated using a Bayesian method from Walsh et al. (2009). Focal mechanism are colored by rake: 150。 $<$ Normal (red) $<30 \circ$; 30॰ $>$ Reverse (blue) $<150 \circ$; 30॰ $>$ Strike slip (green) $>30 \circ$; 150॰ > Strike slip (green) > 150॰. Dashed A to A' line indicates strike of cross-section map. Cross section: Cross-sectional map of focal mechanism projected onto a vertical plane from A to A0. Dashed line (black) location is projected view of plate interface contours. The subducting plate (potentially including plate interface earthquakes) has $\sim 58 \%$ normal focal mechanisms. (c) Three stress inversions calculated in each one of the three regions. Stereonets show the distribution of S1 (red), S2 (green), and S3 (blue) axes, as well as the orientation of SHmax (black dashed lines). The posterior probability mean (solid circle) and mode (open circle) are colored as per stress axis. 


\subsubsection{Gravitational Stresses}

Unlike stress measurements from earthquake data, which only contain information about the directions and relative magnitudes of the principal stresses (Arnold and Townend, 2007), it is straightforward to calculate the magnitude and orientations of gravitationally induced stresses, given the density of crustal rocks, together with crustal structure and surface topography (i.e., stress $=$ density $\times$ gravity $\times$ thickness). Here we concentrate on the stress orientations to compare with the other stress measurements.

We use the topography in the southern part of the Hikurangi margin to calculate the SHmax directions and magnitudes of the gravitationally induced stress field, averaged over the top $\sim 25 \mathrm{~km}$ (the maximum depth of the plate interface in this area) of the crust (Lamb, 2015), with an average density of $2.67 \mathrm{~g} / \mathrm{cm}^{3}$, using the method of Flesch et al. (2001). The Flesch et al. (2001) method involves solving the stress balance equations for an isotropic viscous medium, subject to a mean vertical stress determined by topography, and a horizontal boundary condition of zero deviatoric stress. Using the Flesch et al. (2001) method, vertically averaged deviatoric stresses due to variations in gravitational potential energy were solved using a thin sheet approximation. The modeling was preformed using finite difference methods in MATLAB. The stress field reflects long-term variations in gravitational forces at a length scale of tens of kilometers and thus is representative of these stresses at comparable depths-note that short wavelength shallow stresses at depths $<5 \mathrm{~km}$ may be quite different from those we calculate, reflecting the elastic response to short wavelength topography (Molnar, 2004). Based on the wavelength of the topography in the southern North Island, there is approximately a $\pm 10^{\circ}$ error associated with the SHmax orientations. The gravitational stress field provides a calibration of the magnitude of the total stress field in the Australian plate, and if it dominates the total stress field, then we would expect to see SHmax varying closely with topography, aligned more-or-less parallel (at high points) or orthogonal to (at low points) topographic gradients.

\subsection{Results}

\subsubsection{Shear Wave Splitting}

After incidence angle filtering, 13,807 A and B quality $S$ wave splitting measurements were made from 425 earthquakes. Table 1 presents the number of measurements, circular mean, and $95 \%$ confidence interval calculated for individual stations. Overall, the more measurements there are, the lower the error, with a few exceptions (e.g., stations TRWZ, S001). The widest $95 \%$ confidence interval $\left(\sim 24^{\circ}\right)$ is for station PLWZ. These small confidence intervals emphasizes reliability of the shear wave splitting results.

In the Western and Central Basin regions, there was general agreement between 
measurements made for earthquakes above and below $30 \mathrm{~km}$. The average of the mean fast directions within the Western and Central Basin regions were within $10^{\circ}$ and $14^{\circ}$, respectively, when comparing measurements using earthquakes above and below $30 \mathrm{~km}$. (Figure $3.3 \mathrm{~b}$ and supporting information Figure 8.1). This suggests a similar source of seismic anisotropy for earthquakes in both depth intervals and thus that the anisotropy measured is shallow. With an average raypath of $15 \pm 5 \mathrm{~km}$ and an average regional delay time of $0.15 \mathrm{~s}$, we calculate the strength of anisotropy to be 3.7 $\pm 1.2 \%$, which agrees with the Gledhill and Stuart (1996) estimate of $4 \%$ for the region. If shear waves encountered a deeper region of anisotropy that differed in orientation from those near surface, then the shear waves were likely resplit at the near surface (Crampin and Lovell, 1991) Therefore, we consider the entire set of earthquakes in our further discussions.

In the Western and Eastern regions, the mean fast orientations trend NE-SW to ENE-WSW, approximately parallel to the strike of the major faults in the Australian plate, such as the Wairarapa fault, and to the depth contours of the subducted plate (Figure $3.3 \mathrm{~b}$ and $\mathrm{c}$ and Table 1). In contrast, in the Central Basin region, the mean fast direction orientations trend NW-SE, approximately perpendicular to these faults and to fast orientations in the other regions. Of note is station S022 (highlighted red dashed line) (Figure 3.3b), which is near the Wairarapa fault. This station showed a significant population of fast directions parallel and perpendicular to the Wairarapa fault. This effect is not present at other stations (S021, S023, LTN6, S039, and HOWZ: high-lighted red) (Figure 3.3b and Supporting Information Figure 8.2) along the Wairarapa fault and is therefore considered to be a localized effect.

\subsubsection{Focal Mechanisms}

Using NonLinLoc (Lomax et al., 2000), 384 earthquakes were located with a mean standard deviation (STD) of 0.32 and $0.38 \mathrm{~km}$ in the horizontal and $0.62 \mathrm{~km}$ in the vertical. We used 384 events as inputs for the Bayesian focal mechanism method of Arnold and Townend (2007). Based on the two quality control parameters used in this study, 334 focal mechanisms were deemed appropriate for the stress inversion process. Of these, 314 were located in the subducted plate (Figure 3.4b) based on the plate interface position from Williams et al. (2013). Only focal mechanisms located in the subducting plate were used in the subsequent stress inversion, because of the lower number of shallow earthquakes.

In terms of standard rake conventions (see Figure 3.4), the calculated focal mechanisms consisted of 181 normal, 30 reverse, and 103 strike-slip earthquakes. Normal faulting is dominant in the subducting plate, comprising $\sim 58 \%$ of the earthquakes detected. 


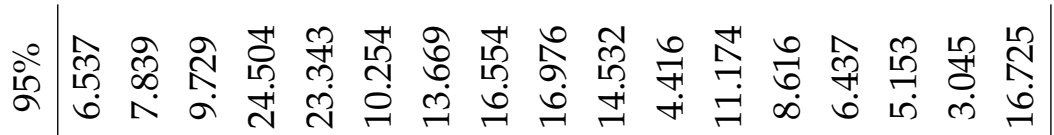

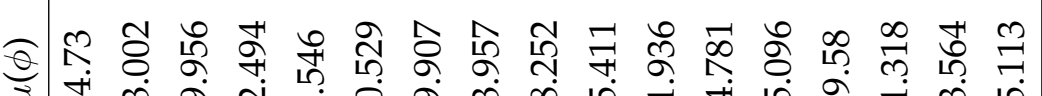

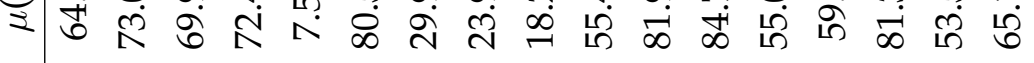

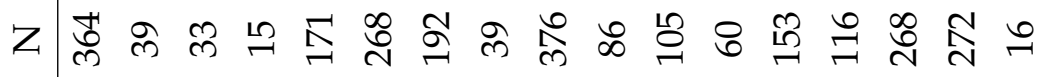

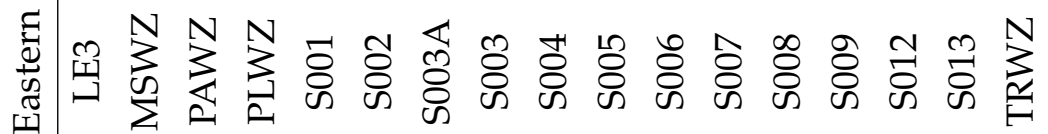

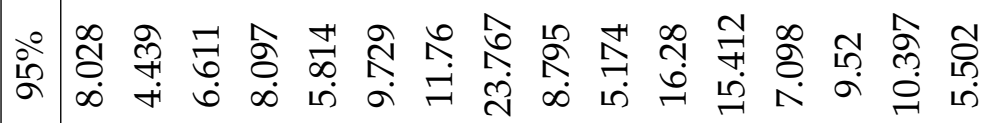

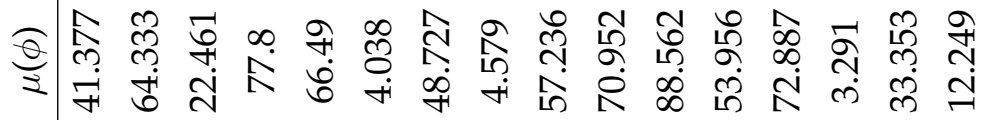

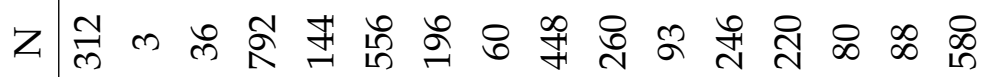


Table 3.2: Information of Clusters Used in Stress Inversion and the Resulting Stress Regime and SHmax Orientation (Degrees East from North)

\begin{tabular}{lllll}
\hline Region & Color & Size & Stress ratio & SHmax mean \\
\hline Western & Light blue & 155 & $0.37 \pm 0.13$ & $53.13 \pm 16.72$ \\
C. Basin & Purple & 99 & $0.60 \pm 0.13$ & $36.51 \pm 16.72$ \\
Eastern & Yellow & 40 & $0.52 \pm 0.28$ & $158.17 \pm 29.41$ \\
\hline
\end{tabular}

Note. Size of cluster indicates the number of focal mechanism used in each cluster. \pm signs indicate the bounds of the 95\% confidence interval for stress ratio and SHmax mean.

\subsubsection{Stress Inversions}

We grouped 294 focal mechanisms into two sets of clusters for stress inversion, one set comprising 20 clusters with an average of 16 focal mechanisms per cluster (supporting information) and the other set comprising 3 clusters, with an average of 98 focal mechanisms per cluster (Figure 3.4 and Table 2). For each cluster, the best fit S1, S2, and S3 are contoured by probability density and are presented with posterior mode and mean values for the three principal stress orientations, and the SHmax orientation (Figure $3.4 \mathrm{c})$.

Table 2 presents the number of focal mechanisms used in each cluster and the resulting SHmax orientation and corresponding 95\% confidence interval, for the Bayesian inversion (Arnold and Townend, 2007). The stress inversions done in the Western and Central Basin regions give similarly tight $95 \%$ confidence intervals for mean SHmax. Given the lower occurrence of earthquakes and mixture of focal mechanisms in the Eastern region of the study area (Figure 3.4b), the cluster there is associated with larger confidence intervals and less constraints than either of the other two clusters. Overall, the tight constraints for the components of stress indicate the dependability of the stress inversion results. In order to further refine the orientations in the stress field a more refined clustering technique was done using nearest neighbor k-means, resulting in 20 clusters and 20 stress inversions. The results can be found in the supporting information.

The stress regimes of the three clusters showed some variation, but the three inversions yielded vertical or subvertical S1 and horizontal S2 and S3, denoting a normal faulting stress regime (Figure 3.4c). The stress inversion located in the Eastern region shows less constraint on S1, S2, and S3, as well as a change of the S2 and S3 orientations to NNW and ENE trend, respectively. The change of the orientations of the principal stresses in the Eastern region is highlighted by the elevated occurrence of strike-slip focal mechanisms in this region (Figure 3.4b). Of note is the slight difference in the 
stress ratio between the Western $(0.37 \pm .13)$ and Central Basin region $(0.60 \pm .13)$. A low stress ratio would indicate that S2 is closer to S1 than to S3 (S1 $>$ S2 $>>S 3$ ), while a high stress ratio indicates $\mathrm{S} 2$ is closer to $\mathrm{S} 3$ than $\mathrm{S} 1$ (S1 $>>\mathrm{S} 2>\mathrm{S} 3$ ).

There is a general agreement between the SHmax directions in this study and the available previous determinations by Townend et al. (2012). SHmax has a clear NESW trend within the Western and Central Basin regions $\left(53.13 \pm 16.72^{\circ}\right.$ and $36.51 \pm$ $16.72^{\circ}$, respectively), more-or-less parallel to the depth contours of the subducting plate (Williams et al., 2013). However, SHmax in the Eastern region have a NNW-SSE $(158.17 \pm 29.41 \circ)$ trend (Figure 3.4c).

\subsubsection{Gravitational Stress Field}

In the Eastern and Western regions, the mean SHmax orientations for gravitational stresses induced by topography ( $35.4 \pm 16.2^{\circ}$ and $59.4 \pm 13.7^{\circ}$, respectively) align parallel to the subducted slab depth contours and the strike of the Wairarapa fault, whereas in the Central Basin region, the SHmax orientation trends approximately perpendicular to the strike of the Wairarapa fault and the depth contours of the plate interface $\left(167.3 \pm 16.4^{\circ}\right)$. In the Eastern region the SHmax orientations of gravitational stresses trend NW, similar to the Western region, but include variability, with trends in a WNW and W orientation, due to topography including the Aorangi mountain range in the south (Figure 3.5 and Table 3).

\subsubsection{Comparison of Methods}

Of the methods presented in this study (shear wave splitting, focal mechanism inversion, and gravitational stress estimation) only the inversion of focal mechanisms are a direct measure of in situ stress, and thus the most reliable. Shear wave splitting fast directions are assumed to align with the orientations of the principal axes of stress, and gravitational stresses are vertical averages (top $25 \mathrm{~km}$ ) based on long wavelength topography and models of crustal structure (tens of kilometers scale). The long wavelength features of the depth-averaged gravitational stress field are likely to be robust because the sources of these stresses are well constrained, but there may be significant short wavelength perturbations due to smaller scale variations in topography and crustal structure.

Figure 3.6 illustrates the robustness of the data calculated throughout this study, showing relatively small $95 \%$ confidence intervals for the three methods in each of the three regions of the study area. The exception is the shear wave fast direction in the Central Basin, which has a $95 \%$ confidence interval of $\sim 70^{\circ}$ (Table 3.4). The larger confidence interval is not due to a lack of coverage or data, but from the bimodal distribution of the mean fast directions in the region (Figure 3.3c)the reason for this remains unclear. In the Western region, the three measurements are oriented NE-SW. The Central Basin region yields variations between the three calculated orientations: 
Table 3.3: Orientation of the Maximum Horizontal Compressive Stress (SHmax) Due To Gravitational Loading at Each Station Calculated via Nearest Neighbor

\begin{tabular}{cccccc}
\hline Western & GS SHmax & Central Basin & GS SHmax & Eastern & GS SHmax \\
\hline HOWZ & 85.15 & LE2 & 16.261 & LE3 & 34.225 \\
LTW1 & 71.399 & LE4 & 47.266 & MSWZ & 13.475 \\
LTW2 & 63.504 & LTN6 & 14.82 & PAWZ & 47.37 \\
LTW3 & 30.816 & S010 & 37.966 & PLWZ & 20.39 \\
S023 & 23.812 & S014 & 58.36 & S001 & 45.349 \\
S025 & 31.089 & S015 & 43.85 & S002 & 8.4299 \\
S026 & 44.902 & S016 & 00.95 & S003 & 33.48 \\
S027 & 44.902 & S017 & 12.43 & S003A & 59.529 \\
S028 & 46.404 & S018 & 22.74 & S004 & 15.774 \\
S029 & 80.017 & S019 & 21.91 & S005 & 26.74 \\
S030 & 58.204 & S020 & 39.38 & S006 & 78.768 \\
S031 & 66.076 & S021 & 19.505 & S007 & 31.58 \\
S032 & 34.911 & S022 & 14.029 & S008 & 68.529 \\
S033 & 86.137 & S040 & 44.39 & S009 & 48.327 \\
S037 & 62.208 & S043 & 30.417 & S012 & 46.63 \\
S039 & 31.32 & S044 & 32.44 & S013 & 47.372 \\
WAIK & 69.47 & & & TRWZ & 47.266 \\
\hline
\end{tabular}

Note. Columns 1, 3, and 5 correspond to the Western, Central Basin, and Eastern regions. The orientations are presented for stations where a mean fast direction was calculated. An estimate of the errors associated with SHmax from gravitational stresses would be approximately $\pm 10^{\circ}$ based on the wavelength of the major topographic features. 


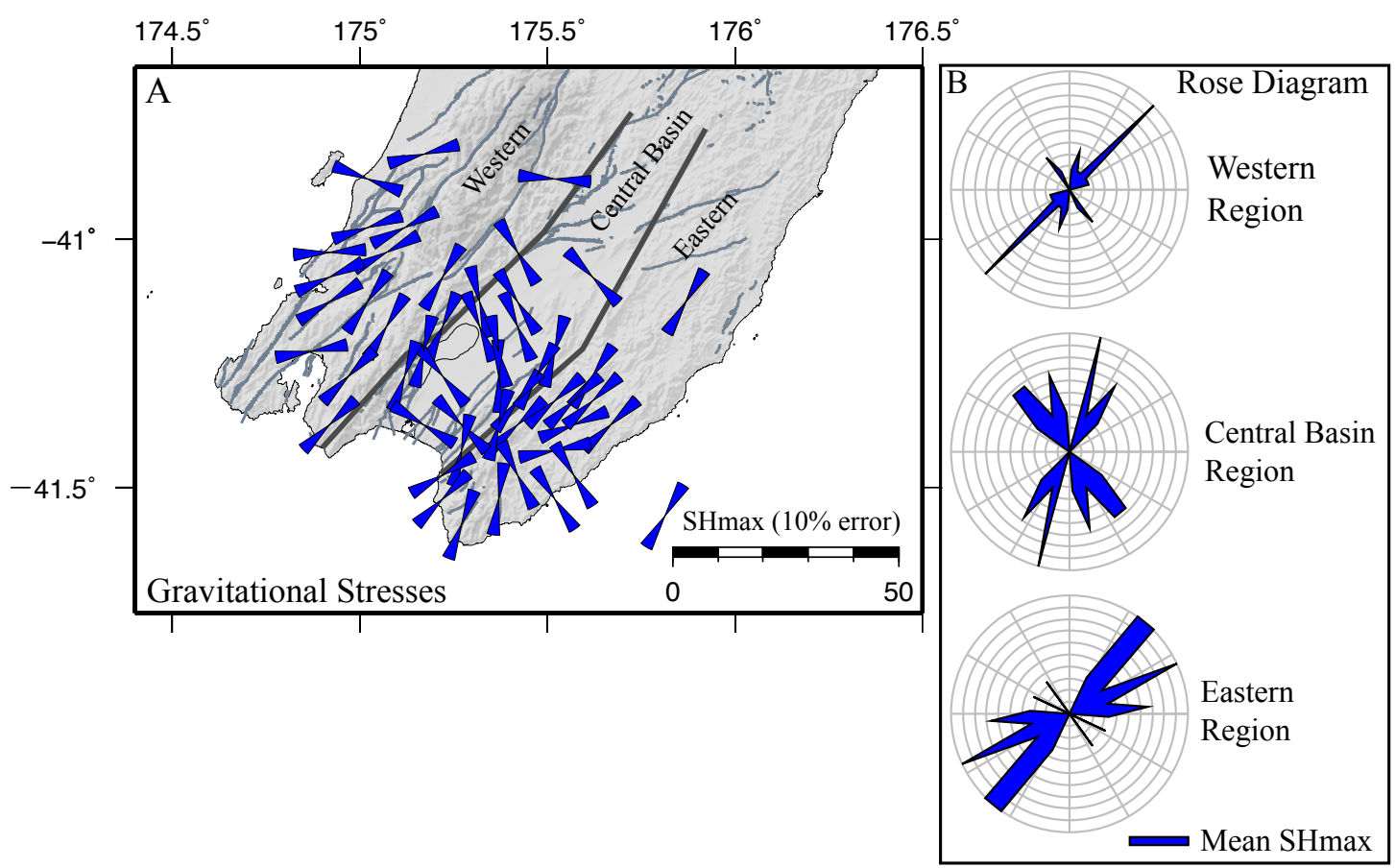

Figure 3.5: (a) Map of SHmax from gravitational stresses including $\pm 10^{\circ}$ error based on wavelength of topography. Orientations of SHmax in the Western and eastern regions align roughly parallel to strike of the mountain ranges and the range-bounding faults, whereas in the Central Basin region, orientations are more perpendicular to the ranges. (b) Rose diagrams displaying the orientations of the mean SHmax from gravitational stresses. Rose diagrams illustrate the spread of the mean SHmax orientations in the Central Basin and Eastern regions. 


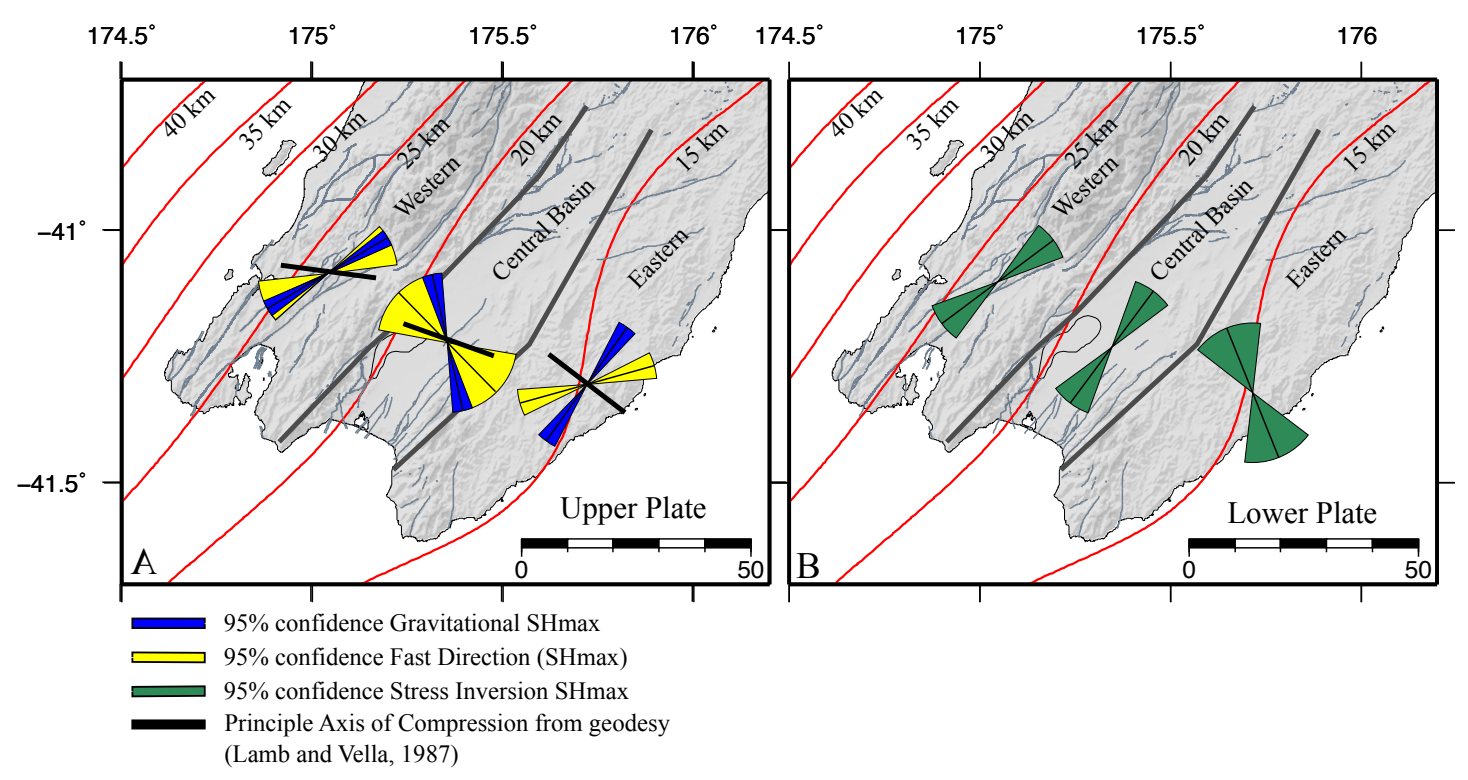

Figure 3.6: Map of (a) mean orientations and $95 \%$ confidence interval of splitting fast directions (yellow), SHmax from gravitational stresses (blue), and the general trend of principal axis of compression (thick black line) (adapted from geodetic measurements in Lamb and Vella (1987)) and (b) SHmax from focal mechanism inversion (green). Thin black lines within the $95 \%$ confidence interval indicate the mean value of the measurements. Red contours and grey faults as in Figure 3.1.

SHmax from focal mechanism inversion NE-SW; fast direction from splitting NW-SE; and SHmax from gravitational stresses NNW-SSE. The Eastern region displays a return of an approximate NE-SW orientation for SHmax based on gravitational stresses and fast direction of splitting. SHmax from focal mechanism stress inversion rotates to a NNW-SSE orientation, oblique to the trend of the plate interface depth contours.

\subsection{Discussion}

\subsubsection{Stresses in the Subducted Pacific Plate}

The SHmax orientations calculated from focal mechanism inversion within the slab are parallel to the strike of the subducting plate and margin in the Western and Central Basin regions, becoming more perpendicular in the Eastern region (Figure 3.4c). The stress orientations are associated with abundant normal and strike-slip faulting in the subducting plate in the Western and Central Basin regions of the subduction zone (Figure 3.4b). These results corroborate those of Reyners et al. (1997), McGinty et al. (2000), Du et al. (2004), and Reyners and Bannister (2007), who found focal mechanisms that ranged from strike-slip to normal within the subducting plate.

Bending of the subducting plate results in outer-arc extension above the neutral plane of the plate, and compression beneath the neutral plane (e.g. Buffett and Becker, 
2012). Previously, Frepoli et al. (1996) showed an in-plane compressional stress regime in the subducting slab in the Southern Tyrrhenian subduction zone for depths ranging from 45 to $165 \mathrm{~km}$. These finding have been further confirmed by detailed numerical modeling done by Babeyko and Sobolev (2008), which have an in-plane maximum compressive stress regime for depths ranging from $40 \mathrm{~km}$ to $100 \mathrm{~km}$. In New Zealand, Arnold and Townend (2007) found an in-plane compressional stress regime northwest of the southern North Island at depths between 100 and $200 \mathrm{~km}$. With the few deep earthquakes in this study we are unable to detect the deeper compressional stress regime. Nonetheless, the abundance of normal faulting in the upper $50 \mathrm{~km}$ of the plate suggests that bending stresses are an important cause of deformation there.

We contend that the abundance of collocated normal and strike-slip faulting in the subducted slab of the southern Hikurangi Margin is due to the oblique nature of the subduction; thus, the stress field in the subducted slab is driven both by bending of the slab (normal events) and a strike-parallel component of plate motion.

The slight change of the stress ratio between the Western $(0.37 \pm 0.13)$ and Central Basin $(0.60 \pm 0.13)$ regions suggest a variable role of the intermediate compressive stress axis (S2) in the two regions. S2 is horizontal in both regions, but relative to S1, $\mathrm{S} 2$ is greater in deeper section of the slab $(>20 \mathrm{~km})$, than it is in the shallow slab. The Western region where S1 $>$ S2 $>>$ S3, at depths of $>20 \mathrm{~km}$, overlaps with Darby and Beavan (2001), Wallace et al. (2004), and Lamb and Smith (2013) affirmations that at depths of $22 \mathrm{~km}$ and greater (on the plate interface) there is slip occurring. Conversely, the Central Basin region where S1 >> S2 > S3, at depth between $20 \mathrm{~km}$ and $15 \mathrm{~km}$, agrees with Darby and Beavan (2001) who suggested that maximum coupling occurs between 16 and $24 \mathrm{~km}$ depth. The greatest stress ratio is found in the Central Basin region (0.60), which is indicative of a more stable normal faulting regime. We would have expected the Central Basin to have the highest stress ratio because it is approximate to the area of the subduction plate that is experiencing the greatest amount of bending, as shown by Henrys et al. (2013) and Williams et al. (2013).

The abrupt change in orientation of SHmax below the Eastern region, compared to the Western and Central Basin regions, suggests that factors other than bending stresses control deformation within the subducting plate (Figure 3.4 and 3.6). The cluster in the Eastern region includes more strike-slip focal mechanisms, with a relatively small proportion of normal events (Figure 3.4b). The lack of normal faulting would be anticipated for a region such as the Eastern region where the curvature of the subducting plate is less (Figure 3.1). This suggests that here bending stresses play a reduced role in the total stress field. 
Table 3.4: Table of Regional Mean Averages for the Orientations of the Fast Direction (FD), SHmax From Gravitational Stresses Based on Topography (GS), and SHmax From Focal Mechanism Inversion (FM)

\begin{tabular}{ccccccc}
\hline Region & Mean FD & FD95\% & Mean GS SHmax & GS95\% & Mean FM SHmax & FM95\% \\
West & 65.6 & \pm 17.65 & 59.4 & \pm 7.85 & 53.13 & \pm 16.72 \\
Basin & 135.7 & \pm 35.35 & 167.3 & \pm 8.20 & 36.51 & \pm 16.72 \\
East & 74.4 & \pm 11.00 & 35.4 & \pm 8.10 & 158.17 & \pm 29.41 \\
\hline
\end{tabular}

Note. Columns 3, 5, and 7 show the 95\% confidence intervals for their respective measurement mean direction.

\subsubsection{Seismic Anisotropy}

In this study there is no clear relationship between the measured delay times and the depth of earthquakes used to measure it, implying that the observed anisotropy is a shallow feature and resides in the top $30 \mathrm{~km}$ of the study area (Figure 3.3a). Furthermore, using the same splitting measurements to develop anisotropic delay time tomography, Wilson (2016) found that the change in delay times across the region is not reflected by change in strength of anisotropy. Furthermore, the similarities between the SHmax from gravity and shear wave fast direction (Figure 3.6a) suggest a correlation. We, therefore, suggest that the observed anisotropy is a consequence of stress-controlled closure of cracks (Crampin, 1994) in the crust of the upper Australian plate. It should be noted that the results in this study do not negate the possibility of the crust itself (i.e., rock type and faults) contributing to some portion of the shear wave splitting.

\subsubsection{Comparing Stress Orientations by Region}

Figure 3.6 and Figure 3.4 show the relationship between the mean fast directions, SHmax from focal mechanisms within the subduction zone, and the orientation of SHmax from gravitationally induced stresses in the Western, Central Basin, and Eastern regions. There is varying agreement between the three types of measurements across the study region, implying that there may be multiple sources contributing to the stress field in the southern Hikurangi subduction system. Figure 3.7 gives a cartoon summary of the individual orientations of these potential sources, such as gravitational stresses (Figure 3.7a), tectonic loading (Figure 3.7b), and bending stresses (Figure 3.7c).

In the Western region, there is clear agreement between the three averaged orientations (Figure 3.6 and Table 3.4). In the upper plate the fast direction is $65.6 \pm 17.65^{\circ}$ and gravitationally induced SHmax is $59.4 \pm 7.85^{\circ}$, while in the subducting plate, SHmax determined by stress inversion is $53.13 \pm 16.72^{\circ}$. SHmax orientations determined by 
Gravitational Stresses: Upper Plate

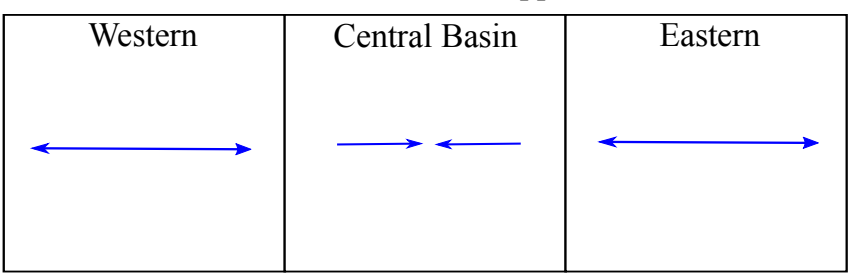

Tectonic Loading: Upper Plate

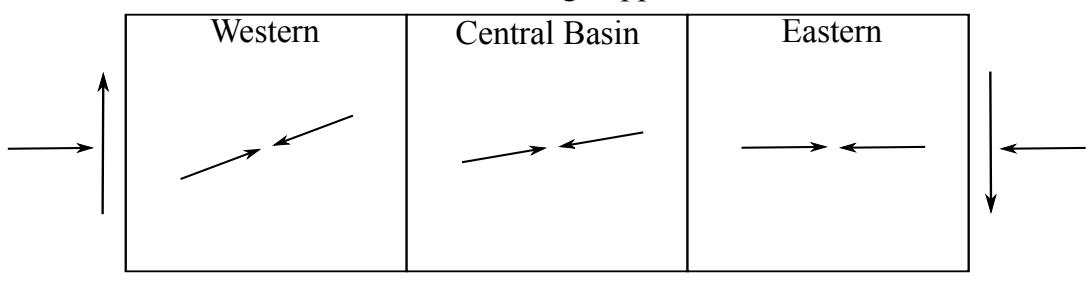

Bending Stresses: Subducting Plate

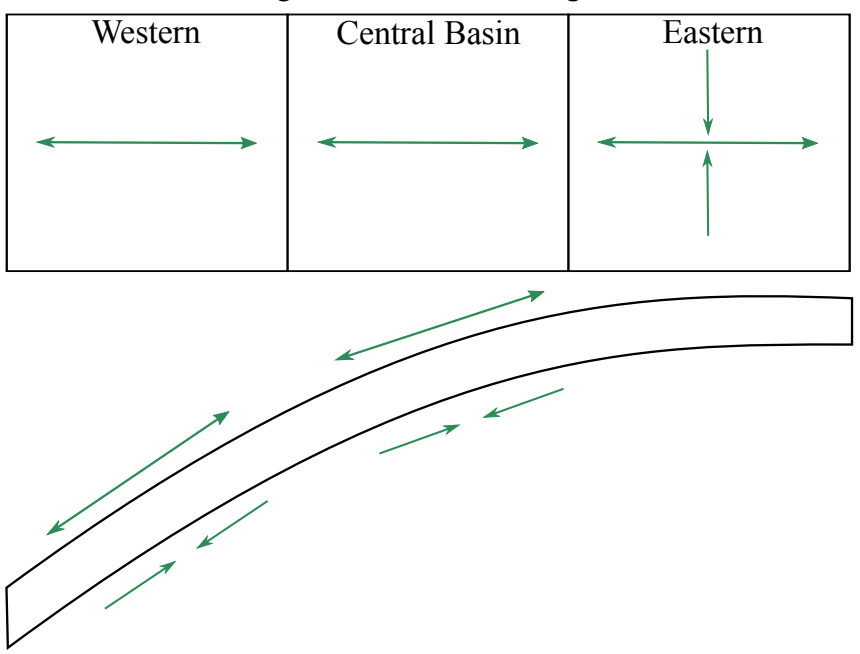

Figure 3.7: Cartoon displaying the extensional and compressional contribution to the total stress field from gravitational stresses (map view), tectonic loading (map view) (see Figure 3.6 caption), and bending stresses (map view and vertical cross section), perpendicular to the strike of the subduction trench. Blue arrows indicate extension or contraction due to gravitational stresses. Black arrows (outside) tectonic loading show orthogonal components of the Australian plate rotation; black arrows (inside) indicate the trend of the principal axis of compression. Green arrows indicate axis of extension above the midline and compression below the midline of the subducting slab. Horizontal and vertical cross sections are approximately perpendicular to plate interface depth contours and the subduction margin. 
the three methods, in this region, are NE-SW. In this region it is not possible to distinguish between bending stresses and gravitational stresses. Importantly, neither of these directions is parallel to the direction of tectonic stress loading, determined from the geodetic data, which is more nearly E-W (Figure 3.6) (Lamb and Vella, 1987; Beavan and Haines, 2001; Lamb and Smith, 2013; Lamb, 2015). This could mean that tectonic loading plays a relatively small role in the Western region, compared to bending and gravitational stresses, in determining the stress field. One reason for this could be that the region is in an early part of the earthquake cycle-for example, after rupture on the Wairarapa fault, which last occurred in 1855 during a M8+ event-and tectonic stress loading will eventually assume a larger component of the total stress with time.

In the Central Basin region, there is a divergence between the three types of measurement for stress orientations (Figure 3.6 and Table 3.4). As in the Western region, SHmax orientations here, from focal mechanisms, trend NE-SW $\left(36.51 \pm 16.72^{\circ}\right)$ in the subducted slab. But shear wave splitting fast directions are NW-SE $\left(135.7 \pm 35.35^{\circ}\right)$ and SHmax orientations calculated from gravitational stresses are subparallel (167.3 $\pm 8.2^{\circ}$ ) to the splitting fast directions. Based on this, the splitting in this region may be more greatly affected by upper plate gravitational stresses than the bending stress within the underlying subducting slab.

The Eastern region again shows a divergence of stress orientation measurements, but in a different manner than in the Central Basin region. The orientation of SHmax from focal mechanisms within the subducting slab is NNW-SSE $\left(158.17 \pm 29.41^{\circ}\right)$, but the orientation of SHmax from gravitational stresses is NE-SW (35.4 \pm 8.1$)$, subparallel to the ENE-WSW $\left(74.4 \pm 11.0^{\circ}\right)$ seismic fast directions (Figure 3.6 and Table 3.4). The NNW-SSE orientation of SHmax from within the subducting slab is $\sim 45^{\circ}$ to the plate interface depth contours here, in contrast to its trench-parallel nature in the Western and Central Basin regions. The fast direction orientations again suggest some gravitational control. Tectonic stress orientations are perpendicular to those from gravitational stresses and may contribute to the rotations measured by anisotropy and focal mechanisms.

\subsection{Summary}

In this study, we analyze the stress field above and below the locked part of the plate interface in the southern part of the obliquely subducting Hikurangi Margin, North Island, New Zealand.

Using new data from the 50 temporary SAHKE stations and 16 permanent GeoNet stations, we derive the orientation of the stress field for clusters of earthquake focal mechanisms and from seismic anisotropy, using 314 and 425 earthquakes, respectively. In addition, we calculate the gravitational stress field as a consequence of topography and crustal structure. 
We distinguish between stresses in the lower subducting Pacific plate (determined from stress inversion of focal mechanisms) and upper overriding Australian plate (determined from shear wave fast directions).

In the northwest of the study region, where the plate interface is at a depth of 20-30 $\mathrm{km}$, the orientation of SHmax from focal mechanism inversion, shear wave fast direction, and gravitational stresses are all NE-SW, parallel to the margin and the depth contours of the plate interface. In the Central Basin region, where the interface is at a depth of 15-20 km, there is clear difference between stresses in the upper and lower plates of the subduction margin, where in the upper plate stresses are orientated orthogonal to the margin, while in the lower plate, stress are orientated parallel to the margin. In the Eastern region, where the plate interface is at a depth $10-15 \mathrm{~km}$, the orientation of the stress field differ in the upper and lower plates, possibly due to the addition of tectonic loading.

We interpret the stress orientations in the Western and Central Basin regions as resulting from bending stresses above the midline of the subducting slab (Figure 3.6 and 3.7). We interpret the abrupt change in the orientation of the stress field from the Central Basin to the Eastern region as a boundary in the subducting slab where bending stresses become minimized. The similarity between the stress field in the subducting and the overriding plate, as well as gravitational stresses, in Western region make it difficult to determine if the subducting plate is influencing the overriding plates stress field. In the Central Basin and Eastern region the gravitational stresses and the shear wave fast direction orientations indicate that gravitational stresses may be largely influencing the stress field of the upper plate (Figure 3.6 and 3.7). The variation in stress orientations in the Eastern region is most likely the result of tectonic stress loading due to oblique plate convergence at the subduction margin (Figure 3.6 and 3.7).

\subsection{Acknowledgements}

All waveform data are available at the IRIS data management center (temporary stations) and the GeoNet data center (permanent stations), funded by the New Zealand Earthquake Commission. The focal mechanisms and shear wave splitting measurements are in the supporting information. Data acquisition was funded by the New Zealand Foundation for Research, Science and Technology, the Japanese Science and Technology Agency, the U.S. National Science Foundation NSF OCE-1061557, and Ministry of Business, Innovation and Employment GNS-MBIE00053. D.E. was funded by scholarships from VUW, and partial support for M.S. was provided by the Tokyo University Earthquake Research Institute International program. T.W. was funded both by a VUW scholarship and Resource Developments Consultants Limited (RDCL). H.H. was funded by a Frank Evison Fellowship and a VUW scholarship. We thank Tim Stern, Stuart Henrys, John Townend, and Rupert Sutherland for helpful discussions, 
and Richard Arnold for providing the focal mechanism inversion codes. Bjorn Lund and an anonymous reviewer provided comments that enhanced the paper. 


\section{Chapter 4}

\section{Illumination of Deformation by Bending Stresses within the Southern Hikurangi Double Benioff Zone}

\subsection{Abstract}

Double Benioff zones are ubiquitous in subduction systems worldwide, but the stresses acting on them are not well known. We characterize stress orientations in the upper and lower bands of a double Benioff zone of the southern Hikurangi margin, New Zealand. Stress orientations were calculated from focal mechanisms with 10 or more polarity picks, using a Bayesian stress inversion technique. In the deeper region of the subduction zone, the stress orientations in the upper band of seismicity are consistent with an extensional stress regime, whereas stress orientations within the lower band of seismicity are consistent with a compressional stress regime. In the shallow region of the subduction zone, the inversion of the upper and lower band of seismicity are consistent with extensional stress regimes. This demonstrates that deep in the subduction zone bending stresses are dominant, whereas in the shallow portion of the subduction zone, slab-pull forces are dominant.

\subsection{Introduction}

Benioff zones provide the most direct evidence for the existence of subducting slabs. The nature and distribution of seismicity within Benioff zones provide constraints on the rheology and stresses in a subducting slab. It is important to characterize these constraints as they can enhance our understanding of deformation, strain partitioning, and the generation of mega-thrust subduction earthquakes. Hasegawa et al. (1978) 
was first to characterize two distinct bands of seismicity within a Benioff zone, referred to as a 'double Benioff zone', located in northeastern region of Honshu, Japan. Double Benioff zones (DBZs) are ubiquitous within subduction zone systems worldwide (Brudzinski et al., 2007). The upper band of seismicity has been interpreted as the faulting of dehydrated and/or metamorphosed upper oceanic crust, whereas the lower band is thought to be faulting of the dehydrating upper mantle (i.e., serpentinized peridotite and antigorite) (Kirby et al., 1996; Peacock, 2001; Yamasaki and Seno, 2003; Zhang et al., 2004; Brudzinski et al., 2007).

The dynamics of stresses acting within the subducting plate resulting in a DBZ are not well understood. Some DBZ studies show down-dip extension in the upper and down-dip compression in the lower band (Engdahl and Scholz, 1977; Hasegawa et al., 1978; Kawakatsu, 1985; Kao and Chen, 1994; Brudzinski et al., 2007). In contrast, Abers (1992); Ratchkovsky et al. (1997); Slancová et al. (2000); Christova and Scholz (2003); Rietbrock and Waldhauser (2004); Brudzinski and Chen (2005) observed downdip extension in both the upper and lower bands of seismicity within various DBZs.

New Zealand provides a favorable opportunity to investigate DBZs because it can be studied from land-based seismic arrays. Benefiting from a dense land based temporary and permanent deployment; this study aims to characterize the stresses present within the southern Hikurangi DBZ, by performing a high-resolution stress inversion analysis.

\subsection{Southern Hikurangi Margin}

East of central New Zealand, the Australian and Pacific plates converge at $\sim 38 \mathrm{~mm} / \mathrm{yr}$ (Figure 4.1; Beavan and Haines, 2001; Beavan et al., 2002). Convergence results in the westward oblique subduction of Pacific plate under the Australian plate. Langridge et al. (2005) calculated that 60 to $90 \%$ of margin-parallel motion is accommodated by faults in the Australian plate, while Wallace et al. (2009) proposed that marginperpendicular motion is accommodated by episodic slip (100s to 1000s of years) on the subduction thrust. The rate of subduction along the length of North Island is not uniform (Walcott, 1984; Reyners, 1998; Wallace et al., 2004, 2009, 2012). There is a slip deficit of $20-30 \mathrm{~mm} / \mathrm{yr}$ along the plate interface beneath the southern North Island (Wallace et al., 2004). The slip deficit region is thought to represent where the overriding Australian plate and the subducting Pacific plate are 'partially locked' or 'coupled' at the plate interface. Darby and Beavan (2001) calculated the depth of the maximumcoupled zone to be between 15 and $24 \mathrm{~km}$, using 10 years of campaign GPS data. Lamb and Smith (2013) using cGPS (up to 2009) data calculated a similar maximum coupling depth at $\sim 25 \mathrm{~km}$. 


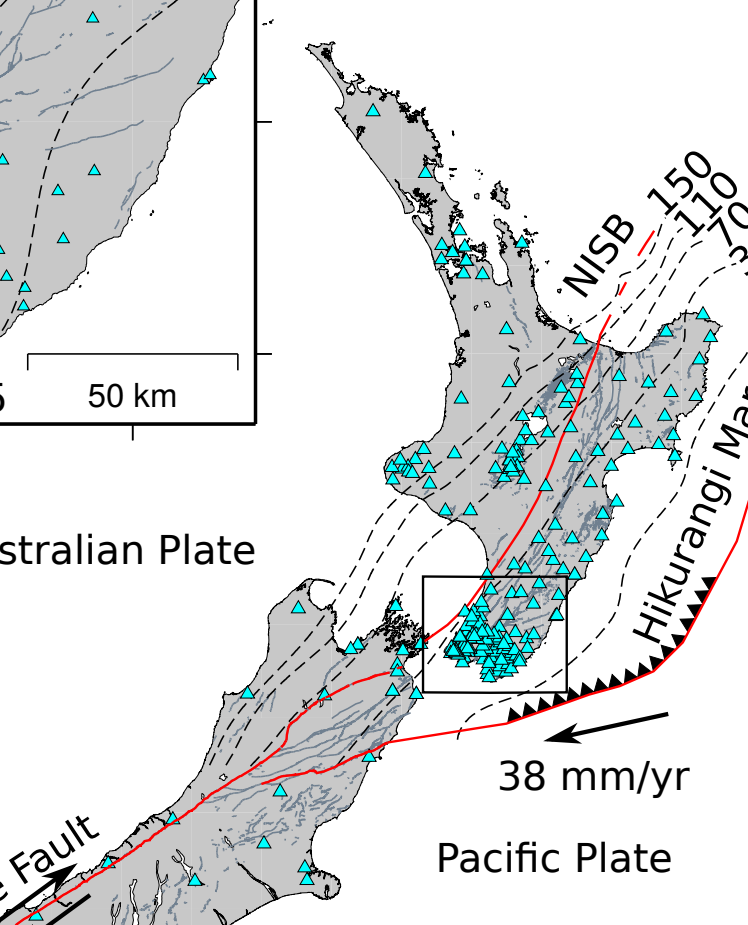

Figure 4.1: Tectonic overview and station locations of seismometers (cyan triangles) used to relocate earthquakes. Red lines indicate plate/major tectonic boundaries, including North Island Seismic Belt (NISB) (Coffin et al., 1998). Grey lines show active faults (https://data.gns.cri.nz/af/; (Langridge et al., 2005)). Dashed lines show depth $(\mathrm{km})$ of subduction plate interface (Williams et al., 2013). Black arrow shows relative plate motion between the Australian and Pacific Plates. Inset: zoomed view of southern North Island, New Zealand, showing density of seismic stations in study area. 


\subsection{Previous Studies}

Relocated earthquakes from Eberhart-Phillips and Reyners (1997); Du et al. (2004) highlighted the existence of a Double Benioff Zone (DBZ) at the southern end of the Hikurangi margin (Figure 4.2). The discreteness of the two bands of seismicity varies along the strike of the subduction margin. In the northern South Island the bands are clearly distinguishable, while in the southern North Island, the two bands coalesce becoming harder to discern (Figure 4.2b and c). McGinty et al. (2000), using 48 upper band focal mechanisms and 12 lower band focal mechanisms, observed stress orientations consistent with down-dip extension throughout the northern South Island and southern North Island. 


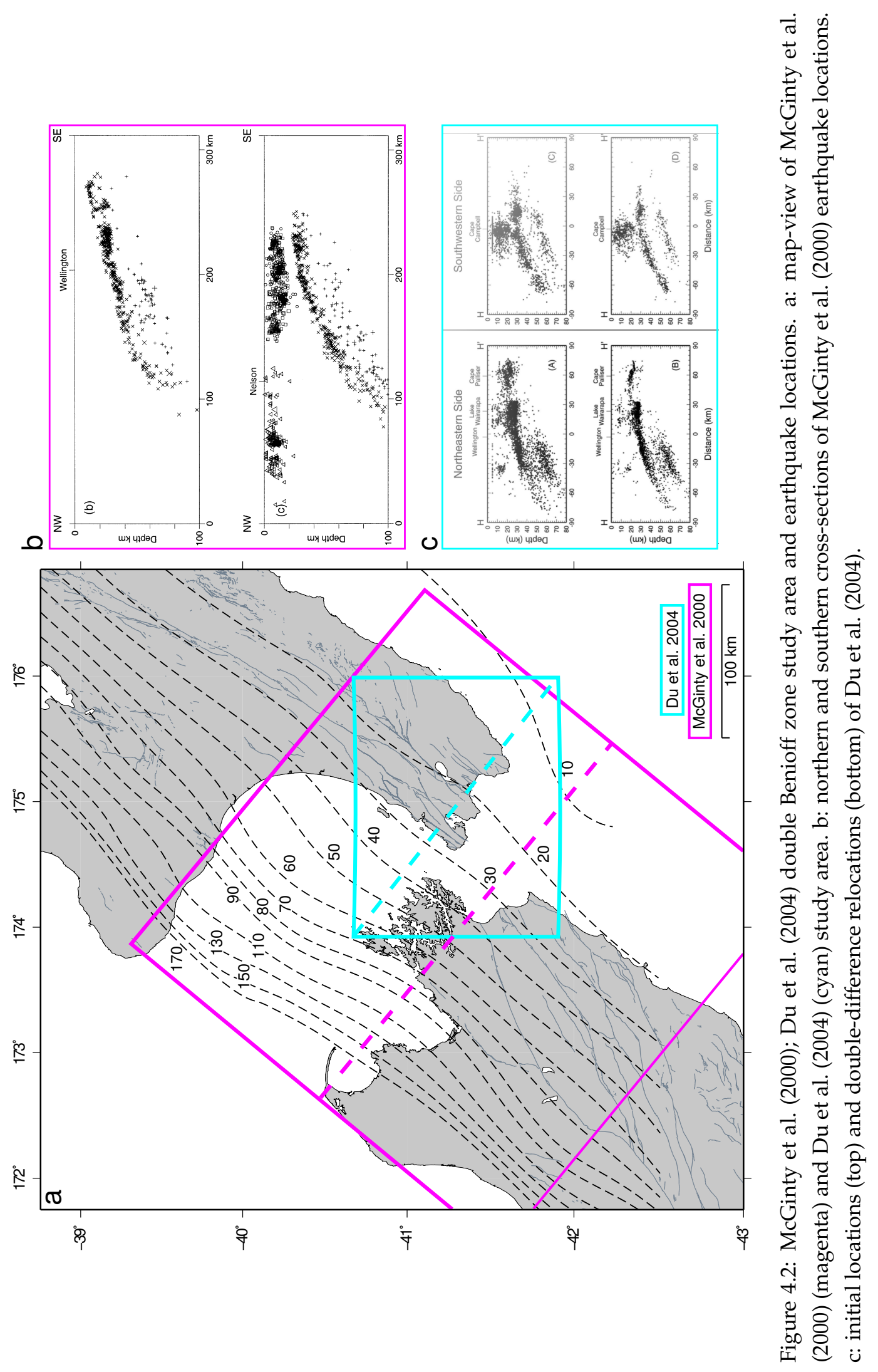




\subsection{Seismic Data}

Seismic data were recorded on the permanent New Zealand-wide GeoNet array (up to 171 stations) and the temporary SAHKE I array (48 short-period and 2 broadband stations) that was deployed from November 2009 to March 2010 (Figure 4.1; Seward et al., 2010). During a nine-month period (September 2009 to May 2010) 678 earthquakes $(\mathrm{M} 2+$ to $\mathrm{M} 5+)$ at depths $25 \mathrm{~km}$ or greater were detected by GeoNet, throughout the southern North Island, New Zealand (Figure 4.3).

\subsection{Methods}

\subsubsection{Earthquake Relocation}

P- and S-wave phase arrivals and first motion polarities were manually picked and located using the Seisan Earthquake Analysis Software (SEISAN) package (Havskov and Ottemoller, 1999). Initial hypocenter locations were calculated using Hypocenter (Lienert et al., 1986; Lienert and Havskov, 1995) and a southern North Island 1D velocity model (Henrys et al., 2013). Final hypocenter locations were determined using NonLinLoc (Lomax et al., 2000), a non-linear location package, and a New Zealand wide 3D velocity model (Eberhart-Phillips et al., 2010).

\subsubsection{Bayesian Focal Mechanism and Stress Inversion}

Focal mechanisms are calculated using a Bayesian approach (Walsh et al., 2009). The Walsh et al. (2009) Bayesian method treats all hypocenter locations as probabilistic, allowing for errors in hypocenter locations, and consequently focal mechanism uncertainties, to be propagated into the final stress inversion.

The stress inversion of focal mechanism data is done using the Bayesian method outlined in Arnold and Townend (2007). This method performs a stress inversion calculation on predetermined clusters of earthquake data, returning the maximum (S1), intermediate (S2), and minimum (S3) compressive stress orientations as posterior probability density functions (PDFs). The maximum horizontal compressive stress (SHmax) orientation is calculated using the Lund and Townend (2007) method.

\subsubsection{Focal Mechanism Clustering}

Three clusters of earthquakes using focal mechanisms calculated using 10 or more polarity picks were classified based upon location within the subducting plate: (1) earthquakes located in the upper half of the seismogenic zone (i.e., plate interface to the neutral plane) and ( 2 and 3 ) earthquakes within the lower half (i.e., neutral plane to bottom of seismogenic zone) of the seismogenic zone (Figure 4.3). The lower half of seismicity is split into two individual clusters, based on the initiation of reverse faulting (at $\sim 130 \mathrm{~km}$, see Figure 4.4). The plate interface used was determined by Williams 

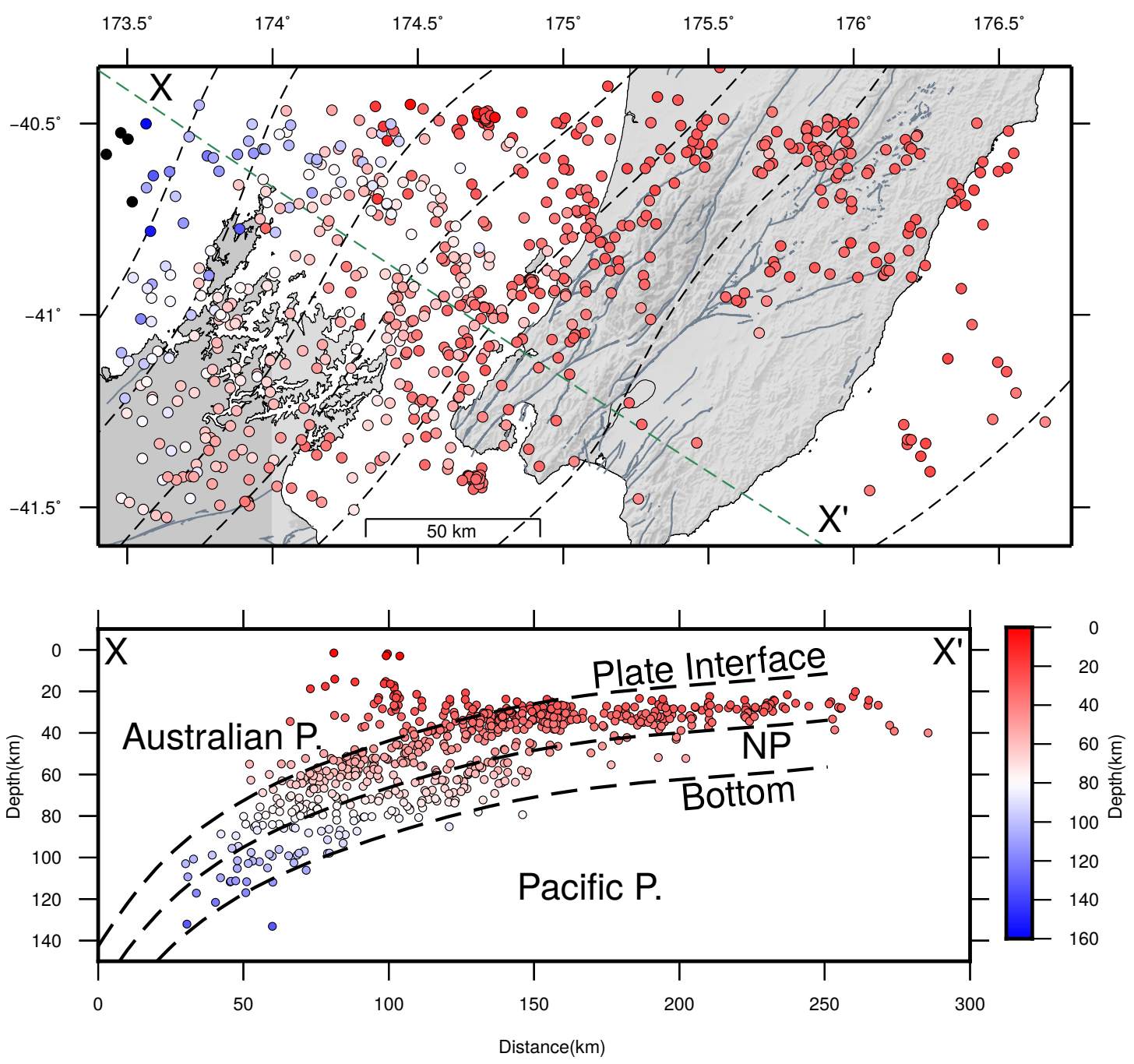

Figure 4.3: Map view and cross-sections of relocated earthquakes, colored by depth, using a 3D (Eberhart-Phillips et al., 2010) velocity model and NonLinLoc (Lomax et al., 2000). Dashed lines indicate plate interface depth $(\mathrm{km})$ between the Australian and Pacific plates. Grey lines show active faults (https://data.gns.cri.nz/af/; (Langridge et al., 2005)). Cross-section projected onto $X$ to $X^{\prime}$ line. In cross section dashed lines show the plate interface (Williams et al., 2013), the neutral plane (NP) and the bottom of the seismogenic zone. 
et al. (2013). The bottom of the seismogenic zone was determined visually, based on earthquake density, after the final relocation of the earthquakes. The neutral plane is identified as the plane that is halfway between the top and bottom of the seismogenic zone within the subducting plate.

\subsection{Results}

\subsubsection{Earthquake Locations}

The 675 earthquakes were relocated with a mean horizontal standard deviation of 1.80 $\mathrm{km}$ East-West, $0.42 \mathrm{~km}$ North-South, and a mean vertical standard deviation of 1.48 $\mathrm{km}$. The bands of the DBZ are not well defined (Figure 4.3). These results are similar to those presented by McGinty et al. (2000) and Du et al. (2004), in that below the southern North Island, the bands of seismicity in the DBZ are less defined, than those to the south. The consolidation of the bands of seismicity is likely due to the lack of depth constraints, resulting from the lack of stations to the NW and directly above the DBZ (Figure 4.1).

\subsubsection{Focal Mechanism and Stress Inversion}

657 of the relocated earthquakes are used as inputs for the Arnold and Townend (2007) Bayesian focal mechanism method. Based on standard rake convention (Figure 4.4), there are 308 normal, 116 reverse, and 223 strike-slip focal mechanisms. This distribution of faulting is comparable to Evanzia et al. (2017), who found predominantly normal faulting with some strike-slip and little reverse faulting in southern North Island, using data recorded only during the November 2009 to March 2010 deployment of the SAHKE I array. Most of the normal faulting is limited to the upper band of seismicity (Figure 4.4 and 4.5). There is relatively little reverse faulting in the upper or lower band until the plate interface is at a depth of $\sim 35 \mathrm{~km}$ (Figure 4.4). Strike-slip faulting is diffuse throughout the upper band, however it is limited in the shallower reaches of the lower band of seismicity (Figure 4.4). Reyners and Eberhart-Phillips (2009) attributed the lack of seismicity in shallower reaches of the lower band to the presence of fluids. At plate interface depths of greater than $\sim 35 \mathrm{~km}$ there are more equal proportions of faulting within the subducting plate. The subducting slab increases from $05^{\circ}$ to $15^{\circ}$ dip at a plate interface depth of $\sim 30 \mathrm{~km}$ (Henrys et al., 2013). At $\sim 40 \mathrm{~km}$ depth, the subducting plate is juxtaposed to the crust-mantle boundary (Moho) on the Australian plate (Reyners and Eberhart-Phillips, 2009; Henrys et al., 2013). The diversification of focal mechanisms at a plate interface depth of greater than $\sim 35 \mathrm{~km}$ indicates a shift in the stress dynamics within the subducting plate.

Based on polarity picks $(>10)$ and location within the subducting plate, 149 focal mechanisms are used for inversion in the upper band, 43 focal mechanisms are used in the down-dip lower band, and 11 focal mechanisms are used in the up-dip lower band 

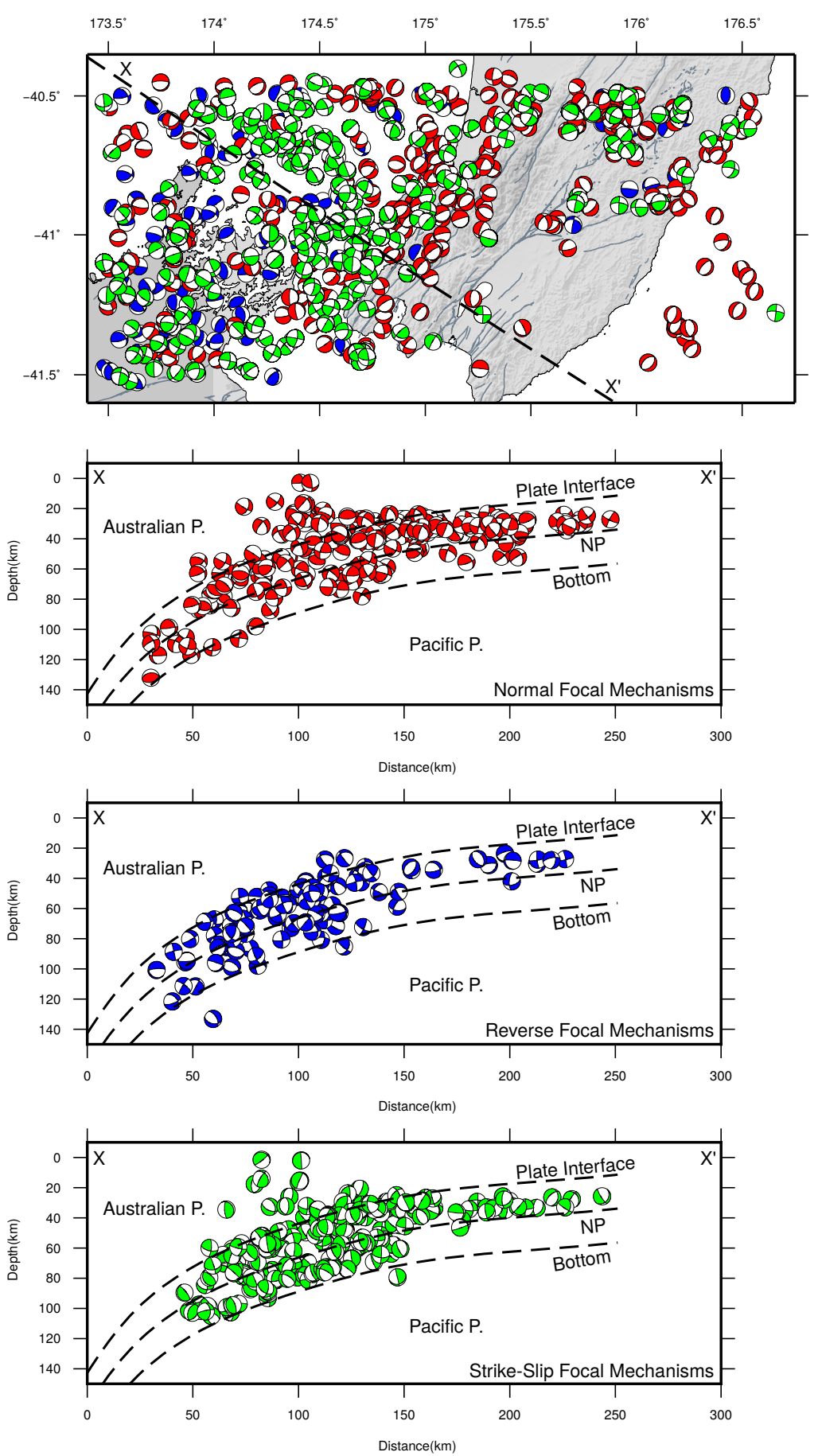

Figure 4.4: Focal mechanism solutions derived using the Walsh et al. (2009) Bayesian method. 657 focal mechanisms (normal: 308, reverse: 116, strikeslip: 223) with at least one polarity pick colored by style: normal $\left(30^{\circ}<\right.$ rake $\left.(\mathrm{R})<150^{\circ}\right)$ (red); reverse $\left(-30^{\circ}<\mathrm{R}<-150^{\circ}\right)$ (blue); strike-slip $\left(-30^{\circ}<\mathrm{R}<30^{\circ}\right.$ and $-150^{\circ}<\mathrm{R}<150^{\circ}$ ) (green). Cross sections projected onto $X$ to $X^{\prime}$ line, as in previous figures. Grey and dashed line in cross sections show location of featured specified in Figure 4.3. 
of seismicity (Figure 4.5).

The inversion of the upper band cluster (cyan) yields a vertical S1 and horizontal S2 and S3, indicating an extensional stress regime (Figure 4.5), with a SHmax orientation of $\sim 060^{\circ}$. The inversion of the down-dip lower band cluster yields a vertical S3 and a horizontal S1 and S2, denoting a compressional stress regime (Figure 4.5), with a SHmax orientation of $\sim 040^{\circ}$. The inversion of the up-dip lower band cluster yields a vertical and horizontal mixing of S1 and S2, while S3 is horizontal, indicating an extensional stress regime (Figure 4.5), with a SHmax orientation of $\sim 050^{\circ}$. All three SHmax orientations are sub-parallel to the relative plate motion between the Pacific and Australian plate, at the southern North Island (Figure 4.1, 4.5; DeMets et al., 1994).

Additionally, three other clusters are generated based upon position within the plate, but regardless of polarity pick numbers: upper band cluster (434 focal mechanisms), down-dip lower band cluster (132 focal mechanism), and up-dip lower band cluster (93 focal mechanism). Inversion results of the three additional clusters show similar results and can be found in supplemental material (Appendix B Figure 3). This indicates that the observed stress orientations are an authentic feature of the DBZ and not an artefact of cluster criteria.

\subsection{Discussion}

\subsubsection{Upper Band Stress Orientations}

Here, as in previous studies (McGinty et al., 2000; Evanzia et al., 2017), the stress orientations in the upper band are indicative of an extensional stress regime with down-dip extension; where $\mathrm{S} 1$ is near vertical and $\mathrm{S} 3$ is oriented in the direction of the dip (Figure 4.5, Appendix B Figure 1, 2).

\subsubsection{Lower Band Stress Orientations}

The compressional stress regime calculated from the down-dip cluster of lower band seismicity in this study (Figure 4.5, Appendix B Figure 1,2) differs from those calculated by McGinty et al. (2000), who found the lower band of seismicity exhibited a down-dip extensional regime, throughout the southern North and northern South Island.

The differences between observations of this study and McGinty et al. (2000) suggests that the 12 focal mechanisms in McGinty et al. (2000) were insufficient to observe the shift in stress dynamics within and along strike of the subduction margin. Although different stress regimes within the lower band of a DBZ are not unique to the southern Hikurangi margin (e.g., Nazca and Aleuntian: see Table S1 in Brudzinski et al. (2007), this studys area of interest is encompassed by the region McGinty et al. (2000) characterized. Additionally, unlike the studies referenced in Brudzinski et al. (2007), 


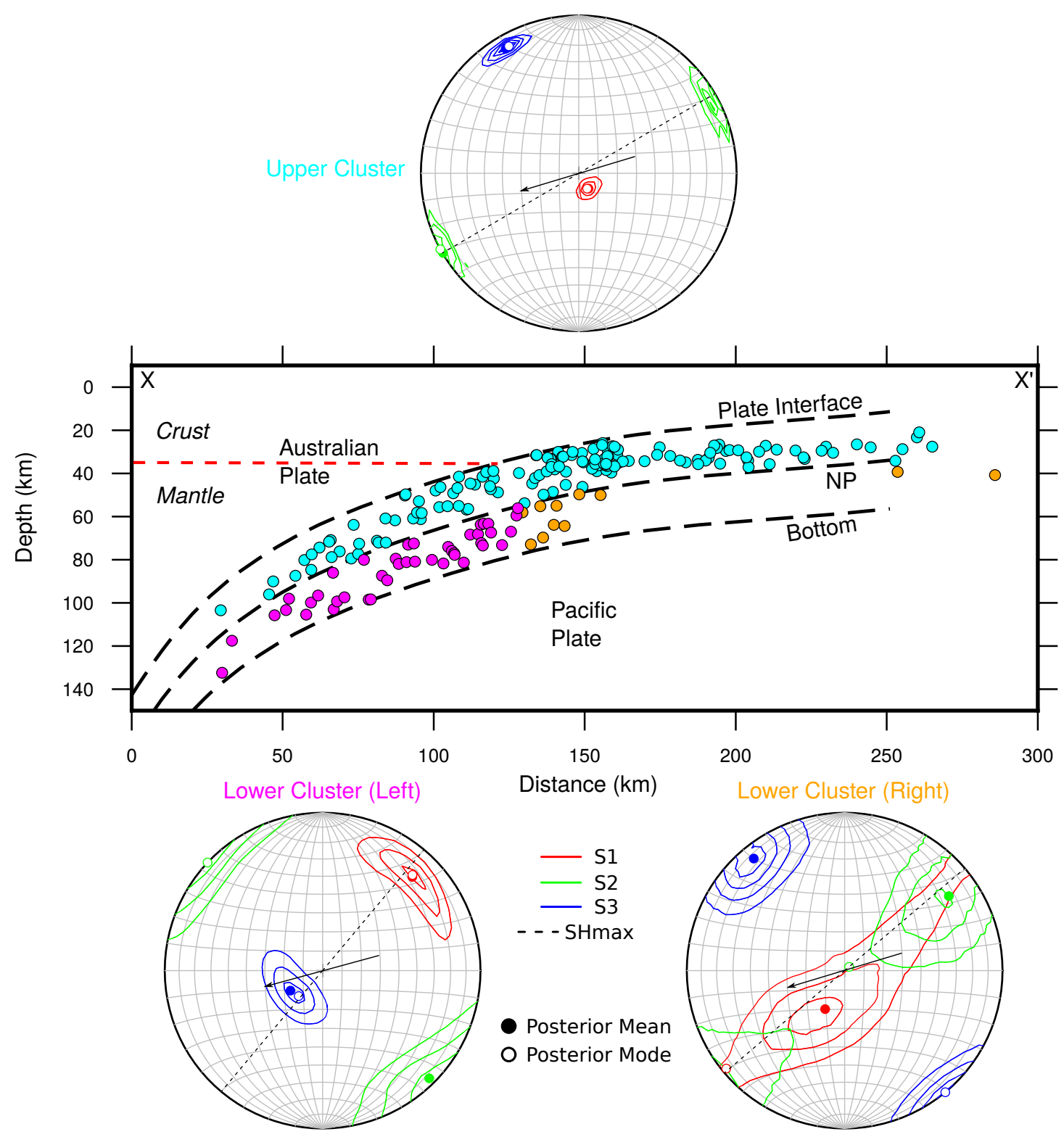

Figure 4.5: Clusters of focal mechanisms with at least 10 polarity picks used as inputs into the Bayesian stress inversion method from Arnold and Townend (2007). Red-dashed line indicates approximate of the Moho (Henrys et al., 2013). Upper cluster (149 focal mechanisms) shown by cyan circles, downdip lower (left) cluster shown by magenta circles (43 focal mechanisms) and up-dip lower (right) cluster shown by orange circles (11 focal mechanisms), mapped on $X$ to $X^{\prime}$ cross-section from previous figures. Stereonets show azimuth of maximum principal stress (S1), intermediate principal stress (S2), and minimum principal stress (S3), shown as the posterior probability density functions (PDFs). The best fitting maximum horizontal stress (SHmax) shown as a dashed line. Black arrows indicate plate convergence direction. Dashed line in cross sections show location of featured specified in Figure 4.3. 
Table 4.1: Adapted from Brudzinski et al. (2007) Supplemental Figure 1. Describing features of DBZ studies done in different locations on the same subduction system. Note: DDE (down-dip extension), DDC (down-dip compression), and DOC (dip-oblique compression). 'New Zealand' indicates this study's results.

\begin{tabular}{cccccccc}
\hline Location & $\begin{array}{c}\text { Longitude } \\
\left(\mathrm{W}^{\circ}\right)\end{array}$ & $\begin{array}{c}\text { Latitude } \\
\left(\mathrm{N}^{\circ}\right)\end{array}$ & $\begin{array}{c}\text { Plate Age } \\
\text { Age }(\mathrm{ma})\end{array}$ & $\begin{array}{c}\text { Events } \\
(\#)\end{array}$ & $\begin{array}{c}\text { Slab } \\
\text { Dip }\left(^{\circ}\right)\end{array}$ & $\begin{array}{c}\text { Upper } \\
\text { Band }\end{array}$ & $\begin{array}{c}\text { Lower } \\
\text { Band }\end{array}$ \\
\hline New Zealand & -7.5 & -42.5 & 90 & 48 & 12 & DDE & DDE \\
New Zealand & -6.5 & -40.75 & 90 & 434 & 225 & DDE & DOC/DDE \\
Nazca & -73.4 & -34.5 & 33 & 39 & 22 & DDE & DDE \\
Nazca & -71.4 & -24.4 & 43 & 176 & 15 & DDE & DDE \\
Nazca & -75.8 & -15.7 & 38 & 71 & 3 & DDE & DDC \\
Aleutian & -161.2 & 53.6 & 55 & 25 & 49 & DDE & DDE \\
Aleutian & -179.8 & 50.5 & 56 & 87 & 36 & DDE & DDC \\
\hline
\end{tabular}

this compressional regimes shortening orientation is oblique to the dip direction (Figure 4.5). This is likely to be due to the oblique nature of subduction at the southern Hikurangi margin. The compressional stress regime could result from the bending of the subducting Pacific plate (e.g. Buffett and Becker, 2012).

\subsubsection{Stress Orientations in Double Benioff Zones}

In a global context, subducting slabs (e.g., Nazca, Aleutian, New Zealand: in this study) that show variation in stress orientations in the lower band of seismicity also have a lower subduction dip angle (Table 4.1; Brudzinski et al., 2007). The rate of change of the subduction dip in the southern North Island is greater compared to most of the northern South Island (Appendix B Figure 1). Extension in the upper band and compression in the lower band is indicative of bending forces (Buffett and Becker, 2012).

Bending moment $(M)$ is defined as (Watts, 2001), where $(E)$ is Young's modulus, $(H)$ is elastic plate thickness, $(\nu)$ is Poisson's ratio, and $(R)$ is the radius of curvature:

$$
M=-\frac{E H^{3}}{12\left(1-\nu^{2}\right) R}
$$

Based on slab dips in the southern North Island and the northern South Island (Appendix B Figure 1, 2), a Young's modulus $(E)$ of $2 \times 10^{11} \mathrm{~N} / \mathrm{m}^{2}$ (Cohen and Darby, 2003), elastic plate thickness $(H)$ of $4.5 \times 10^{4} \mathrm{~m}$, Poisson's ratio $(\nu)$ of 0.235 (EberhartPhillips et al., 2005), and the radius of curvature $(R)$ of $1.49 \times 10^{5} \mathrm{~m}$ and $2.25 \times 10^{5}$ $\mathrm{m}$, respectively (Appendix Figure 2), bending moment $(M)$ is $-1.079 \times 10^{19} \mathrm{~N} / \mathrm{m}^{2}$ for the southern North Island and $-7.415 \times 10^{18} \mathrm{~N} / \mathrm{m}^{2}$ for the northern South Island. The 
greater bending moment in the southern North Island, compared to southern South Island, further confirms the bending stresses are present, as shown by the stress inversions. Assuming McGinty et al. (2000) accurately characterized the stress orientations in their area of interest (Appendix B Figure 1); overall slab-pull forces are dominant within the subducting Pacific plate at the southern Hikurangi Margin. Given the subduction dip changes and the coeval bending stresses observed in this study, it is likely McGinty et al. (2000) had insufficient focal mechanisms to differentiate between areas where bending and slab-pull stresses are dominant.

As previously stated, the two bands of seismicity of the double Benioff zone are more distinct and separated below the northern South Island, than they are below the southern North Island (Figure 4.2). As shown in Appendix Figures 9.1 and 9.2, the region of the subducting plate below the southern North Island is experiencing more bending forces than the region below the northern South Island. As a result of the bending forces, the subducting plate below the southern North Island is likely experiencing a loss in elastic strength causing increased faulting and thus increase dehydration. This may be one reason for the abrupt onset of reverse faulting and the coalescing of the band of seismicity in the down-dip section of the subducting plate below the southern North Island (Figure 4.4).

The key observation is that the DBZ with division of upper and lower bands of contrasting stress patterns is confined to the Hikurangi margin beneath the southern North Island. We suggest that subduction in southern North Island beneath the $150 \mathrm{~km}$ thick lithosphere of the overriding Australian plate, with the absence of an asthenospheric wedge (Stern et al., 2006; Dimech et al., 2017), may have promoted stronger bending here by forcing the Pacific Plate more strongly downwards with a smaller radius of curvature. This way, stresses from bending rather than slab pull dominate the stress regime in this region.

\subsection{Conclusion}

In the deeper region of the subduction zone the upper band of seismicity within the southern Hikurangi DBZ is indicative of down-dip tension, while the lower band shows compression (Figure 4.5 and 4.6). In the shallow region of the subduction zone, down-dip tension is observed in both the upper and lower bands of seismicity. We interpret the upper extensional and lower compressional stress regimes, of the deep subduction zone, as a result of the bending of the subducting Pacific plate (Figure 4.5 and 4.6). The bending stresses we observe may result from the interaction between the subducting Pacific plate and the overly thickened Australian lithosphere. Based on the observations of this study and the slab dip geometry (Williams et al., 2013), north of the study there should be even greater bending forces. We interpret the upper and lower extensional stress regimes, of the shallow subduction zone, as a result of the slab-pull 
forces (Figure 4.5 and 4.6). Globally, the magnitude of deformation within subducting plates by bending stress is dependent on initial dip of the subducting plate and the rate at which the dip angle increases. As subduction dip characteristics are unique to subduction systems globally, and can vary within individual subduction zones themselves, the dynamics of stress controlling DBZ faulting distribution are likely equally variable.

\subsection{Acknowledgements}

The SAHKE experiments were possible because of the collaborative efforts of GNS Science, Victoria University of Wellington, University of Tokyo, Japan (Earthquake Research Institute), the University of Southern California, and the Ministry of Economic Development, Crown Minerals. Thank you to EQC for support and GeoNet for use of the seismic data. Partial funding was provided by MBIE [grant number: 00053]. We'd like to thank Richard Arnold, John Townend, David Walsh, and Bjorn Lund for use of their codes. 

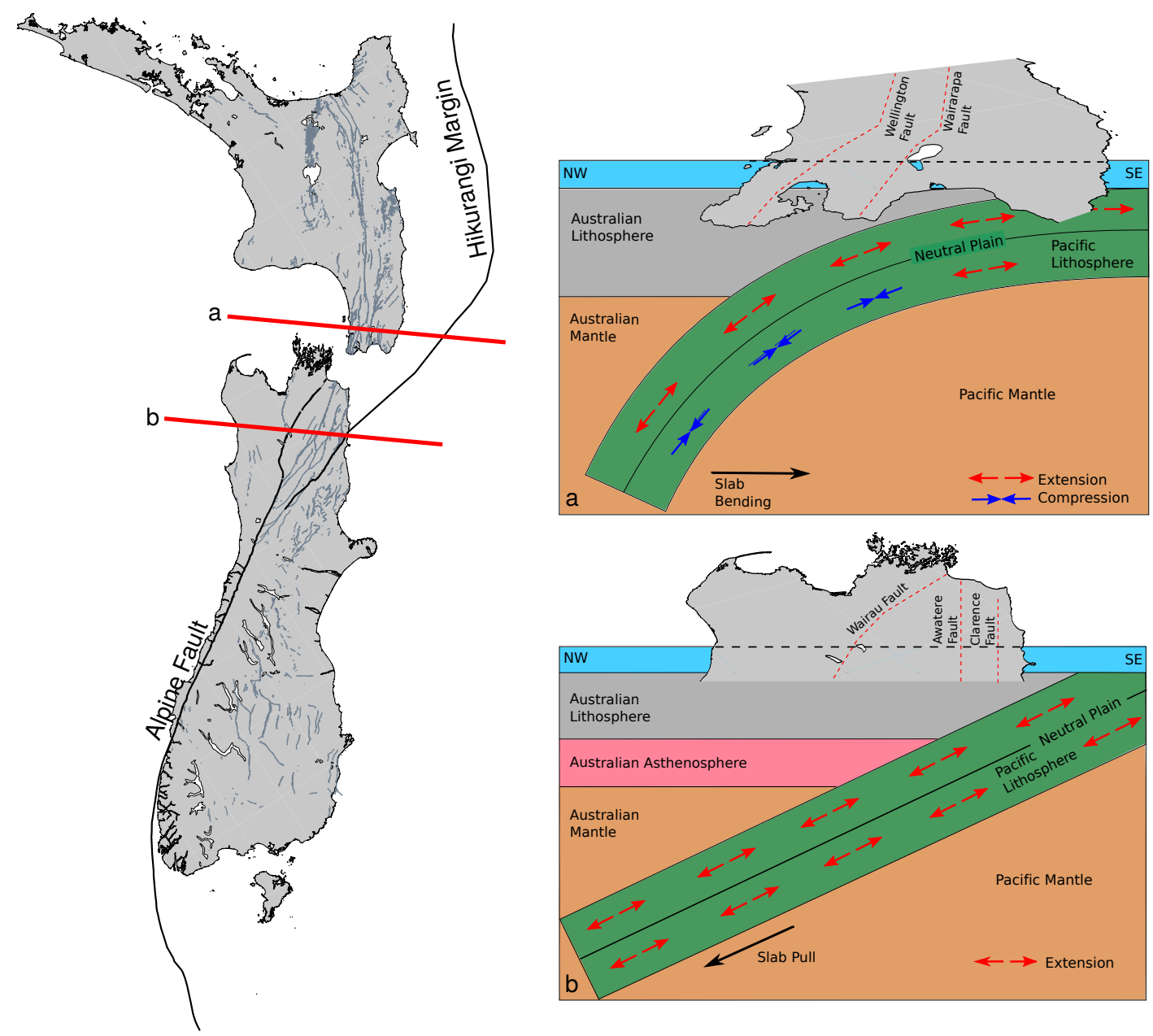

Figure 4.6: Cartoon (not to scale) of the distribution of extensional and compressive stress regimes within the subducting Pacific beneath the southern North Island and beneath the northern South Island, New Zealand. (Left) Red-lines indicate cross-section locations. (a): Above the neutral plane extension is pervasive, whereas below the neutral plane, compression dominates. The stress state within the subducting slab is the result of rollback of Pacific plate (black arrow). (b): Above and below the neutral plane extension is dominant (McGinty et al., 2000). The stress state within the subducting slab is the result of slab pull (black arrow). Grey and the red dashed lines approximate the location of local active faults (https://data.gns.cri.nz/af/). Black lines indicate plate/major tectonic boundaries, including North Island Seismic Belt (NISB) (Coffin et al., 1998). Black dashed line shows cross-section location. 
Chapter 4. Illumination of Deformation by Bending Stresses within the Southern Hikurangi Double Benioff Zone 


\title{
Chapter 5
}

\section{Stress and Structure Controlled}

\author{
Anisotropy Revealed by a
}

High-Density Seismic Transect

Across Southern North Island, New

Zealand

\subsection{Abstract}

Local earthquakes recorded on an array of 291 seismic stations placed $300 \mathrm{~m}$ apart are used to examine seismic anisotropy across the southern North Island, New Zealand. The high-density array provides a unique opportunity to gain in depth knowledge of seismic anisotropy from local earthquakes. We calculated shear-wave splitting measurements on 142 stacks composed of traces from five adjacent seismic stations on 21 local earthquakes. The resulting splitting measurements showed no dependence of fast azimuth and delay time on back azimuth, station-event distance, or angle of incidence. The average ( $\pm 95 \%$ confidence interval) fast azimuth trended N-S $\left(18^{\circ} \pm 12\right)$ west of the Wellington fault. Between the Wellington and Wairarapa faults, the average fast azimuth trended NNE-SSW $\left(65^{\circ} \pm 12\right)$. The average fast azimuth trended NNW-SSE both in the Wairarapa basin $\left(-37^{\circ} \pm 11\right)$ and east of the Wairarapa basin $\left(08^{\circ} \pm 10\right)$. The average delay time across the study area was $0.175 \mathrm{~s} \pm 0.014$. We conclude the anisotropy observed west of the Wairarapa fault is derived from local fault structures. East of the Wairarapa fault we conclude the fast azimuth is due to stress-aligned micro cracks in the upper $15 \mathrm{~km}$ of the Australian plate and that the fast azimuth is parallel to the orientation of maximum horizontal compression direction (SHmax). We interpret the variation we see in the south-eastern section of the study region as the result of 
a change in relative amplitudes of the three principal stress axes due to an increased influence from gravitational and tectonic loading stress.

\subsection{Introduction}

The stress field is one of the principal controlling factors on a region's earthquake faulting processes (Kusznir et al., 1991; Zoback, 1992; Townend et al., 2012). Parameters of the stress field can be measured using a variety of methods including but not limited to borehole measurements, focal mechanism inversion, and shear-wave anisotropy. Yet, these measurements are usually only available in low resolution (10's of kms) due to the station spacing of typical seismic studies. The objective of this study is to examine in high resolution how the anisotropy, and therefore the stress field, evolves across the southern North Island, New Zealand.

Previous passive seismic experiments in New Zealand (e.g., Wilson et al., 2004; Harrison and White, 2006; Seward et al., 2010; Thurber et al., 2012, etc.), have used arrays with station spacing of $10 \mathrm{~s} \mathrm{~km}$ or have been confined to a small study area. Making use of data collected during a dense array deployment allows for the unique opportunity to analyze earthquake data on a large number of closely spaced (100s m) seismic stations, while implementing methods (i.e., station stacking) usually reserved for active source experiments.

\subsubsection{SAHKE II Experiment}

We use earthquakes recorded on all available 291 short-period 3-component stations spaced approximately every $300 \mathrm{~m}$ (some $150 \mathrm{~m}$ ) across the southern North Island, New Zealand (Figure 5.1). These stations composed a third (two-thirds were vertical component stations only) of the SAHKE II deployment, which was the second phase of a two-phase seismic experiment designed to investigate the characteristics of the subduction zone interface beneath the southern North Island (Henrys et al., 2013). The SAHKE experiment, phase-one (I) and phase-two (II) was a collaborative effort between GNS Science, Victoria University of Wellington, University of Tokyo, Japan (Earthquake Research Institute), and the Ministry of Economic Development, Crown Minerals. During the active portion of the SAHKE II experiment, the stations were left recording for 6 - 8 hours each day for six days (March 9th - 14th 2011), for the purpose of collecting earthquake data.

Although the stress field of the southern North Island has been previously examined at a regional scale (Townend et al., 2012; Evanzia et al., 2017), this study is uniquely capable of tracking changes in the anisotropy and stress field orientations with high precision, due the amount (291) and density (300 m and/or $150 \mathrm{~m}$ spacing) of the SAHKE II stations (Figure 5.1). 


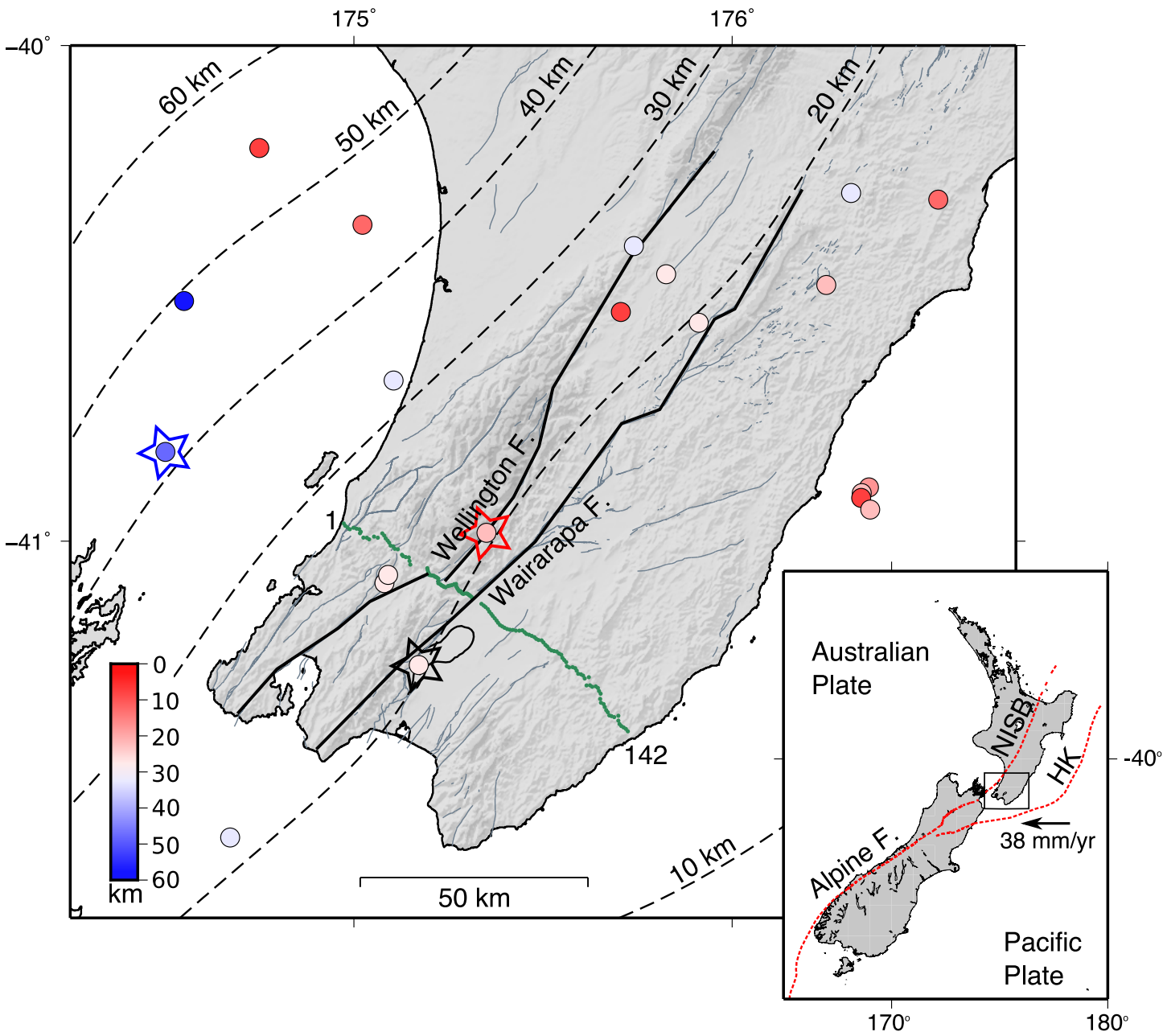

Figure 5.1: SAHKE II array and Tectonics. Location of 142 stacks of 291 high frequency seismic stations (green circles - appears as green line). 21 earthquakes (red, white, and blue circles) colored by depth are used as sources for this anisotropy study. Dashed-black lines show plate interface depth (Williams et al., 2013). Thick-black lines and grey lines show active faults (https://data.gns.cri.nz/af/; (Langridge et al., 2005)). Black-starred earthquake is used in Figure 5.3 and 5.5, blue-starred earthquake is used in Figure 5.4, and the red-starred earthquake is used in Figure 5.6. Map-inset: New Zealand tectonics showing location of plate boundaries (red-dashed lines, Coffin et al. (1998)) (e.g., Alpine Fault, Hikurangi Margin (HK), and North Island Seismic Belt (NISB)). Plate motion vector (Beavan and Haines, 2001). Black box indicates location of study area. 


\subsubsection{Shear-wave Anisotropy}

Seismic anisotropy, or shear-wave splitting, is the measurement of the time delay between two polarized orthogonal shear-waves resulting from a shear-wave entering an anisotropic medium. Crustal anisotropy is thought most often to result from differential stresses preferentially closing cracks that are aligned perpendicular to the maximum principal stress direction (Nur, 1971), but can be the result of tangible geologic features (Leary et al., 1990). This micro-crack structure within the crust results in a decrease in velocity for shear-waves traversing the cracks relative to shear-waves that parallel the cracks. The relationship between shear-wave velocity and cracks translates to the shear-wave fast azimuth roughly paralleling the maximum horizontal compressive stress (SHmax) orientation (e.g., Crampin, 1994).

Geologic features that can cause shear-wave anisotropy include but are not limited to aligned rock fabric, fault structures, and sedimentary bedding planes (Savage et al., 1989; Crampin and Peacock, 2005; Leary et al., 1990). Fabric-related anisotropy can manifest throughout the crust, resulting from shearing or metamorphism, which in turn can cause the alignment of anisotropic minerals (Do Nascimento et al., 2002; Okaya et al., 2016) (Do Nascimento et al., 2002; Okaya et al., 2016). Structural fabrics would affect shear wave splitting by controlling the fast polarization azimuth of vertically propagating shear-waves (Liu et al., 2008). Because of the various geologic and tectonic features that can result in anisotropy, results of any anisotropy study need to be examined in concert with other studies.

\subsection{Tectonic and Geologic Setting}

The North Island, New Zealand is on the Australian side of the Australian-Pacific plate boundary. East of the southern North Island is the southern terminus of the Hikurangi margin, where the Pacific plate is obliquely subducting beneath the Australian plate at $38 \mathrm{~mm} / \mathrm{yr}$ (Beavan and Haines, 2001; Beavan et al., 2002) (Figure 5.1).

Walcott (1984) and more recently others (Reyners, 1998; Wallace et al., 2004, 2009, 2012) have demonstrated that slip on the plate interface varies along the length of the Hikurangi margin beneath the North Island. Making use of high-resolution decadal campaign and continuous global positioning system (GPS) data, Wallace et al. (2004); Beavan et al. (2007) showed that the southern North Island is located over a locked zone of the plate interface, where the overriding and subducting plates are partially coupled, resulting in a slip deficit of $20-30 \mathrm{~mm} / \mathrm{yr}$. Adjacent to the locked zone, numerous episodes of slow slip occur on the plate interface. These slow-slip events last from weeks to months and occur offshore to the west of the study region, at depths from 30 - 60 km (Beavan et al., 2007; Wallace and Beavan, 2010; Lamb and Smith, 2013; Wallace et al., 2014).

NE-SW striking dextral strike-slip and reverse faults are the dominant tectonic on- 
shore features of the southern North Island (Langridge et al., 2016, Figure 5.1). The major on-shore faults (e.g., Wellington and Wairarapa faults) accommodate 60 - 90\% of margin-parallel motion (Langridge et al., 2005), whereas motion on the subduction thrust accommodates some of the margin-perpendicular motion (Wallace et al., 2012). Using retriangulated geodetic measurements Walcott (1978), and later Lamb and Vella (1987), as well as Beanland and Haines (1998), demonstrated that dextral shear is the principal form of deformation west of the Wairarapa fault, whereas east of the fault, compression is the principal cause of deformation.

In a continental context, the crust throughout New Zealand consists of various volcanic, sedimentary, plutonic, and metamorphic basement terranes (Mortimer, 2004) (Figure . The upper crust of the southern North Island is predominantly made from sedimentary terranes. The western region of the study area consists of sandy-mudstones (Rakaia Terrane), the central region (the Wairarapa basin) is made up of limestones overlaying sand and mudstones (Pahau Terrane), and the eastern region of the area, the East Coast Allochthon is predominantly ophiolitic, volcanic and sedimentary (sand and siltstones) rocks that were thrust over the southern North Island from the northeast in the late Oligocene (Begg et al., 2000; Lee and Begg, 2002; Mortimer, 2004). In the eastern region of the Rakaia Terrane, there is a minimum expression of the Haast Schist (Mortimer, 2004). It should be noted that within the the Rakaia, Pahau, and East Coast Allochthon Terranes are marked by predominantly westward steeply dipping beds, with azimuth of NE-SW (Begg et al., 2000; Lee and Begg, 2002). Although there are no known large metamorphic terranes at the surface in the southern North Island, in the northern South Island, there are mafic to ultra mafic igneous and sedimentary rocks becoming increasing schist-like towards the west (Begg et al., 2000). Based on velocity modeling, Eberhart-Phillips and Reyners (1997) identified a high-velocity (Vp 6.5 $6.7 \mathrm{~km} / \mathrm{s}$ ) and relatively low $\mathrm{Vp} / \mathrm{Vs}$ associated with high-grade schist in the northern South Island. Making use of shear-wave splitting azimuthal data and receiver function calculations, Savage et al. (2007) suggested the presences of dipping anisotropic body, likely blueschist, in the lower crust below the westernmost southern North Island.

\subsection{Previous Studies}

There have been several shear-wave splitting studies done in the southern North Island, New Zealand, which examined crustal and upper mantle anisotropy. Gledhill and Stuart (1996), using local earthquakes recorded on the temporary Tararua array, calculated a fast azimuth of $51^{\circ} \pm 18$ for the crust of the Australian plate and $41^{\circ} \pm$ 15 in the underlying mantle, which is sub-parallel to the strike of the subduction zone and major crustal geological structures (Gledhill, 1991). Later, Marson-Pidgeon and Savage (1997), Marson-Pidgeon et al. (1999), and Marson-Pidgeon and Savage (2004), using teleseismic S, ScS, and SKS events, obtain similar fast azimuths (NE-SW) that were sub-parallel to the subduction zone. Brisbourne et al. (1999); Audoine et al. 


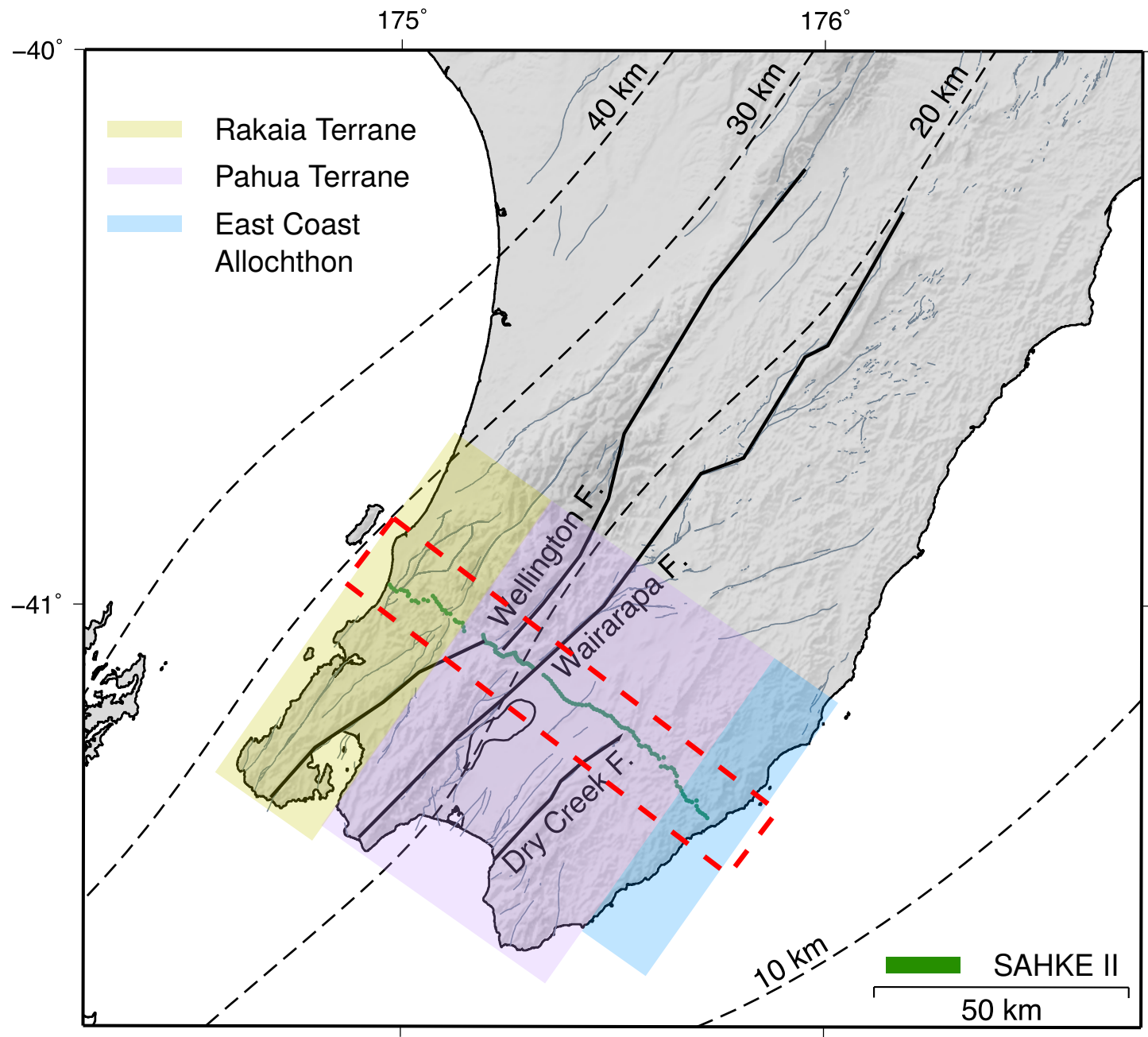

Figure 5.2: Map of major geologic terranes at the southern North Island, New Zealand. From west to east: Rakaia Terrane (yellow), Pahau Terrane (purple), and East Coast Allochthon (blue) (Mortimer, 2004). Major bedding and fault are orientated NE-SW. Minor faults, foliation, and bedding plane orientations vary throughout the terranes and in proximity to the SAHKE II array (reddashed box) vary (see Appendix C). 
(2000) determined that the anisotropy (NE-SW fast azimuth) calculated from deeper earthquakes in the region were reflective of trench-parallel flow of the mantle. Most recently Evanzia et al. (2017), using local earthquakes recorded on the SHAKE I array, observed a regional variation in fast azimuth across southern North Island. Evanzia et al. (2017) calculated a NE-SW $\left(65^{\circ} \pm 17\right)$ fast azimuth west of the Wairarapa fault, NW-SE $\left(-45^{\circ} \pm 35\right)$ in the central southern North Island, between the Wairarapa and Dry Creek faults, and ENE-WSW $\left(74^{\circ} \pm 11\right)$ east of the Dry Creek fault. In conjunction with stress field observations in the subducting slab and gravitational stresses, Evanzia et al. (2017) postulated that the fast azimuths calculated in the crust resulted from the transfer of bending stresses and/or gravitational stresses in the west, predominately from gravitational stresses in the central region, and a combination of gravitational stresses and tectonic loading stresses in the eastern region of the southern North Island.

\subsection{Seismic Data}

The SAHKE II array was deployed for six days, recording each day for 6 - 8 hours through the late night to early morning. During these periods 21 local earthquakes $\left(\mathrm{M}_{L} 1.4\right.$ to $\mathrm{M}_{L}$ 3.3) were detected by GeoNet (https : / www . geonet . org . nz /), ranging from depths of 5 to $56 \mathrm{~km}$. Figure 5.3 shows an example of a clearly recorded earthquake on the SAHKE II array.

\subsection{Shear-Wave Analysis Methods}

Using GeoNet derived origin times (https://www.geonet.org.nz/) the 21 detected earthquakes were cut out of the SAHKE II dataset. We linearly stacked the raw seismic data for five adjacent stations aligning on the theoretical TauP software (Crotwell et al., 1999) shear-wave arrival using the ak135 velocity model (Kennett et al., 1995, Figure 5.4). To reduce the effect of one bad station measurement (if present) the stacking was done with a sliding window, where each window would have three overlapping stations (e.g. Stack 1: A, B, C, D, E; Stack 2: C, D, E, F, G; Stack 3: E, F, G, $\mathrm{H}, \mathrm{I})$. There are some gaps present in the SAHKE II array (Figure 5.3); stations juxtaposed across these gaps were not stacked. After the sliding-window stacking was performed we had a total of 142 stacks of data per event. Figure 5.5 shows an example of a recorded wave from an earthquake moving across the stacked stations from SW to NE. First arriving P- and S-phases were repicked on the stacked stations by hand using standard methods, using the Seismic Analysis Code (SAC) (Goldstein et al., 2003; Goldstein and Snoke, 2005).

We use the Multiple Filter Automatic Splitting Technique (MFAST) (Savage et al., 2010) to calculate crustal anisotropy parameters (e.g., fast azimuth and delay times) for individual stacked-event pairs. Commencing with the pre-picked S-phase arrivals, 

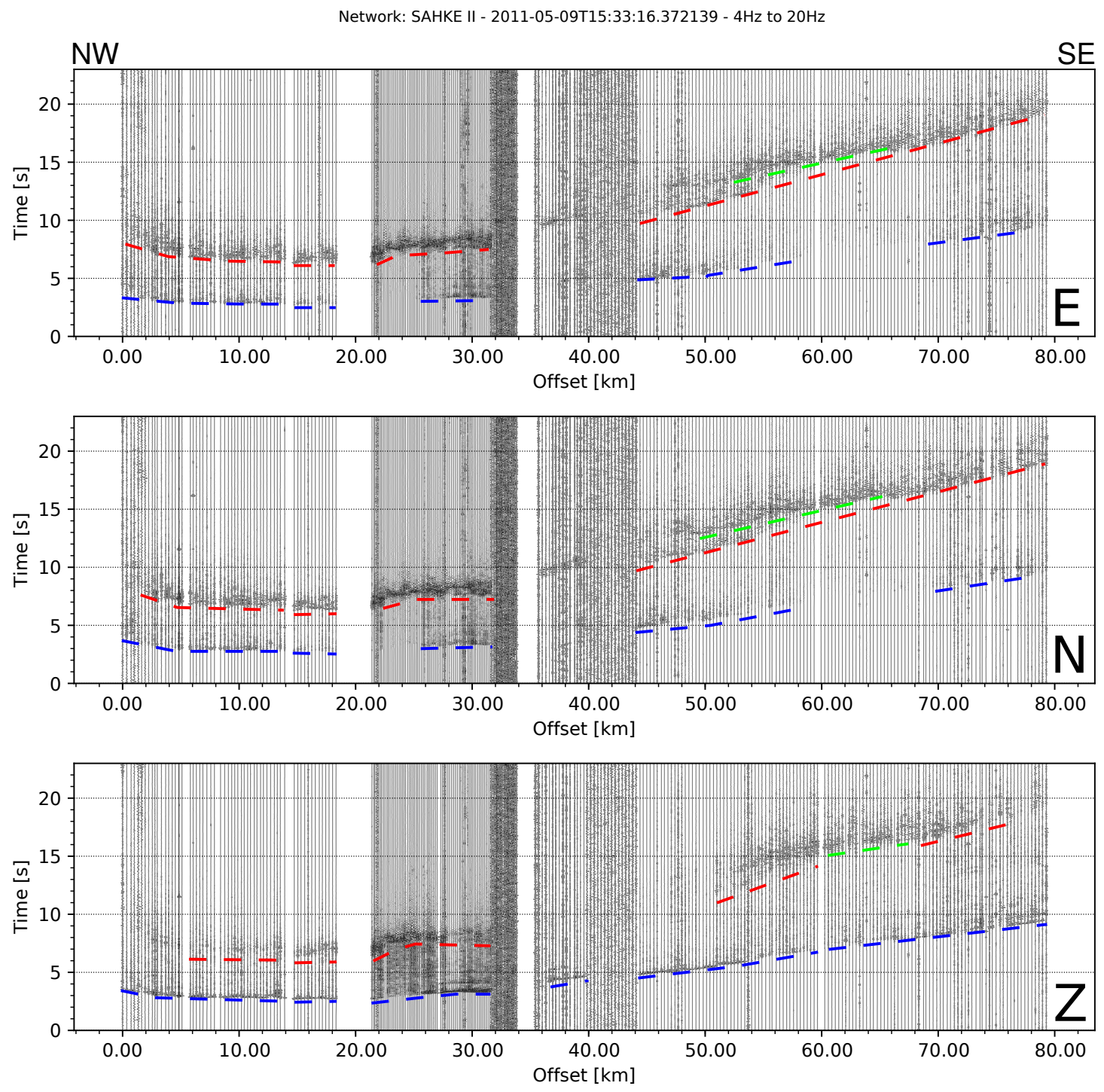

Figure 5.3: An example of an earthquake (black star Figure 5.1) recorded on the SAHKE II array, with a bandpass filter of $4 \mathrm{~Hz}$ to $20 \mathrm{~Hz}$. An offset distance of zero indicates the location of the westernmost station. The P-wave (blue) arrival can clearly be seen in the vertical component and is less continuous in the horizontal components. S-wave (red) arrival is visible along the array. In the larger offsets a secondary phase (green), possibly a reflection, can be seen after the S-wave, with possible commingling of the phases in the furthest east stations. White spaces show gaps in the array due to inaccessible terrain. 
2011-05-13T13:27:37.156 - 2011-05-13T13:27:59.156

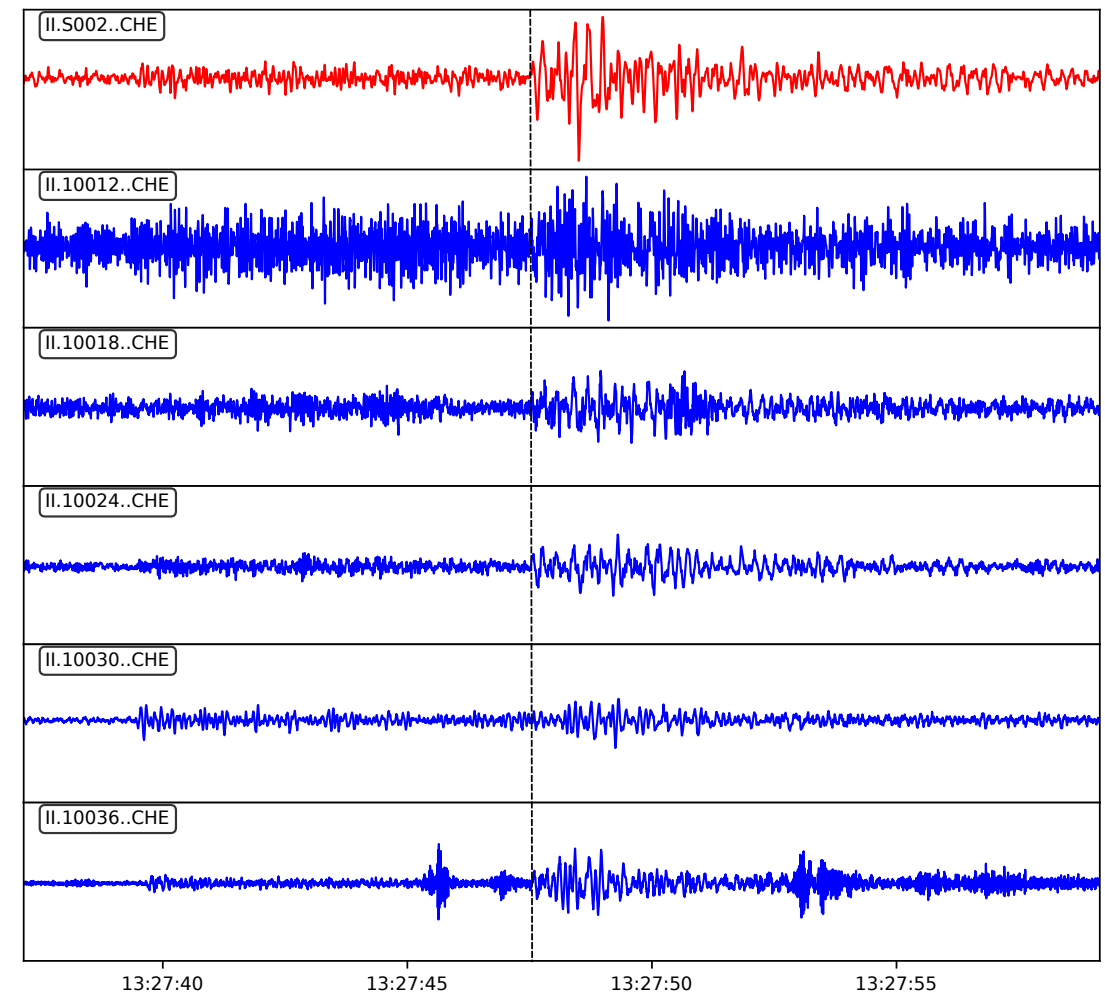

Figure 5.4: Stacked data example. Traces (blue) from five adjacent stations in the SAHKE II array, stacked (aligned on TauP theoretical S-pick) to make final trace (red). Stacked trace (red) used to pick shear-wave for use in MFAST program. Dashed line indicated shear-wave arrival. 
MFAST determines the best filter for a given trace by finding the maximum product of signal to noise ratio (SNR) and bandwidth. A grid search, using the best filter and multiple measurement windows, is done over the fast azimuth and delay time parameter space to determine the two values which best correct for splitting. The best fitting fast azimuth and delay time parameters are chosen by identifying the minimum of the smallest eigenvalue for the corrected particle motion (Silver and Chan, 1991), with corrections for error bars by Walsh et al. (2013). The most stable solution is determined by the application of an unsupervised cluster analysis (Teanby et al., 2004) to the fast azimuth and delay time parameters. After the splitting analysis is complete, MFAST grades the stacked-event pair measurements from A - D, based on four criteria: (I) SNR, (II) fast azimuth and delay time uncertainty, (III) cluster uniqueness, and (IV) if the measurement is null (Savage et al., 2010; Wessel et al., 2010).

A measurement is null when the arriving shear-wave has not been split; this occurs when there is little to no anisotropy or when the particle motion of a wave traveling through an anisotropic medium is aligned parallel or perpendicular to the fast azimuth. MFAST identifies measurements as null if the delay time is within $80 \%$ of highest value in the grid search (1.0 s) or if the fast azimuth is within $20^{\circ}$ of the incoming polarization direction or its perpendicular. Graphically, a null measurement can be identified by the presence of two narrow bands in the confidence interval of the fast azimuth. The U-shaped confidence interval allows for any amount of splitting parallel to the incoming polarization directions (Savage et al., 2010).

\subsection{MFAST Splitting Results}

342 A- and B-quality splitting measurements were calculated over the 142 stacks using 19 local earthquakes. Figure 5.6 shows an example of an A-quality measurement and graphically displays the processing steps taken by MFAST to calculate anisotropy parameters and measurement quality. A- and B- quality splitting measurement calculated from unstacked traces from all earthquakes, the four closest earthquakes to the SAHKE II array, five random earthquakes, and a single earthquake can be found in the Supplemental Material (Appendix C Figure S1 S20). All splitting measurements, stacked and unstacked, give similar average splitting measurements.

Because shear-wave splitting results from local earthquakes are often scattered ((Gledhill, 1991; Zhang et al., 2007; Johnson et al., 2011; Karalliyadda and Savage, 2013; Savage et al., 2016) we investigate whether some splitting result parameters (e.g., back azimuth, delay time, fast azimuth) are dependent on one another. Density contour plots show that there are no strong correlations between splitting parameters (Figure 5.7, Appendix C Figures S4, S9, S14, S19). We see scatter associated with the fast azimuths from local earthquake sources (Figure 5.8). Because of the scatter, we are unable to determine much information from rose diagrams alone; as in previous studies (Savage 

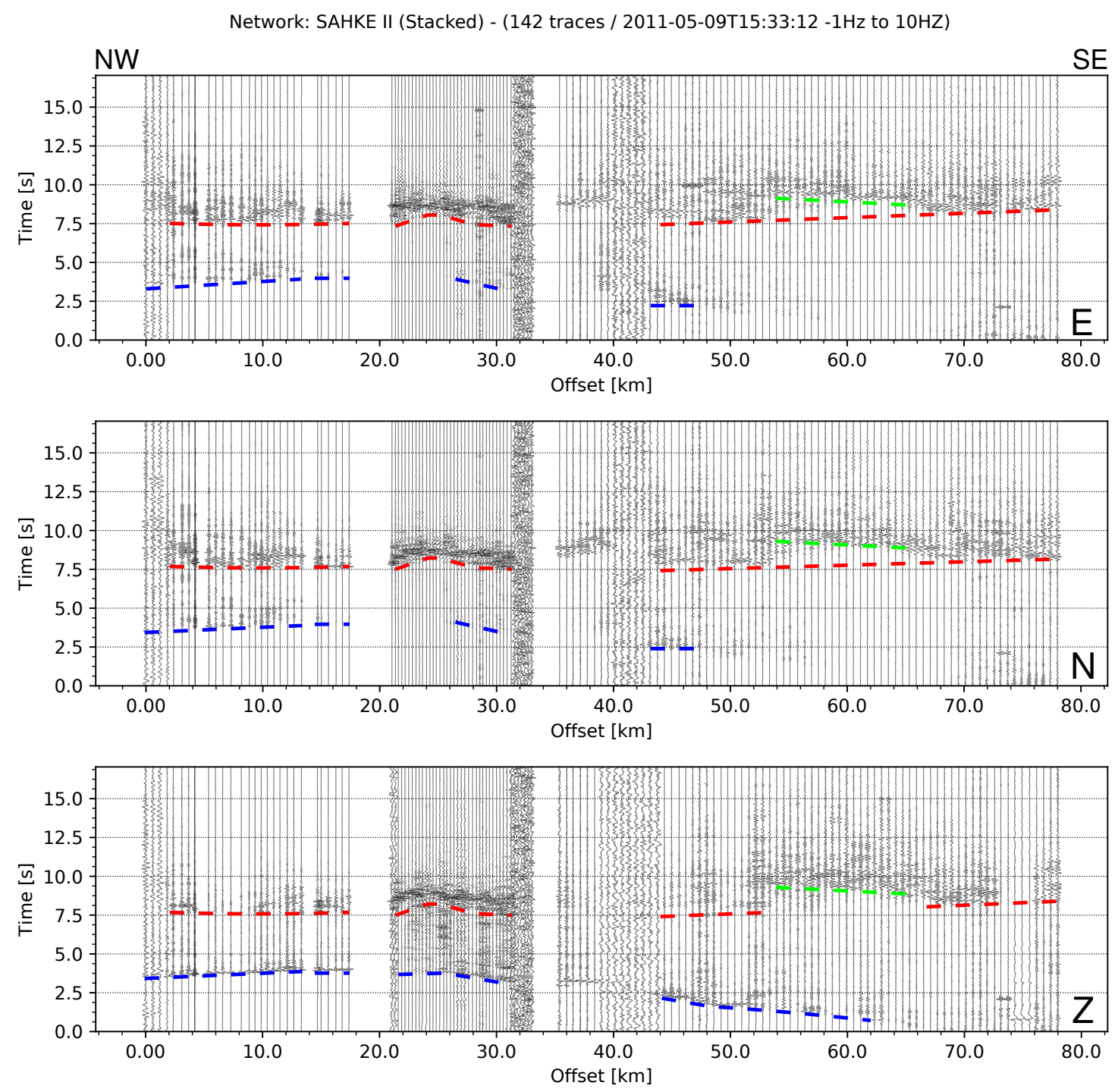

Figure 5.5: Stacked data from raw data from Figure 5.3. Pattern of arrivals are conserved after the stacking processes. The incoming shear-wave (red-dashed line) is now flattened because the traces were trimmed around it. Dashed lines are as indicated in Figure 5.3. 
et al., 2016; Evanzia et al., 2017) it is necessary to examine the average fast azimuths.

Figure 5.6: Example of splitting results from MFAST of stack 123 on the SAHKE II array. Top label is measurement ID. (a) Bandpass filtered $(0.2-3 \mathrm{~Hz})$ East (e), North (n), and vertical ( $\mathrm{z}$ ) waveforms. Solid line is the shear-wave arrival. Dashed lines are minimum (1) start and maximum (4) end times for windows used in processing. Grey window is the window chosen as the best measurement. (b) Rotated waveforms into incoming polarization direction (p) and its perpendicular $(\mathrm{p}+)$, for original filtered (top) and the waveforms corrected for delay time (bottom). Dashed lines are the maximum (2) start and minimum (3) end times for other measurement windows. Dashed lines 1 and 4 and grey window are as they were in (a). Solid line (red) is the shearwave arrival. (c) Fast direction azimuth and delay time for each window as a function of window number. $X$ marks the chosen fast direction/delay time and window. (d) Clusters of five or more measurements as a function of fast direction and delay time. $\mathrm{X}$ marks the chosen final cluster. (e) Original (left) and corrected (right) waveform (top) and particle motion (bottom) for the final window (grey). (f), similar to (d), but include contours of the smallest eigenvalues of the covariance matrix for the final measurement $(X)$. Bottom label gives final grade, fast direction azimuth, and delay time, including errors for splitting measurement.

West of the Wairarapa fault the average fast azimuths generally trend between NNW-SSE and NNE-SSW, where as east of the Wairarapa fault there is more variation, but the trend is typically NW-SE and N-S east of the Dry Creek fault (Figure 5.9). The variation in the average fast azimuth calculated in this study, is sub-parallel to parallel with averages made by Evanzia et al. (2017) on stations in the SAHKE I network, which lie in close proximity to the SAHKE II array (Figure 5.9). After combining and calculating the mean of four subregions (1: West of the Wellington fault [green]; 2: between the Wellington and Wairarapa faults [tan]; 3: inside the Wairarapa basin [red]; 4: East of the Wairarapa basin [blue]) of fast azimuths, there is clear variation west and east of the Wairarapa fault (Figure 5.9, Table 5.1). The average fast azimuths west of the Wellington fault and between the Wellington and Wairarapa faults are N-S $\left(18^{\circ} \pm 12\right)$ and NNE-SSW $\left(65^{\circ} \pm 12\right)$, respectively, whereas the average fast azimuth in the Wairarapa basin and east of the Wairarapa basin are both NNW-SSE, $-37^{\circ} \pm 11$ and $08^{\circ} \pm 10$, respectively (Figure 5.9).

In order to assess the validity of the stacking methods implemented in this study we take a sample of the unstacked seismic traces of two regions (west of the Wellington fault and in the Wairarapa basin) and rotate them into the fast azimuth (Table 5.1) and a perpendicular azimuth (fast azimuth $+90^{\circ}$ ) (Figure 5.10, red and blue respectively). Some traces west of the Wellington fault and from within the Wairarapa basin show earlier arrivals for those traces rotated into the fast azimuth (Figure 5.10). Variable 
Event: 2011-05-09_11-11-36 Stack: 123 Filter: 0.2-3.0 hz

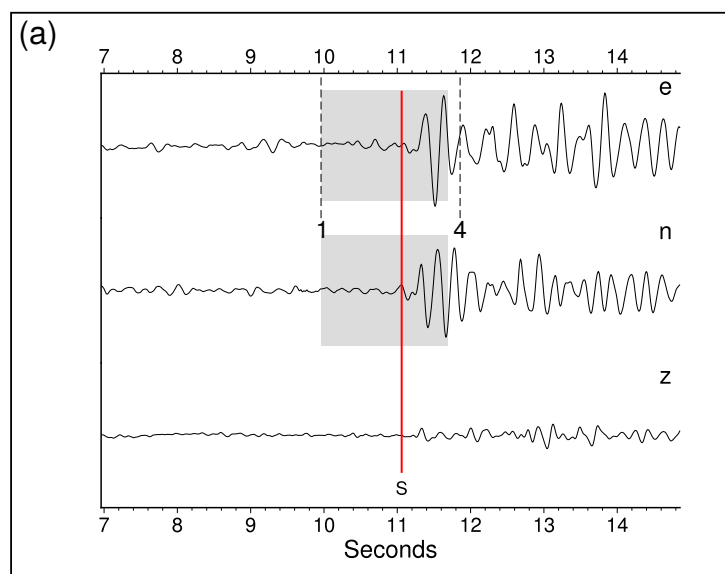

(b)

(c)

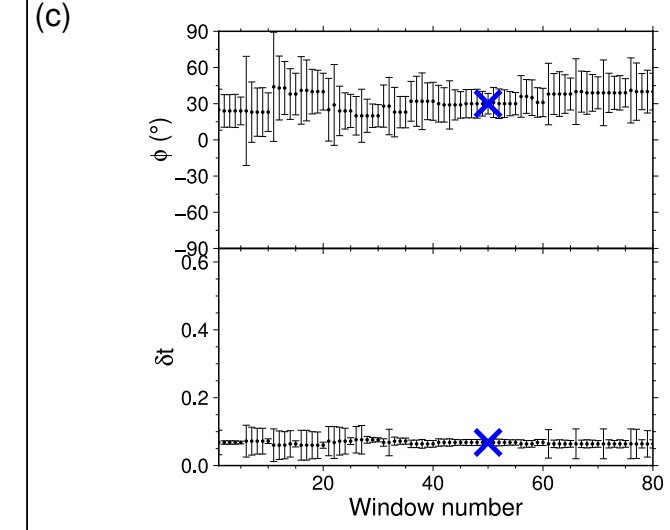

(d)
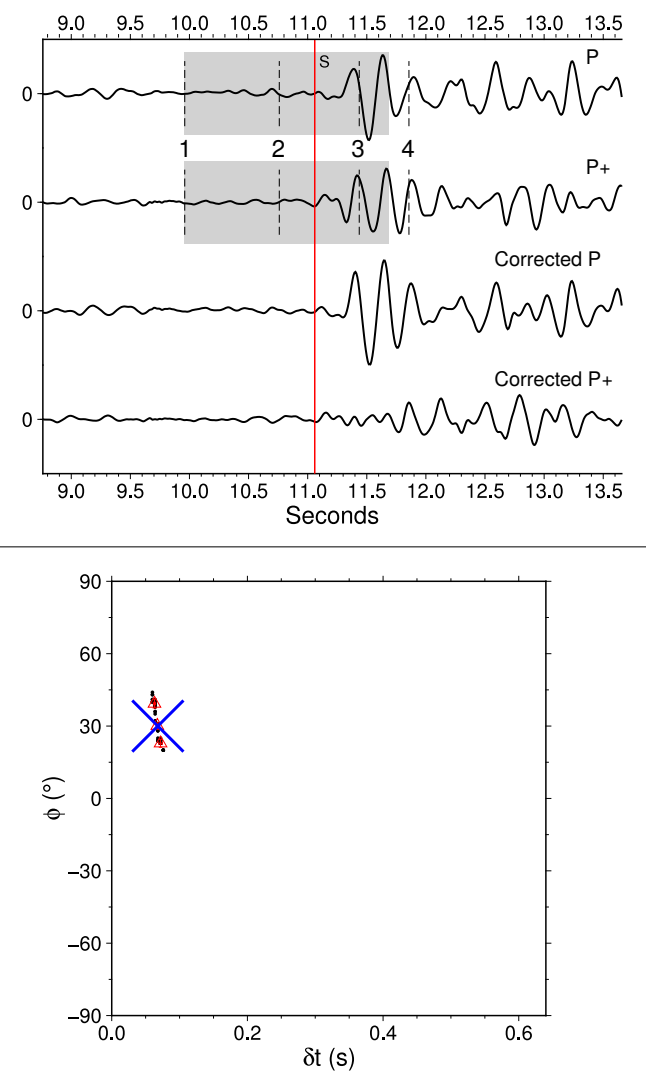

(e)
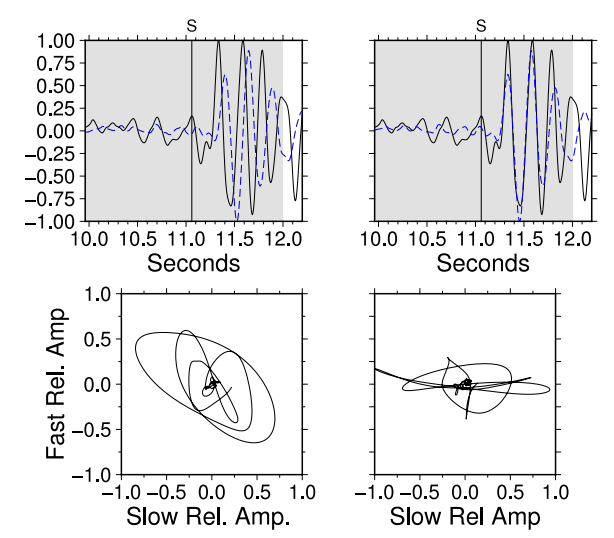

(f)

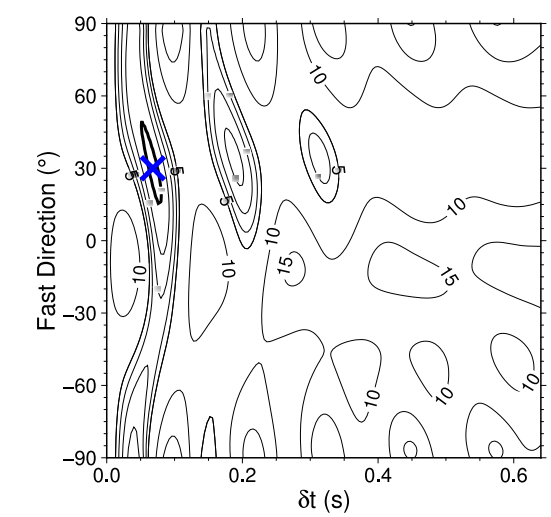

Grade: $\mathrm{ACl}$

Fast Azimuth: $30.0+/-8.5$

Delay Time: $0.068+/-0.007$ 

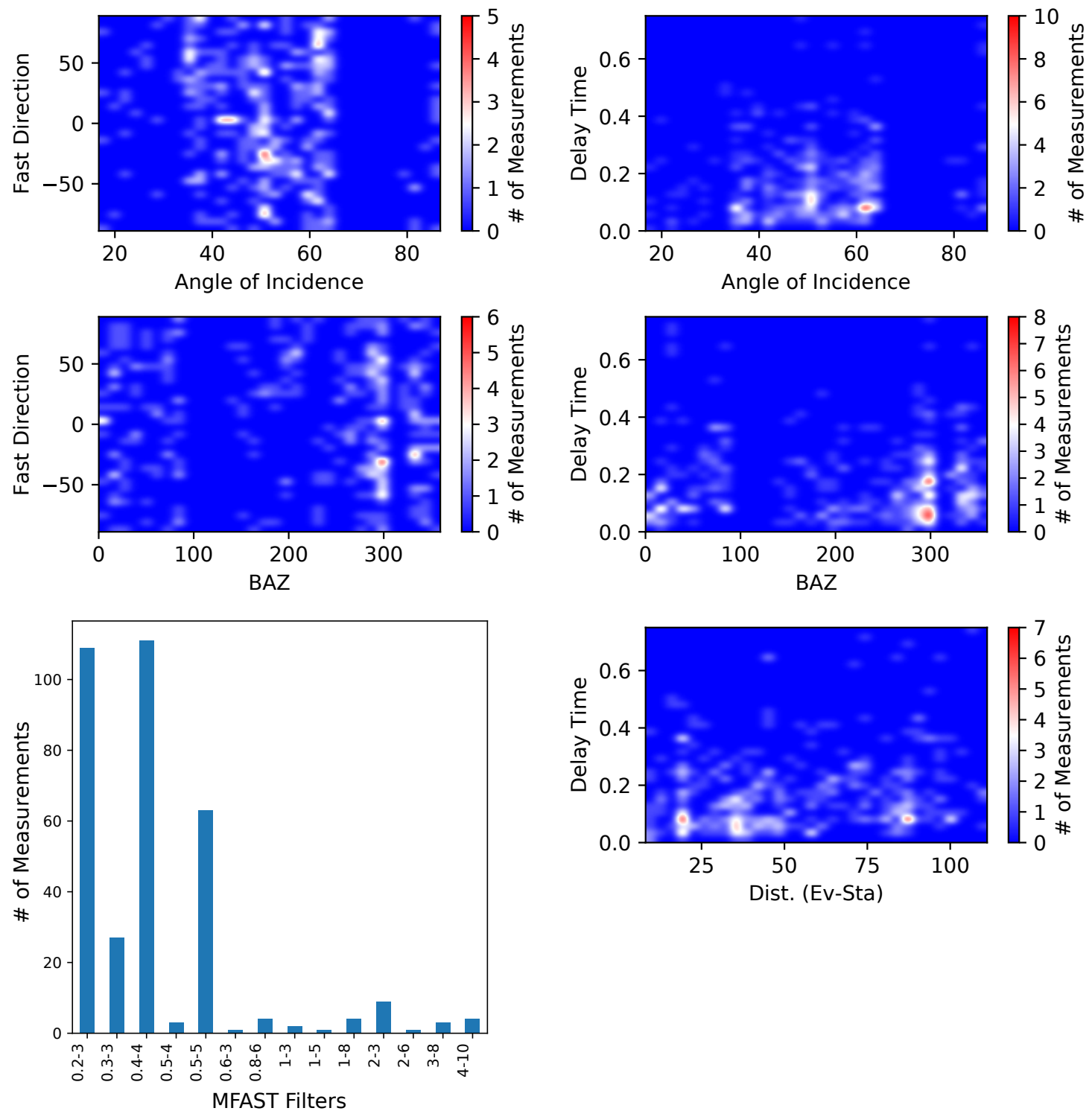

Figure 5.7: Density plots comparing various attributes of all A and B splitting measurements made using MFAST and filters used in splitting. Measurement attributes compared are: angle of incidence, back azimuth, delay time, distance (earthquake - station), and fast direction azimuth. Hotter colors (reds) indicated a higher occurrence. Lower frequency $(0.25 \mathrm{~Hz})$ filters gave more high quality ( $\mathrm{A}$ and $\mathrm{B}$ quality) measurements. No one attribute is dependent on any other, indicating a singular source for the anisotropy measurements calculated. 


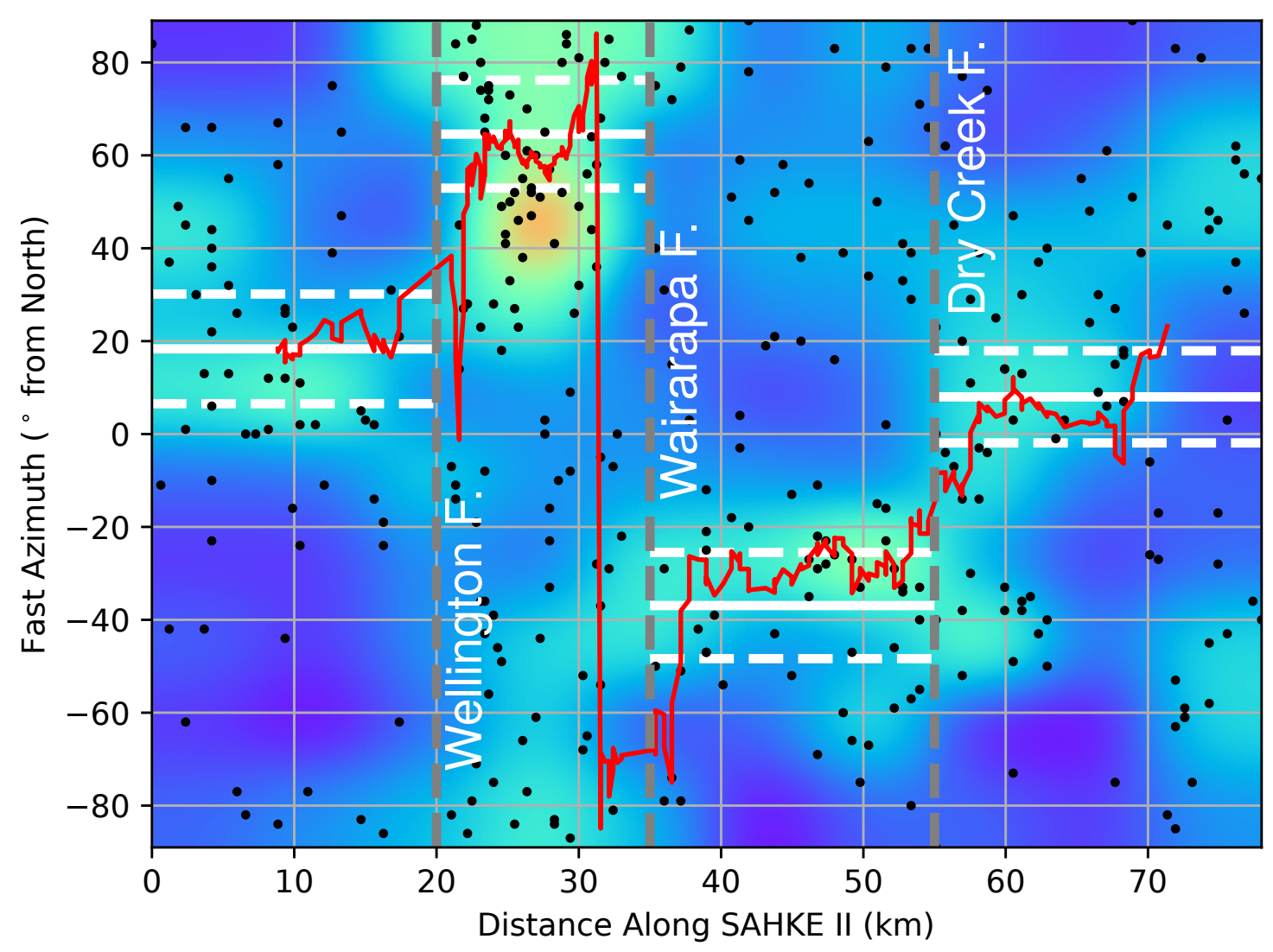

Figure 5.8: Fast azimuth (degrees from North) measurements from all stacked traces as a function of distance along the SAHKE II array. Distance $0 \mathrm{~km}$ indicates location of westernmost seismic station. Black dot are fast azimuth measurements. Oranges, yellows and greens indicate increase density of measurements. Red-line is the 20-point moving average. Dashed-grey lines separate difference regions of interest (from West-East, see Figure 5.1 and 5.8): West-coast to the Wellington fault, Wellington fault to the Wairarapa fault, the Wairarapa Basin, and Dry Creek fault to East-coast. Solid-white lines mark the average fast azimuth and dashed-white lines show the $95 \%$ confidence intervals. 


\begin{tabular}{ccccccc}
\hline Region & Stations & \# of Stacks & Fast Az. & $95 \%$ CI & Delay Time & $95 \%$ CI \\
\hline West of Well. & 55 & $001-029$ & $18^{\circ}$ & \pm 12 & $0.144 \mathrm{~s}$ & \pm 0.027 \\
Well. - Wair. & 89 & $030-070$ & $65^{\circ}$ & \pm 12 & $0.181 \mathrm{~s}$ & \pm 0.027 \\
Wair. - DC. & 67 & $071-103$ & $-37^{\circ}$ & \pm 11 & $0.173 \mathrm{~s}$ & \pm 0.029 \\
East of DC. & 80 & $104-142$ & $08^{\circ}$ & \pm 10 & $0.189 \mathrm{~s}$ & \pm 0.026 \\
All Regions & 291 & $001-142$ & $21.56^{\circ}$ & \pm 06 & $0.175 \mathrm{~s}$ & \pm 0.014 \\
West & 17 & N $/ \mathrm{A}$ & $66^{\circ}$ & \pm 18 & $0.132 \mathrm{~s}$ & \pm 0.016 \\
Basin & 17 & N $/ \mathrm{A}$ & $-43^{\circ}$ & \pm 35 & $0.167 \mathrm{~s}$ & \pm 0.025 \\
East & 16 & N/A & $74^{\circ}$ & \pm 11 & $0.165 \mathrm{~s}$ & \pm 0.028 \\
\hline
\end{tabular}

Table 5.1: Averaging fast direction across SAHKE II array. Averaging over four groups of stacks: (1) west of the Wellington fault; (2) between the Wellington and Wairarapa fault; (3) in the Wairarapa Basin; (4) east of the Dry Creek fault. Italicized regions (West, Basin, East) indicate measurements made by Evanzia et al. (2017). Column 1 identifies the region, column 2 identifies the number of stations in that region, column 3 identifies the number of stacks in the region, columns 4 and 5 give the average fast azimuth and 95\% confidence interval, and columns 6 and 7 give the average delay time and $95 \%$ confidence interval.

delay times between even closely spaced traces indicate that the fast azimuth and delay time can change rapidly.

\subsection{Discussion}

The lack of a strong relationship between the splitting parameters (Figure 5.7) and given that averages using all data, data from the four closest earthquake, data from five random, and data from a single earthquake (Appendix C Figure S1 S20) yield similar results implies a similar local source for the measured anisotropy and shows the stacked measurements are not heavily dominated by a single earthquake. It is unlikely that the majority of the observed local source of anisotropy is the result of larger regional structural fabrics (i.e., aligned rock fabric, fault structures, and sedimentary bedding plains) because there are no known pervasive metamorphic or finely-wellbedded sedimentary terranes across the southern North Island. Based on the finding from Savage et al. (2007) of dipping beds of blueschist in the westernmost southern North Island, if this feature continued north, then it could account for some of the scatter we observe at the westernmost stations.

The measured splitting is not from a pervasive anisotropy along the whole wave path because the delay times do not vary with station-event distance or depth (Figure 5.7), which suggests it is probably the result of a near surface feature. Assuming the anisotropy is limited to the crust (15 $\pm 5 \mathrm{~km}$ or above) (Evanzia et al., 2017), an average shear-wave velocity of $3.5 \mathrm{~km} / \mathrm{s}$ (Eberhart-Phillips et al., 2010), and an average delay time of $0.175 \pm 0.014 \mathrm{~s}$, we estimate the strength of anisotropy to be $4.2 \pm 0.5 \%$, which 


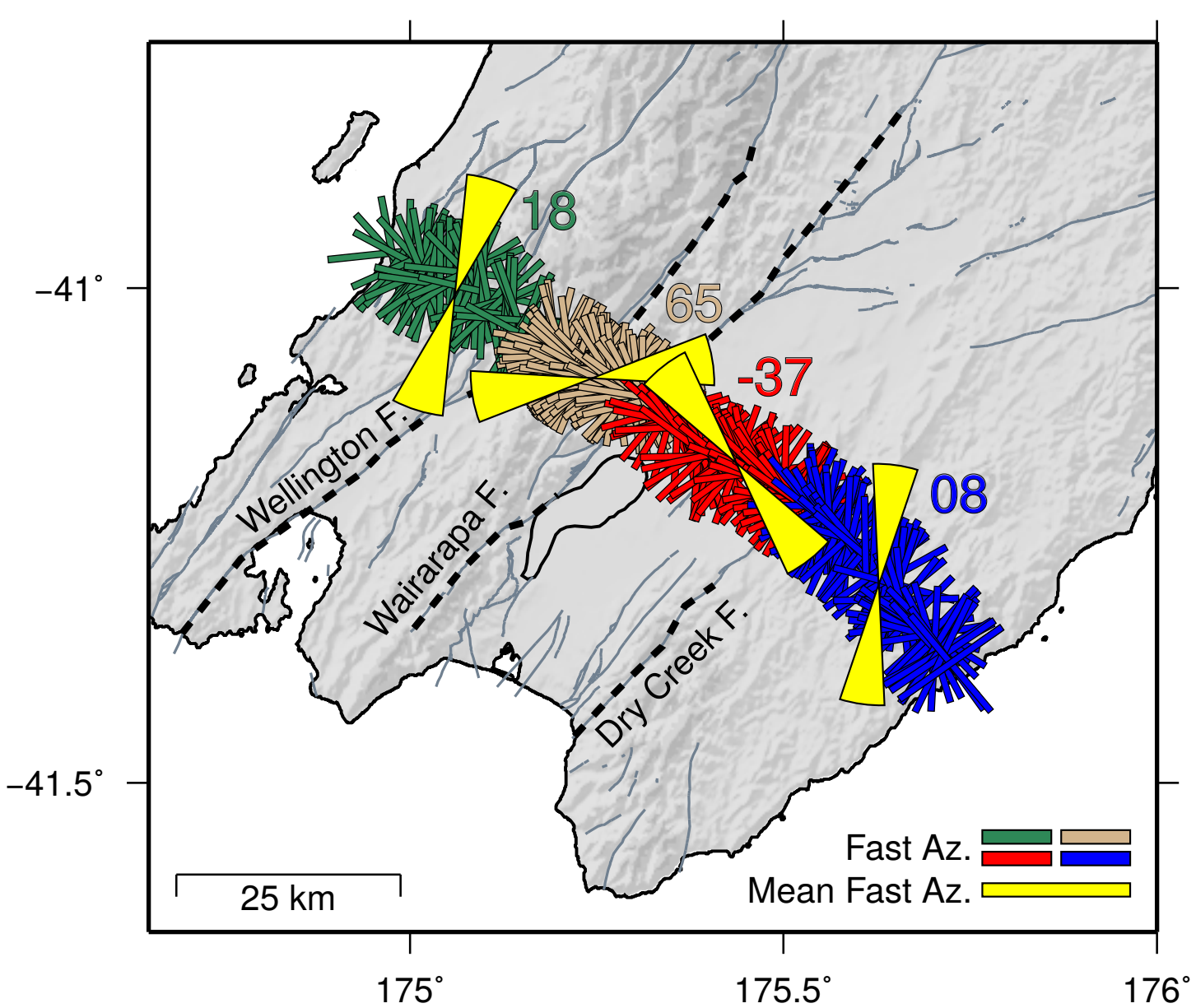

Figure 5.9: Circular-mean fast azimuth for each stack. Colors (e.g., green, tan, red, blue) indicate grouping of mean azimuths for averaging. Colored numbers and yellow wedges indicate the average fast direction azimuth and 95\% confidence interval for groups over which they lie.

agrees well with previous estimations done by Gledhill and Stuart (1996); Evanzia et al. (2017), who calculated anisotropy strength of $4 \%$ and $3.7 \pm 1.2 \%$, respectively, in the southern North Island. Crampin (1994) noted that with anisotropy from micro-cracks within the crust tend to result in $1.5 \%$ to $4.5 \%$ strength in anisotropy, which is similar to the $4.2 \pm 0.5 \%$ found in this study.

\subsubsection{West of Wairarapa Fault}

West of the Wairarapa fault the fast azimuths generally trend between NNW-SSE and NNE-SSW (Figure 5.8 and 5.9). West of the Wellington fault where the average fast azimuth is NNE-SSW $\left(18^{\circ} \pm 12\right)$ and the major fault structures strike NE-SW (Van Dissen and Berryman, 1996) (Figure 5.11). Between the Wairarapa and Wellington fault, we observe a rotation of the average fast azimuth trending NE-SW $\left(65^{\circ} \pm 12\right)$, which is coeval with a change rotation in strike of the Wellington fault from NNE-SSW to NESW (Figure 5.11). There is no clear relationship between various splitting parameters 
(Figure 5.7), but there is a clear alignment of the fast azimuth to the prevailing NW-SE trending faults. Therefore, the fast azimuth west of the Wairarapa fault is likely the result of near-surface structural sources (i.e., faults). It is possible that the scatter we observed is due to the opening and closing of cracks parallel and perpendicular to the fast azimuth (i.e., SHmax) (Crampin, 1994).

The average fast azimuth of $65^{\circ} \pm 12$ observed between the Wellington and Wairarapa faults in this study, is similar to the average fast azimuth of $66^{\circ} \pm 18$ observed in west of the Wairarapa fault by Evanzia et al. (2017). However, west of the Wellington fault, the average fast azimuth of $18^{\circ} \pm 12$ found in this study differs significantly from the more regional Evanzia et al. (2017) fast azimuth observations. This would suggest that the fast azimuth of $18^{\circ} \pm$ observed west of the Wellington fault, is a more localized feature, or that measurements from stations between the Wellington and Wairarapa faults dominated the average fast azimuth west of the Wairarapa fault in the Evanzia et al. (2017) study.

\subsubsection{East of Wairarapa Fault}

East of the Wairarapa fault there is a clear change in the trend of the average fast azimuth. In the Wairarapa basin the average fast azimuth trends NNW-SSW $\left(-37^{\circ} \pm 11\right)$, which is oblique, nearly perpendicular, to the orientation of the major local fault system (Figure 5.8, 5.9, and 5.11). The average fast azimuth of $-37^{\circ} \pm 11$ observed across the Wairarapa basin, is similar to those observed by Evanzia et al. (2017), who calculated an average fast azimuth of $-44^{\circ} \pm 35$ throughout the Wairarapa basin. This fast azimuth and the NW-SE orientation of the major faults would suggest a non-structural origin for the fast azimuth, unlike west of the Wairarapa fault. The rotation of the fast azimuth is likely due to the rotation of sigma one (maximum compressive stress direction) or a drop in amplitude of sigma one relative to sigma two (median compressive stress direction) and three (minimum compressive stress direction). On a regional scale, Evanzia et al. (2017) identified this rotation and attributed it to an increased contribution to the stress field by gravitational and tectonic loading stresses.

East of the Dry Creek fault, the average fast direction is NNW-SSE $\left(08^{\circ} \pm 10\right)$. The average fast azimuth of $08^{\circ} \pm 10$ east of the Dry Creek fault is significantly different than the regional average of $74^{\circ} \pm 11$, calculated by Evanzia et al. (2017). This may be due to the larger area that Evanzia et al. (2017) averaged the fast azimuth over. As shown in Figure 3 of Evanzia et al. (2017) average fast azimuths differ significantly in the northern and southern East region. Similar to west of the Wellington fault, this difference suggests the average fast azimuth observed in this study result from localized features that are not pervasive throughout the region. Figure 5.11 shows that the fast azimuth east of the Dry Creek fault is similar in orientation to faults in the easternmost southern North Island. It is possible that some of the splitting in this area is the result of unknown near surface fault structures. The differences in the average fast azimuth 

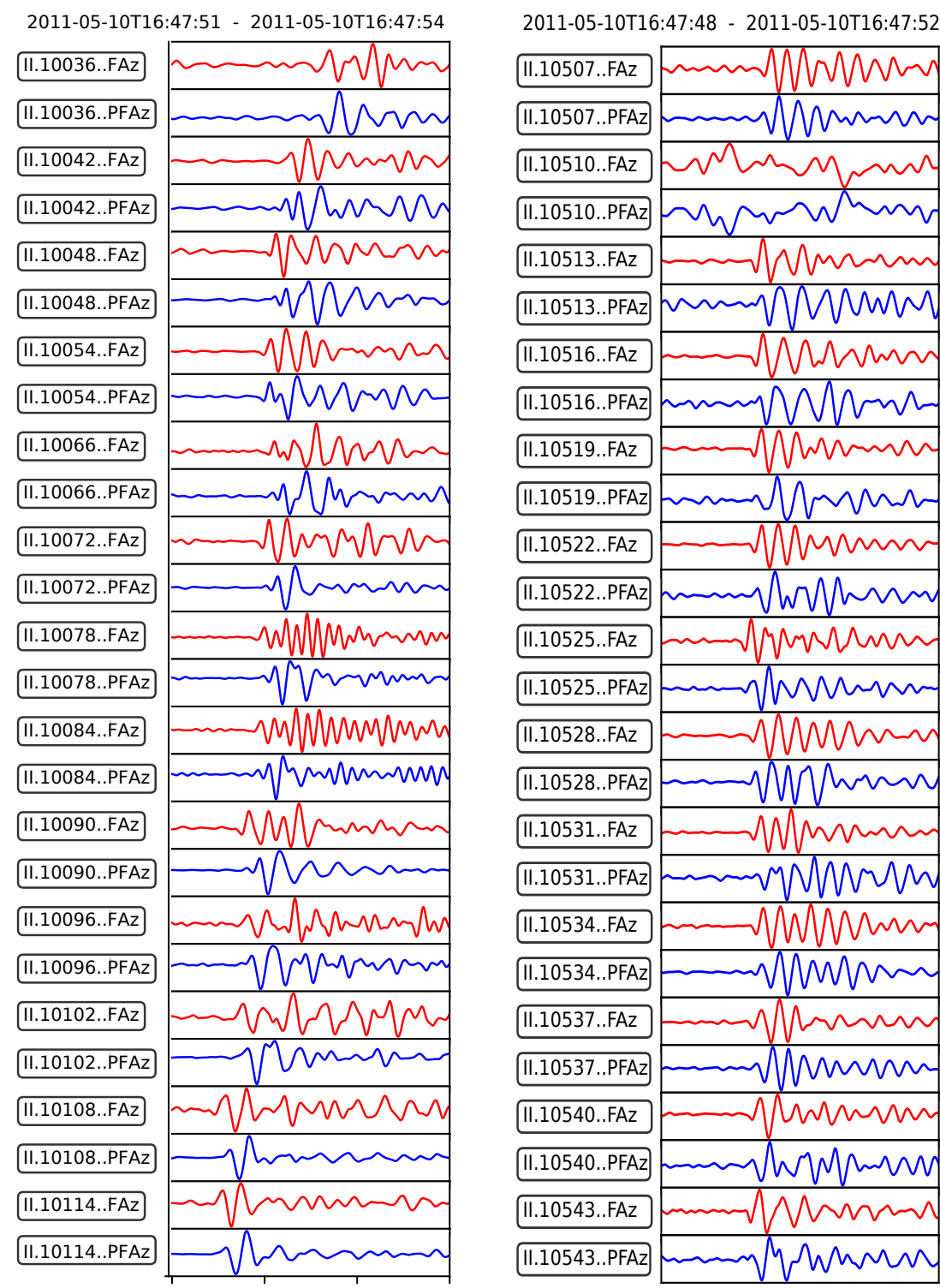

Figure 5.10: The result of rotating a sample of the raw (no-offset) unstacked seismic traces into the fast azimuth (red) and its perpendicular (blue) calculated using MFAST. Right: Region 1 (West of the Wellington fault); Left: Region 3: (the Wairarapa Basin). Overall the traces rotated in the fast azimuth orientation arrive slightly earlier than those rotated perpendicular to that orientation. Not all traces show the same amount of time difference; this is to be expected because the fast azimuth orientation is an average, and that the fast azimuth changes rapidly across the SAHKE II line. Additionally, some pairs of rotated traces are similar, others are not, showing the presence of scattering. 


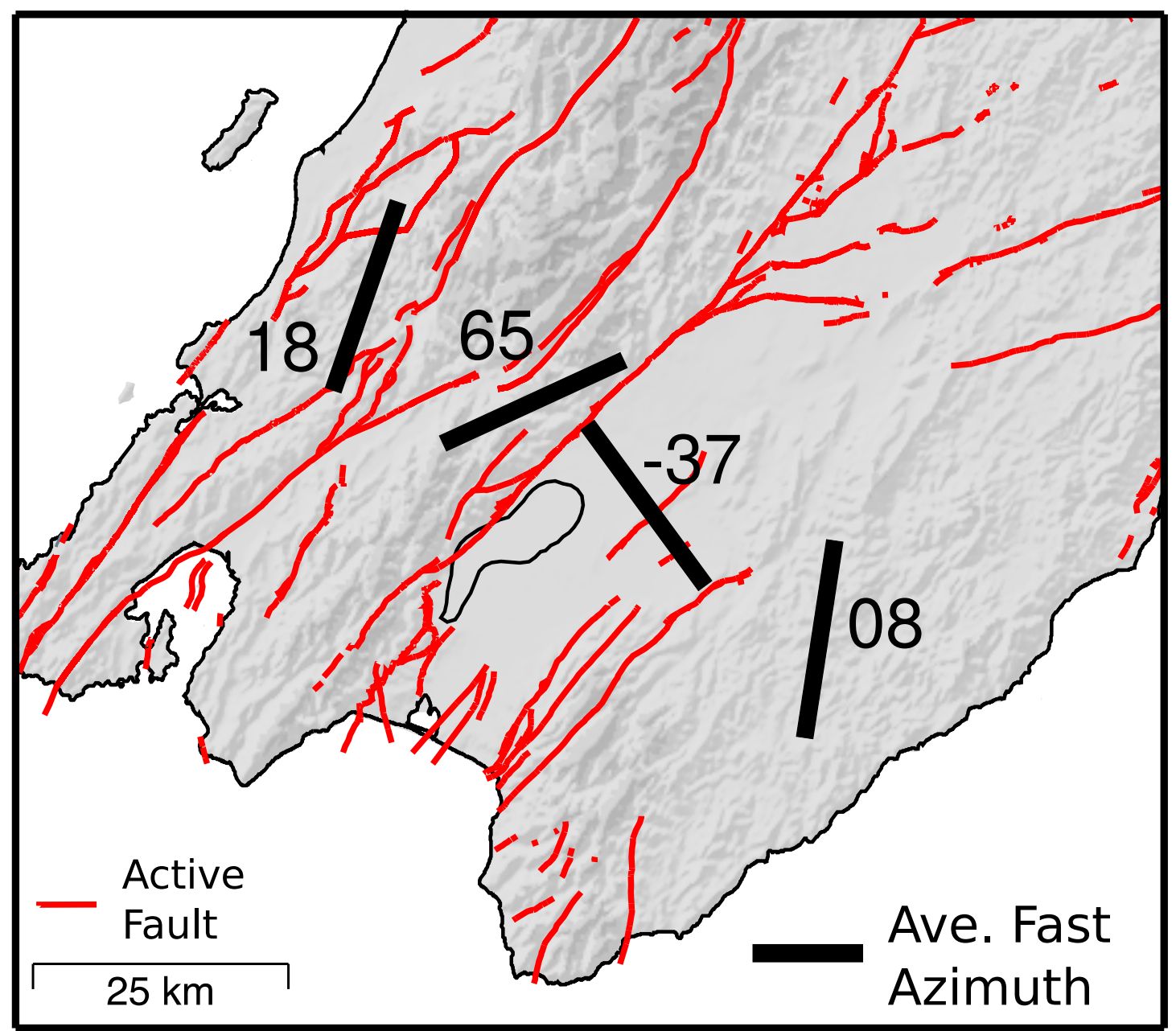

Figure 5.11: Average fast azimuth along the SAHKE II array. West of the Wairarapa fault the fast azimuth orientation is similar to the strike of the local faults. In the Wairarapa basin, the fast azimuth is oblique of the strike of the local faults.

observed in this and the Evanzia et al. (2017) study demonstrates that either variation in rotation of the principal stress axes (sigma one, two, and three) from contributions to the stress field by gravitational and tectonic loading stresses are not consistent or that the fast azimuth observed in this study results from something more localized such as small fault structures.

\subsection{Conclusions}

Making use of 21 local earthquakes and 291 stations, we evaluated seismic anisotropy across the southern North Island, New Zealand (Figure 5.1). To bolster the SNR we stacked five adjacent stations (Figure 5.4), with a sliding window overlapping three stations, totaling 142 stacked stations. As shown in Figure 5.7, the lack of splitting parameters dependence allowed us to average all available splitting measurements. We calculated an average delay time of $0.175 \mathrm{~s}$ and estimated the strength of anisotropy 
to be $4.2 \pm 0.5 \%$, which is on par with Gledhill and Stuart (1996) $4 \%$ and Evanzia et al. (2017) $3.7 \pm 1.2 \%$. West of the Wellington fault we attributed the anisotropy and resulting fast azimuths to structure-controlled sources in the upper $15 \mathrm{~km}$ of the Australian plate (Figure 5.11). Between the Wairarapa and Wellington faults the anisotropy is structures-controlled by the major NW-SE striking faults (Figure 5.11). East of the Wairarapa fault, the fast azimuth results suggest a non-structural stress-controlled seismic anisotropy, and is reflective of the SHmax orientation.

This study shows that passive and active source seismic experiments do not have to be mutually exclusive, in terms of data collection or analysis method. Given the right experimental parameters, passive and active source methodology can be interchangeable. It would be advantageous for experimenters to have to not be beholden to single seismic experiment paradigm when carrying out in large seismic experiments.

\subsection{Acknowledgements}

All waveform data is available at the IRIS data management center (temporary stations) (https://ds.iris.edu/ds/nodes/dmc/), funded by NSF, and the GeoNet data center (permanent stations) (https:/ / www.geonet.org.nz/), funded by the New Zealand Earthquake Commission. The shear-wave splitting measurements are in the supplemental material. Data acquisition was funded by the New Zealand Foundation for Research Science and Technology, the Japanese Science and Technology Agency, and the National Science Foundation, USA (NSF OCE-1061557). Wed like to thank the individual landowners, Greater Wellington Council, Transpower, Department of Conservation, and the regional Iwi who allowed for the use of land during the SAHKE II project. DE was funded by scholarships from VUW, and partial support for MS was provided by VUW research and study leave grant and MBIE grant GNS-MBIE 00053 (contract CO5X1605). We thank Anya Seward, Tim Stern, and the entire SAHKE II field team for deployment and collection of the data. 
Chapter 5. Stress and Structure Controlled Anisotropy Revealed by a High-Density Seismic Transect Across Southern North Island, New Zealand 


\section{Chapter 6}

\section{Preliminary Examination of Long-Term and Short-Term Strain Rates in Central New Zealand}

\subsection{Abstract}

We determine strain parameters (i.e., shear strain rate, dilatation, vorticity) from the southern North Island to the northern South Island, New Zealand, using continuous Global Positioning System (cGPS) data. This study makes use of daily position solutions calculated by GeoNet to generate three station-velocity datasets: (1) Long-term; (2) Inter-Slow-Slip Event (Inter-SSE); (3) Co-seismic movement during the $2016 \mathrm{M}_{W} 7.8$ Kaikōura earthquake. Long-term station velocities showed high shear strain rates in the Wairarapa and Cook Strait regions, overall compressional dilation, and overall positive (clockwise) vorticity. Inter-SSE station velocities showed elevated shear strain rates in the Cook Strait region, overall compressional dilation, and overall positive (clockwise) vorticity. Co-seismic station velocities resulted in extremely high shear strain rates in the Kaikōura region of the South Island, predominant compressional dilation, and positive (clockwise) vorticity in North Island and negative (counter-clockwise) vorticity in South Island. Preliminary dislocation modeling shows locking to be above $\sim 20 \mathrm{~km}$ depth, and that SSEs have accommodated $\sim 65 \%$ of slip in their locations below the southern North Island during the observed cGPS epochs. Strain parameters calculated using long-term station velocities are applicable to long-term forecasting of seismic hazards, whereas strain parameters calculated from inter-SSE strain parameters would be more suitable for short-term seismic hazard forecasting (e.g., aftershock hazard assessment) in the southern North Island and northern South Island. 


\subsection{Introduction}

In 2015 there were $>8000$ earthquakes $(M>1)$ in southern North Island and northern South Island (https: / /quakesearch.geonet.org.nz/). The sources of the numerous earthquakes are the southern Hikurangi subduction zone and the NE-SW transpressional crustal faults in the Australian plate above. The presence and seismically active nature of these tectonic features highlight the need to characterize them in order to mitigate the hazards they represent. Observations of strain can aid in the understanding of seismic hazards by characterizing seismic deformation associated with the southern Hikurangi subduction zone and the numerous surface faults in the southern North and northern South Island. The installation of a dense continuous Global Positioning System (cGPS) network (Figure 6.1) has facilitated an in-depth study of strain rates in central New Zealand. Controls on strain rates in North Island are greater than in South Island, due to the cGPS network station distribution $(\sim 20 \mathrm{~km}$ and $\sim 100 \mathrm{~km}$ station spacing, respectively).

\subsubsection{Tectonic Setting}

In the vicinity of central New Zealand, the contemporary Pacific-Australian plate boundary consists of the oblique subduction of the Pacific plate under the Australian plate at $38 \mathrm{~mm} / \mathrm{yr}$ (Figure 6.1) (Beavan and Haines, 2001; Beavan et al., 2002). Slip along the Hikurangi margin is not uniform (Walcott, 1984). Wallace et al. $(2004,2009,2012)$ showed there to be a slip deficit of $20-30 \mathrm{~mm} / \mathrm{yr}$ on the plate interface below the southern North Island. The presence of a slip deficit is an indication that the overriding Australian plate is 'partially locked' or 'coupled' to the subducting Pacific plate. Down-dip of the coupled region on the plate interface, slow-slip events (SSEs) occur approximately every six years on the plate interface, lasting weeks to months, at depths of 30 to $60 \mathrm{~km}$ (Wallace and Beavan, 2010; Lamb and Smith, 2013; Wallace et al., 2014). Coupling of the plate interface could result in transfer of stress to the Australian plate, leading to more and larger overriding plate earthquakes and/or could result in a large stress release via mega-thrust subduction earthquake. The stress analysis of Evanzia et al. (2017) (see Chapter 3) indicates that stress transfer between the overriding and subducting plates is mainly occurring in the western region of southern North Island. Wallace et al. (2009) estimated that the southern Hikurangi margin coupled section is theoretically capable of producing a $\mathrm{M}_{W} 8.2$ to $\mathrm{M}_{W} 8.7$ earthquake.

Crustal faults in southern North Island and northern South Island consist of NE-SW trending dextral transpressional faults (Figure 6.1, New Zealand active fault database, www.gns.cri.nz). 60 to $90 \%$ of margin-parallel motion is accommodated by major onshore faults such as the Wellington and Wairarapa faults (Langridge et al., 2005), whereas it has been proposed by Wallace et al. (2009) that margin-perpendicular motion is accommodated on the subduction thrust by episodic slip on scale of 100s to 


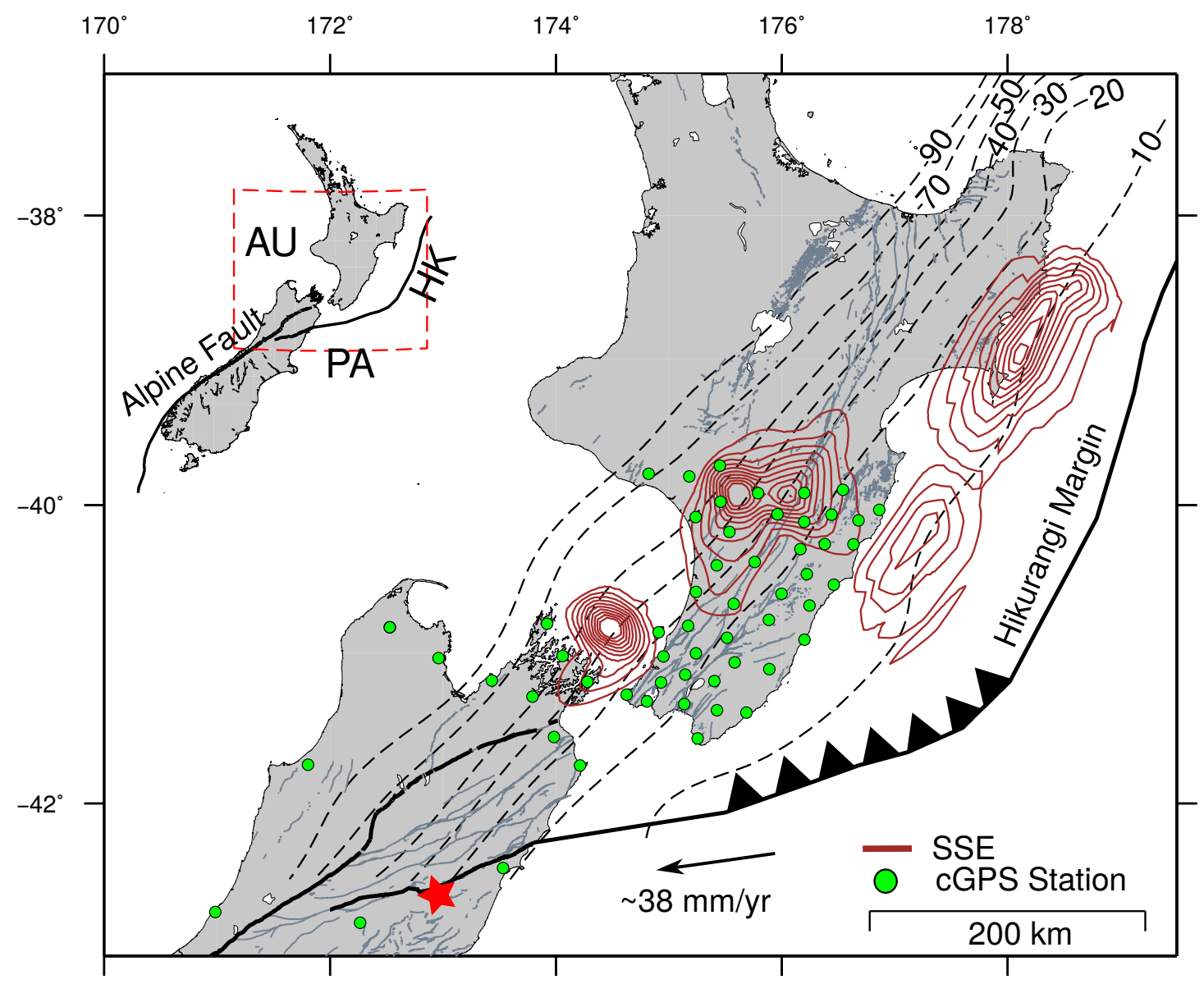

Figure 6.1: Tectonics of the North Island and Northern South Island. Location of continuous global positioning system (cGPS) stations (green circles). Regions of slip during slow-slip events (SSEs) are indicated by brown lines. Redstar shows epicenter location of $\mathrm{M}_{W} 7.8$ Kaikōura earthquake (Kaiser et al., 2017). Dashed-black lines show plate interface depth (Williams et al., 2013). Thick-black lines show plate boundaries (Coffin et al., 1998) and grey lines show active faults (https://data.gns.cri.nz/af/). Map-inset: New Zealand tectonics showing location of plate boundaries (black lines): Alpine Fault and Hikurangi Margin (HK), in relative relation to Australian plate (AU) and Pacific plate (PA) (Coffin et al., 1998). 
1000s of years.

\subsubsection{Previous GPS Studies}

In the previous four decades there have been numerous geodetic studies examining tectonic movement, strain rates, slow-slip events (SSEs), and plate coupling at the southern Hikurangi margin (e.g., Walcott, 1978, 1984; Lamb and Vella, 1987; Darby and Beavan, 2001; Wallace et al., 2004, 2009, 2012; Lamb and Smith, 2013; Lamb, 2015; Beavan et al., 2016). Walcott (1978), Lamb and Vella (1987), and Beanland and Haines (1998) demonstrated that the region east of the Wairarapa fault is dominated by compression (i.e., shortening rate $>$ shear rate), whereas the region west of the Wairarapa fault is dominated by dextral shear deformation (i.e., shortening rate $<$ shear rate). Lamb (2015), using a smoothed velocity field calculated from decadal cGPS strain parameters, showed a zone of high dextral strain rate from the central South Island up into the eastern region of the North Island, with extension in the central North Island, and compression elsewhere.

The largest earthquake in New Zealand since 1855 occurred in late 2016 and was located in the eastern region of the northern South Island (Figure 6.1). The $2016 \mathrm{M}_{W} 7.8$ Kaikoura earthquake resulted in tsunamis, tens of thousands of landslides, and infrastructural damage (Kaiser et al., 2017). The complex rupture involved at least 15 separate faults extending $150 \mathrm{~km}$ from northern Canterbury to the Cook Strait (Hamling et al., 2017; Cesca et al., 2017). The earthquake ruptured with oblique right-lateral thrust motion (Kaiser et al., 2017; Zheng et al., 2017). A maximum surface displacement of 10-12 m (predominantly dextral) was observed on the Kekerengu fault (Van Dissen and Little, 2017). Coulomb modeling of the Kaikoura earthquake indicated that the southern extents of the Awatere and Clarence faults in the South Island are in regions of increased stress, and that the Ohariu, Wellington, and Wairarapa faults, in the southern North Island, have been brought closer to failure (Xu et al., 2018). Wallace et al. (2017) observed SSEs west of the southern North Island and along the east coast of the North Island in the days following the Kaikoura earthquake. These triggered SSEs demonstrate that the Kaikōura earthquake affected slip along the Hikurangi plate interface.

This study expands upon previous cGPS strain studies (Wallace and Beavan, 2010; Lamb and Smith, 2013) by assessing strain parameters using two station velocity datasets that are referred to as (1) long-term and (2) inter-SSE (short-term). The utilization of the various datasets allows for the characterization of the effects of SSEs on strain parameters. This study provides new strain parameters for consideration when assessing long-term and short-term seismic hazards in the southern North Island and northern South Island of New Zealand. Additionally we present observations of strain parameters resulting from co-seismic movement from the 2016 Kaikōura earthquake. 


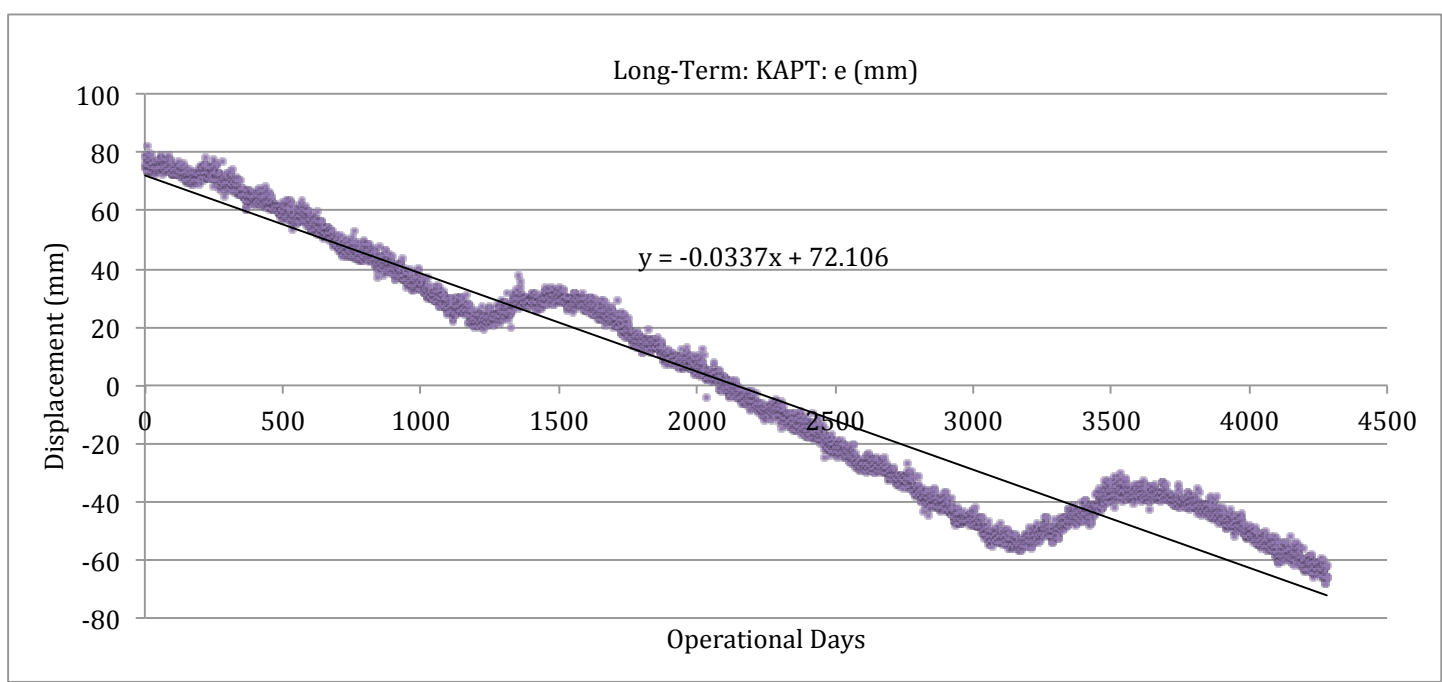

Figure 6.2: Example of longterm displacement $(\mathrm{mm})$ measure at the cGPS station (KAPT) located on Kapiti Island, off the east coast of the southern North Island (Figure 6.1). Kapiti slow-slip events (SSEs) are clearly discernible as deviations from the predominantly linear displacement pattern.

\subsection{Methodology}

\subsection{1 cGPS Station Velocities}

cGPS station velocities are derived by calculating the daily average displacement over time for both the eastern and northern components. The long-term cGPS station velocity dataset is determined by a linear best-fit for the daily solutions over the entire operational duration of the cGPS site (years to decades, pre-2016 Kaikōura earthquake), if no earthquakes were present in the data. The inter-SSE station velocity dataset is calculated by the linear best-fit of only inter-SSE time periods. Non-SSE time periods were determined visually on a station by station basis, as individual stations are affected in different ways by SSEs. Examples of removed SSEs are the Kapati 2003, Manawatu 2004-2005, Southern Hawke's Bay 2006, and the Kapiti 2008 events (Wallace and Beavan, 2010). The clear instances of displacement due to earthquakes (e.g. 2013 Seddon earthquake) were removed for both datasets. The co-seismic Kaikoura dataset is calculated by measuring offset between the day before the Kaikoura earthquake and four days after. A period of four days was used in order to capture enough data points to make reasonably good measurement of offset.

For the purposes of dislocation modeling, the long-term and inter-SSE datasets are transformed from the International Terrestrial Reference Frame (ITRF2008) (Altamimi et al., 2012) to an Australian plate Reference Frame (AURF), using the methods outlined in Chapter 2 (Methods: Reference Frame Transformation). Dislocation theory was first described by Steketee (1958); this study uses the methods outlined in Okada (1985, 1992) and Lamb and Smith (2013) to model changes in surface displacement due to 


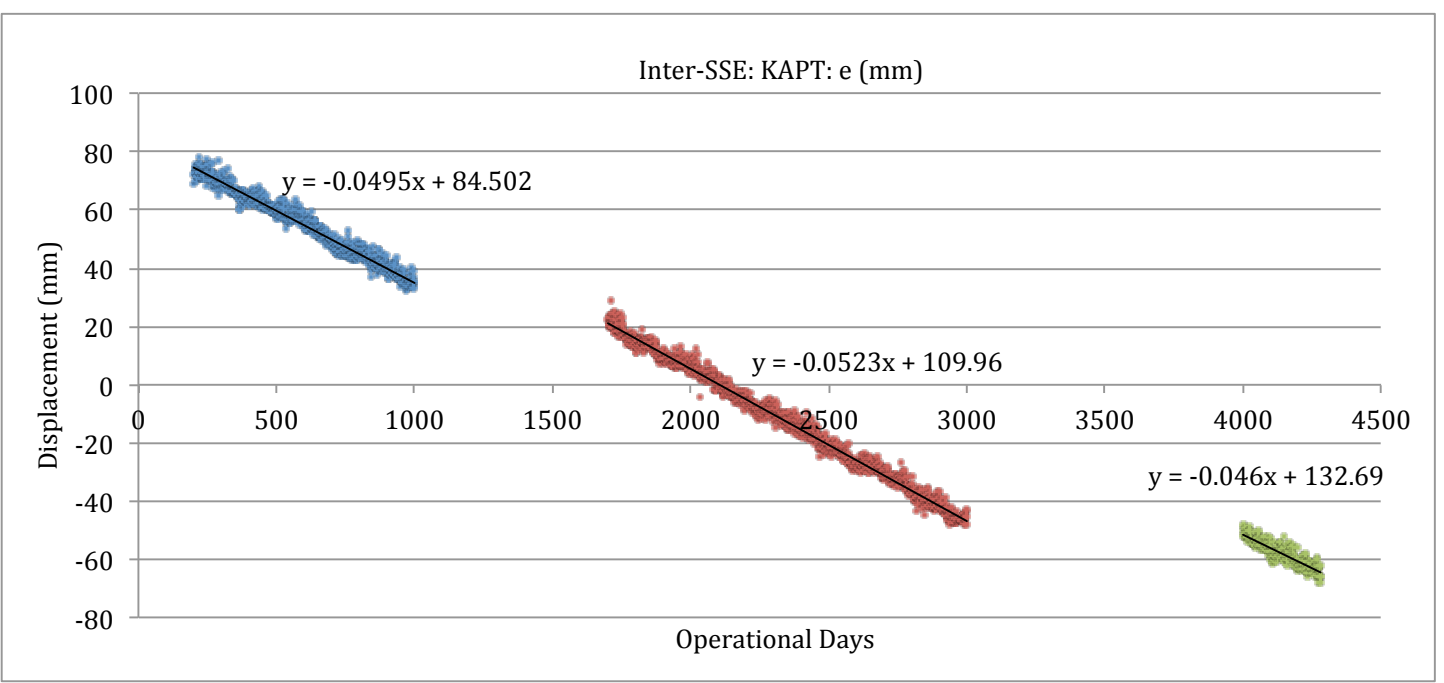

Figure 6.3: Example of inter slow-slip event (interSSE) displacement (mm) measure at the cGPS station (KAPT) located on Kapiti Island, off the east coast of the southern North Island (Figure 6.1. Inter-SSE time periods measured on linear segments of cGPS displacement.

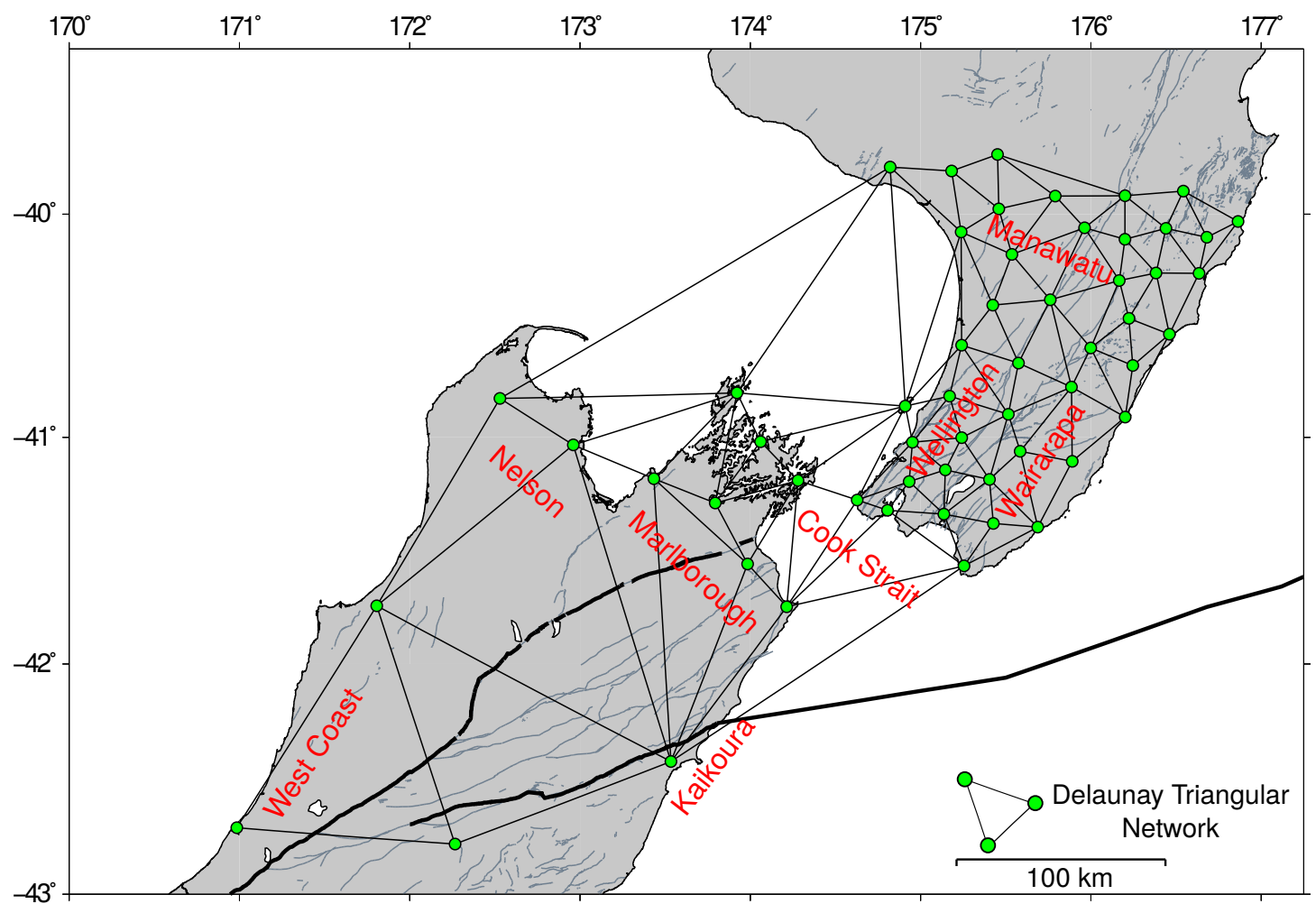

Figure 6.4: The Delauney network shows the triangular region that the strain parameters were calculated within, for the long-term and inter-SSE datasets. Red location markers refer to areas of interesting in subsequent sections. Thick black and grey lines are as indicated in Figure 6.1. 
varying amounts of slip along the subduction plate interface. It was necessary to transform the cGPS velocities from an ITRF2008 reference frame to a AUS reference frame, because the method requires one block of the dislocation model to be stable. In the simple models used in this study the 'locking point' identifies the boundary between slip and no slip on the plate interface. The dislocation modeling done in this study expands on the work done by Lamb and Smith (2013), by taking advantage of the longer time period now available for cGPS measurements (2000 - 2016 pre-Kaikōura earthquake), allowing an improved understanding of the effects of SSEs.

\subsubsection{Shear Strain Rate, Dilatation, Vorticity}

Shear strain rate, dilatation, and vorticity are calculated using the Lamb $(2000,2015)$ method. Strain parameters are calculated from the spatial derivatives of the velocities and are then modeled as a continuous function in a triangular (Delauney) network (Figure 6.4). Strain rates are derived as spatial derivatives of velocities $u, v$ parallel to $x, y$ axes respectively:

$$
\begin{gathered}
\dot{\gamma}_{1}=\frac{\partial u}{\partial x}-\frac{\partial v}{\partial y} ; \quad \dot{\gamma}_{2}=\frac{\partial u}{\partial y}+\frac{\partial v}{\partial x} \\
\dot{\Gamma}=\sqrt{{\dot{\gamma_{1}}}^{2}+\dot{\gamma}_{2}^{2}} \\
\dot{\omega}=\frac{1}{2}\left(\frac{\partial u}{\partial y}-\frac{\partial v}{\partial x}\right) ; \quad \dot{\Delta}=\frac{1}{2}\left(\frac{\partial u}{\partial x}+\frac{\partial v}{\partial y}\right)
\end{gathered}
$$

Shear shear strain rate $\left(\dot{\Gamma}: \dot{\gamma}_{1}\right.$ and $\left.\dot{\gamma}_{2}\right)$ describes the rate of horizontal shape change, vertical vorticity $(\dot{\omega})$ defines the rotation of a rigid body, and dilatation $(\dot{\Delta})$ describes the expansion and contraction, per unit area, of a horizontal area.

\subsection{Results}

\subsection{1 cGPS Station Velocities}

cGPS station velocities are most affected when located above or in proximity to the SSEs (Figure 6.4 and 6.5). The cGPS long-term velocities of sites located nearest to Wellington, in the southern North Island, were affected little by SSEs. This may be due to the long duration of the cGPS site (2000 - present), indicating that the SSEs are effectively averaged out. Long-term station velocities trend more northward than inter-SSE station velocities, as a result of the occurrence of SSEs (Figure 6.5). This is due to the eastward and up-dip slip direction of the SSEs (Wallace et al., 2009; Wallace and Beavan, 2010). There is little to no evidence of SSEs at stations in Nelson, Kaikōura, and West Coast of the South Island and stations located in the Wairarapa region of North Island (Figure 6.4 and 6.5). 


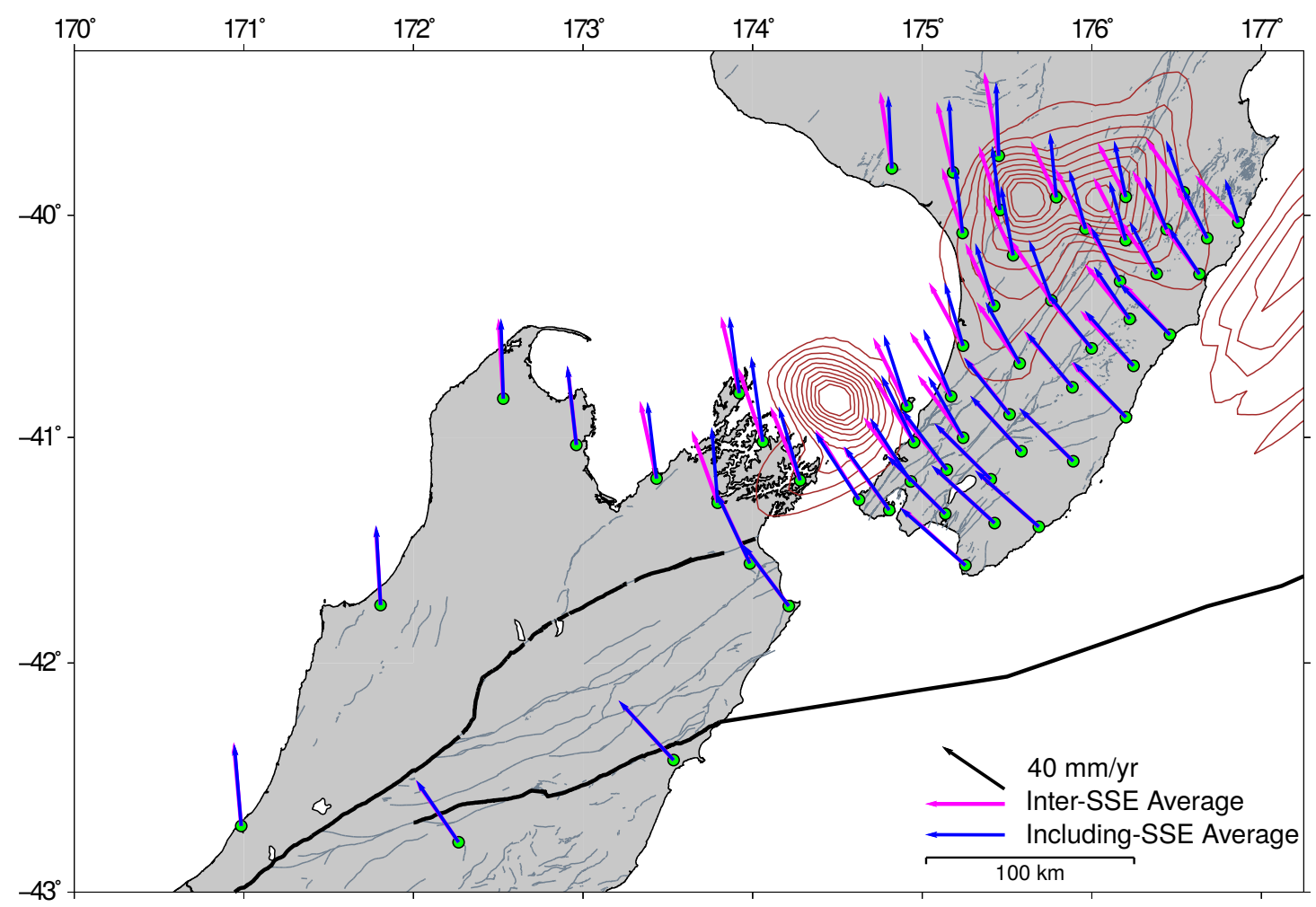

Figure 6.5: cGPS velocities calculated from daily-solutions excluding SSEs (inter-SSE, magenta) and velocities calculated including SSEs (long-Term, blue) in the ITRF2008 reference frame. Thick black, grey, and brown lines are as indicated in Figure 6.1.

After transformation of velocities into the Australian Plate Reference Frame (Lamb and Smith, 2013) the cGPS velocties generally trend in the Pacific-Australian plate convergence direction. Similar variations in station velocities can be seen due to SSEs (Figure 6.6).

\subsubsection{Long-Term Strain Rate Parameters}

\section{Long-Term Shear Strain Rate}

The highest shear strain rates ( 2 to $3 \times 10^{-7} / \mathrm{yr}$ ) are observed in the Marlborough region of South Island, the Wellington region of North Island, and the Cook Strait region (Figure 6.8). The shear strain rates are lower in the Wairarapa region of the southern North Island. This coincides with regional faulting patterns (www.gns.cri.nz), which show relatively little faulting in the Wairarapa region. The low shear strain rates ( 0 to $1 \times 10^{-7} / \mathrm{yr}$ ) in the Wairarapa also corresponds to the higher plate interface coupling in the Wairarapa region of the southern North Island (Wallace et al., 2004, 2009, 2012). The shear strain rates observed in this study are larger than those calculated by Beavan and Haines (2001) $\left(\sim .25 \times 10^{-7} / \mathrm{yr}\right)$ using campaign GPS, but are similar to those calculated by Lamb (2015) $\left(\sim 2 \times 10^{-7} / \mathrm{yr}\right)$ using a combination of cGPS and 


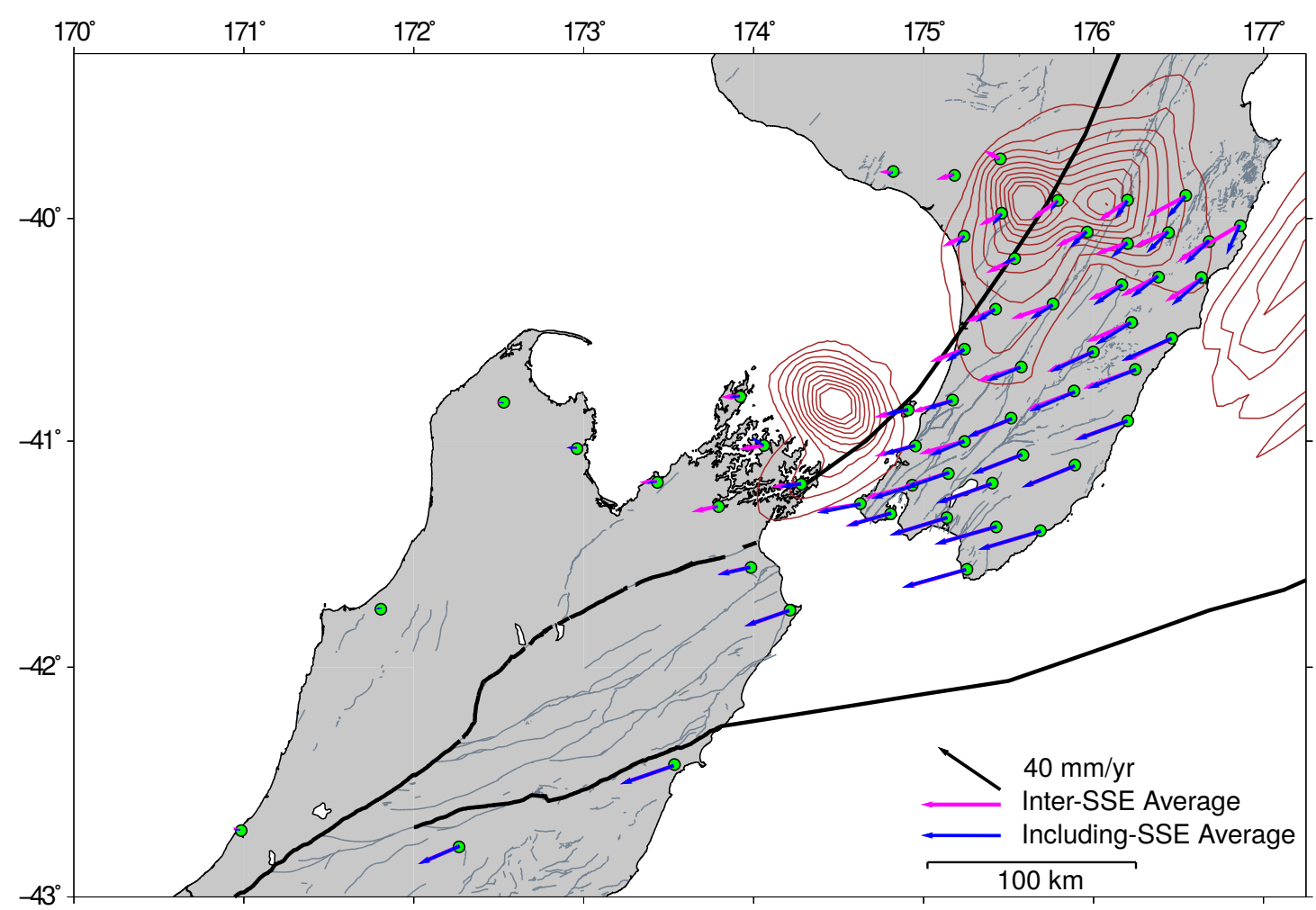

Figure 6.6: cGPS velocities calculated from daily-solutions excluding SSEs (inter-SSE, magenta) and calculated including SSEs (long-term, blue) in an Australian plate reference frame. Thick black, grey, and brown lines are as indicated in Figure 6.1.

campaign GPS data.

\section{Long-Term Dilation}

There is little variation in dilation throughout southern North Island and northern South Islands, with compression (red: -1.5 to $0 \times 10^{-7} / \mathrm{yr}$ ) dominating most of the region (Figure 6.8). The compressional dilation rates observed here are again larger than those calculated by Beavan and Haines (2001) $\left(.15 \times 10^{-7} / \mathrm{yr}\right)$, but are again similar to Lamb (2015) (-1.5 to $\left.-0.5 \times 10^{-7} / \mathrm{yr}\right)$. This is expected, given the prevalence of transpressional faulting and the proximity of the study area to the subduction trench. The expansion (blue) in the Manawatu region of the North Island and Marlborough region of the South Island (Figure 6.8) are possibly artifacts due to short station operating durations or edge effects. Short operating durations of cGPS sites result in the inclusion of only one or two SSEs, which would highly skew a station's velocity. This could be clearly seen in the Kapiti cGPS station record (Figure 6.2) if the record only contain daily solutions from day 2500 to day 4250 . This duration would result in an average displacement over time that would be much more skew to a eastward direction (i.e., a less negative slop). 


\section{Long-Term Vorticity}

The entirety of the study region is undergoing positive (clockwise) rotation ( 1 to $3^{\circ}$ $\times 10^{-7} / \mathrm{yr}$ ) (Figure 6.8). Regions of increased positive rotation are co-located with increased shear strain rates in the southern North Island. Similar amounts of clockwise rotation have been observed previously by Wallace et al. (2004) $\left(0.5\right.$ to $\left.3.8^{\circ} \times 10^{-7} / \mathrm{yr}\right)$ and Lamb (2015) $\left(\sim 2^{\circ} \times 10^{-7} / \mathrm{yr}\right)$.

\subsubsection{Inter-SSE (Short-Term) Strain Rate Parameters}

\section{Inter-SSE Shear Strain Rate}

Overall the North Island exhibits a lower inter-SSE shear strain rate than that of the South Island ( 0 to $1 \times 10^{-7} / \mathrm{yr}$ and 1 to $2 \times 10^{-7} / \mathrm{yr}$, respectively) (Figure 6.9). The highest shear strain rates $\left(2 \times 10^{-7} / \mathrm{yr}\right)$ are observed between the Cook Strait region and the North and South Islands. Unlike the long-term shear strain rates, the inter-SSE shear strain rates are similar to those calculated by Beavan and Haines (2001) ( .25 $\times$ $\left.10^{-7} / \mathrm{yr}\right)$. This may indicate that the campaign GPS datum from the southern North Island used by Beavan and Haines (2001) was collected during an inter-SSE time period. The large regions of high shear strain rate associated with the Manawatu region in North Island could be related to the tectonics of Taupo Volcanic Zone (TVZ).

\section{Inter-SSE Dilatation}

As was seen in the long-term dilation (Figure 6.8), the study area is predominantly under compression (Figure 6.9). There are several small areas of expansion in the Marlborough region of the northern South Island and the Manawatu region of the North Island (Figure 6.9). The small area of expansion in the Manawatu region is likely the southern continuation of the TVZ. The lower inter-SSE compressional dilatation rates ( $\sim 75$ to $\left.0 \times 10^{-7} / \mathrm{yr}\right)$ are similar to those calculated by Beavan and Haines (2001) (1.5 to $\left.0 \times 10^{-7} / \mathrm{yr}\right)$.

\section{Inter-SSE Vorticity}

As seen in Wallace et al. (2004), Lamb (2015), and the previously calculated vorticity (Figure 6.8), the entire study area is rotating positively (clockwise) (Figure 6.9). The magnitude of rotation calculated using inter-SSE station velocities are less than those calculated with long-term station velocities $\left(1\right.$ to $2^{\circ} \times 10^{-7} / \mathrm{yr}$ and 1 to $3^{\circ} \times 10^{-7} / \mathrm{yr}$, respectively).

\subsubsection{Co-Seismic 2016 Kaikōura Earthquake}

cGPS stations in the vicinity of the 2016 Kaikoura earthquake are very limited (Figure 6.7). A as a result, the associated strain rate parameters are extrapolated over distances of several 10s of kms. 


\section{Co-Seismic Shear Strain Rate}

Co-seismic shear strain rates are greatest nearest the epicenter of the Kaikōura earthquake extending north along the east coast of the northern South Island, mimicking the rupture propagation direction (Litchfield et al., 2016; Bradley et al., 2017) (Figure 6.7 and 6.10). The area of high shear strain rate encompasses a large majority of the recorded aftershocks located north of and along the east coast (see Figure 4 in Cesca et al., 2017) of the northern South Island.

\section{Co-Seismic Dilatation}

There are several distinct regions of expansion (blue) and compression (red) resulting from the Kaikōura earthquake. There is compression in northern South Island and the western half of North Island (Figure 6.10). Compressional axes mimic the shear strain rate pattern, radiating out in a semi-circular manner from the northwest coast of the South Island (Figure 6.10). Extension is observed along the entirety of the east coast of the North Island and the West Coast region of the South Island. Extensional axes along the east coast of the North Island show that extension is oriented E-W (Figure 6.10).

\section{Co-Seismic Vorticity}

The southern North Island responded to the Kaikoura earthquake by rotating in a positive direction (clockwise), while the northern South Island rotated in a negative (counter clockwise) direction (Figure 6.10). Some regions of negative rotation are present in the north of the study area. 


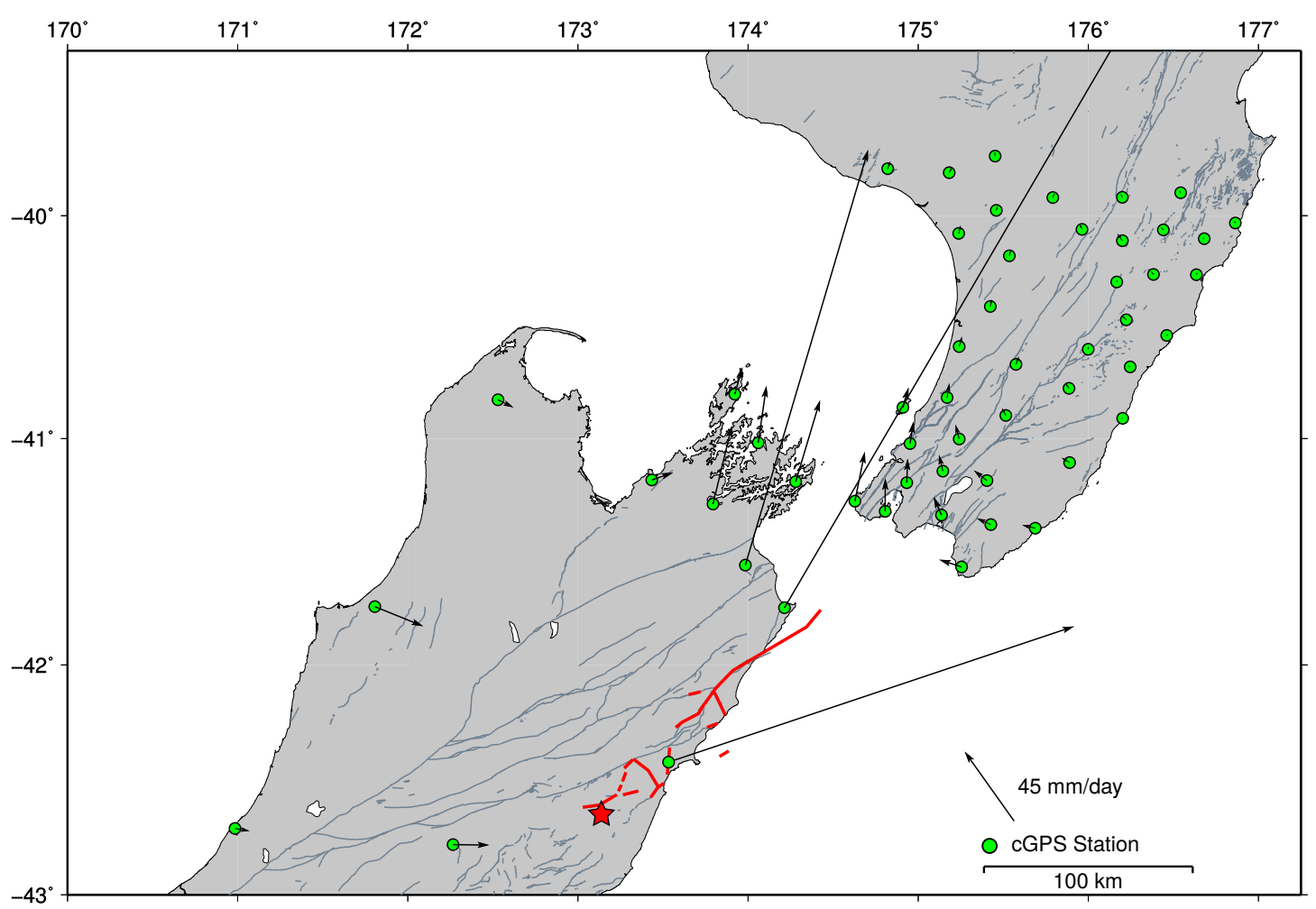

Figure 6.7: cGPS velocities calculated from offset due to $2016 \mathrm{M}_{W} 7.8$ Kiakoura earthquake in ITRF2008 reference frame. Velocities determined via offset between 13th - 17th of November 2016. As expected the velocities (black-arrows) of those stations closest in proximity to the hypocenter are most greatly affected. Red star is epicenter of $2016 \mathrm{M}_{W} 7.8$ Kiakoura earthquake and red lines are ruptured faults (Kaiser et al., 2017; Cesca et al., 2017). Grey lines indicate active faults (https://data.gns.cri.nz/af/). 


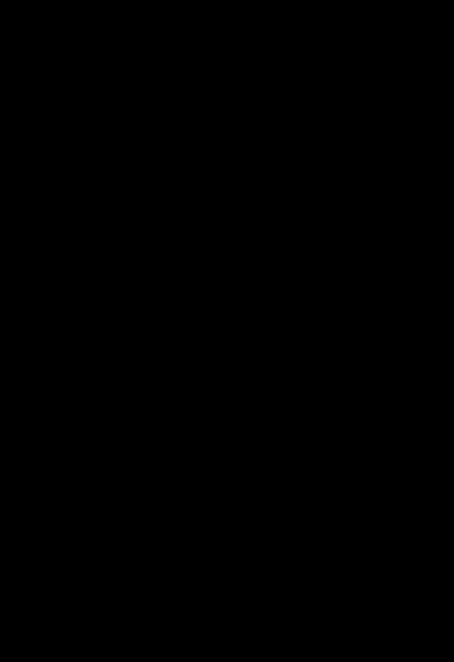

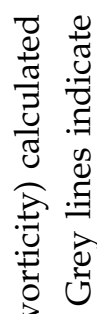

द्:

营

$\overline{0}$

悹 売

๑

के

ฮี

क्र

क्षे

है ठ

సีّ

:

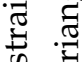

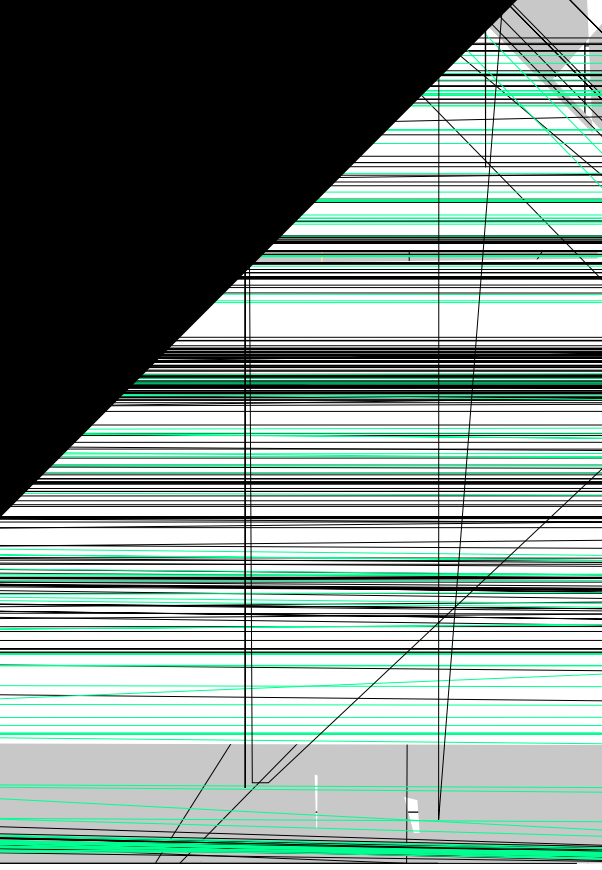

हृ च

का

임

छี

8 劳

प艹

एँ

‡

离 $\frac{0}{n}$

"ฮี

ن

ฮ

¿

\&

का ए

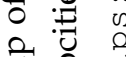

ฮี

$\varangle$ क

囟

总总 

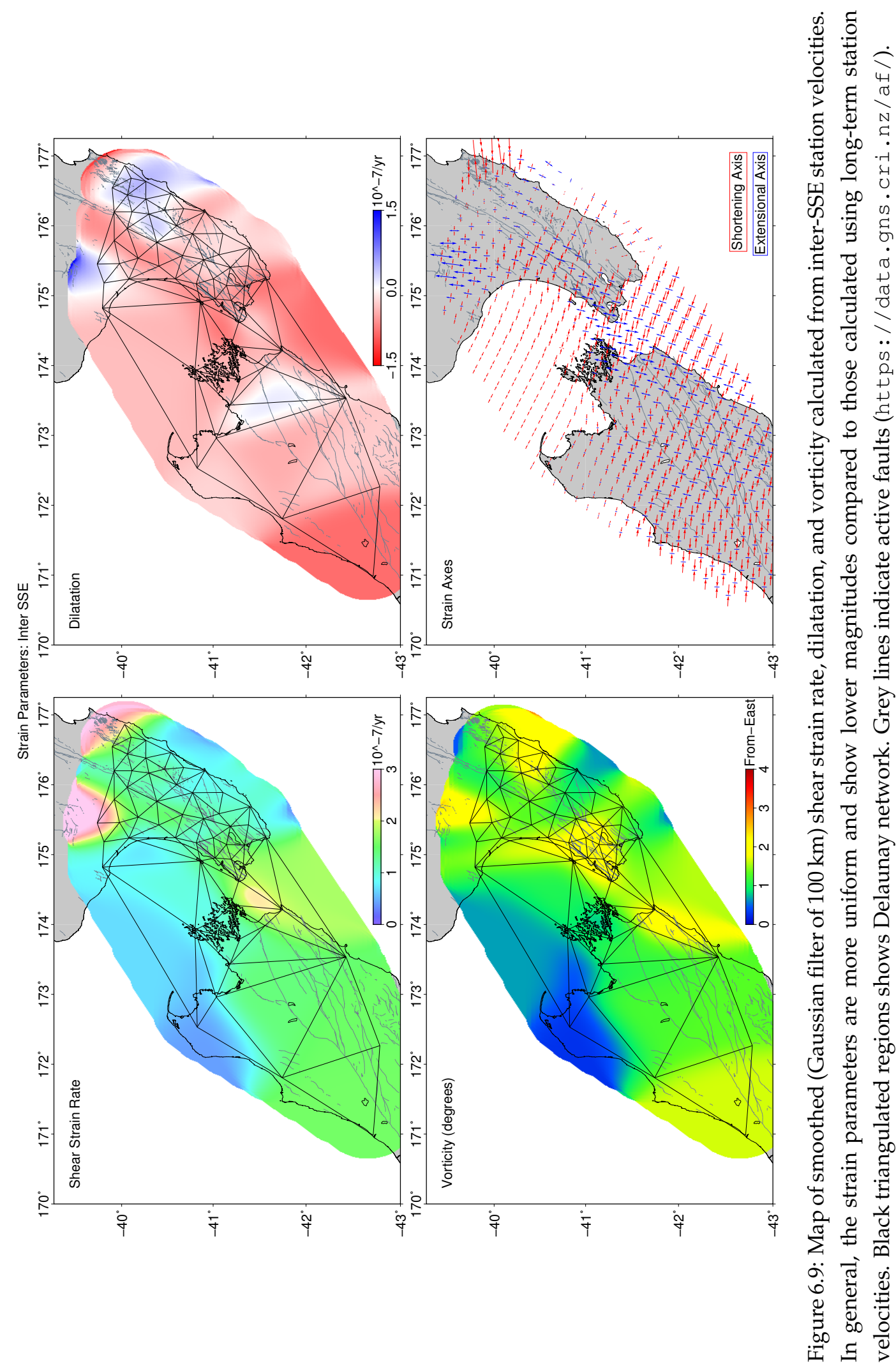


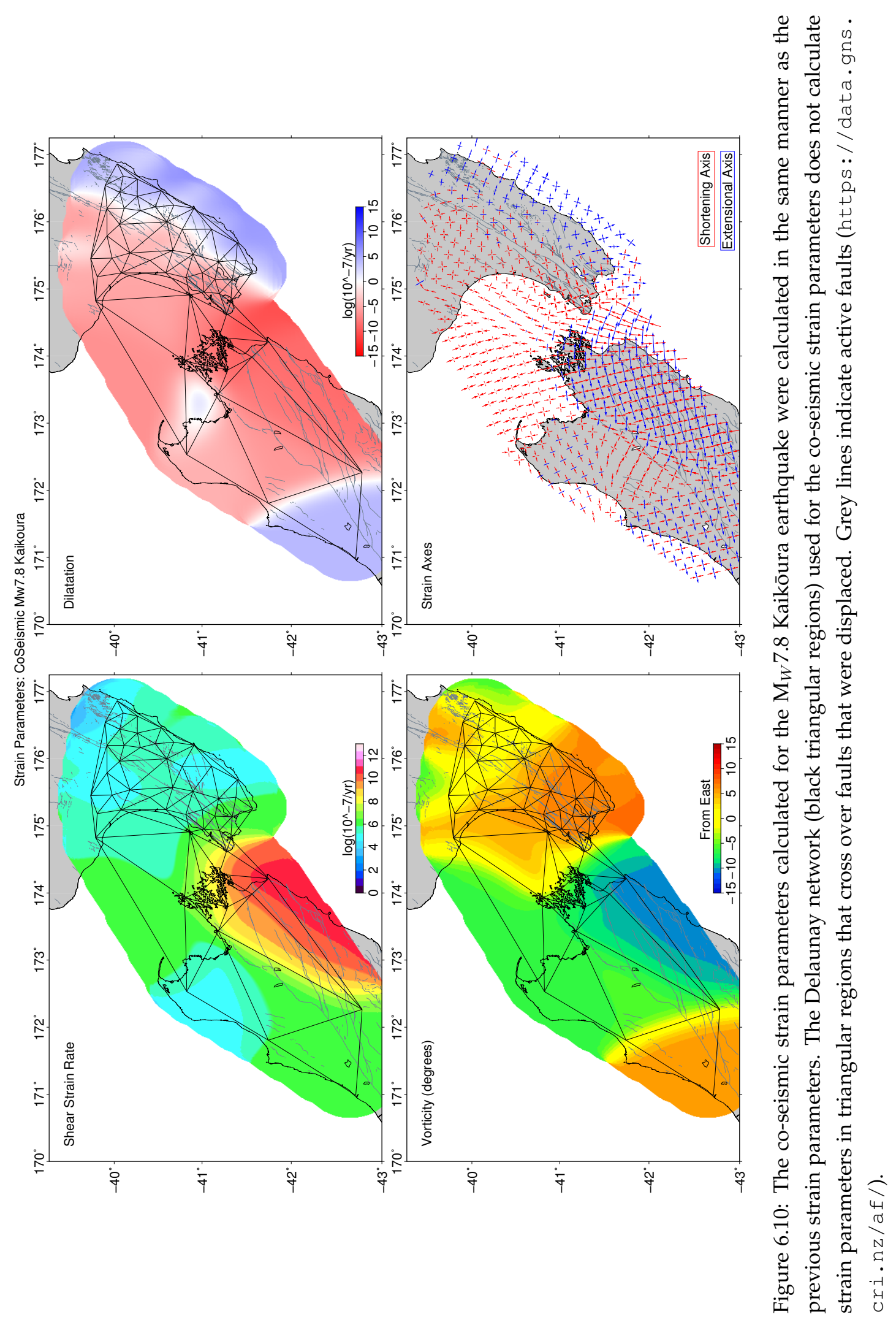




\subsection{Discussion}

\subsubsection{Comparing Strain Parameters}

The variation in strain rate parameters is illustrated with a series of $\pm 10 \mathrm{~km}$ swath profiles across the four regions of central New Zealand: (1) Manawatu North Island (Figure 6.11), (2) Southern North Island (Figure 6.12), (3) Cook Strait (Figure 6.13), and (4) Northern South Island (Figure 6.14).

\section{Manawatu North Island}

Overall, there is no major differences between long-term and inter-SSE strain parameters in the Manawatu region of the North Island (Figure 6.11). In general, strain parameters calculated from inter-SSE velocities are more dispersive than those calculated using long-term velocities. The increase in shear strain rate and vorticity, and the variation in dilatation on the eastern end of the cross-section are probably the result of the long-term effects of SSEs in the Southern Hawke's Bay and the Manawatu regions (Wallace and Beavan, 2010).

\section{Southern North Island}

Long-term and inter-SSE strain parameters show similar patterns, but differ in magnitude, in the southern North Island (Figure 6.12). Shear strain rate and vorticity calculated from long-term velocities show an increased magnitude $\left(2\right.$ to $3 \times 10^{-7} / \mathrm{yr}, \sim 3^{\circ} \times$ $\left.10^{-7} / \mathrm{yr}\right)$ off the west coast of the southern North Island to the Wairarapa region $(\sim 75$ $\mathrm{km}$ to $\sim 175 \mathrm{~km}$, see Figure 6.12). The differences in strain parameters can be attributed to the long-term effects of the Kapiti SSEs (Wallace and Beavan, 2010), which are located just south of the cross-section off the west coast of the southern North Island (Figure 6.1).

\section{Cook Strait}

Figure 6.13 shows the largest variations in strain parameter magnitudes. Elevated strain parameter magnitudes (shear strain rate: $\sim 3 \times 10^{-7} / \mathrm{yr}$, vorticity: $\sim 3^{\circ} \times 10^{-7} / \mathrm{yr}$, dilatation: $0.5 \times 10^{-7} / \mathrm{yr}$ ) calculated in the Cook Strait from both datasets span greater distances $(\sim 40 \mathrm{~km}$ to $\sim 150 \mathrm{~km}$ ) than those calculated in the other regions (compare Figure 6.12, 6.13, and 6.14). The longer wavelength features in Figure 6.13 are likely artifacts related to the increased size of the triangular regions that the strain parameters are calculated within (Figure 6.4). There is a noticeable increase in magnitude of all long-term strain parameters, compared to inter-SSE strain parameters (Figure 6.13). The increase in magnitude can be attributed to the long-term effects of Kapati SSEs (Wallace and Beavan, 2010). 


\section{Northern South Island}

Figure 6.14 shows there is little to no difference between long-term and inter-SSE strain parameters. This is expected as there is no record of SSEs in this region (Figure 6.1) (Wallace et al., 2004; Wallace and Beavan, 2010).

\subsubsection{Co-Seismic Strain Rates of 2016 Kaikōura Earthquake}

The limited extent of the high shear strain rate and the rotations of North Island and South Islands as distinct blocks (Figure 6.10) may indicate why aftershocks were predominantly restricted to near by and cos-seismically ruptured faults at northeastern coast of South Island and the Cook Strait region (see Figure 4 in Cesca et al., 2017). Though principally compressional, the dilatation response to the Kaikoura earthquake was extensional in the eastern half of the North Island (Figure 6.10). It is possible that the extension observed in the eastern half of the North Island is the result of triggered SSEs (Wallace et al., 2017). The extension may have resulted in the accommodation of some of the stress that has built-up in this region due to the coupled nature of the plate interface (Wallace and Beavan, 2010). Based on these preliminary results it is unclear over what time period this extension persisted and how much, if any, stress has been accommodated.

\subsubsection{Preliminary Analysis Mega-thrust Locking Depths}

The strain rate data can be modeled in terms of slip on the underlying subduction mega-thrust with a simplistic elastic dislocation model.

Based on the higher density of the cGPS network (Figure 6.1), the prevalence of previous studies (e.g., Lamb and Smith, 2013; Henrys et al., 2013), and the location of the coupled plate interface (Wallace et al., 2004, 2009, 2012), preliminary dislocation modeling was performed (in AUS reference frame) along a profile across the southern North Island (cross-section shown in Figure 6.12). Here, the location of the fully locked versus freely slipping sections of the subduction mega-thrust and the influence of SSEs are expressed in terms of an effective coupling factor of either 0 and 1 (e.g. Lamb and Smith (2013)).

Model 1 (long-term velocities, Figure 6.15) gives a locking point depth of $\sim 21 \mathrm{~km}$ on the plate interface. This depth is between the locking points calculated by Lamb and Smith (2013), $15 \mathrm{~km}$ in the central North Island to $35 \mathrm{~km}$ in the northern South Island and Darby and Beavan (2001), who found maximum coupling ranged from 16 $\mathrm{km}$ to $24 \mathrm{~km}$, in the southern North Island. 

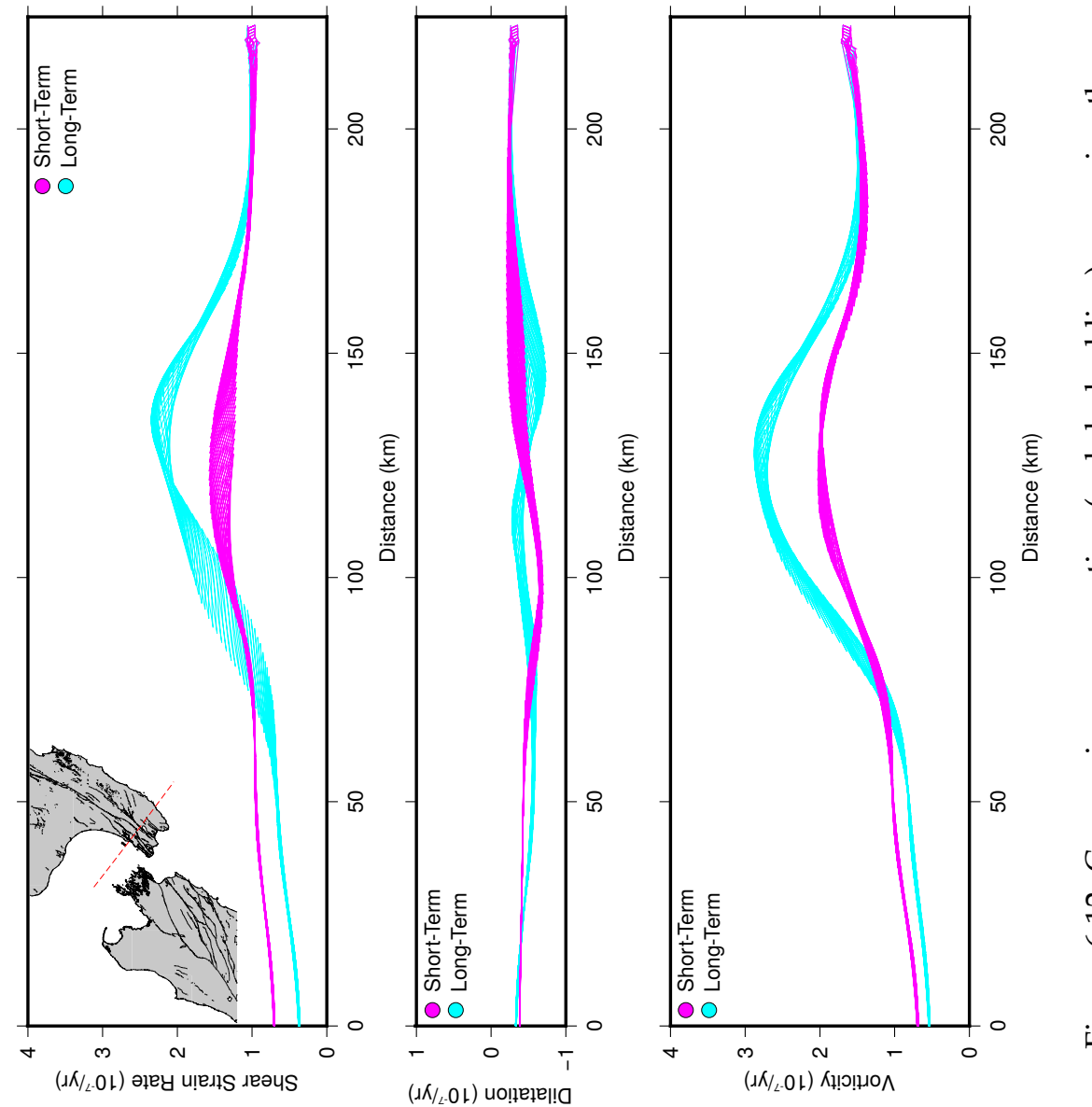

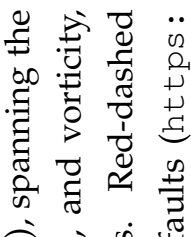

島

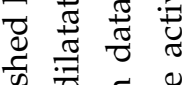

要过

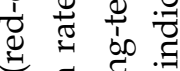

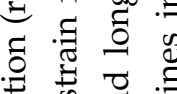

总

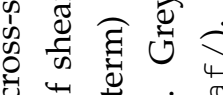

पे 苛

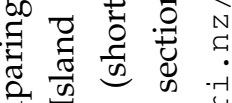

द्व ज्ञ का

ठี

$\ddot{\sim} Z$ Z

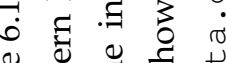

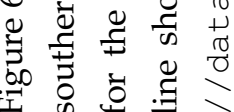

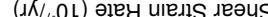
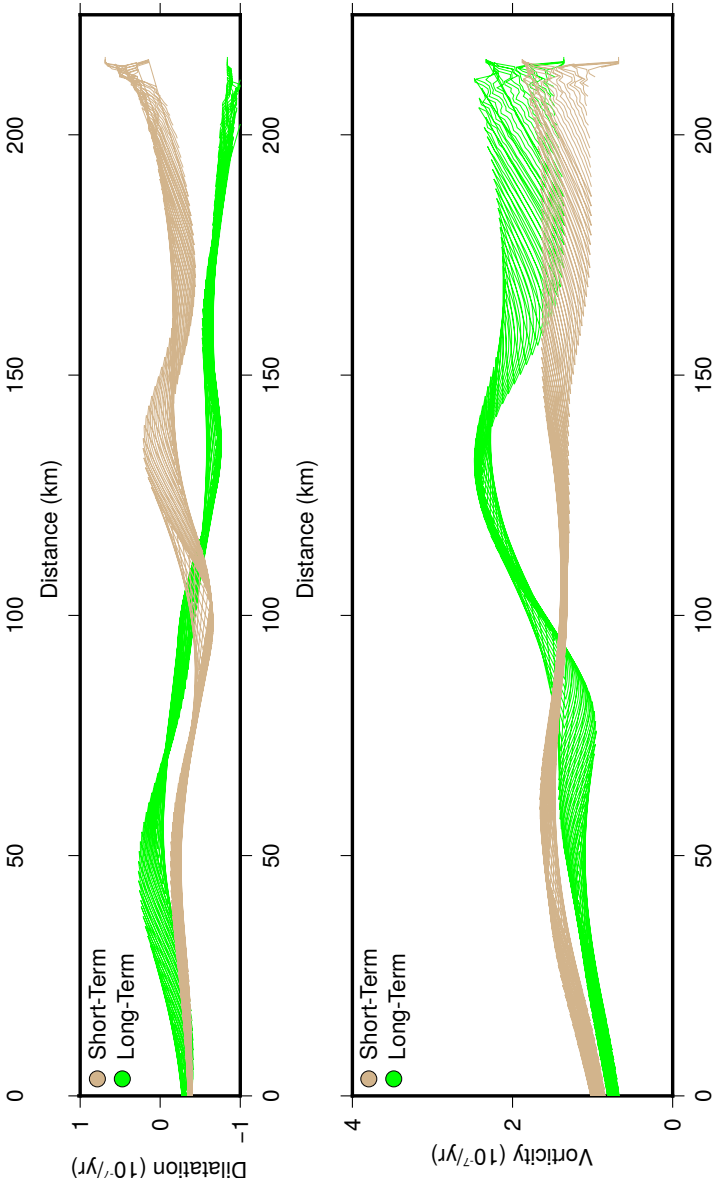

Ð

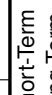

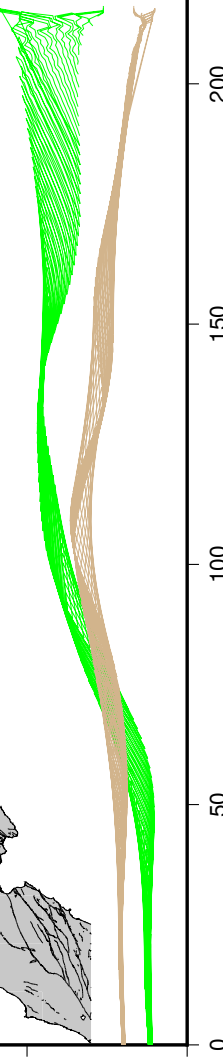

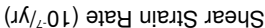

(\lrcorner $K /\llcorner .0 \mathrm{~L})$ uo!!̣e!e!!

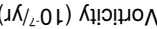

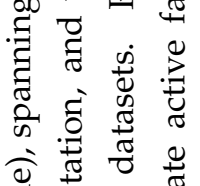

要要

요 ठृ

造

ह

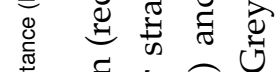

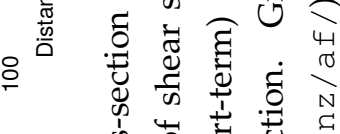

is

ठु च ह क क

की ज्ञ

है

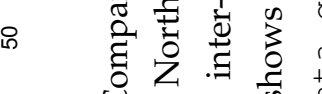

$\because$ 吾

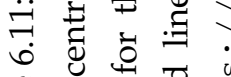

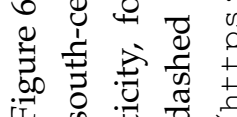




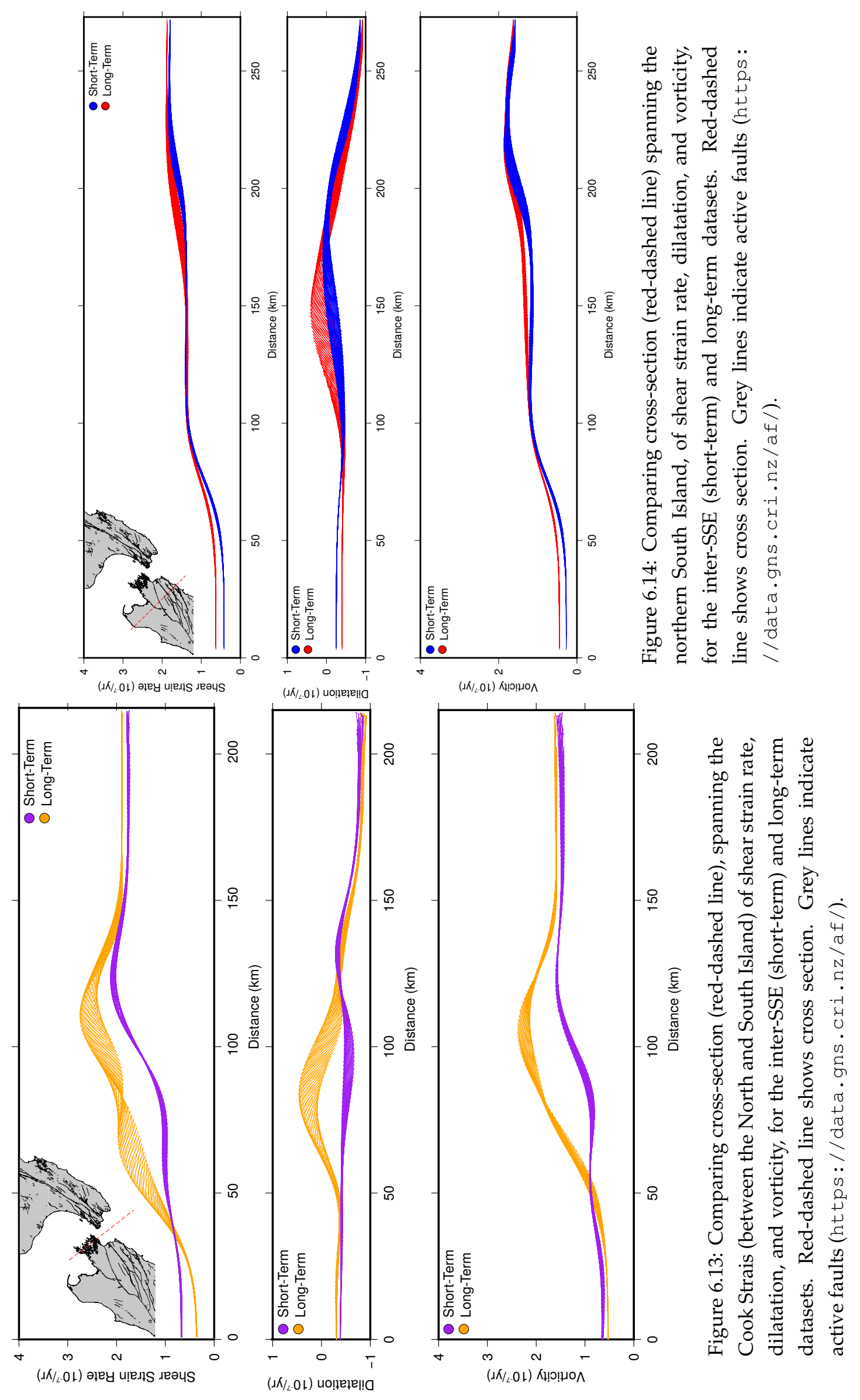


Long-Term (Inter SSE \& SSES)

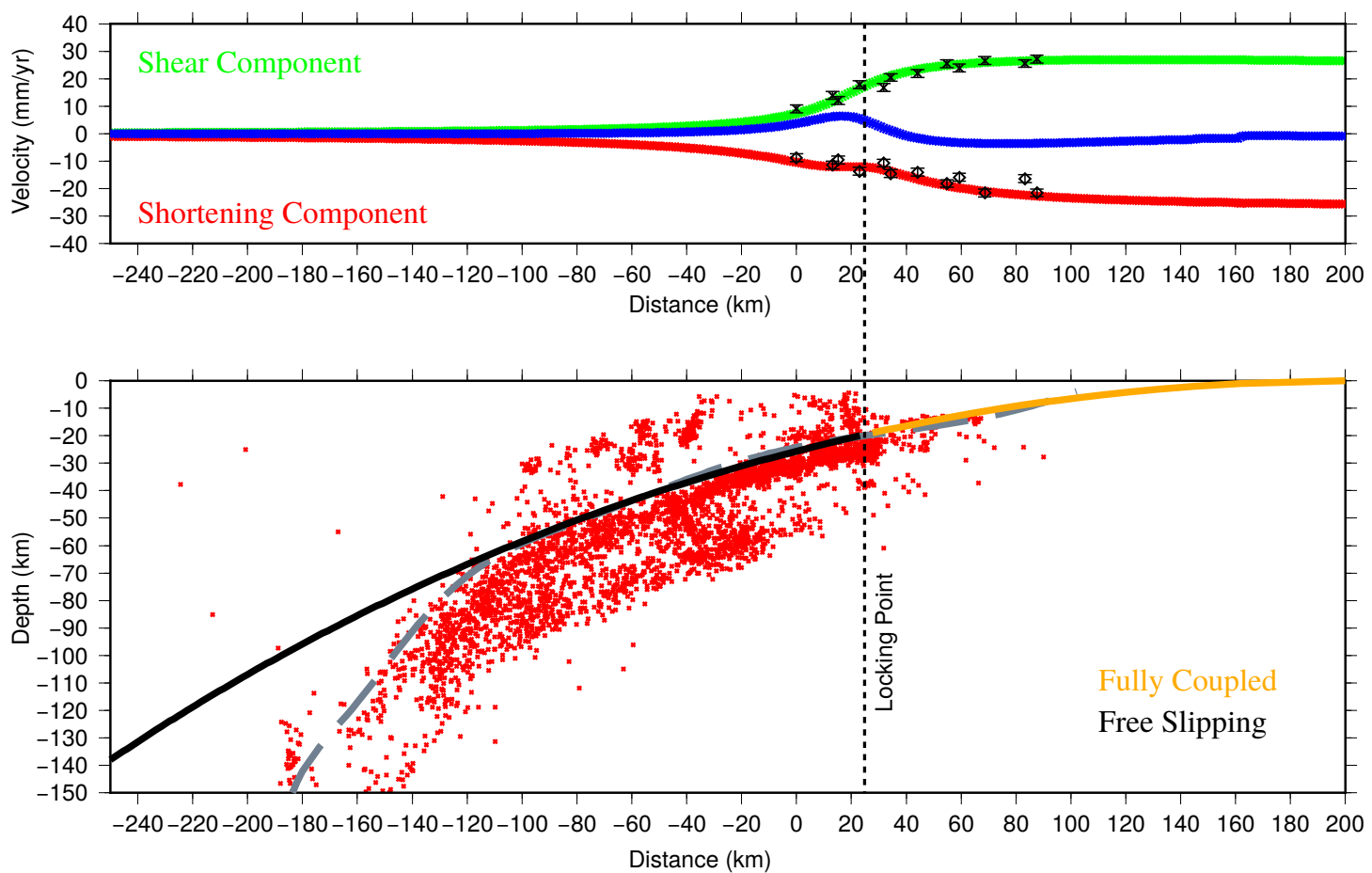

Figure 6.15: Dislocation modeling results calculated using station velocities from the long-term dataset, with a single locking point and two patches: (1) free slipping; (2) fully coupled. Green line is modeled shear component and red line is modeled shortening component. Using plate interface and dip models from Williams et al. (2013, Grey-dashed line) and the best fitting parameter $\left(\chi^{2}=2.17\right)$, a locking depth of $\sim 21 \mathrm{~km}$ was calculated. $\chi^{2}$ is a measure of goodness of fit, based on the sum of the difference between the observed and expected calculated values. Shear components of nearby stations are projected plotted as black "Xs" and the shortening components are plotted as black diamonds. Vertical displacement (blue line) modeled but is not calculated. Seismicity plotted as small red dots (Eberhart-Phillips and Reyners, 2009).

Model 2 (inter-SSE velocities, Figure 6.16), shows a locking point depth of $\sim 22 \mathrm{~km}$, with a westward (negative direction) shift of $10 \mathrm{~km}$, compared to model 1 (compare Figure 6.15 and 6.16). To some extent a horizontal shift can be recognized in Figure 6.12 , by the westward movement of the shear strain rate inflection point. A locking depth of $\sim 22 \mathrm{~km}$ is similar to previously derived depths by Darby and Beavan (2001) and Lamb and Smith (2013).

In order to constrain the effects of SSEs on total slip, a preliminary model 3 was generated with three patches: (1) fully coupled, (2) partially coupled, and (3) free slipping (Figure 6.14). Assuming a locking point depth of $\sim 20 \mathrm{~km}$ (based on long-term velocity dislocation modeling, Figure 6.15), it was found that SSEs accommodate $65 \%$ of slip motion on the plate interface in this region during the epoch of the cGPS observations (Figure 6.14). We would expect that over longer time periods, when there is 


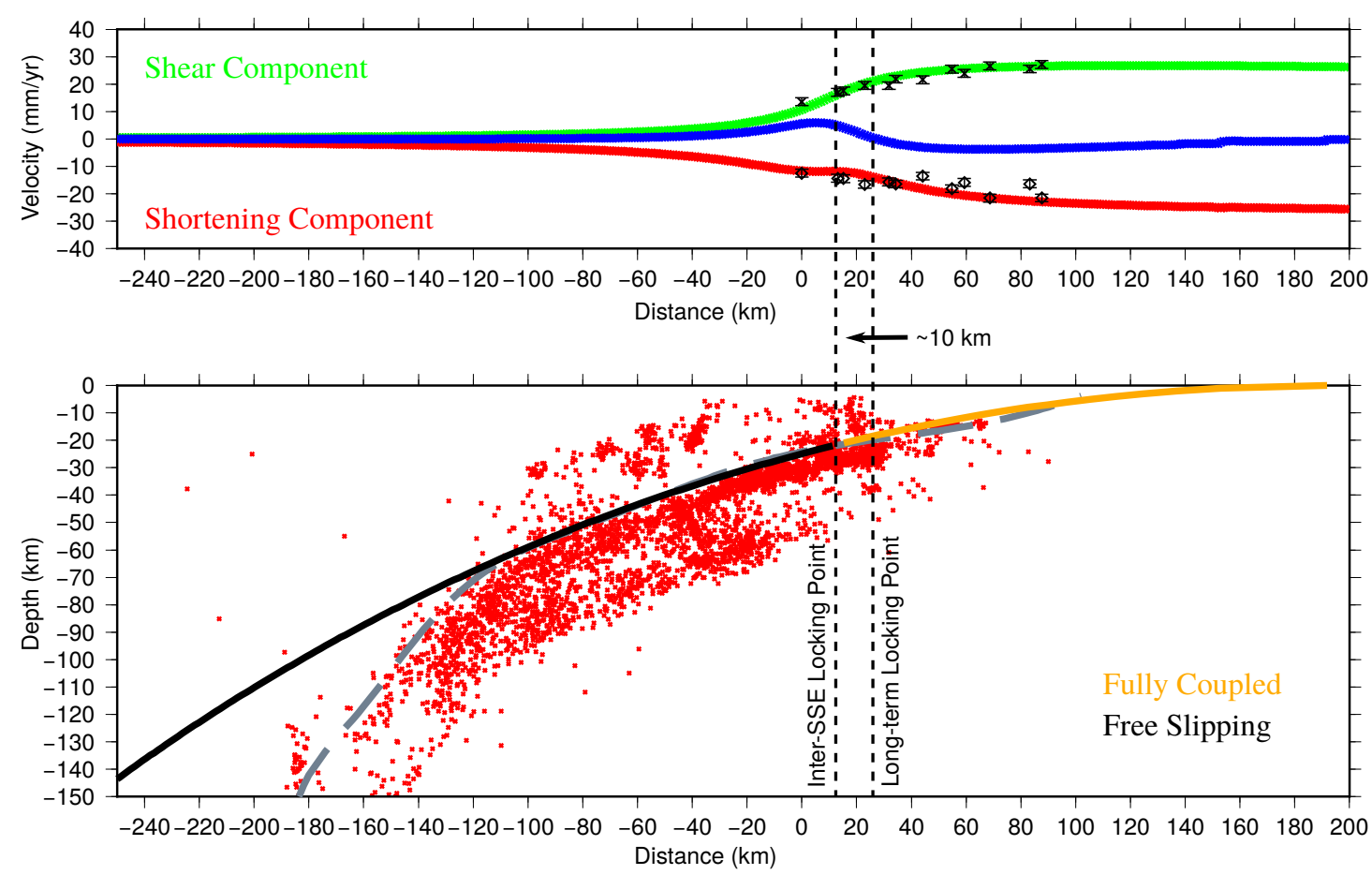

Figure 6.16: Dislocation modeling results calculated using station velocities from the inter-SSE dataset, with a single locking point and two patches: (1) free slipping; (2) fully coupled. Using plate interface and dip models from Williams et al. (2013, Grey-dashed line) and the best fitting parameter $\left(\chi^{2}=\right.$ 2.97), a locking depth of $\sim 22 \mathrm{~km}$ was calculated. For other plot components see Figure 6.15.

enough time to average out SSEs, that the full plate velocity will be accommodated by slip on the subduction mega-thrust in the region of the SSEs.

\subsection{Conclusions}

In this study we determined strain rate parameters in central New Zealand, using three datasets of various station velocities: (1) long-term, (2) inter-SSE, and (3) co-seismic movement of the $2016 \mathrm{M}_{W} 7.8$ Kaikōura earthquake.

High shear strain rates in the Wellington and Cook Strait regions, overall compressional dilation, and overall positive (clockwise) vorticity was calculated using longterm cGPS station velocities (Figure 6.8). High shear strain rates in the Cook Strait region, overall compressional dilation, and overall positive (clockwise) vorticity was calculated using inter-SSE cGPS station velocities (Figure 6.9). These strain parameters best characterize what to expect over short time intervals (months to years).

Preliminary results showed the highest shear strain rates are coeval with surface ruptures and encompass the region with the highest rates of aftershocks of the Kairkōura 
Short-Term (Inter SSE: 2 Slipping Patches)

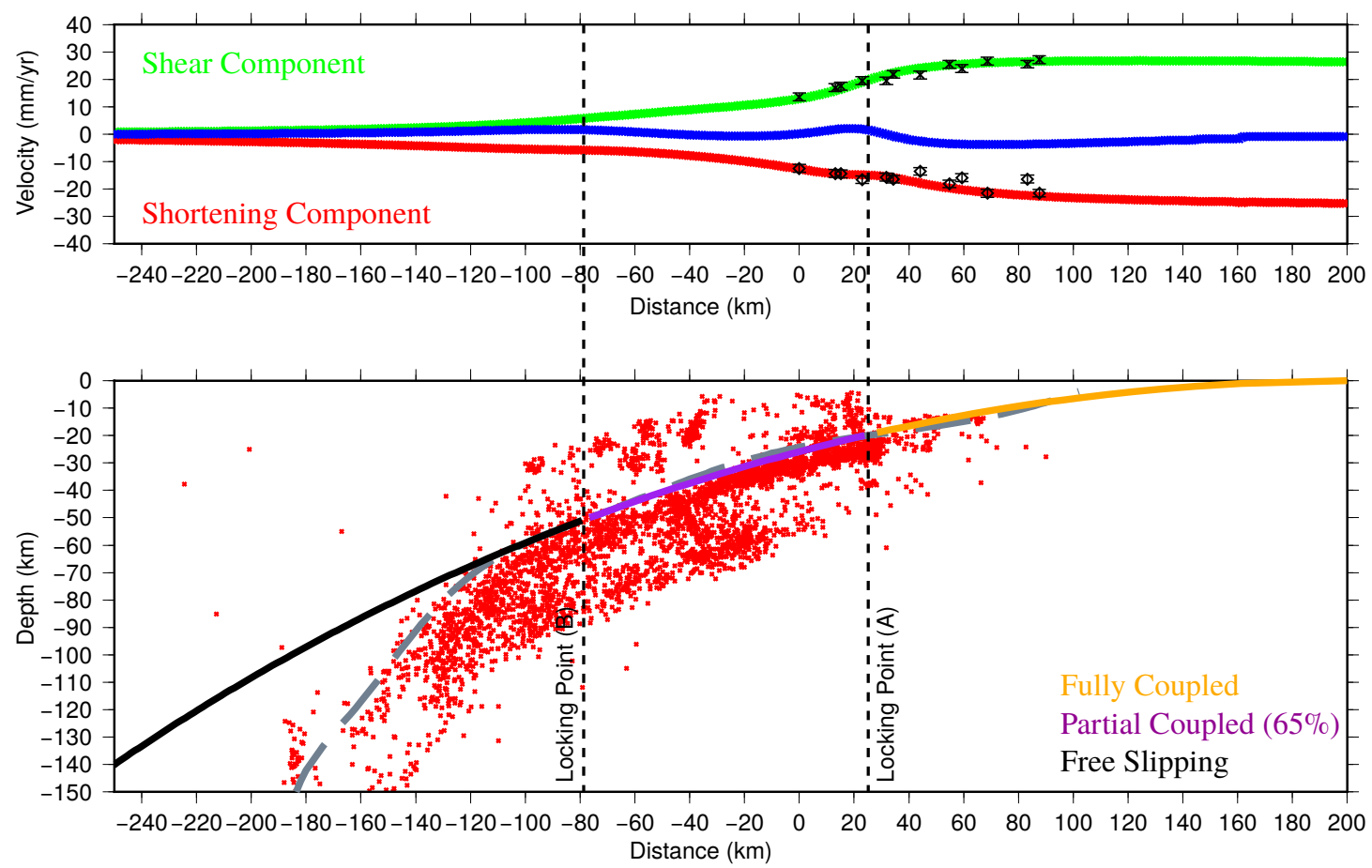

Figure 6.17: Dislocation modeling results calculated using station velocities from the inter-SSE dataset, with a two locking points and three patches: (1) free slipping; (2) partially coupled: $65 \%$; (3) fully coupled. Using plate interface and dip models (Williams et al., 2013, , Grey-dashed line) and the best fitting parameter $\left(\chi^{2}=2.04\right)$, a locking depth of $20.43 \mathrm{~km}$ was calculated. For other plot components see Figure 6.15.

earthquake. The extensional response to the Kaikoura earthquake in the eastern half of the southern North Island may have accommodated some of the accumulated stress due to the coupled plate interface.

The variation of the long-term and inter-SSE strain parameters indicates that the dynamics of locked portion of the southern Hikurangi subduction system not only vary on mega-thrust earthquake cycles (100s of years), but also on SSE time scales $(<10$ years). It is likely that the short-term dynamic changes of the couple zone would affect the characteristics (i.e., timing and hypocenter) of a subduction mega-thrust earthquakes and/or large crustal earthquakes (i.e. 2016 Kaikoura).

\subsection{Acknowledgements}

All cGPS data are available at the GeoNet management center (https : / / www - geonet . org.nz/data/types/geodetic), funded by the New Zealand Earthquake Commission. I'd like to thank Simon Lamb for helpful discussions and providing the strain parameter calculation codes, as well as, Euan Smith for helpful discussions and pro- 
viding the reference frame transformation codes. 
Chapter 6. Preliminary Examination of Long-Term and Short-Term Strain Rates in Central New Zealand 


\section{Chapter 7}

\section{Conclusions}

\subsection{A Review of Stress Orientations and Strain Rates at the Southern Hikurangi Margin}

Stress orientations, anisotropy, and strain parameters throughout the coupled region of the southern Hikurangi subduction zone have been investigated by comparing mircoseismicity, gravitational potential energy, shear-wave splitting, and cGPS data. This study provides observations, which will provide background information for a more robust and region specific seismic hazard assessment of the southern North Island, New Zealand and the subduction mega-thrust below.

\subsubsection{Subducting Pacific Plate}

Analysis within Chapters 3 and 4 characterize stress orientations of the double Benioff zone within the subducting Pacific plate, beneath the southern North Island. Stress orientations within the upper band of seismicity are consistent with an extensional regime (Figure 7.1). Stress orientations within the down-dip lower band of seismicity are consistent with a compressional regime (Figure 7.1). Stress orientations within the up-dip lower band of seismicity are consistent with an extensional regime (Figure 7.1). In the deeper region of the subduction zone, where there is upper extensional and lower compressional stress regimes, indicate bending forces. In the shallow region of the subduction zone, where there upper and lower extensional stress regimes, indicate slab-pull forces. Based on shape of the plate interface, it is likely that the bending stresses are also dominant within the slab in the northern region the Whanganui basin as well.

Coalescing of the two bands of seismicity in the deeper region of the double Benioff zone (Figure 4.2) could indicate that bending stresses are resulting in the loss of elastic strength throughout the subducting plate. Another possible explanation for the merging of the two bands of seismicity are that in all three previous DBZ studies (McGinty 
et al. (2000); Du et al. (2004); this thesis) those earthquakes in the deeper reaches of the subduction zone have large depth uncertainties, because there are no seismometers directly above those earthquakes (i.e., all studies used only land based seismic stations).

\subsubsection{Overriding Australian Plate}

Analysis within Chapters 3, 5, and 6 characterized seismic anisotropy, stress orientations, and strain parameters in the overriding Australian plate at the southern North and northern South Islands. Observations of shear-wave splitting fast azimuth of N-S to NE-SW west of the Wairarapa fault is the result of structural sources (i.e. faults) and indicated shear deformation is the dominant factor (Figure 7.1). Within the Wairarapa Basin we observe an average fast azimuth orientation of NW-SE to NNW-SSE, near perpendicular to the Wairarapa fault and the subduction trench. Unlike west of the Wairarapa fault, within the Wairarapa basin, the fast azimuth is reflective of the SHmax orientation. A SHmax orientation of NW-SE to NNW-SSE and the prevalence of NNESSW trending reverse faulting indicate that shortening compressional deformation is dominant (Figure 7.1). In the eastern region of the southern North Island, deformation due to shearing and shortening is present (Figure 7.1). The stress field in this area is likely being complicated by large amounts of fluids with high fluid pressures (Reyners and Eberhart-Phillips, 2009; Bassett et al., 2014).

Although it is unclear to what extent, it seems likely that the underplated material (pink-region Figure 7.1), plays a significant role in the distribution of fluids (the strength of the upper plate) in the region. Based on interpretations of fluid distribution in the Rakaia and Pahua Terranes by Reyners and Eberhart-Phillips (2009) in relation to active faults mapped by Henrys et al. (2013), fluids from the subducting plate are predominantly flowing into the reverse fault zones, which initiate on the trenchward side of the underplated material surface within the Wairarapa basin.

Analysis of gravitational stress orientations in Chapter 3, show that GPE SHmax orientations west of the Wariarapa fault trend NE-SW, within the Wairarapa Basin trend NW-SE, and trend NE-SW in the eastern southern North Island (Figure 3.5 and 3.6). The similarity between the fast azimuth and gravitational SHmax orientations, in the Wairarapa basin, suggest that GPE stresses are a major component of the near surface stress field and should possibly be taken into account when assessing future seismic hazards in this region.

\section{cGPS Strain Parameters}

Analysis in Chapter 6 of inter-SSE (months-years) and long-term (years-decades) strain parameters, show increased rates of shear strain in the the Wellington and Cook Strait regions of the southern North Island (Figure 6.8, 6.9, 6.11-14). Inter-SSE and long-term strain parameters show southern North and northern South Island to be dominated by clockwise rotation and compressional dilatation. Preliminary dislocation models 
showed there to be a difference between the effective locking point (point between couple and free-slip) depth of the plate interface of the couple zone when using longterm and inter-SSE cGPS datasets. This indicates that characteristics of the coupled zone dynamics not only vary on mega-thrust earthquake cycles (100s of years), but also on SSE time scales ( $<10$ years). It would stand to reason that the short-term dynamic changes of the couple zone may effect how the zone reacts to subduction mega-thrust earthquakes and/or to large crustal earthquakes (i.e. 2016 Kaikoura). 


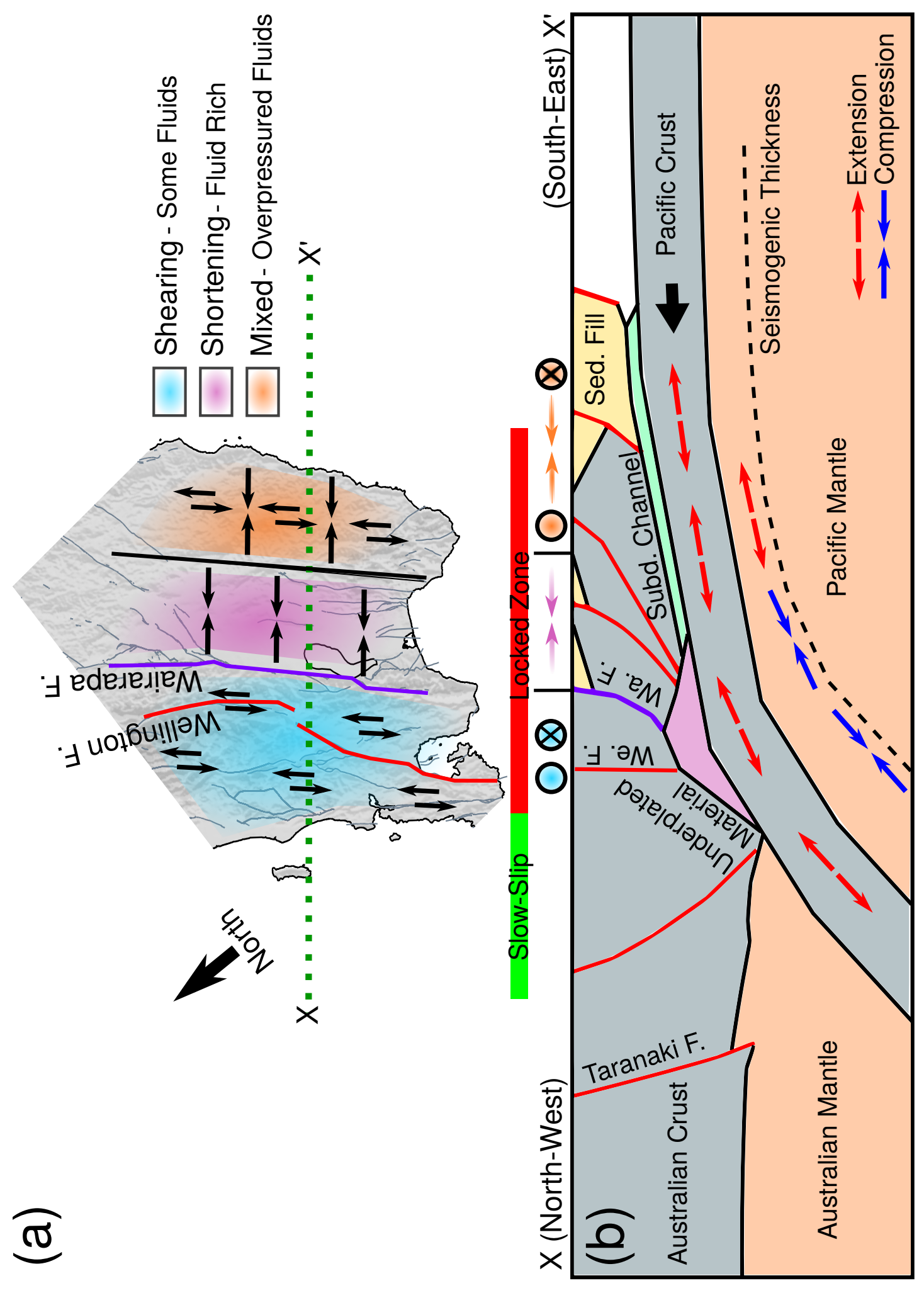


Figure 7.1: (a) West of the Wairarapa fault (red-line) the fast azimuth orientation indicates the crust is dominated by simple shear deformation. Within the Wairarapa basin the fast azimuth orientation indicates the crust is dominated by compressional deformation. East of the Wairarapa basin compression and shear deformation is present. Crustal fluid distribution based on interpretations of Reyners and Eberhart-Phillips (2009); Bassett et al. (2014). Dashed-green line indicates cross-section location of (b). Active faults (grey-lines, https: //data.gns.cri.nz/af/, Langridge et al. (2005)). (b) Adapted from Henrys et al. (2013) Figure 10. The north-west down-dip region of the subduction zone is dominated by bending stresses, juxtaposed to a underplated material (pink-region) and the Australian Moho. Dashedblack line shows extent of seismogenic thickness of the subducting Pacific plate. Red lines (purple for Wairarapa fault only) indicate active faults.

\subsection{Overriding and Subducting Plate Interaction}

Chapter 3, 4, and 5 demonstrates variations in the transfer of stresses between the subducting plate and the overriding plate, below the southern North Island, across the coupled region. Parallel trench plate motion is predominantly being accommodated west of the Wairarapa fault, where bending forces within the subducting plate are greatest and here is a transition from a coupled to freely-slipping plate interface (Figure 7.1). East of the Wairarapa fault, perpendicular trench motion is being accommodated by the shortening within the Wairarapa basin (Figure 7.1), above a region of the subducting plate that is dominated by slab-pull forces and coupling on the plate interface is greatest.

\subsection{Future Work}

The observation made in Chapter 4 (Stress Orientations in a Double Benioff Zone: the Southern Hikurangi Margin, New Zealand), combined with observations made during previous studies on the Hikurangi Subduction Zone further north, indicate that the dynamics of deformation within the subducting Pacific plate vary along the length of the southern Hikurangi Margin. A study of the northern extent of the southern Hikurangi Double Benioff Zone (HDBZ) would highlight the evolution of stresses within the subducting Pacific plate along the entirety of the New Zealand section of the southern Hikurangi Margin.

The observation made in Chapter 5 (Crustal Anisotropy Across Southern North Island, New Zealand Revealed by a High Density Seismic Array) showed that over relatively short distances the stress field can be governed by different factors. A study using an array designed with similar characteristics of the SAHKE II array, spanning various sections of the North Island, in turn traversing different sections of major fault systems, would allow for in-depth characterization of the evolution of stresses across the North Island. A study of this nature, when combined with the previously postulated study, would 
allow for comprehensive study of the interactions of stresses within the subducting Pacific plate and the overriding Australian plate, further expanding upon the study done in Chapter 3 of this thesis. 


\section{Bibliography}

Abers, G. A. (1992). Relationship between shallow-and intermediate-depth seismicity in the Eastern Aleutian Subduction Zone. Geophysical research letters, 19(20):20192022.

Allen, R. V. (1978). Automatic earthquake recognition and timing from single traces. Bulletin of the Seismological Society of America, 68(5):1521-1532.

Altamimi, Z., Métivier, L., and Collilieux, X. (2012). ITRF2008 plate motion model. Journal of geophysical research: solid earth, 117(B7).

Arnold, R. and Townend, J. (2007). A Bayesian approach to estimating tectonic stress from seismological data. Geophysical Journal International, 170(3):1336-1356.

Audoine, E., Savage, M. K., and Gledhill, K. (2000). Seismic anisotropy from local earthquakes in the transition region from a subduction to a strike-slip plate boundary, New Zealand. Journal of Geophysical Research: Solid Earth, 105(B4):8013-8033.

Babeyko, A. and Sobolev, S. (2008). High-resolution numerical modeling of stress distribution in visco-elasto-plastic subducting slabs. Lithos, 103(1):205-216.

Balfour, N., Savage, M., and Townend, J. (2005). Stress and crustal anisotropy in Marlborough, New Zealand: evidence for low fault strength and structure-controlled anisotropy. Geophysical Journal International, 163(3):1073-1086.

Bassett, D., Sutherland, R., and Henrys, S. (2014). Slow wavespeeds and fluid overpressure in a region of shallow geodetic locking and slow slip, Hikurangi subduction margin, New Zealand. Earth and Planetary Science Letters, 389:1-13.

Beanland, S. and Haines, J. (1998). The kinematics of active deformation in the North Island, New Zealand, determined from geological strain rates. New Zealand Journal of Geology and Geophysics, 41(4):311-323.

Beavan, J., Ellis, S., Wallace, L., and Denys, P. (2007). Kinematic constraints from GPS on oblique convergence of the Pacific and Australian plates, central South Island, New Zealand. A Continental Plate Boundary: Tectonics at South Island, New Zealand, pages $75-94$. 
Beavan, J. and Haines, J. (2001). Contemporary horizontal velocity and strain rate fields of the Pacific-Australian plate boundary zone through New Zealand. Journal of Geophysical Research: Solid Earth, 106(B1):741-770.

Beavan, J., Tregoning, P., Bevis, M., Kato, T., and Meertens, C. (2002). Motion and rigidity of the Pacific Plate and implications for plate boundary deformation. Journal of Geophysical Research: Solid Earth, 107(B10).

Beavan, J., Wallace, L. M., Palmer, N., Denys, P., Ellis, S., Fournier, N., Hreinsdottir, S., Pearson, C., and Denham, M. (2016). New Zealand GPS velocity field: 1995-2013. New Zealand Journal of Geology and Geophysics, 59(1):5-14.

Begg, J., Johnston, M., and McSaveney, E. (2000). Geology of the Wellington area.

Berens, P. et al. (2009). CircStat: a MATLAB toolbox for circular statistics. J Stat Softw, 31(10):1-21.

Berryman, K. and Beanland, S. (1991). Variation in fault behaviour in different tectonic provinces of New Zealand. Journal of structural geology, 13(2):177-189.

Böhm, J., Niell, A., Tregoning, P., and Schuh, H. (2006). Global Mapping Function (GMF): A new empirical mapping function based on numerical weather model data. Geophysical Research Letters, 33(7).

Bradley, B. A., Razafindrakoto, H. N., and Polak, V. (2017). Ground-Motion Observations from the 14 November $2016 \mathrm{M} \mathrm{w} 7.8$ Kaikoura, New Zealand, Earthquake and Insights from Broadband Simulations. Seismological Research Letters, 88(3):740-756.

Brisbourne, A., Stuart, G., Kendall, J., et al. (1999). Anisotropic structure of the Hikurangi subduction zone, New Zealandintegrated interpretation of surface-wave andbody-wave observations. Geophysical Journal International, 137(1):214-230.

Brudzinski, M. R. and Chen, W.-P. (2005). Earthquakes and strain in subhorizontal slabs. Journal of Geophysical Research: Solid Earth, 110(B8).

Brudzinski, M. R., Thurber, C. H., Hacker, B. R., and Engdahl, E. R. (2007). Global prevalence of double Benioff zones. Science, 316(5830):1472-1474.

Buffett, B. and Becker, T. (2012). Bending stress and dissipation in subducted lithosphere. Journal of Geophysical Research: Solid Earth, 117(B5).

Buffett, B. A. (2006). Plate force due to bending at subduction zones. Journal of Geophysical Research: Solid Earth, 111(B9).

Cahill, T. and Isacks, B. L. (1986). An apparent double-planed Benioff Zone beneath northern Chile resulting from misidentification of reflected phases. Geophysical Research Letters, 13(4):333-336. 
Castellazzi, C., Savage, M. K., Walsh, E., and Arnold, R. (2015). Shear wave automatic picking and splitting measurements at Ruapehu volcano, New Zealand. Journal of Geophysical Research: Solid Earth, 120(5):3363-3384.

Cesca, S., Zhang, Y., Mouslopoulou, V., Wang, R., Saul, J., Savage, M., Heimann, S., Kufner, S.-K., Oncken, O., and Dahm, T. (2017). Complex rupture process of the Mw 7.8, 2016, Kaikoura earthquake, New Zealand, and its aftershock sequence. Earth and Planetary Science Letters, 478:110-120.

Christova, C. and Scholz, C. H. (2003). Stresses in the Vanuatu subducting slab: A test of two hypotheses. Geophysical research letters, 30(15).

Coffin, M., Gahagan, L., and Lawver, L. (1998). Present-day plate boundary digital data compilation. University of Texas Institute for geophysics technical report, 174(5).

Cohen, S. C. and Darby, D. J. (2003). Tectonic plate coupling and elastic thickness derived from the inversion of a steady state viscoelastic model using geodetic data: Application to southern North Island, New Zealand. Journal of Geophysical Research: Solid Earth, 108(B3).

Comte, D., Dorbath, L., Pardo, M., Monfret, T., Haessler, H., Rivera, L., Frogneux, M., Glass, B., and Meneses, C. (1999). A double-layered seismic zone in Arica, northern Chile. Geophysical Research Letters, 26(13):1965-1968.

Cornell, C. A. (1968). Engineering seismic risk analysis. Bulletin of the seismological society of America, 58(5):1583-1606.

Crampin, S. (1981). A review of wave motion in anisotropic and cracked elastic-media. Wave motion, 3(4):343-391.

Crampin, S. (1994). The fracture criticality of crustal rocks. Geophysical Journal International, 118(2):428-438.

Crampin, S. and Lovell, J. H. (1991). A decade of shear-wave splitting in the Earth's crust: what does it mean? what use can we make of it? and what should we do next? Geophysical Journal International, 107(3):387-407.

Crampin, S. and Peacock, S. (2005). A review of shear-wave splitting in the compliant crack-critical anisotropic Earth. Wave motion, 41(1):59-77.

Crotwell, H. P., Owens, T. J., and Ritsema, J. (1999). The TauP Toolkit: Flexible seismic travel-time and ray-path utilities. Seismological Research Letters, 70(2):154-160.

Darby, D. and Beavan, J. (2001). Evidence from GPS measurements for contemporary interplate coupling on the southern Hikurangi subduction thrust and for partitioning of strain in the upper plate. Journal of Geophysical Research: Solid Earth, 106(B12):30881-30891. 
DeMets, C., Gordon, R. G., Argus, D., and Stein, S. (1990). Current plate motions. Geophysical journal international, 101(2):425-478.

DeMets, C., Gordon, R. G., Argus, D. F., and Stein, S. (1994). Effect of recent revisions to the geomagnetic reversal time scale on estimates of current plate motions. Geophysical research letters, 21(20):2191-2194.

Diehl, T., Deichmann, N., Kissling, E., and Husen, S. (2009). Automatic S-wave picker for local earthquake tomography. Bulletin of the Seismological Society of America, 99(3):1906-1920.

Dimech, J.-L., Stern, T., and Lamb, S. (2017). Mantle earthquakes, crustal structure, and gravitational instability beneath western North Island, New Zealand. Geology, 45(2):155-158.

Do Nascimento, A. F., Bezerra, F. H., and Takeya, M. K. (2004). Ductile Precambrian fabric control of seismic anisotropy in the Açu dam area, northeastern Brazil. Journal of Geophysical Research: Solid Earth, 109(B10).

Do Nascimento, A. F., Pearce, R. G., and Takeya, M. K. (2002). Local shear wave observations in Joao Câmara, northeast Brazil. Journal of Geophysical Research: Solid Earth, 107(B10).

Du, W.-x., Thurber, C. H., Reyners, M., Eberhart-Phillips, D., and Zhang, H. (2004). New constraints on seismicity in the Wellington region of New Zealand from relocated earthquake hypocentres. Geophysical Journal International, 158(3):1088-1102.

Eberhart-Phillips, D., Bannister, S., and Ellis, S. (2014). Imaging P and S attenuation in the termination region of the Hikurangi subduction zone, New Zealand. Geophysical Journal International, 198(1):516-536.

Eberhart-Phillips, D. and Reyners, M. (1997). Continental subduction and threedimensional crustal structure: The northern South Island, New Zealand. Journal of Geophysical Research: Solid Earth, 102(B6):11843-11861.

Eberhart-Phillips, D. and Reyners, M. (2009). Three-dimensional distribution of seismic anisotropy in the Hikurangi subduction zone beneath the central North Island, New Zealand. Journal of Geophysical Research: Solid Earth, 114(B6).

Eberhart-Phillips, D., Reyners, M., Bannister, S., Chadwick, M., and Ellis, S. (2010). Establishing a versatile 3-D seismic velocity model for New Zealand. Seismological Research Letters, 81(6):992-1000.

Eberhart-Phillips, D., Reyners, M., Chadwick, M., and Chiu, J.-M. (2005). Crustal heterogeneity and subduction processes: 3-D Vp, Vp/Vs and $\mathrm{Q}$ in the southern North Island, New Zealand. Geophysical Journal International, 162(1):270-288. 
Engdahl, E. and Scholz, C. (1977). A double Benioff zone beneath the central Aleutians: An unbending of the lithosphere. Geophysical Research Letters, 4(10):473-476.

Evanzia, D., Wilson, T., Savage, M. K., Lamb, S., and Hirschberg, H. (2017). Stress Orientations in a Locked Subduction Zone at the Southern Hikurangi Margin, New Zealand. Journal of Geophysical Research: Solid Earth, 122(10):7895-7911.

Flesch, L. M., Haines, A. J., and Holt, W. E. (2001). Dynamics of the India-Eurasia collision zone. Journal of Geophysical Research: Solid Earth, 106(B8):16435-16460.

Frechet, J. (1985). Sismogenese et doublets sismiques. PhD thesis, Universite Scientifique et Medicale de Grenoble.

Frepoli, A., Selvaggi, G., Chiarabba, C., and Amato, A. (1996). State of stress in the Southern Tyrrhenian subduction zone from fault-plane solutions. Geophysical Journal International, 125(3):879-891.

Gledhill, K. (1991). Evidence for shallow and pervasive seismic anisotropy in the Wellington region, New Zealand. Journal of Geophysical Research: Solid Earth, 96(B13):21503-21516.

Gledhill, K. and Stuart, G. (1996). Seismic anisotropy in the fore-arc region of the Hikurangi subduction zone, New Zealand. Physics of the earth and planetary interiors, 95(3):211-225.

Goldstein, P., Dodge, D., Firpo, M., and Minner, L. (2003). 85.5 SAC2000: Signal processing and analysis tools for seismologists and engineers. International Geophysics, 81:1613-1614.

Goldstein, P. and Snoke, A. (2005). SAC availability for the IRIS community. Incorporated Institutions for Seismology Data Management Center Electronic Newsletter, 7(1).

Gross, R., Green, A. G., Horstmeyer, H., and Begg, J. H. (2004). Location and geometry of the Wellington fault (New Zealand) defined by detailed three-dimensional georadar data. Journal of Geophysical Research: Solid Earth, 109(B5).

Haines, A. and Holt, W. (1993). A procedure for obtaining the complete horizontal motions within zones of distributed deformation from the inversion of strain rate data. Journal of Geophysical Research: Solid Earth, 98(B7):12057-12082.

Hamling, I. J., Hreinsdóttir, S., Clark, K., Elliott, J., Liang, C., Fielding, E., Litchfield, N., Villamor, P., Wallace, L., Wright, T. J., et al. (2017). Complex multifault rupture during the $2016 \mathrm{M}$ w 7.8 Kaikōura earthquake, New Zealand. Science, 356(6334):eaam7194. 
Harrison, A. and White, R. S. (2006). Lithospheric structure of an active backarc basin: the Taupo Volcanic Zone, New Zealand. Geophysical Journal International, 167(2):968990.

Hasegawa, A., Umino, N., and Takagi, A. (1978). Double-planed deep seismic zone and upper-mantle structure in the Northeastern Japan Arc. Geophysical Journal International, 54(2):281-296.

Hasegawa, A., Yoshida, K., and Okada, T. (2011). Nearly complete stress drop in the 2011 Mw 9.0 off the Pacific coast of Tohoku Earthquake. Earth, planets and space, 63(7):35.

Havskov, J. and Ottemoller, L. (1999). SEISAN earthquake analysis software. Seismological Research Letters, 70(5):532-534.

Henrys, S., Wech, A., Sutherland, R., Stern, T., Savage, M., Sato, H., Mochizuki, K., Iwasaki, T., Okaya, D., Seward, A., et al. (2013). SAHKE geophysical transect reveals crustal and subduction zone structure at the southern Hikurangi margin, New Zealand. Geochemistry, Geophysics, Geosystems, 14(7):2063-2083.

Heron, D. w. Geological map of New Zealand 1:250,000. GNS Science geological map 1 (2nd edition).

Hudnut, K. and Taber, J. (1987). Transition from double to single Wadati-Benioff seismic zone in the Shumagin Islands, Alaska. Geophysical Research Letters, 14(2):143-146.

Isacks, B. and Barazangi, M. Geometry of Benioff zones' Lateral segmentation and downwards bending of the subducted lithosphere. Island Arcs, Deep Sea Trenches, and Back-Arc Basins, Maurice Ewing Ser, 1:99-115.

Johnson, J. H., Savage, M. K., and Townend, J. (2011). Distinguishing between stressinduced and structural anisotropy at Mount Ruapehu Volcano, New Zealand. Journal of Geophysical Research: Solid Earth, 116(B12).

Kaiser, A., Balfour, N., Fry, B., Holden, C., Litchfield, N., Gerstenberger, M., DAnastasio, E., Horspool, N., McVerry, G., Ristau, J., et al. (2017). The 2016 Kaikōura, New Zealand, earthquake: preliminary seismological report. Seismological Research Letters, 88(3):727-739.

Kao, H. and Chen, W.-P. (1994). The double seismic zone in Kuril-Kamchatka: the tale of two overlapping single zones. Journal of Geophysical Research: Solid Earth, 99(B4):6913-6930.

Karalliyadda, S. (2014). S-wave splitting in the transpressional zone of New Zealand plate-boundary: Implications for deformation and dynamics. 
Karalliyadda, S. and Savage, M. (2013). Seismic anisotropy and lithospheric deformation of the plate-boundary zone in South Island, New Zealand: inferences from local S-wave splitting. Geophysical Journal International, 193(2):507-530.

Kato, A., Sakai, S., and Obara, K. (2011). A normal-faulting seismic sequence triggered by the 2011 off the Pacific coast of Tohoku Earthquake: Wholesale stress regime changes in the upper plate. Earth, planets and space, 63(7):43.

Kawakatsu, H. (1985). Double seismic zone in Tonga. Nature, 316(6023):53-55.

Kennett, B., Engdahl, E., and Buland, R. (1995). Constraints on seismic velocities in the Earth from traveltimes. Geophysical Journal International, 122(1):108-124.

Kirby, S., Engdahl, R. E., and Denlinger, R. (1996). Intermediate-depth intraslab earthquakes and arc volcanism as physical expressions of crustal and uppermost mantle metamorphism in subducting slabs. Subduction top to bottom, pages 195-214.

Kita, S., Okada, T., Hasegawa, A., Nakajima, J., and Matsuzawa, T. (2010). Anomalous deepening of a seismic belt in the upper-plane of the double seismic zone in the Pacific slab beneath the Hokkaido corner: Possible evidence for thermal shielding caused by subducted forearc crust materials. Earth and Planetary Science Letters, 290(3-4):415-426.

Krischer, L. (2015). hypoDDpy: hypoDDpy 1.0.

Kusznir, N., Vita-Finzi, C., Whitmarsh, R., England, P., Bott, M., Govers, R., Cartwright, J., and Murrell, S. (1991). The distribution of stress with depth in the lithosphere: Thermo-rheological and geodynamic constraints [and discussion]. Philosophical Transactions of the Royal Society of London A: Mathematical, Physical and Engineering Sciences, 337(1645):95-110.

Lamb, S. (2000). Active deformation in the Bolivian Andes, South America. Journal of Geophysical Research: Solid Earth, 105(B11):25627-25653.

Lamb, S. (2015). Kinematics to dynamics in the New Zealand Plate boundary zone: implications for the strength of the lithosphere. Geophysical Journal International, 201(2):552-573.

Lamb, S. and Smith, E. (2013). The nature of the plate interface and driving force of interseismic deformation in the New Zealand plate-boundary zone, revealed by the continuous GPS velocity field. Journal of Geophysical Research: Solid Earth, 118(6):3160-3189.

Lamb, S. and Vella, P. (1987). The last million years of deformation in part of the New Zealand plate-boundary zone. Journal of structural geology, 9(7):877-891. 
Langridge, R., Ries, W., Litchfield, N., Villamor, P., Van Dissen, R., Barrell, D., Rattenbury, M., Heron, D., Haubrock, S., Townsend, D., et al. (2016). The New Zealand active faults database. New Zealand Journal of Geology and Geophysics, 59(1):86-96.

Langridge, R., Van Dissen, R., Cochran, U., Litchfield, N., Berryman, K., Begg, J., Villamor, P., Heron, D., Nicol, A., and Townsend, D. (2005). Active faulting and paleoearthquakes in the Wairarapa and Wellington regions. In Proceedings Volume: The 1855 Wairarapa Fault Symposium: Te Papa Tongarewa Museum of New Zealand, pages 49-65.

Leary, P. C., Crampin, S., and McEvilly, T. V. (1990). Seismic fracture anisotropy in the Earth's crust: An overview. Journal of Geophysical Research: Solid Earth, 95(B7):1110511114.

Lee, J. and Begg, J. (2002). Geology of the Wairarapa area: scale 1: 250,000. Lower Hutt: Institute of Geological \& Nuclear Sciences Limited. Institute of Geological \& Nuclear Sciences, $1(250,000)$.

Lienert, B. R., Berg, E., and Frazer, L. N. (1986). HYPOCENTER: An earthquake location method using centered, scaled, and adaptively damped least squares. Bulletin of the Seismological Society of America, 76(3):771-783.

Lienert, B. R. and Havskov, J. (1995). A computer program for locating earthquakes both locally and globally. Seismological Research Letters, 66(5):26-36.

Litchfield, N., Benson, A., Bischoff, A., Hatem, A., Barrier, A., Nicol, A., Wandres, A., Lukovic, B., Hall, B., Gasston, C., et al. (2016). 14th November 2016 M 7.8 Kaikoura earthquake. Preliminary surface fault displacement measurements, Version 2. GNS Science.

Litchfield, N., Van Dissen, R., Sutherland, R., Barnes, P., Cox, S., Norris, R., Beavan, R., Langridge, R., Villamor, P., Berryman, K., et al. (2014). A model of active faulting in New Zealand. New Zealand Journal of Geology and Geophysics, 57(1):32-56.

Liu, Y., Zhang, H., Thurber, C., and Roecker, S. (2008). Shear wave anisotropy in the crust around the San Andreas fault near Parkfield: spatial and temporal analysis. Geophysical Journal International, 172(3):957-970.

Lomax, A. (2011). The NonLinLoc software guide, 6.0. ALomax Scientific, MouansSartoux, France, http://alomax. free. fr/nlloc.

Lomax, A., Michelini, A., and Curtis, A. (2009). Encyclopedia of Complexity and Systems Science: Earthquake Location, Direct, Global-Search Methods. Springer.

Lomax, A., Virieux, J., Volant, P., and Berge-Thierry, C. (2000). Probabilistic earthquake location in $3 \mathrm{D}$ and layered models. In Advances in seismic event location, pages 101134. Springer. 
Lund, B. and Townend, J. (2007). Calculating horizontal stress orientations with full or partial knowledge of the tectonic stress tensor. Geophysical Journal International, 170(3):1328-1335.

Marson-Pidgeon, K. and Savage, M. K. (1997). Frequency-dependent anisotropy in Wellington, New Zealand. Geophysical Research Letters, 24:3297-3300.

Marson-Pidgeon, K. and Savage, M. K. (2004). Modelling shear wave splitting observations from Wellington, New Zealand. Geophysical Journal International, 157(2):853864.

Marson-Pidgeon, K., Savage, M. K., Gledhill, K., and Stuart, G. (1999). Seismic anisotropy beneath the lower half of the North Island, New Zealand. Journal of Geophysical Research: Solid Earth, 104(B9):20277-20286.

McCaffrey, R., Wallace, L. M., and Beavan, J. (2008). Slow slip and frictional transition at low temperature at the Hikurangi subduction zone. Nature Geoscience, 1(5):316320.

McCrory, P. A., Blair, J. L., Waldhauser, F., and Oppenheimer, D. H. (2012). Juan de Fuca slab geometry and its relation to Wadati-Benioff zone seismicity. Journal of Geophysical Research: Solid Earth, 117(B9).

McGinty, P., Reyners, M., and Robinson, R. (2000). Stress directions in the shallow part of the Hikurangi subduction zone, New Zealand, from the inversion of earthquake first motions. Geophysical Journal International, 142(2):339-350.

Molnar, P. (2004). Interactions among topographically induced elastic stress, static fatigue, and valley incision. Journal of Geophysical Research: Earth Surface, 109(F2).

Mortimer, N. (2004). New Zealand's geological foundations. Gondwana Research, $7(1): 261-272$.

Nur, A. (1971). Effects of stress on velocity anisotropy in rocks with cracks. Journal of Geophysical Research, 76(8):2022-2034.

Nur, A. and Simmons, G. (1969). Stress-induced velocity anisotropy in rock: An experimental study. Journal of Geophysical Research, 74(27):6667-6674.

Okada, Y. (1985). Surface deformation due to shear and tensile faults in a half-space. Bulletin of the seismological society of America, 75(4):1135-1154.

Okada, Y. (1992). Internal deformation due to shear and tensile faults in a half-space. Bulletin of the Seismological Society of America, 82(2):1018-1040.

Okaya, D., Christensen, N. I., Ross, Z. E., and Wu, F. T. (2016). Terrane-controlled crustal shear wave splitting in Taiwan. Geophysical Research Letters, 43(2):556-563. 
Peacock, S. M. (2001). Are the lower planes of double seismic zones caused by serpentine dehydration in subducting oceanic mantle? Geology, 29(4):299-302.

Power, W., Wallace, L., and Reyners, M. (2008). Tsunami hazard posed by earthquakes on the Hikurangi subduction zone interface. GNS Science.

Ratchkovsky, N. A., Pujol, J., and Biswas, N. N. (1997). Relocation of earthquakes in the Cook Inlet area, south central Alaska, using the joint hypocenter determination method. Bulletin of the Seismological Society of America, 87(3):620-636.

Reyners, M. (1998). Plate coupling and the hazard of large subduction thrust earthquakes at the Hikurangi subduction zone, New Zealand. New Zealand Journal of Geology and Geophysics, 41(4):343-354.

Reyners, M. (2011). Lessons from the destructive Mw 6.3 Christchurch, New Zealand, earthquake. Seismological Research Letters, 82(3):371-372.

Reyners, M. and Bannister, S. (2007). Earthquakes triggered by slow slip at the plate interface in the Hikurangi subduction zone, New Zealand. Geophysical research letters, 34(14).

Reyners, M. and Eberhart-Phillips, D. (2009). Small earthquakes provide insight into plate coupling and fluid distribution in the Hikurangi subduction zone, New Zealand. Earth and Planetary Science Letters, 282(1):299-305.

Reyners, M., Robinson, R., and McGinty, P. (1997). Plate coupling in the northern South Island and southernmost North Island, New Zealand, as illuminated by earthquake focal mechanisms. Journal of Geophysical Research: Solid Earth, 102(B7):15197-15210.

Rietbrock, A. and Waldhauser, F. (2004). A narrowly spaced double-seismic zone in the subducting Nazca Plate. Geophysical Research Letters, 31(10).

Robinson, R. (1986). Seismicity, structure and tectonics of the Wellington region, New Zealand. Geophysical Journal International, 87(2):379-409.

Savage, M. (1999). Seismic anisotropy and mantle deformation: what have we learned from shear wave splitting? Reviews of Geophysics, 37(1):65-106.

Savage, M., Aoki, Y., Unglert, K., Ohkura, T., Umakoshi, K., Shimizu, H., Iguchi, M., Tameguri, T., Ohminato, T., and Mori, J. (2016). Stress, strain rate and anisotropy in Kyushu, Japan. Earth and Planetary Science Letters, 439:129-142.

Savage, M., Shih, X., Meyer, R., and Aster, R. (1989). Shear-wave anisotropy of active tectonic regions via automated S-wave polarization analysis. Tectonophysics, 165(14):279-292. 
Savage, M., Wessel, A., Teanby, N., and Hurst, A. (2010). Automatic measurement of shear wave splitting and applications to time varying anisotropy at Mount Ruapehu volcano, New Zealand. Journal of Geophysical Research: Solid Earth, 115(B12).

Savage, M. K., Park, J., and Todd, H. (2007). Velocity and anisotropy structure at the Hikurangi subduction margin, New Zealand from receiver functions. Geophysical Journal International, 168(3):1034-1050.

Seward, A., Henrys, S., Henderson, M., Sutherland, R., Stern, T., Savage, M., Mochizuki, K., Sato, H., Iwasaki, T., Kennedy, C., et al. (2010). Seismic Array HiKurangi Experiment (SAHKE); Field Acquisition Report. GNS Science Report 2010, 48:62p.

Seward, A., Henrys, S., Okaya, D., Stern, T., Savage, M., Sato, H., Iwasaki, T., Sutherland, R., and Henderson, M. (2011). Seismic Array HiKurangi Experiment II (SAHKE II). Onshore Active Source Acquisition Report, GNS Science Report, 50:73.

Shen, Z.-K., Jackson, D. D., and Ge, B. X. (1996). Crustal deformation across and beyond the Los Angeles basin from geodetic measurements. Journal of Geophysical Research: Solid Earth, 101(B12):27957-27980.

Silver, P. G. and Chan, W. W. (1991). Shear wave splitting and subcontinental mantle deformation. Journal of Geophysical Research: Solid Earth, 96(B10):16429-16454.

Slancová, A., Špičák, A., Hanuš, V., and Vaněk, J. (2000). How the state of stress varies in the Wadati-Benioff zone: indications from focal mechanisms in the WadatiBenioff zone beneath Sumatra and Java. Geophysical Journal International, 143(3):909930.

Smalley, R. F. and Isacks, B. L. (1987). A high-resolution local network study of the Nazca Plate Wadati-Benioff Zone under western Argentina. Journal of Geophysical Research: Solid Earth, 92(B13):13903-13912.

Smith, S. W., Knapp, J. S., and McPherson, R. C. (1993). Seismicity of the Gorda plate, structure of the continental margin, and an eastward jump of the Mendocino triple junction. Journal of Geophysical Research: Solid Earth, 98(B5):8153-8171.

Stein, S. and Wysession, M. (2009). An introduction to seismology, earthquakes, and earth structure. John Wiley \& Sons.

Steketee, J. (1958). On Volterra's dislocations in a semi-infinite elastic medium. Canadian Journal of Physics, 36(2):192-205.

Stern, T., Stratford, W., and Salmon, M. (2006). Subduction evolution and mantle dynamics at a continental margin: Central North Island, New Zealand. Reviews of Geophysics, 44(4). 
Stirling, M., McVerry, G., Gerstenberger, M., Litchfield, N., Van Dissen, R., Berryman, K., Barnes, P., Wallace, L., Villamor, P., Langridge, R., et al. (2012). National seismic hazard model for New Zealand: 2010 update. Bulletin of the Seismological Society of America, 102(4):1514-1542.

Stirling, M. W., Verry, G. H. M., and Berryman, K. R. (2002). A new seismic hazard model for New Zealand. Bulletin of the Seismological Society of America, 92(5):18781903.

Stirling, M. W., Wesnousky, S. G., and Berryman, K. R. (1998). Probabilistic seismic hazard analysis of New Zealand. New Zealand Journal of Geology and Geophysics, 41(4):355-375.

Tarantola, A. (1987). Inverse problem theory: Method for data fitting and model parameter estimation. Elsevier, 613.

Tarantola, A. and Valette, B. (1982). Inverse problems= quest for information. J. geophys, 50(3):150-170.

Teanby, N., Kendall, J.-M., and Van der Baan, M. (2004). Automation of shear-wave splitting measurements using cluster analysis. Bulletin of the Seismological Society of America, 94(2):453-463.

Thurber, C., Roecker, S., Feenstra, J., Lord, N., O’Brien, G., Pesicek, J., Bannister, S., and Townend, J. (2012). Seismic site characterization for the Deep Fault Drilling Project (DFDP), Alpine fault, New Zealand: Preliminary results from the WIZARD array. In AGU Fall Meeting Abstracts.

Townend, J. (2006). What do faults feel? Observational constraints on the stresses acting on seismogenic faults. Earthquakes: Radiated energy and the physics of faulting, pages 313-327.

Townend, J., Sherburn, S., Arnold, R., Boese, C., and Woods, L. (2012). Threedimensional variations in present-day tectonic stress along the Australia-Pacific plate boundary in New Zealand. Earth and Planetary Science Letters, 353:47-59.

Townend, J. and Zoback, M. D. (2001). Implications of earthquake focal mechanisms for the frictional strength of the San Andreas fault system. Geological Society, London, Special Publications, 186(1):13-21.

Van Dissen, R. and Little, T. (2017). Surface fault rupture during the Mw 7.8 Kaikoura earthquake, New Zealand, with specific comment on the Kekerengu Fault-one of the country's fastest slipping onland active faults. In EGU General Assembly Conference Abstracts, volume 19, page 11483. 
Van Dissen, R. J. and Berryman, K. R. (1996). Surface rupture earthquakes over the last 1000 years in the Wellington region, New Zealand, and implications for ground shaking hazard. Journal of Geophysical Research: Solid Earth, 101(B3):5999-6019.

Walcott, R. (1978). Present tectonics and late Cenozoic evolution of New Zealand. Geophysical Journal International, 52(1):137-164.

Walcott, R. (1984). The kinematics of the plate boundary zone through New Zealand: a comparison of short-and long-term deformations. Geophysical Journal International, 79(2):613-633.

Walcott, R. (1998). Modes of oblique compression: Late Cenozoic tectonics of the South Island of New Zealand. Reviews of geophysics, 36(1):1-26.

Waldhauser, F. and Ellsworth, W. L. (2000). A double-difference earthquake location algorithm: Method and application to the northern Hayward fault, California. Bulletin of the Seismological Society of America, 90(6):1353-1368.

Wallace, L., Barnes, P., Beavan, J., Van Dissen, R., Litchfield, N., Mountjoy, J., Langridge, R., Lamarche, G., and Pondard, N. (2012). The kinematics of a transition from subduction to strike-slip: An example from the central New Zealand plate boundary. Journal of Geophysical Research: Solid Earth, 117(B2).

Wallace, L. M., Bartlow, N., Hamling, I., and Fry, B. (2014). Quake clamps down on slow slip. Geophysical Research Letters, 41(24):8840-8846.

Wallace, L. M. and Beavan, J. (2006). A large slow slip event on the central Hikurangi subduction interface beneath the Manawatu region, North Island, New Zealand. Geophysical Research Letters, 33(11).

Wallace, L. M. and Beavan, J. (2010). Diverse slow slip behavior at the Hikurangi subduction margin, New Zealand. Journal of Geophysical Research: Solid Earth, 115(B12).

Wallace, L. M., Beavan, J., McCaffrey, R., and Darby, D. (2004). Subduction zone coupling and tectonic block rotations in the North Island, New Zealand. Journal of Geophysical Research: Solid Earth, 109(B12).

Wallace, L. M. and Eberhart-Phillips, D. (2013). Newly observed, deep slow slip events at the central Hikurangi margin, New Zealand: Implications for downdip variability of slow slip and tremor, and relationship to seismic structure. Geophysical Research Letters, 40(20):5393-5398.

Wallace, L. M., Kaneko, Y., Hreinsdóttir, S., Hamling, I., Peng, Z., Bartlow, N., DAnastasio, E., and Fry, B. (2017). Large-scale dynamic triggering of shallow slow slip enhanced by overlying sedimentary wedge. Nature Geoscience, 10(10):765. 
Wallace, L. M., Reyners, M., Cochran, U., Bannister, S., Barnes, P. M., Berryman, K., Downes, G., Eberhart-Phillips, D., Fagereng, A., Ellis, S., et al. (2009). Characterizing the seismogenic zone of a major plate boundary subduction thrust: Hikurangi Margin, New Zealand. Geochemistry, Geophysics, Geosystems, 10(10).

Wallace, L. M., Webb, S. C., Ito, Y., Mochizuki, K., Hino, R., Henrys, S., Schwartz, S. Y., and Sheehan, A. F. (2016). Slow slip near the trench at the Hikurangi subduction zone, New Zealand. Science, 352(6286):701-704.

Walsh, D., Arnold, R., and Townend, J. (2009). A Bayesian approach to determining and parametrizing earthquake focal mechanisms. Geophysical Journal International, 176(1):235-255.

Walsh, E., Arnold, R., and Savage, M. (2013). Silver and Chan revisited. Journal of Geophysical Research: Solid Earth, 118(10):5500-5515.

Watts, A. B. (2001). Isostasy and Flexure of the Lithosphere. Cambridge University Press.

Webb, T. H. and Anderson, H. (1998). Focal mechanisms of large earthquakes in the North Island of New Zealand: slip partitioning at an oblique active margin. Geophysical journal international, 134(1):40-86.

Wessel, A., Savage, M., Teanby, N., et al. (2010). Manual for the Multiple Filter Automatic Splitting Technique (MFAST) processing codes, Version 2.0.

Williams, C. A., Eberhart-Phillips, D., Bannister, S., Barker, D. H., Henrys, S., Reyners, M., and Sutherland, R. (2013). Revised interface geometry for the Hikurangi subduction zone, New Zealand. Seismological Research Letters, 84(6):1066-1073.

Wilson, C. K., Jones, C. H., Molnar, P., Sheehan, A. F., and Boyd, O. S. (2004). Distributed deformation in the lower crust and upper mantle beneath a continental strike-slip fault zone: Marlborough fault system, South Island, New Zealand. Geology, 32(10):837-840.

Wilson, T. (2016). Seismic Anisotropy at the Hikurangi Subduction Margin.

Xu, W., Feng, G., Meng, L., Zhang, A., Ampuero, J. P., Bürgmann, R., and Fang, L. (2018). Transpressional Rupture Cascade of the 2016 Mw 7.8 Kaikoura Earthquake, New Zealand. Journal of Geophysical Research: Solid Earth.

Yamasaki, T. and Seno, T. (2003). Double seismic zone and dehydration embrittlement of the subducting slab. Journal of Geophysical Research: Solid Earth, 108(B4).

Zhang, H., Liu, Y., Thurber, C., and Roecker, S. (2007). Three-dimensional shear-wave splitting tomography in the Parkfield, California, region. Geophysical Research Letters, $34(24)$. 
Zhang, H., Thurber, C. H., Shelly, D., Ide, S., Beroza, G. C., and Hasegawa, A. (2004). High-resolution subducting-slab structure beneath northern Honshu, Japan, revealed by double-difference tomography. Geology, 32(4):361-364.

Zheng, A., Wang, M., Yu, X., and Zhang, W. (2017). Source rupture process of the 2016 Kaikoura, New Zealand earthquake estimated from the kinematic waveform inversion of strong-motion data. Geophysical Journal International, 212(3):1736-1746.

Zinke, J. C. and Zoback, M. D. (2000). Structure-related and stress-induced shear-wave velocity anisotropy: observations from microearthquakes near the Calaveras Fault in Central California. Bulletin of the Seismological Society of America, 90(5):1305-1312.

Zoback, M. L. (1992). First-and second-order patterns of stress in the lithosphere: The World Stress Map Project. Journal of Geophysical Research: Solid Earth, 97(B8):1170311728. 


\section{Chapter 8}

\section{Appendix A: Stress Orientations Throughout the Southern Hikurangi Margin}

This chapter provides appendix material for Chapter 3: Stress Orientations Throughout the Southern Hikurangi Margin. Description of Content: The following includes figures of location and split of earthquakes used to determine the location of probable anisotropy, an enlarged version of a smaller figure in the paper that allows a more detailed looked of the splitting results presented in the paper, a second cluster scheme and the resulting stress inversions (with an associated table), a table of focal mechanism parameters and tables of stress inversion results associated with the three clusters of inverted focal mechanisms. 

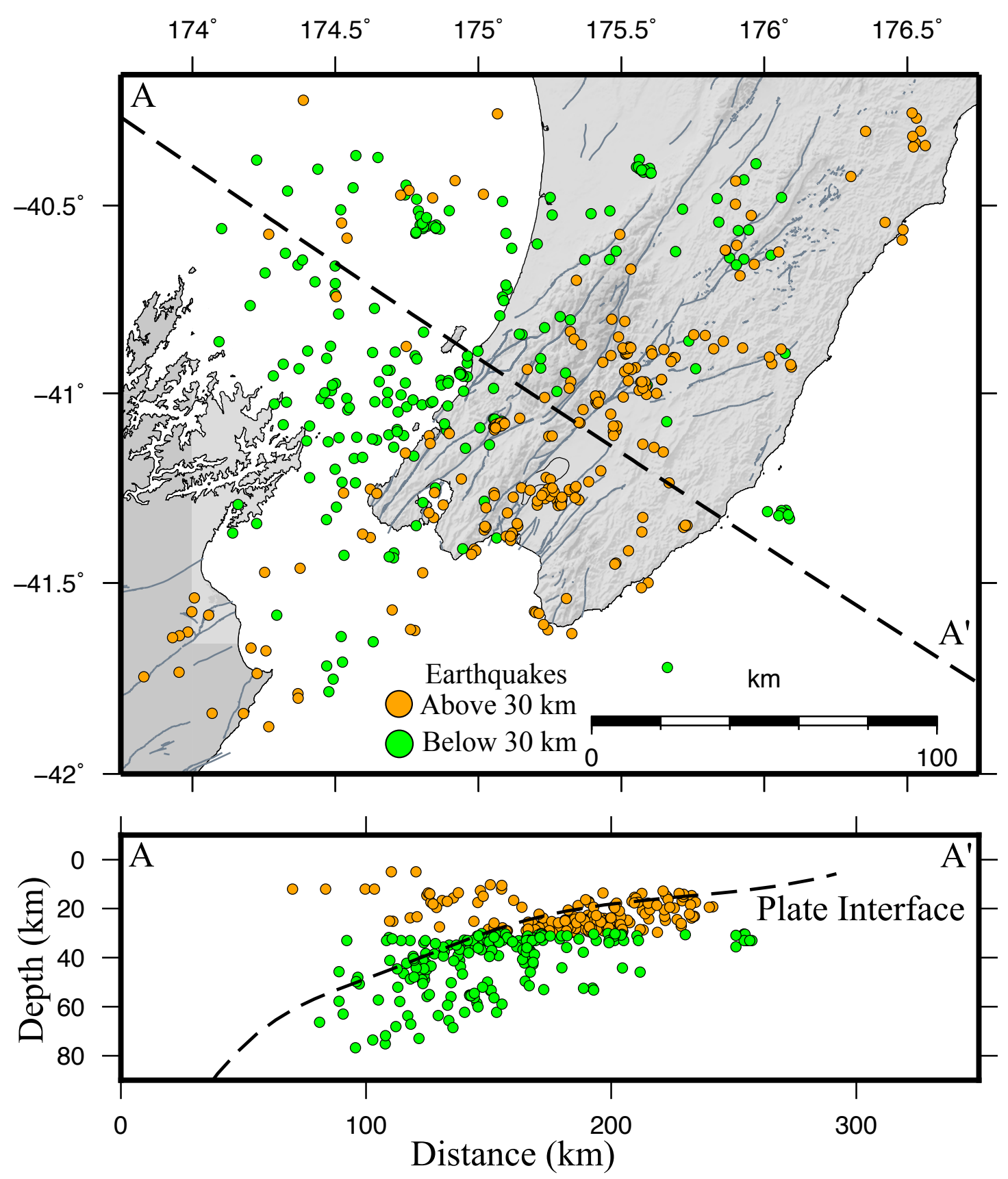

Figure 8.1: Locations of earthquakes, above (orange) and below (green) 30 $\mathrm{km}$, used to calculate fast directions. Bold grey lines show traces of active faults and topography on grey scale. A to A shows orientation of cross sectional map. Cross-section: Cross sectional map from A to A, showing depth of earthquakes. Plate interface (black dashed line) calculated projected from Williams et al. (2013). 


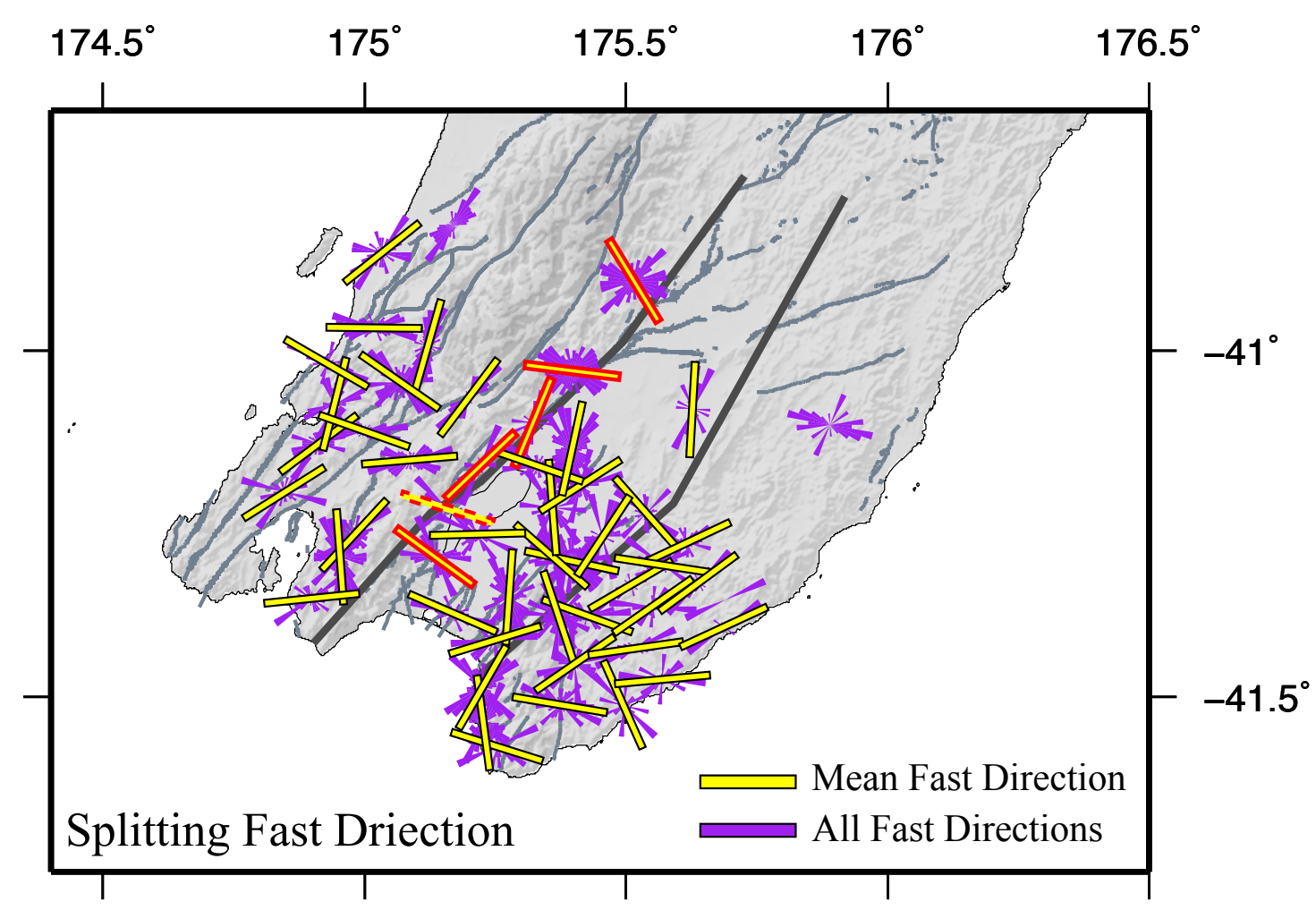

Figure 8.2: Enlarged version of Figure 3B. All (purple) and mean (yellow) fast direction measurements from earthquakes of all depths. Results show clear variation in splitting in the Western, Central Basin, and Eastern regions. Station S022 (highlighted dashed-red) is located near the Wairarapa fault. This station showed significant fast direction measurements parallel and perpendicular to the Wairarapa Fault. This effect is not present at other stations (S021, S023, LTN6, S039, HOWZ) (highlighted red). 

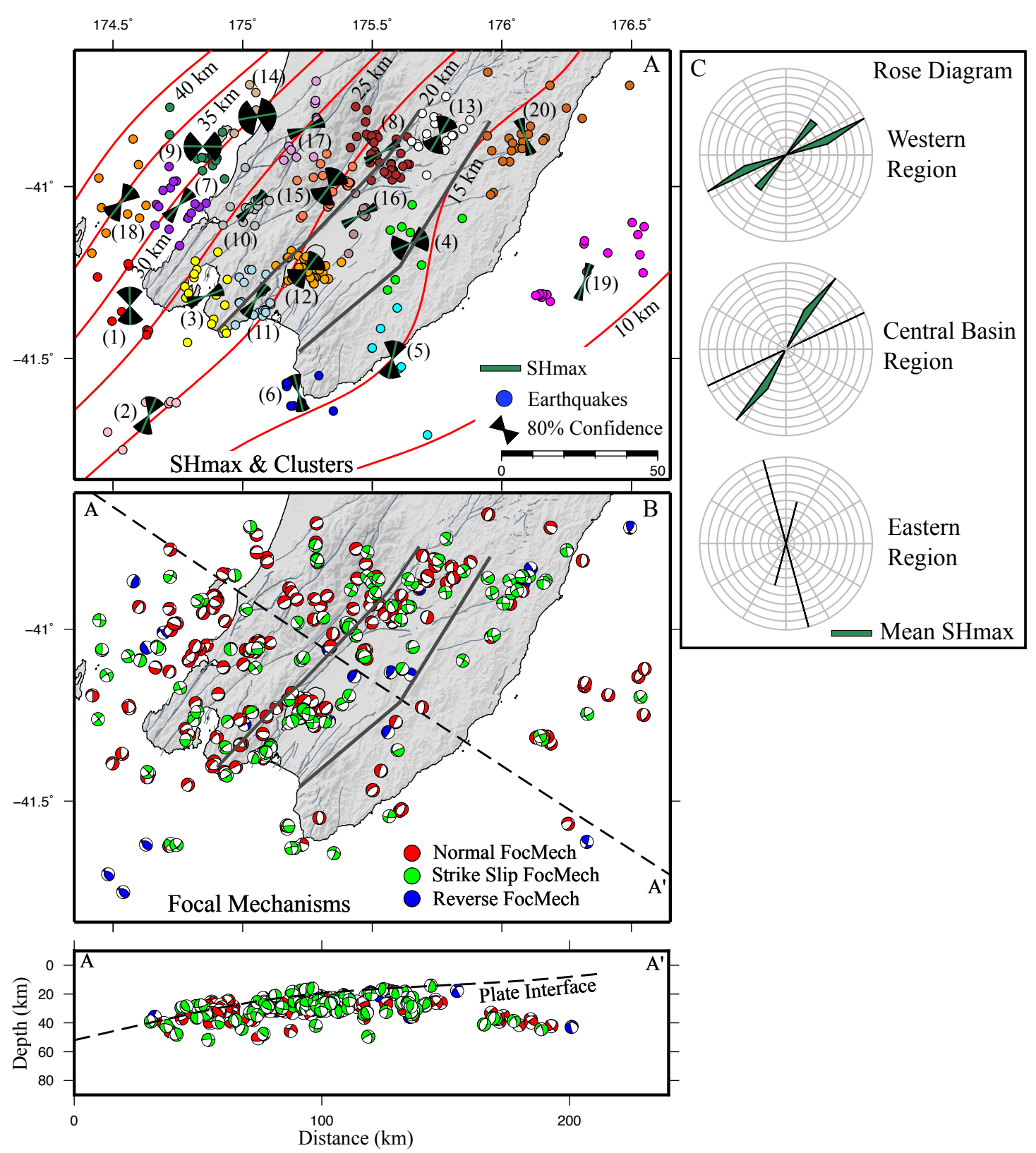

Figure 8.3: Map of Bayesian calculated focal mechanisms and clusters of focal mechanisms, calculated using the K-means algorithm, used to calculate stress parameters. Red contours and grey faults are as in Figure 1. (A): SHmax (green) and $80 \%$ confidence intervals (black wedges), and associated clusters of focal mechanisms. Numbers next to cluster indicate cluster number. (B): Focal mechanisms calculated using a Bayesian method from Walsh et al. (2009). Focal mechanism are colored by rake: $-150^{\circ}<$ Normal (red) $<-30^{\circ} ; 30^{\circ}<$ Reverse (blue) $<150^{\circ} ; 30^{\circ}>$ Strike-Slip (green) $>-30^{\circ} ; 150^{\circ}<$ Strike-Slip (purple) $<-150^{\circ}$. In total 314 focal mechanisms were calculated (181 normal, 30 reverse, and 103 strike-slip). Dashed A to A line indicates strike of cross-section map. Cross-section: Cross sectional map of focal mechanism with depth from A to A. Dashed line (black) location is projected view of plate interface contours. (C) Rose diagram of average SHmax orientations in the three regions. 
0.31

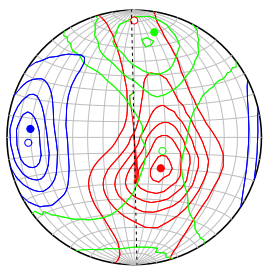

Red (1): 8

0.66

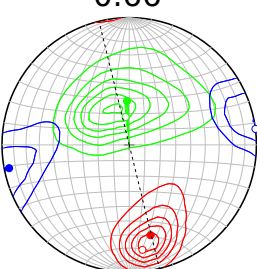

Blue (6): 9
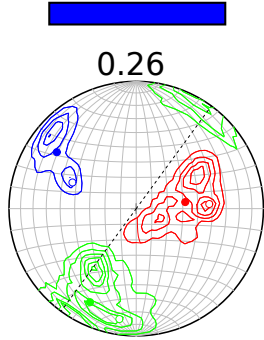

Light Blue (11): 20

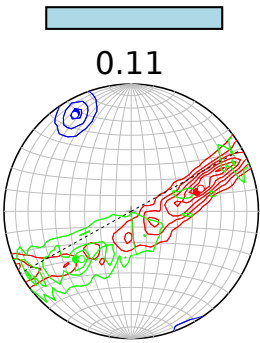

Rosy Brown (16): 9

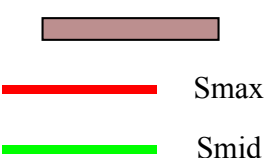

0.58

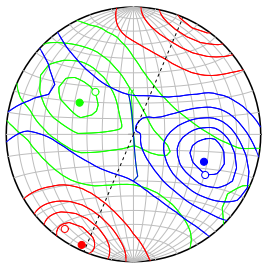

Pink (2): 6

0.49

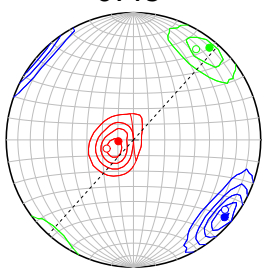

Purple (7): 15

0.87

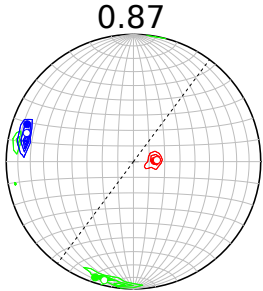

Orange (12): 40

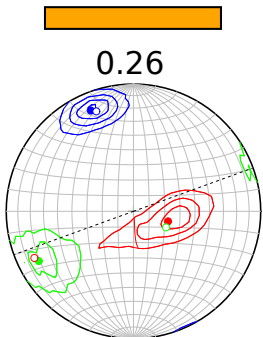

Plum (17): 11
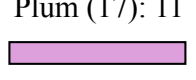

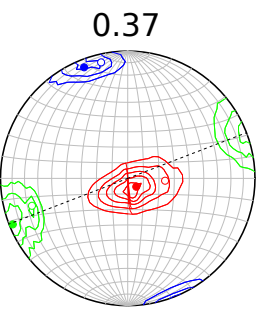

Yellow (3): 16

0.28

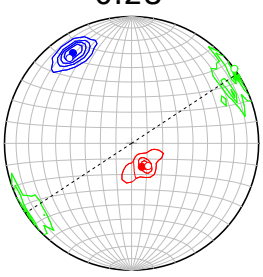

Brown (8): 35

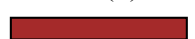

0.69

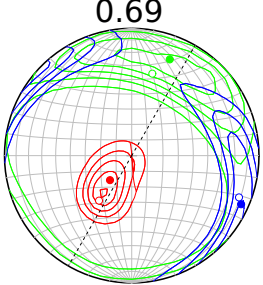

White (13): 17

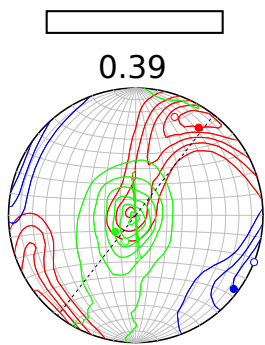

Dark Orange (18): 9

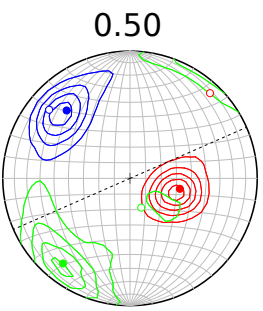

Green (4): 8

0.79

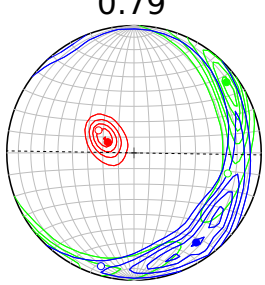

Sea Green (9): 17

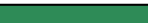

0.73

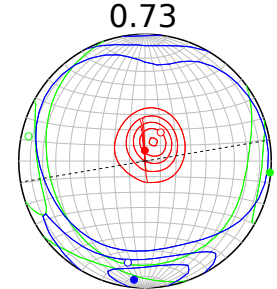

Tan (14): 6

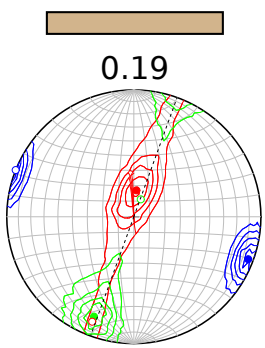

Magenta (19): 17

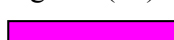

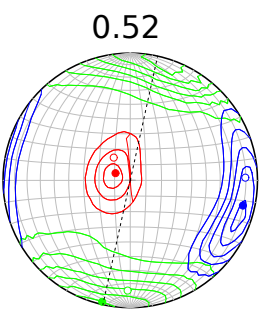

Cyan (5): 8

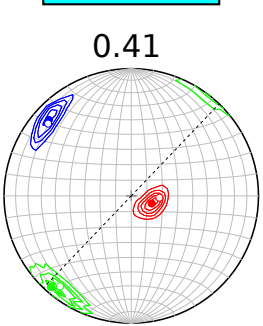

Grey (10): 25
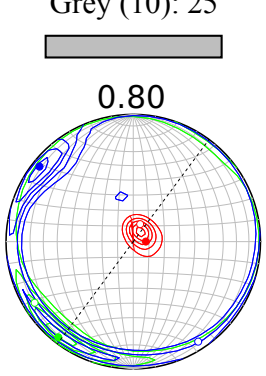

Coral (15): 17

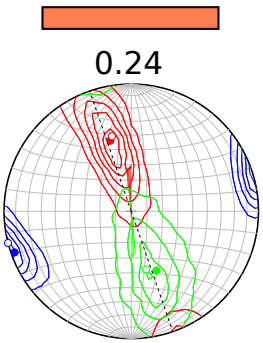

Chocolate (20): 21

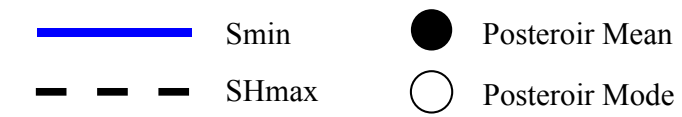

Figure 8.4: 20 stress regimes from the 20 clusters of focal mechanisms, shown as stereonets displaying the distribution of S1 (red), S2 (green), and S3 (blue) axes, as well as the orientation of SHmax axes (black dashed lines). The posterior mean (solid circle) and mode (open circle) are colored as per stress axis. The corresponding cluster color and number is printed below its stereonet. For locations of clusters see similar colored clusters in Figure S3. Number above stereonet indicates the stress ratio. Number following : indicates the number of focal mechanisms used in the stress inversion of the cluster. 


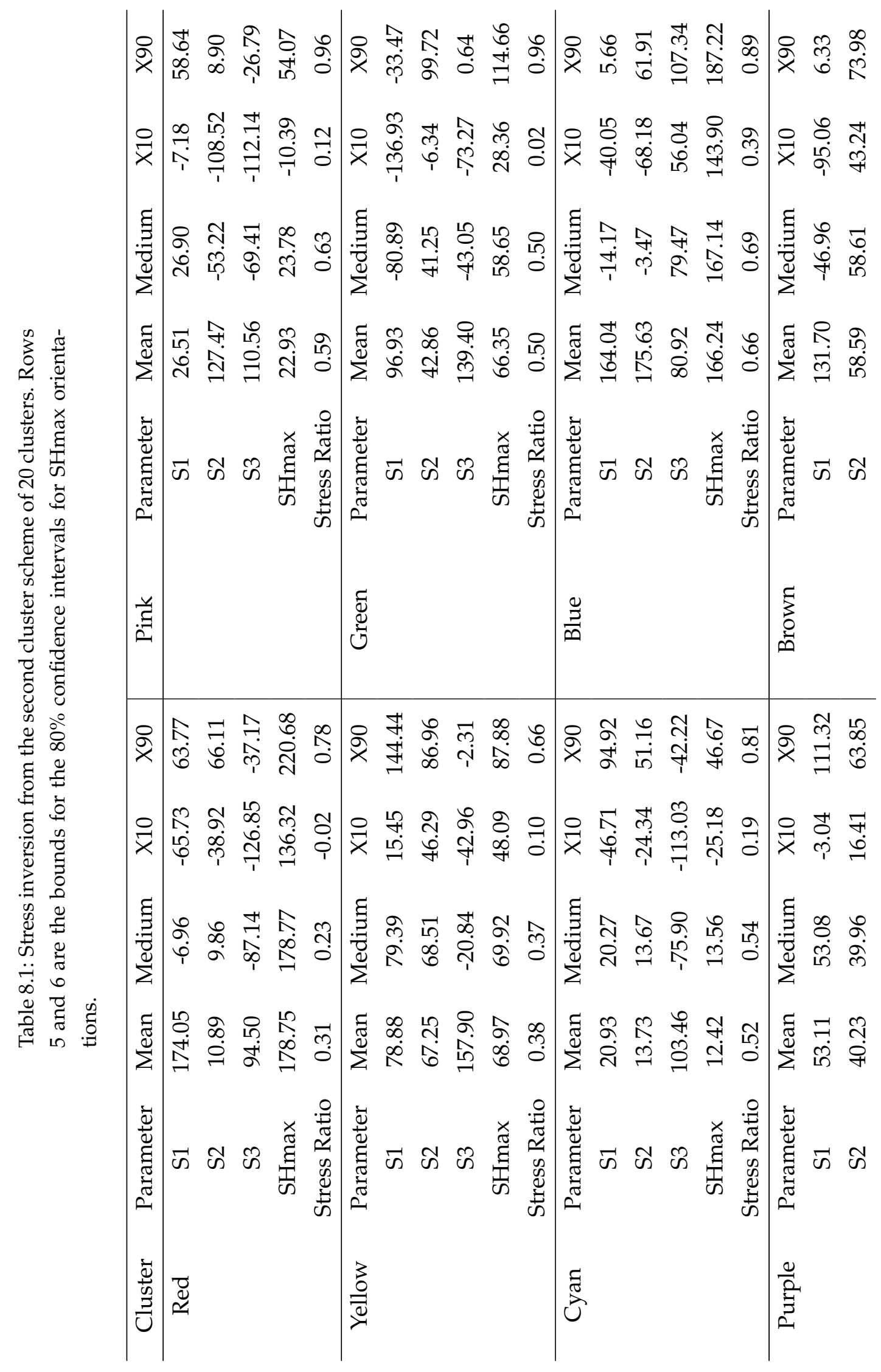




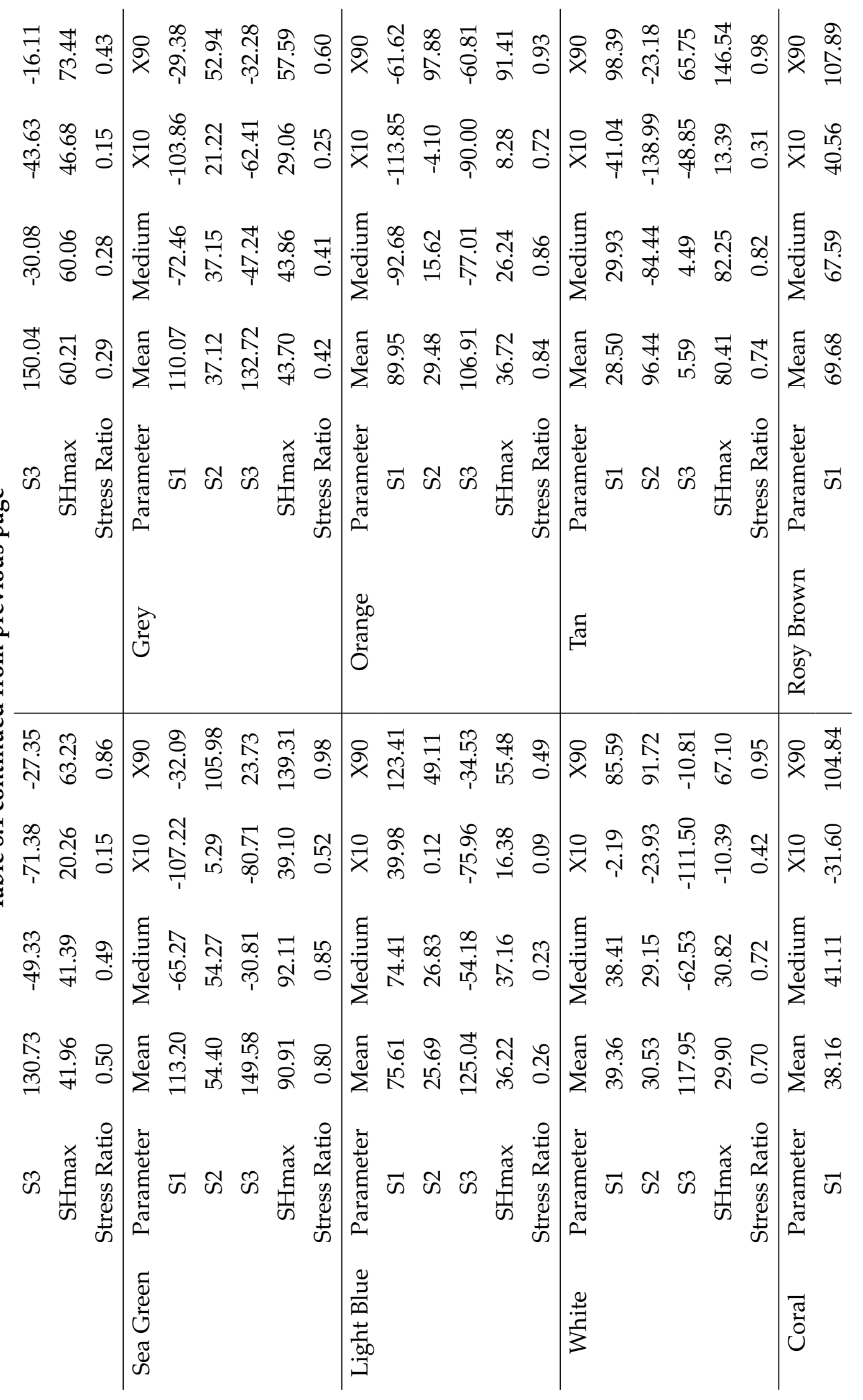




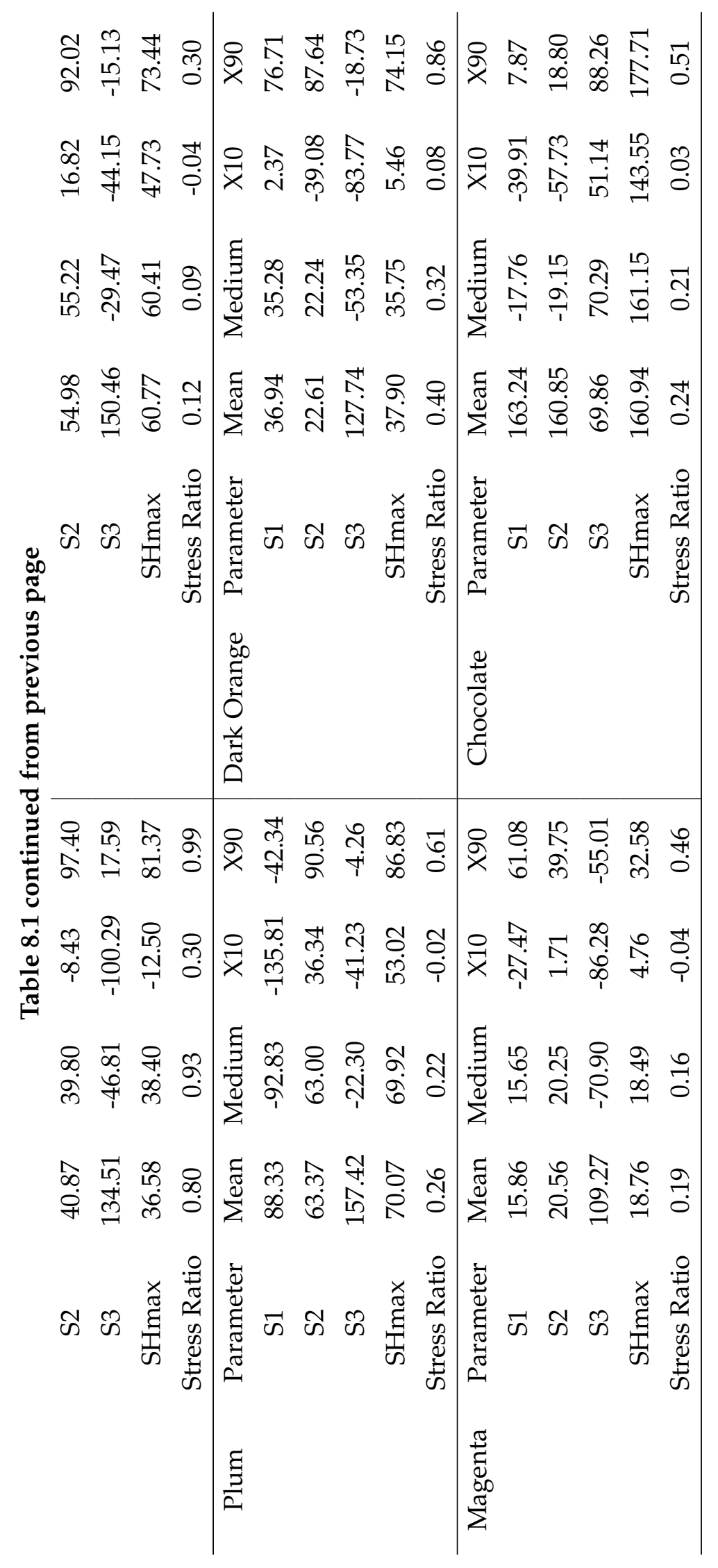




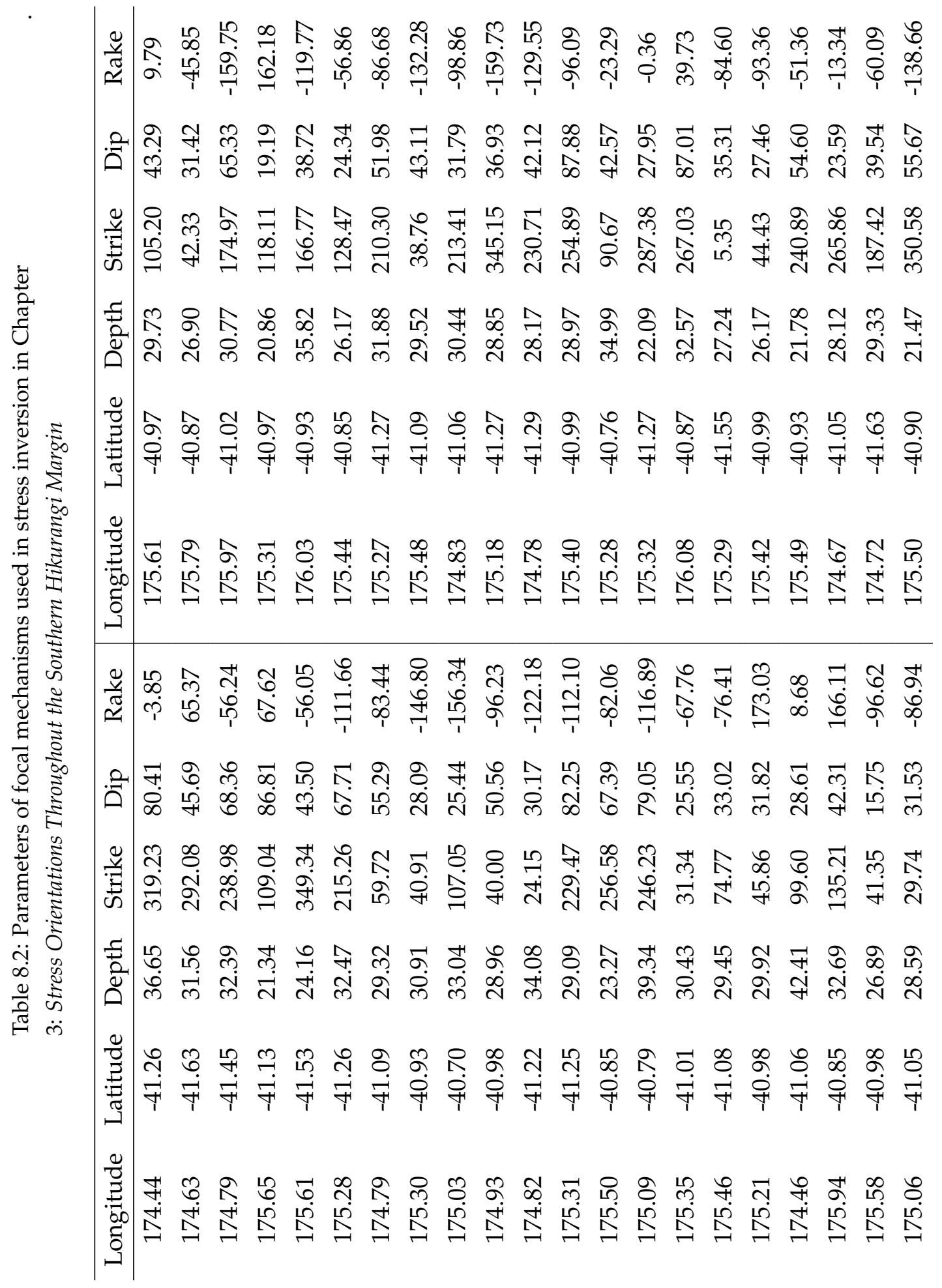




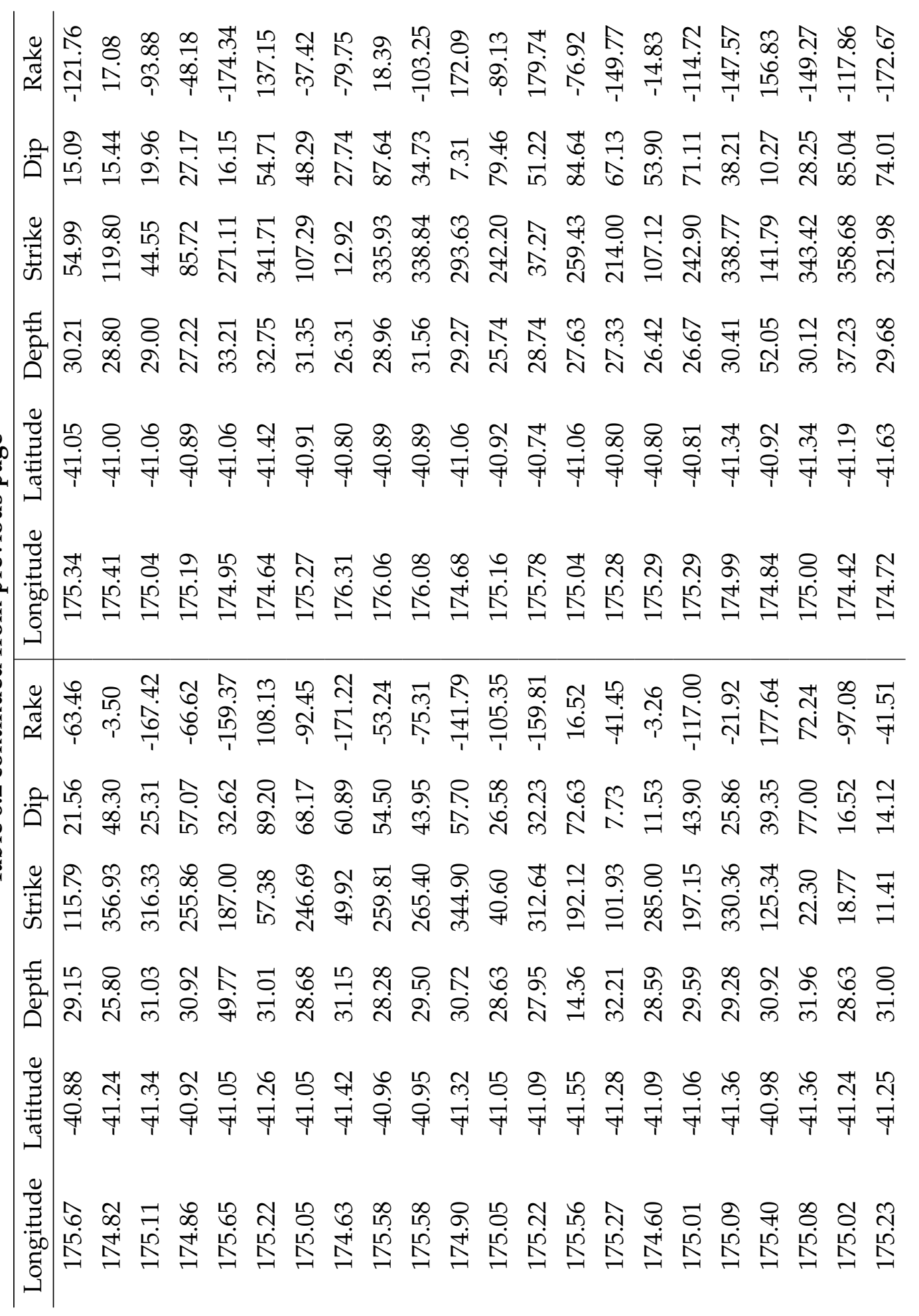




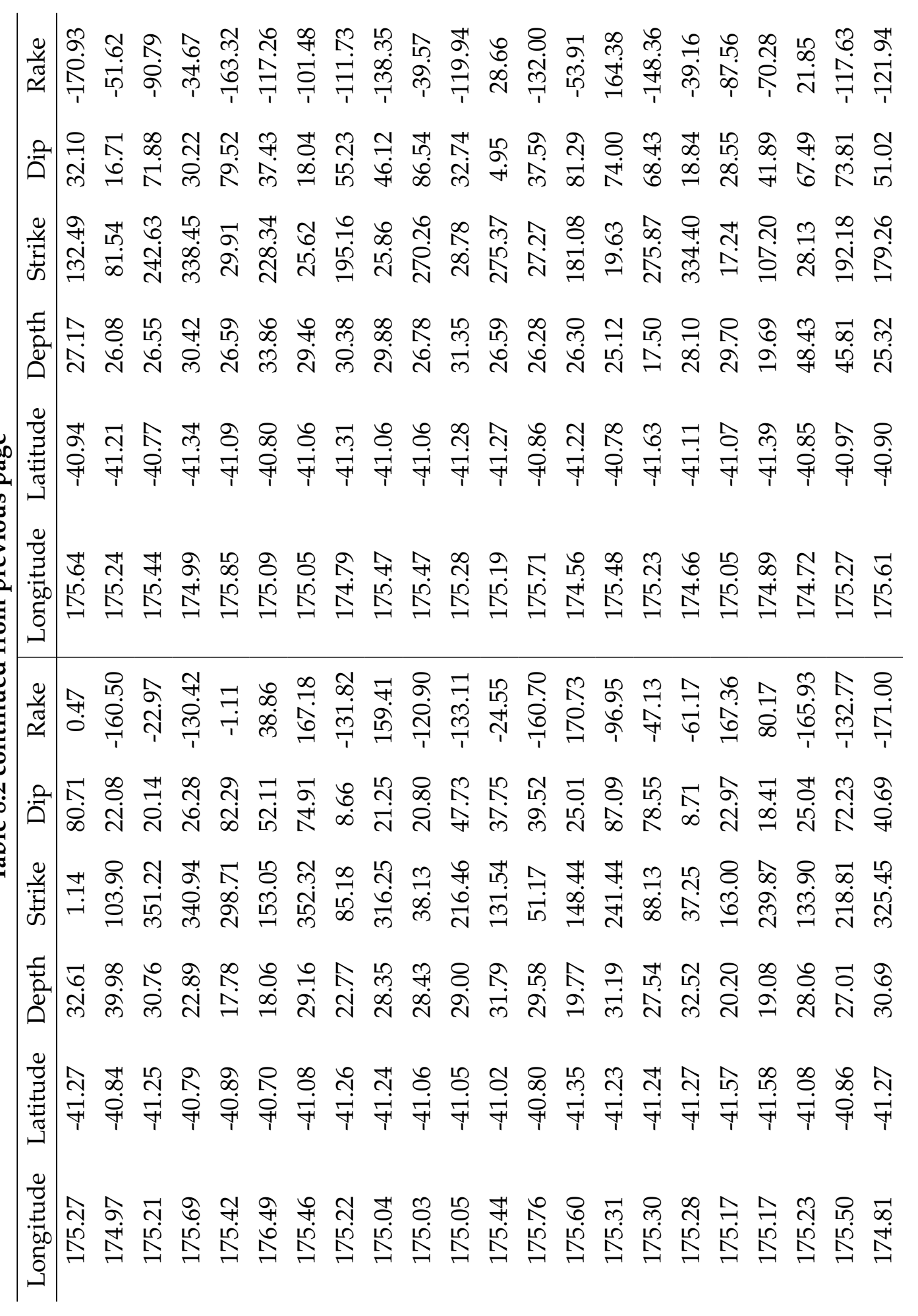




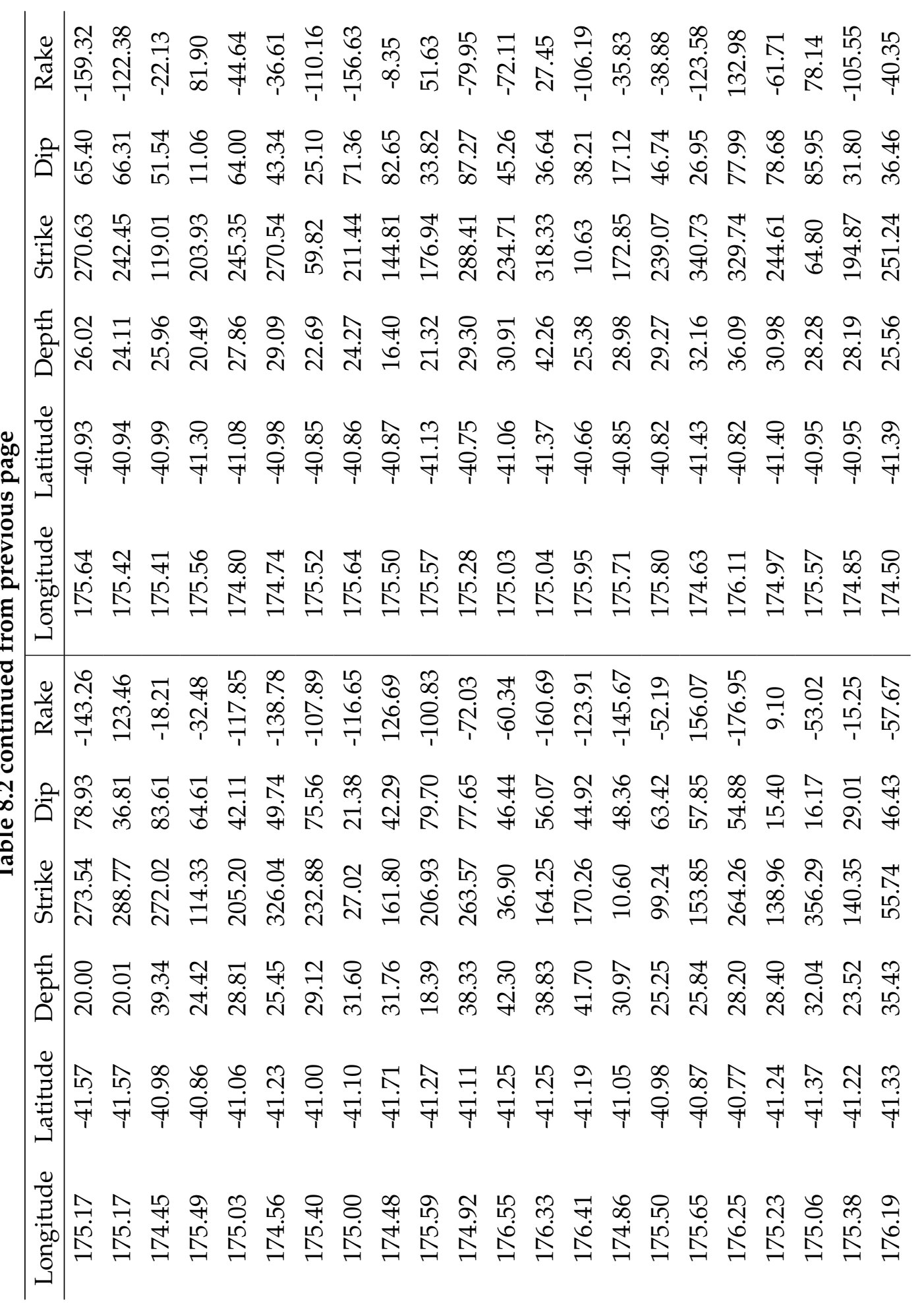




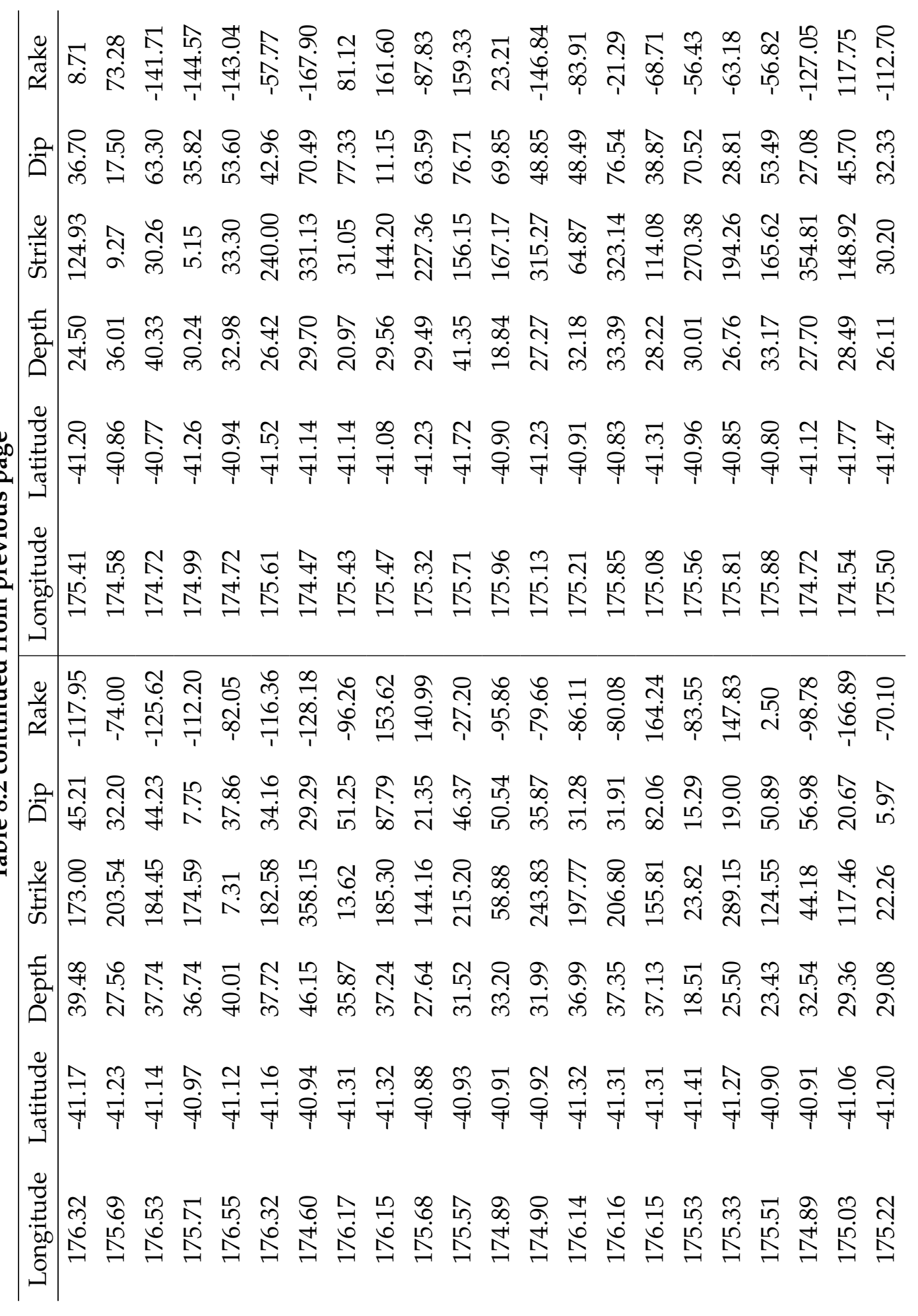




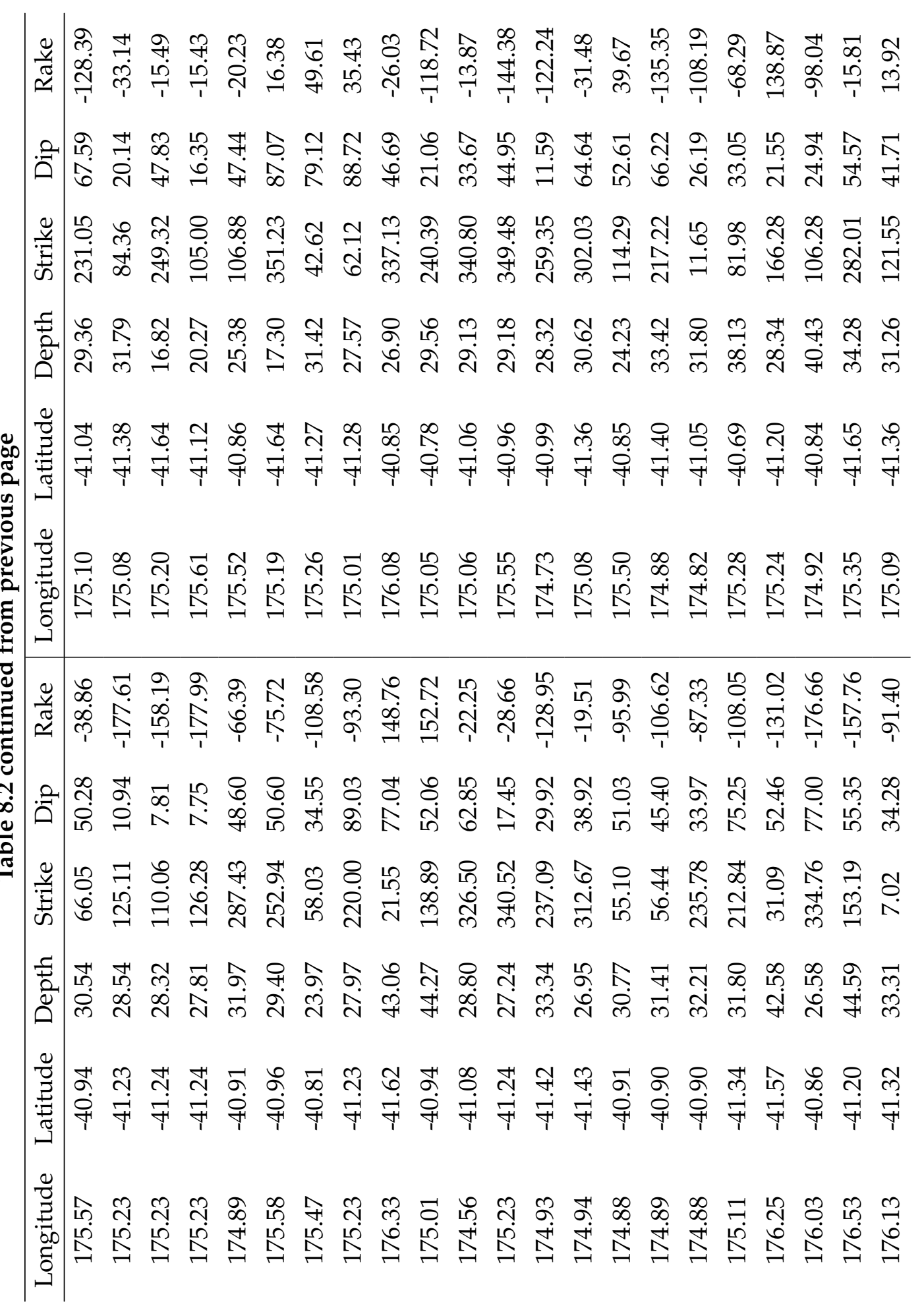




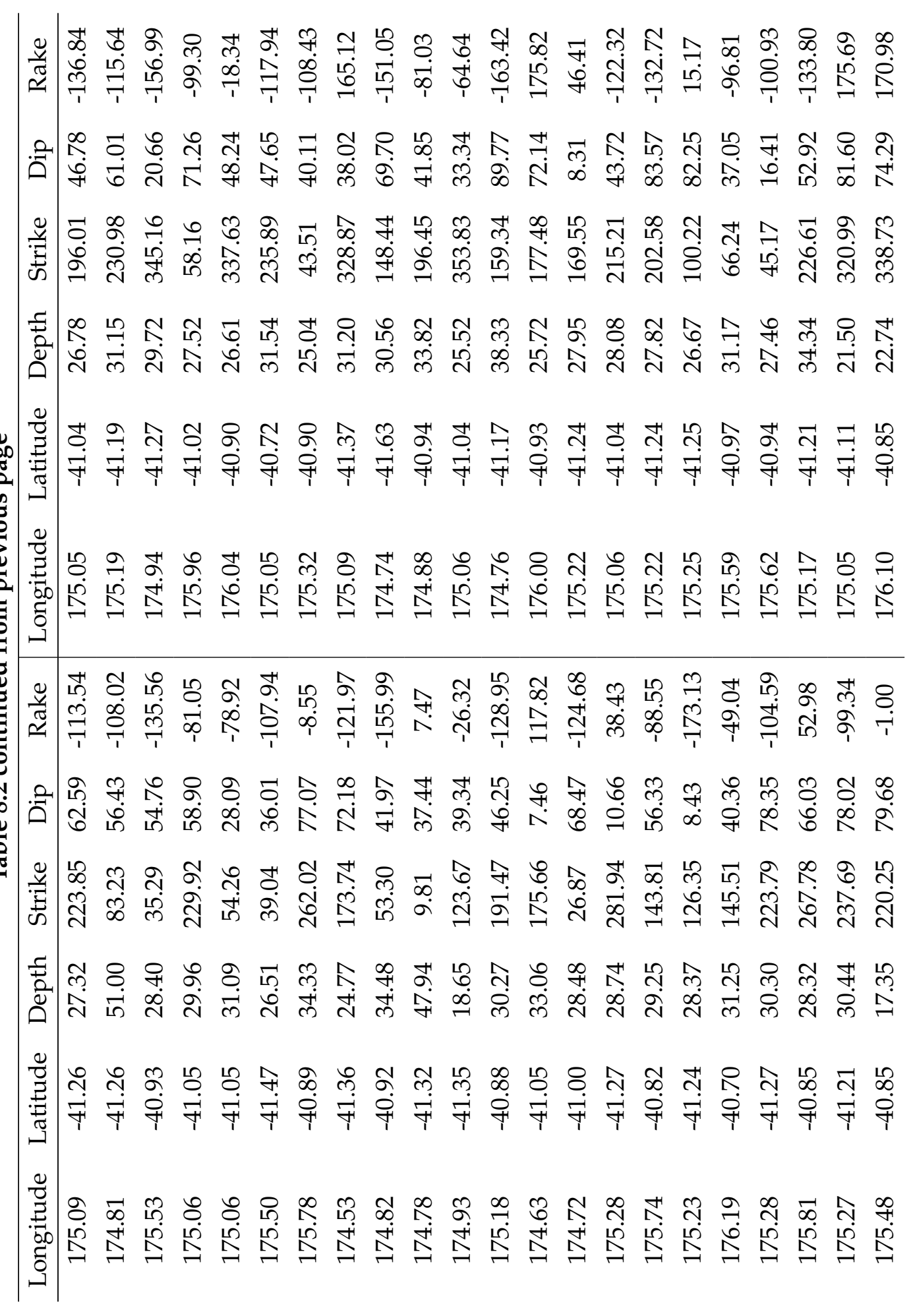




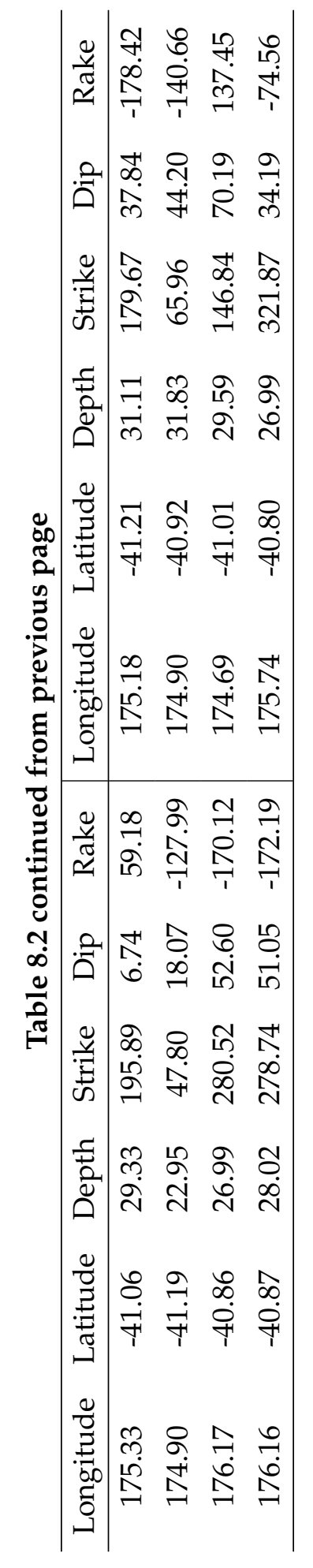


Table 8.3: Results of stress inversion for the Western Region of the study region. Mean and Medium values calculated using the Bayesian method. X2.5 and X97.5 indicate the $95 \%$ confidence interval bounds. Map indicated parameters calculated using the Map method, embedded in the Bayesian program (for comparisons only).

\begin{tabular}{cccccc}
\hline Parameter & Mean & Map & Median & X2.5 & X97.5 \\
\hline S1 & 137.62 & 141.92 & -41.85 & -97.35 & 14.77 \\
S2 & 51.38 & 51.92 & 51.44 & 33.45 & 68.96 \\
S3 & 143.29 & 141.92 & -36.63 & -52.55 & -21.35 \\
SHmax & 53.13 & 54.00 & 53.01 & 36.11 & 69.56 \\
Nu & 0.37 & 0.40 & 0.38 & 0.26 & 0.51 \\
\hline
\end{tabular}

Table 8.4: Results of stress inversion for the Central Basin Region of the study region. Mean and Medium values calculated using the Bayesian method. X2.5 and X97.5 indicate the $95 \%$ confidence interval bounds. Map indicated parameters calculated using the Map method, embedded in the Bayesian program (for comparisons only).

\begin{tabular}{cccccc}
\hline Parameter & Mean & Map & Median & X2.5 & X97.5 \\
\hline S1 & 72.57 & 72.69 & 71.56 & 35.87 & 120.54 \\
S2 & 36.89 & 34.62 & 36.23 & 20.47 & 59.69 \\
S3 & 124.03 & 121.15 & -56.61 & -73.15 & -33.47 \\
SHmax & 36.51 & 37.33 & 36.11 & 19.91 & 53.36 \\
Nu & 0.61 & 0.60 & 0.60 & 0.46 & 0.74 \\
\hline
\end{tabular}

Table 8.5: Results of stress inversion for the Eastern Region of the study region. Mean and Medium values calculated using the Bayesian method. X2.5 and X97.5 indicate the $95 \%$ confidence interval bounds. Map indicated parameters calculated using the Map method, embedded in the Bayesian program (for comparisons only).

\begin{tabular}{cccccc}
\hline Parameter & Mean & Map & Median & X2.5 & X97.5 \\
\hline S1 & 146.36 & 148.85 & -32.61 & -74.40 & 1.70 \\
S2 & 168.57 & 169.62 & -11.47 & -52.49 & 28.99 \\
S3 & 71.64 & 72.69 & 71.96 & 39.13 & 101.97 \\
SHmax & 158.18 & 156.59 & 158.34 & 127.69 & 186.51 \\
Nu & 0.53 & 0.50 & 0.53 & 0.25 & 0.81 \\
\hline
\end{tabular}




\section{Chapter 9}

\section{Appendix B: Illumination of Deformation by Bending Stresses within the Southern Hikurangi Double Benioff Zone}

This chapter provides appendix material for Chapter 4: Stress Orientations in a Double Benioff Zone. Description of Content: The following includes a table of focal mechanism parameters and tables of stress inversion parameter results associated with the three clusters of inverted focal mechanisms. Figures showing the difference between this study's region of interest and the study region of McGinty et al. (2000) and comparison of of the radius of curvature of the subducting Pacific plate at the southern North Island and the northern South Island. The three additional stress inversions (and parameters) of the clusters of focal mechanisms, regardless of number of polarity picks. 
Table 9.1: Earthquake magnitude distribution. No magnitudes were calculated during this study, earthquake magnitude calculated by GeoNet.

\begin{tabular}{c|c} 
Magnitude & \# of Earthquakes \\
\hline$<1.50$ & 01 \\
$1.50-1.75$ & 15 \\
$1.75-2.00$ & 69 \\
$2.00-2.25$ & 179 \\
$2.25-2.50$ & 186 \\
$2.50-2.75$ & 112 \\
$2.75-3.00$ & 56 \\
$3.00-3.25$ & 28 \\
$3.25-3.50$ & 11 \\
$3.50-3.75$ & 12 \\
$3.75-4.00$ & 03 \\
$4.00-4.25$ & 04 \\
$4.25-4.50$ & 03 \\
$4.50-4.75$ & 01 \\
$>4.75$ & 00 \\
\hline
\end{tabular}




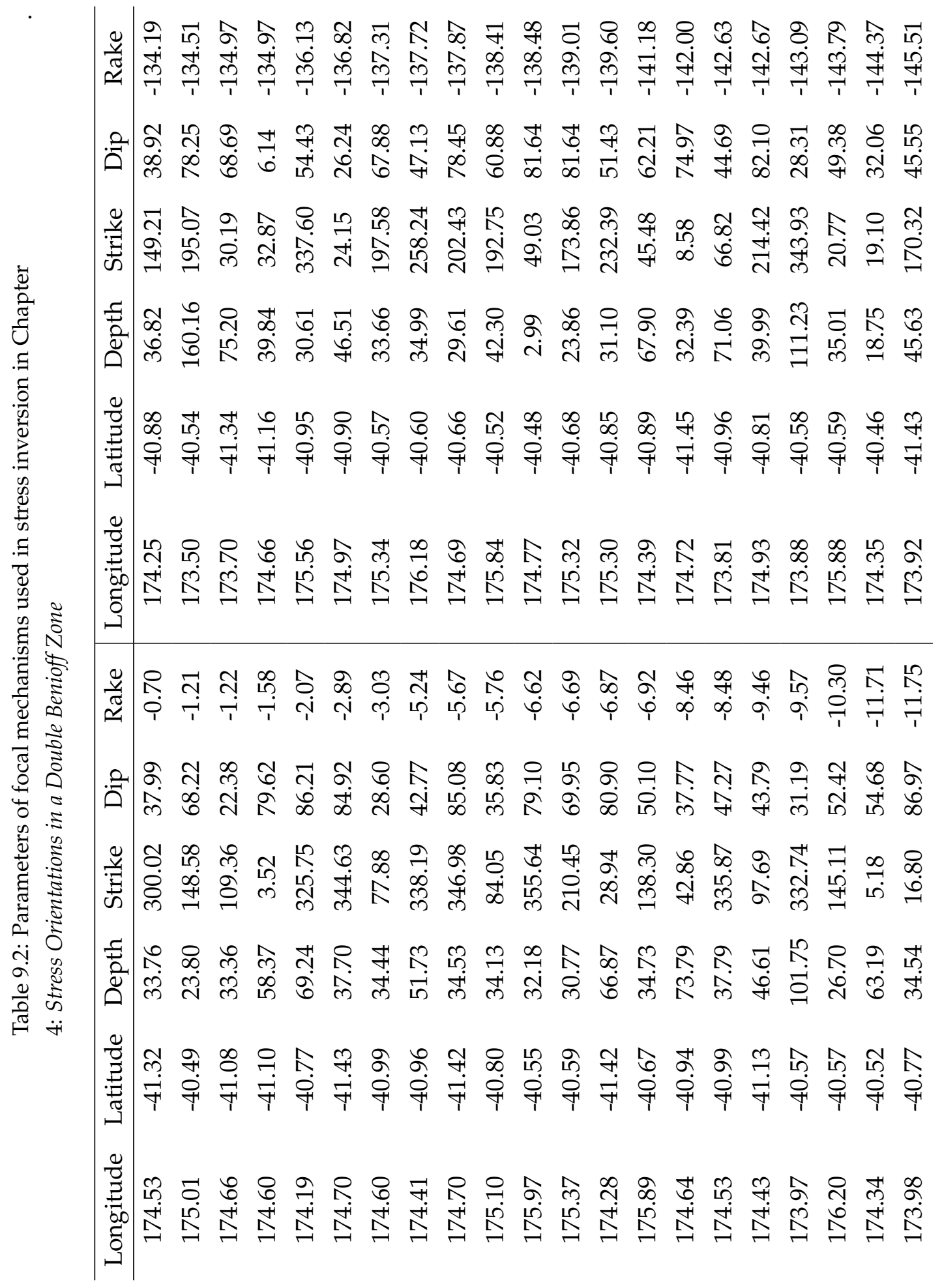




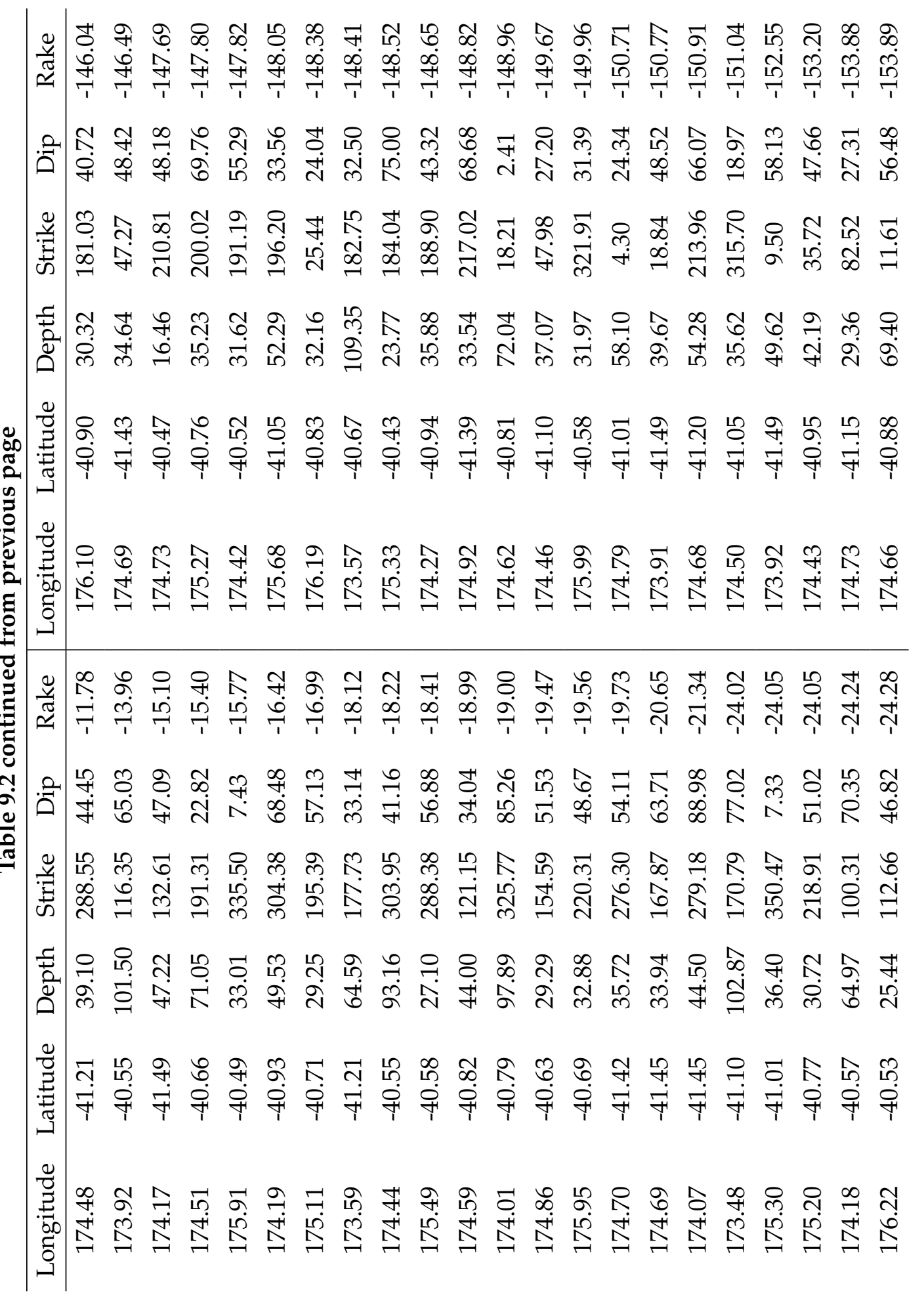




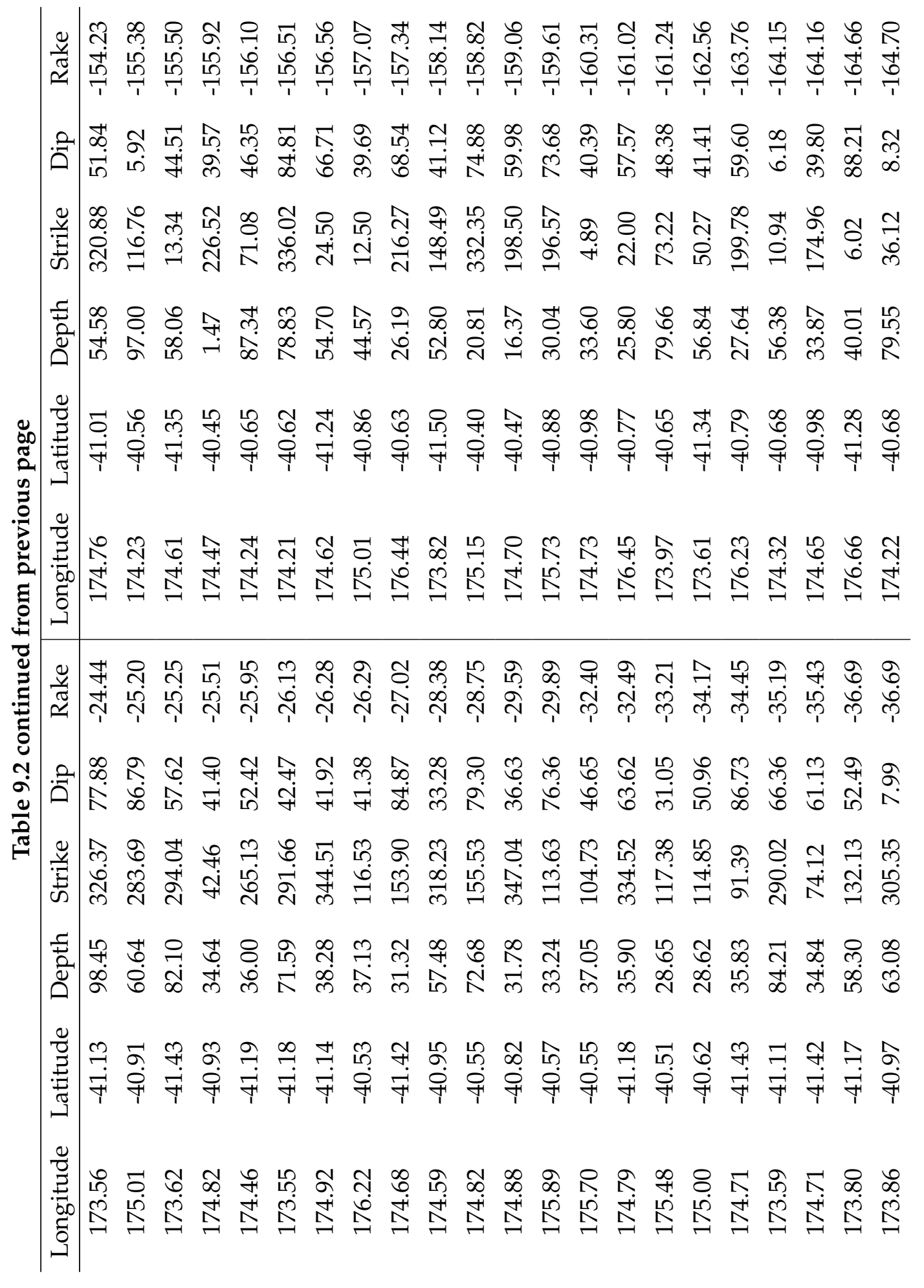


ఖ

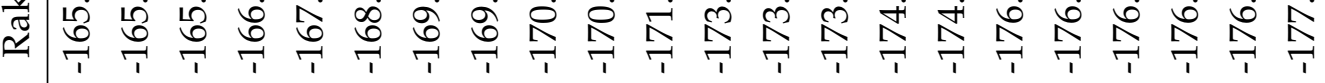

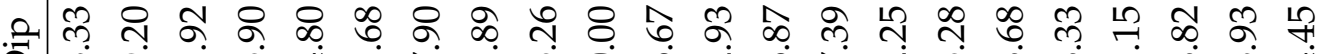

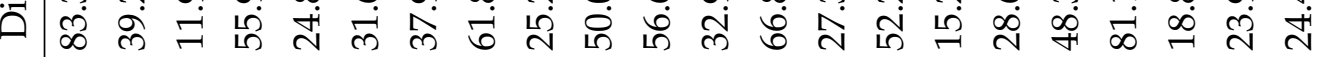

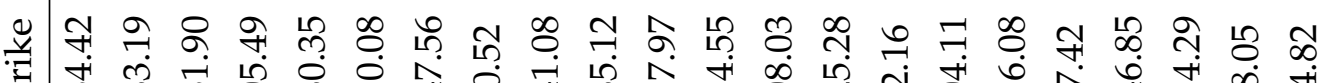

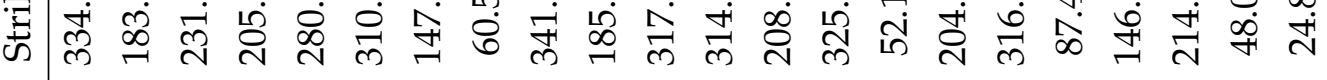

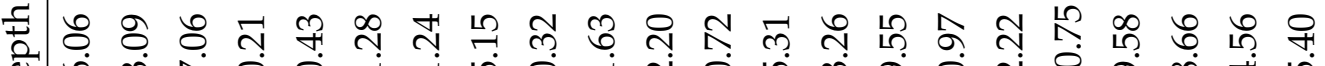

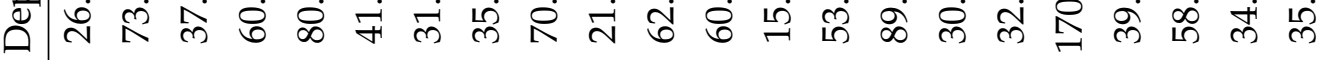

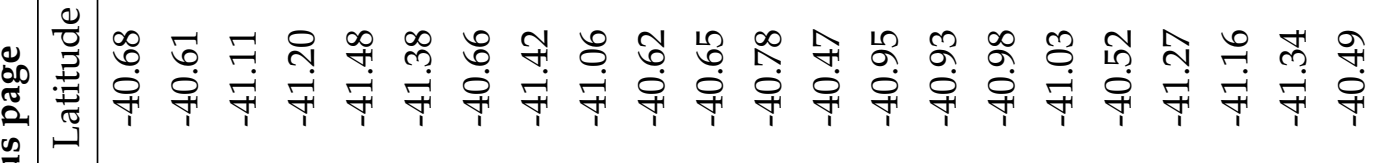

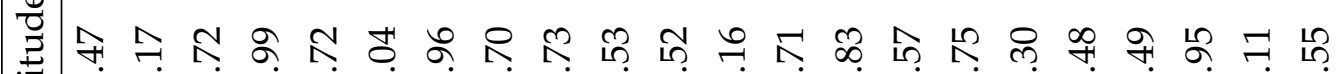
:

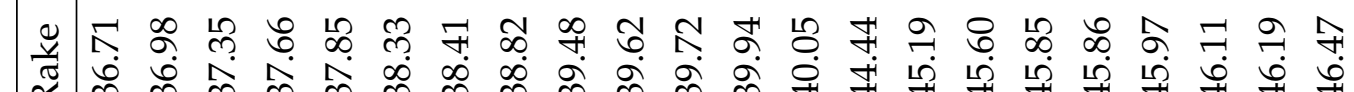
بิ

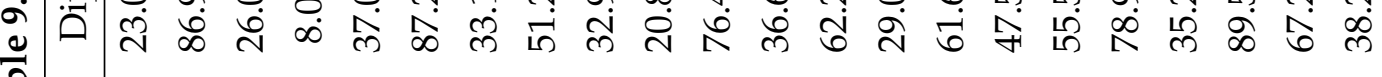
๘

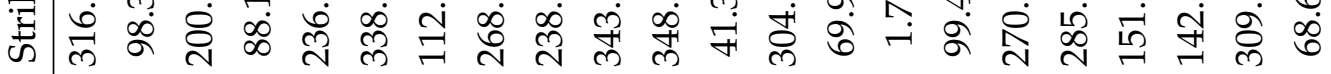

ㄷำ ดัँ

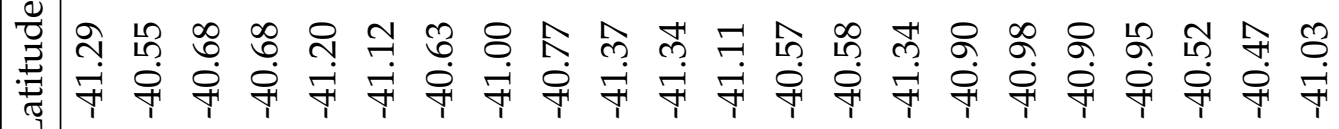

馬

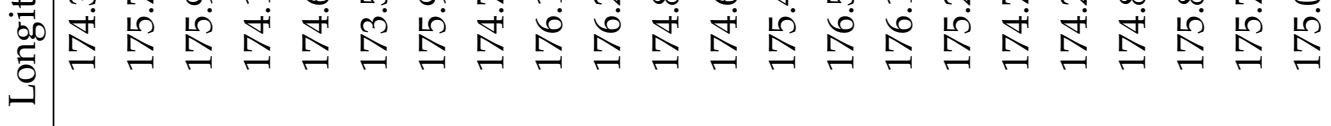




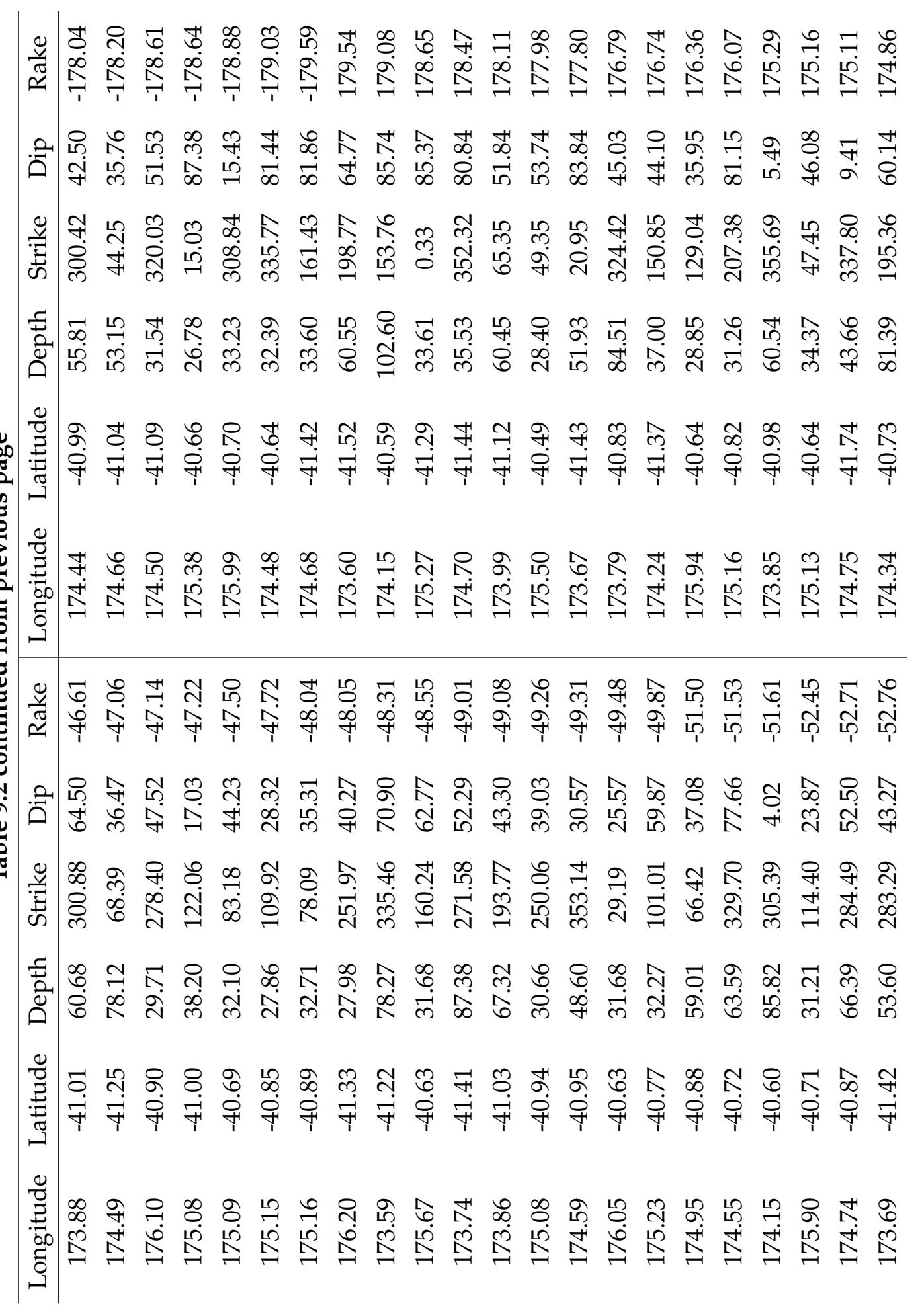




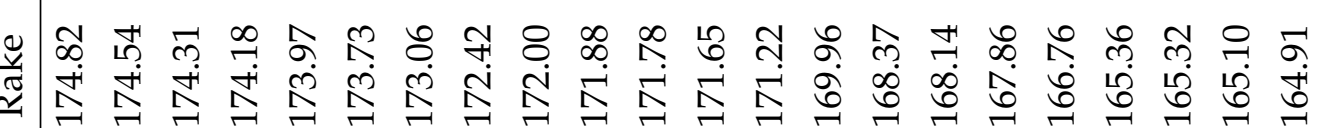

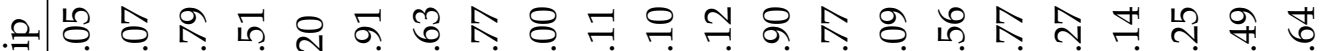

ดि

ఝ

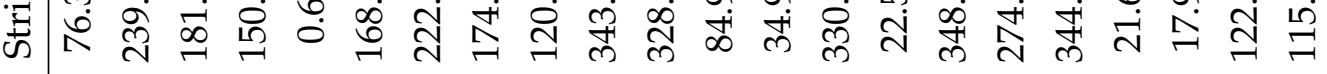

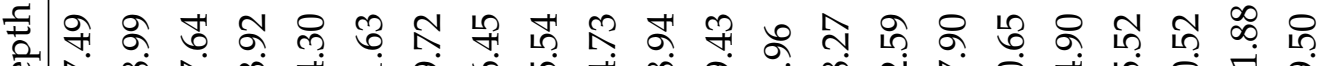
众 手

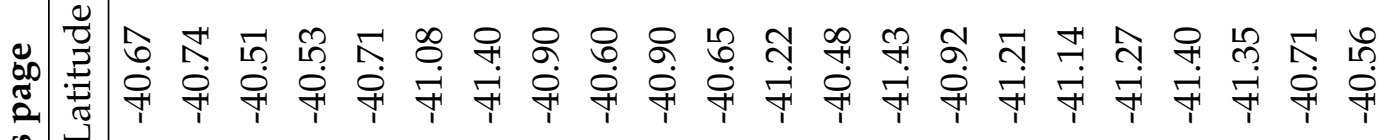

ఫँ

:

幽 ॠ

ㅂ.

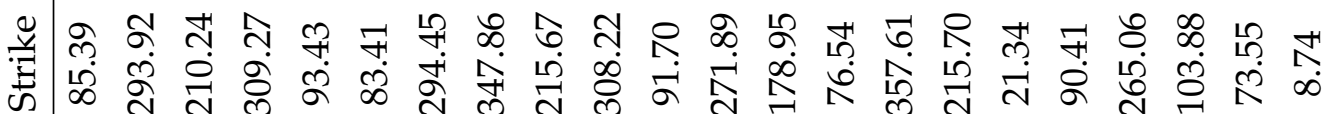

节

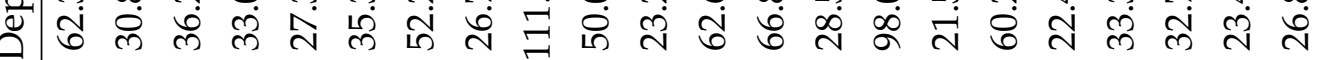

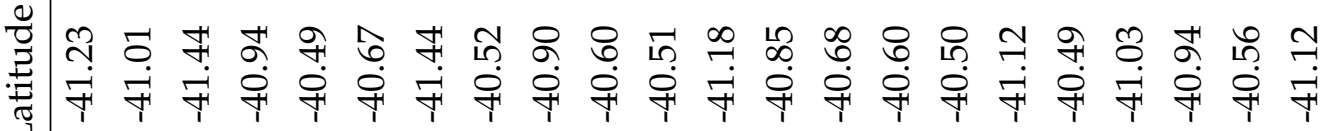

苟在

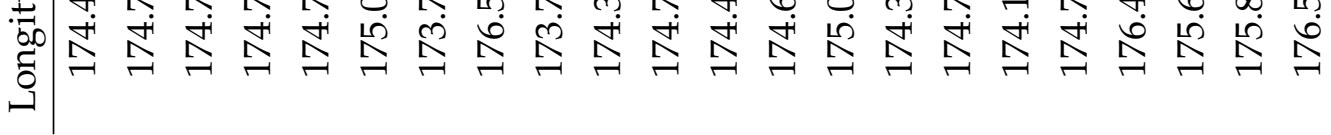




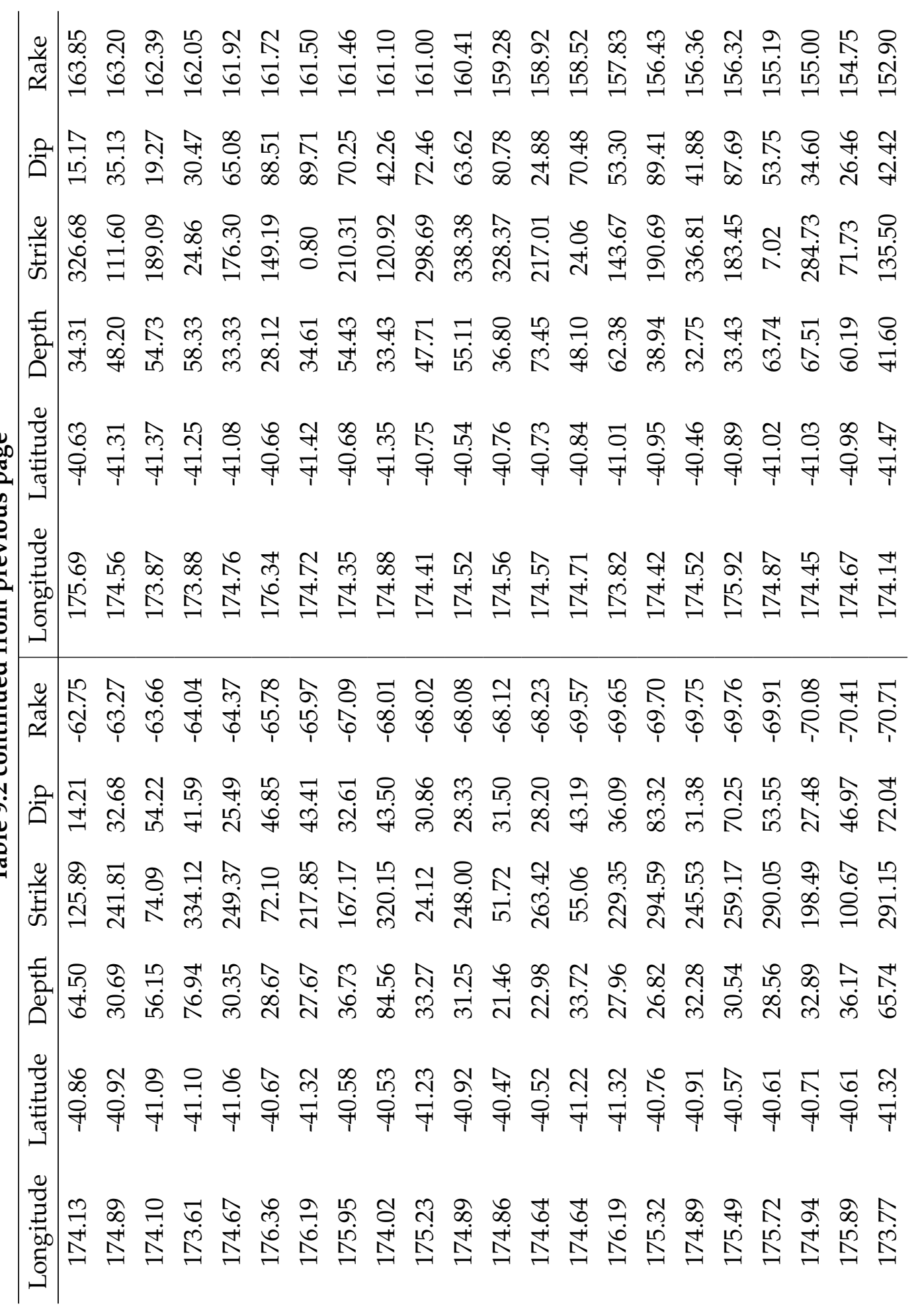


ঋ ๘ กิ

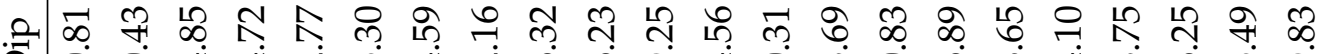

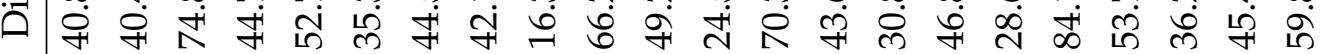

ע ज्ञ

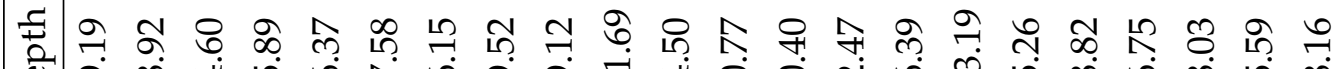
สं $\infty$ सं

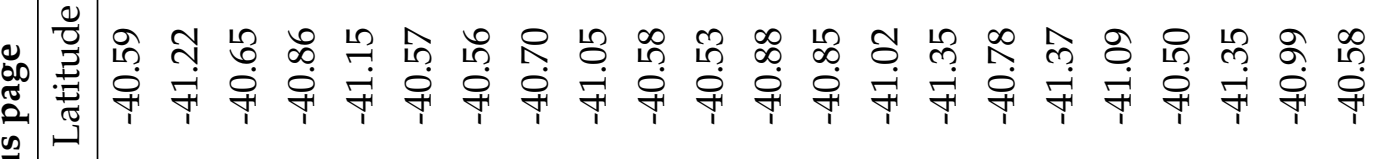

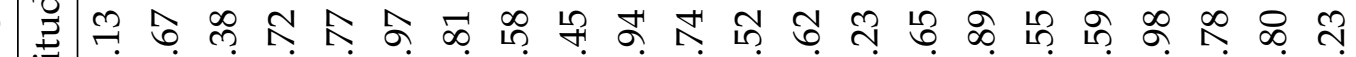
घं

ฆ

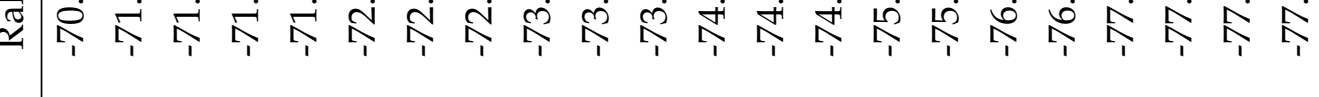

๙ู. @

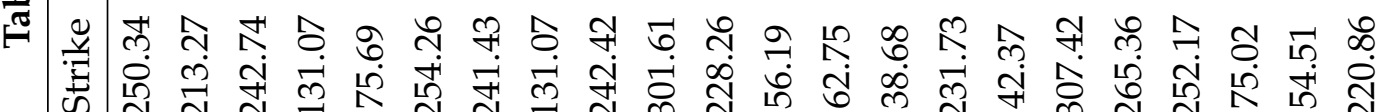

휴 ㄴํ बे

गु

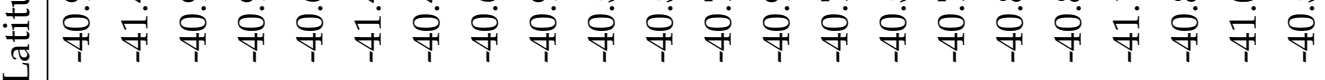

गี

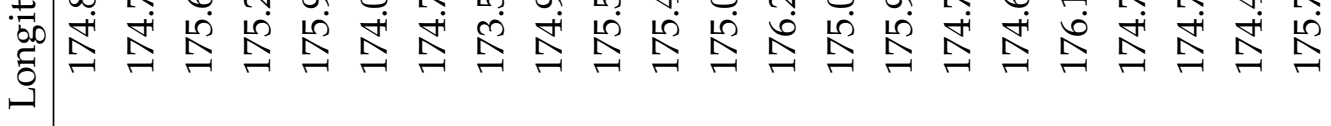




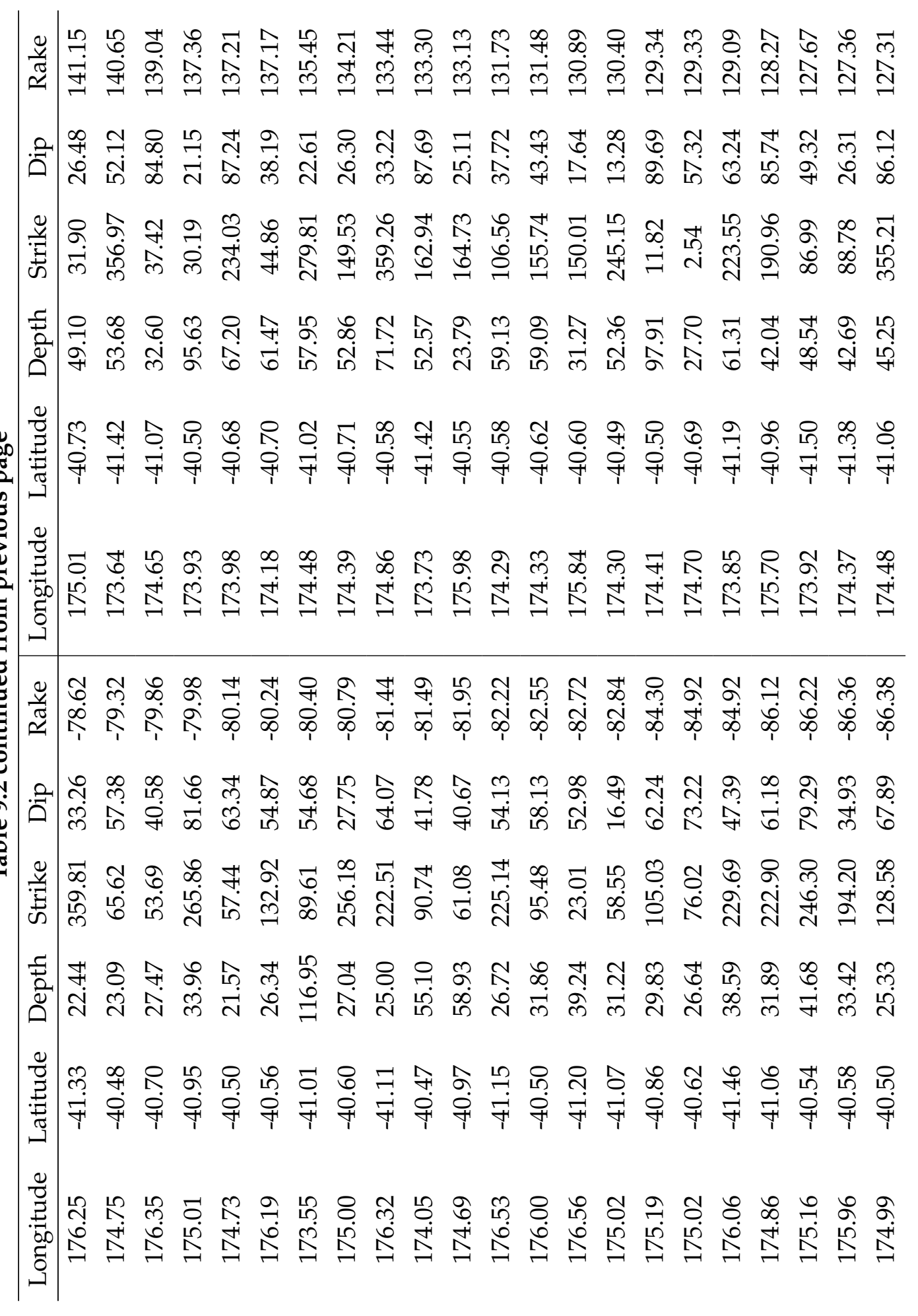




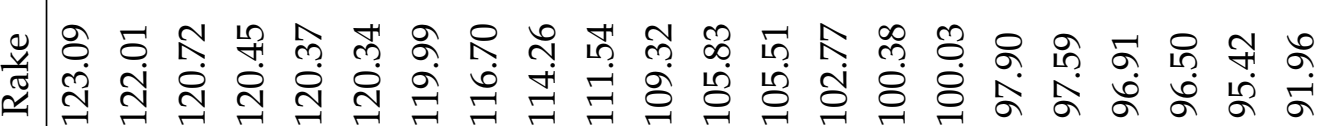

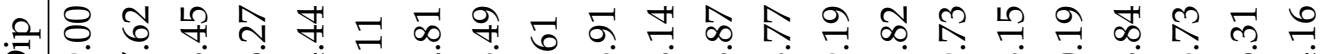

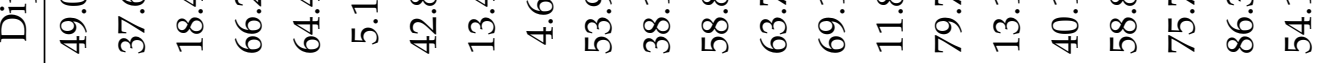

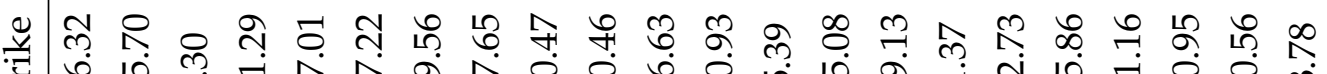

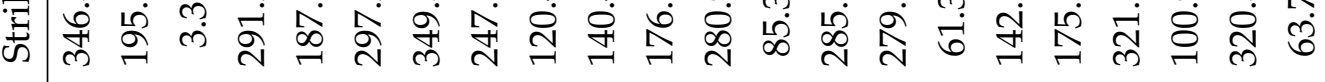

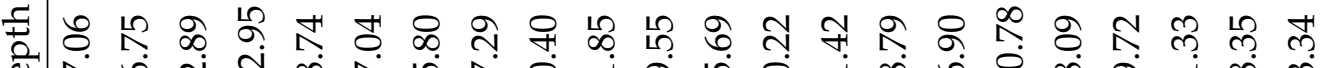

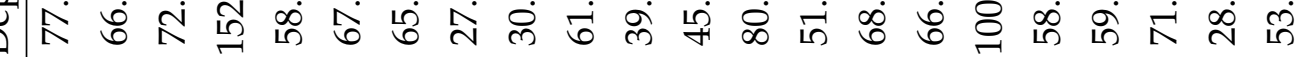

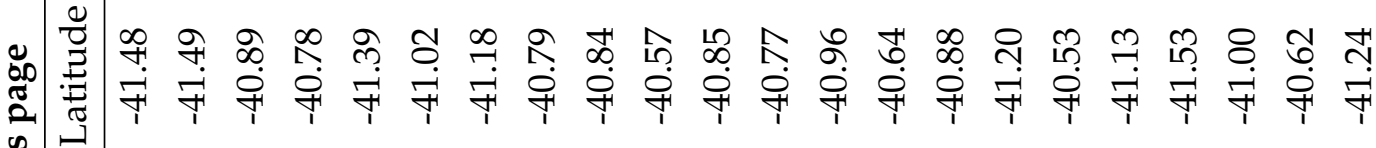

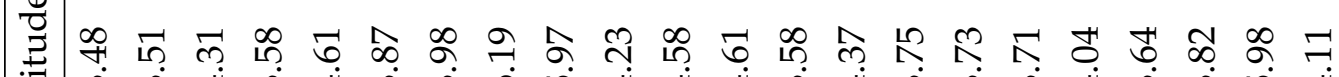

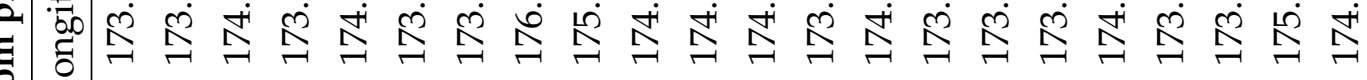

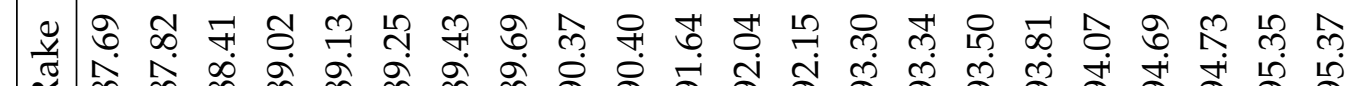

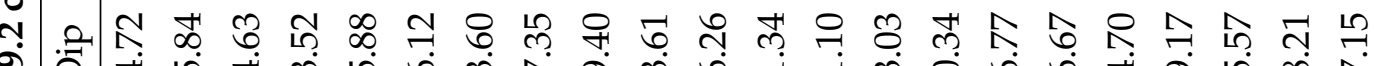

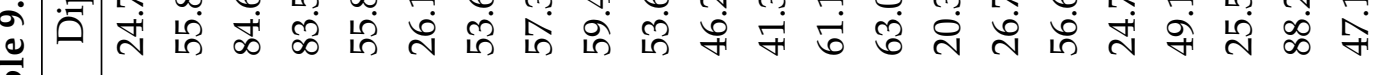
ส

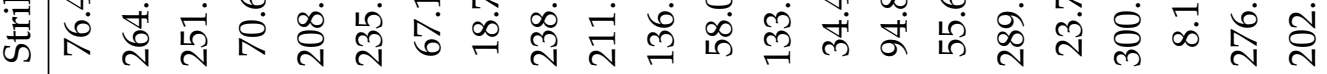

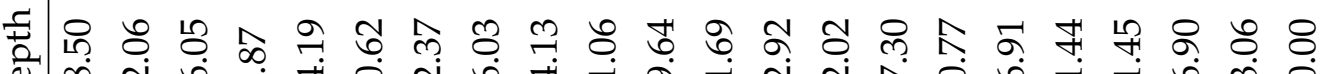
बें लं क्र

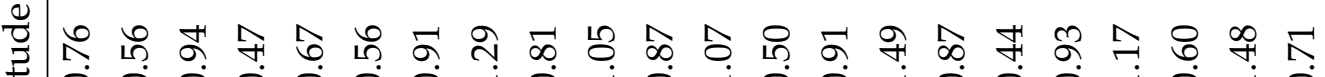

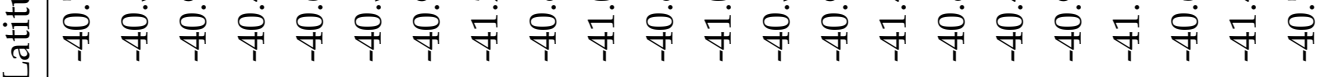

牙局

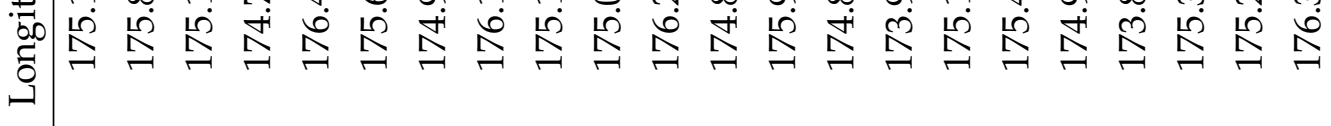




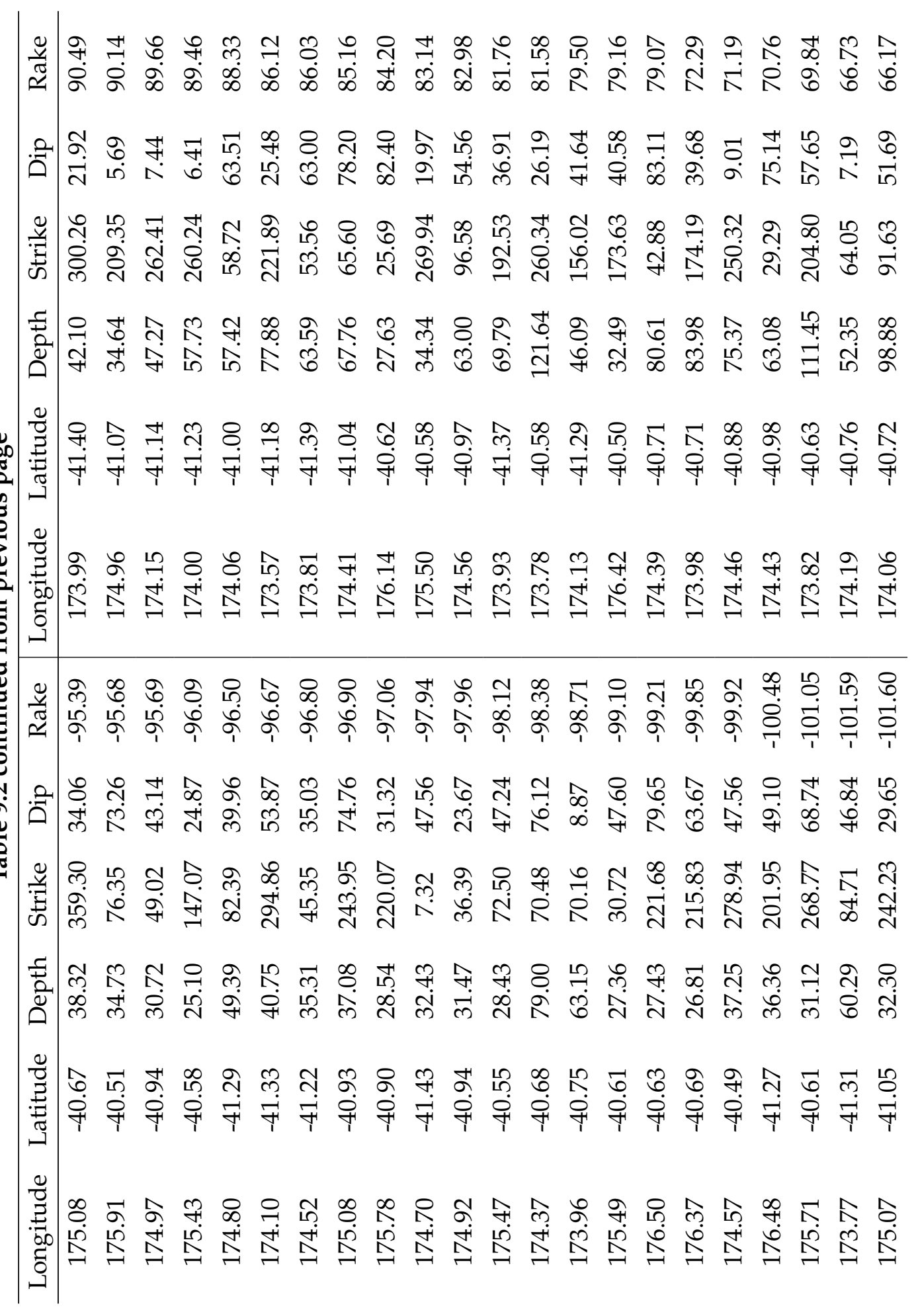




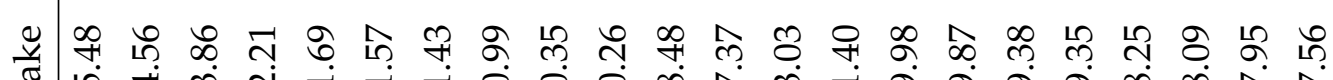
ஊ

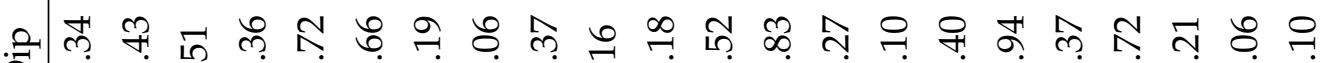
जिए में ๘ స

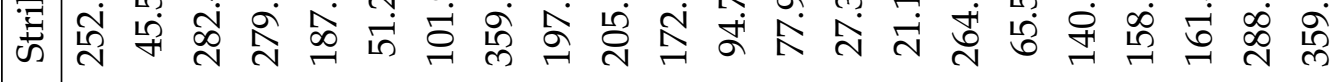

₹

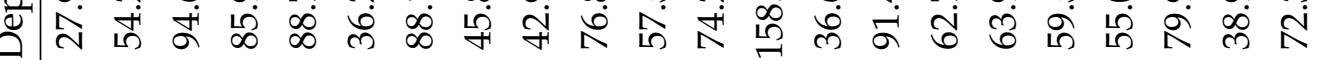

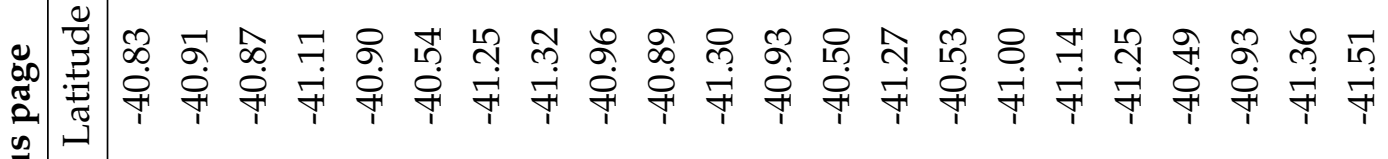

矛

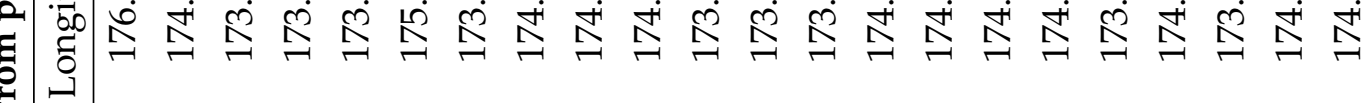

ஜ

ॠ

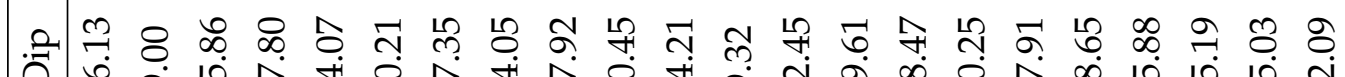

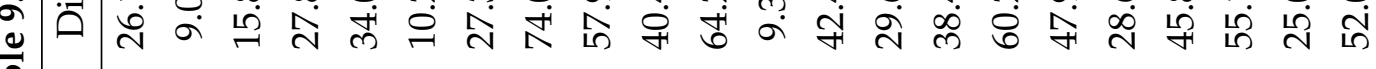

๙ ज ป̀

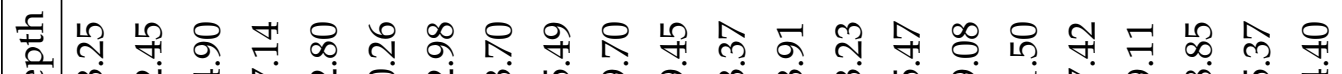

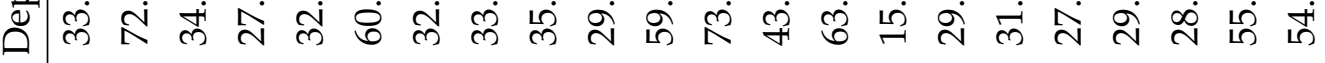

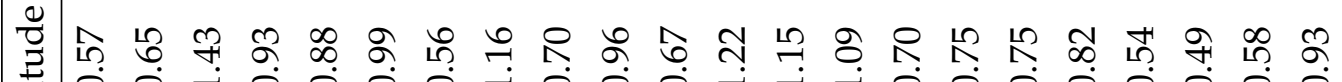

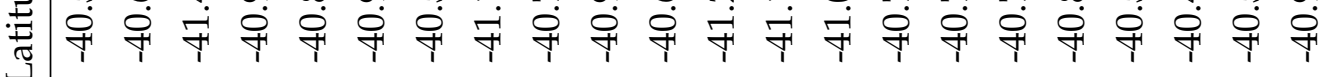

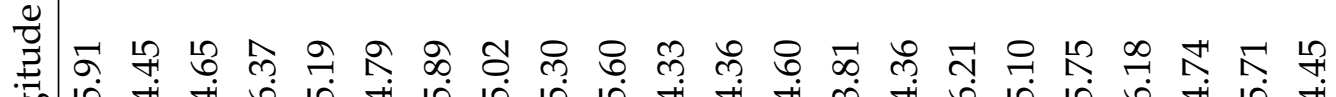

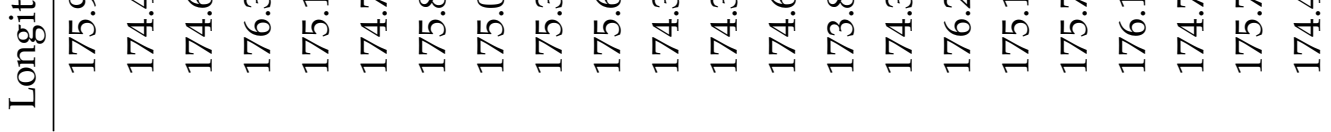




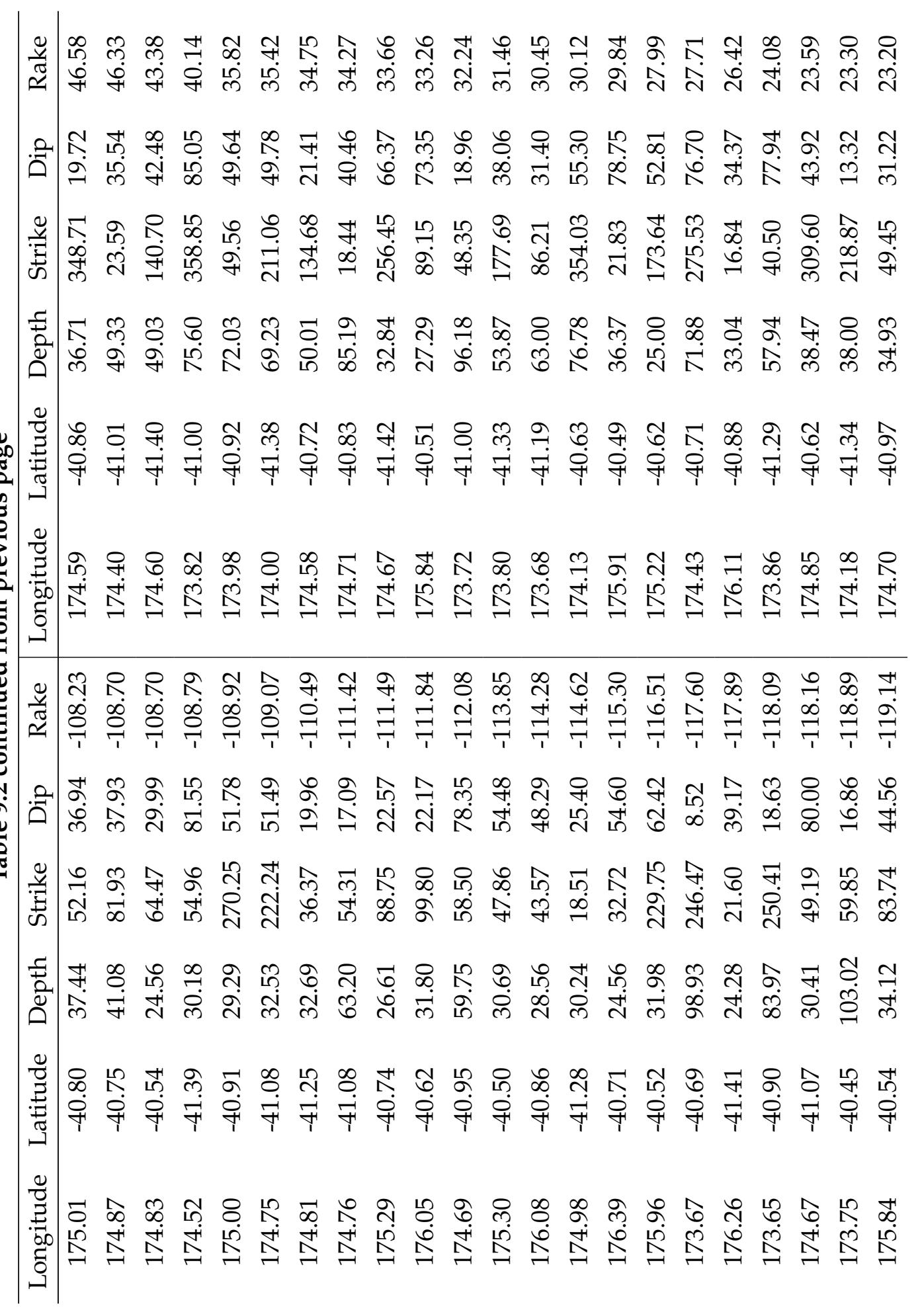




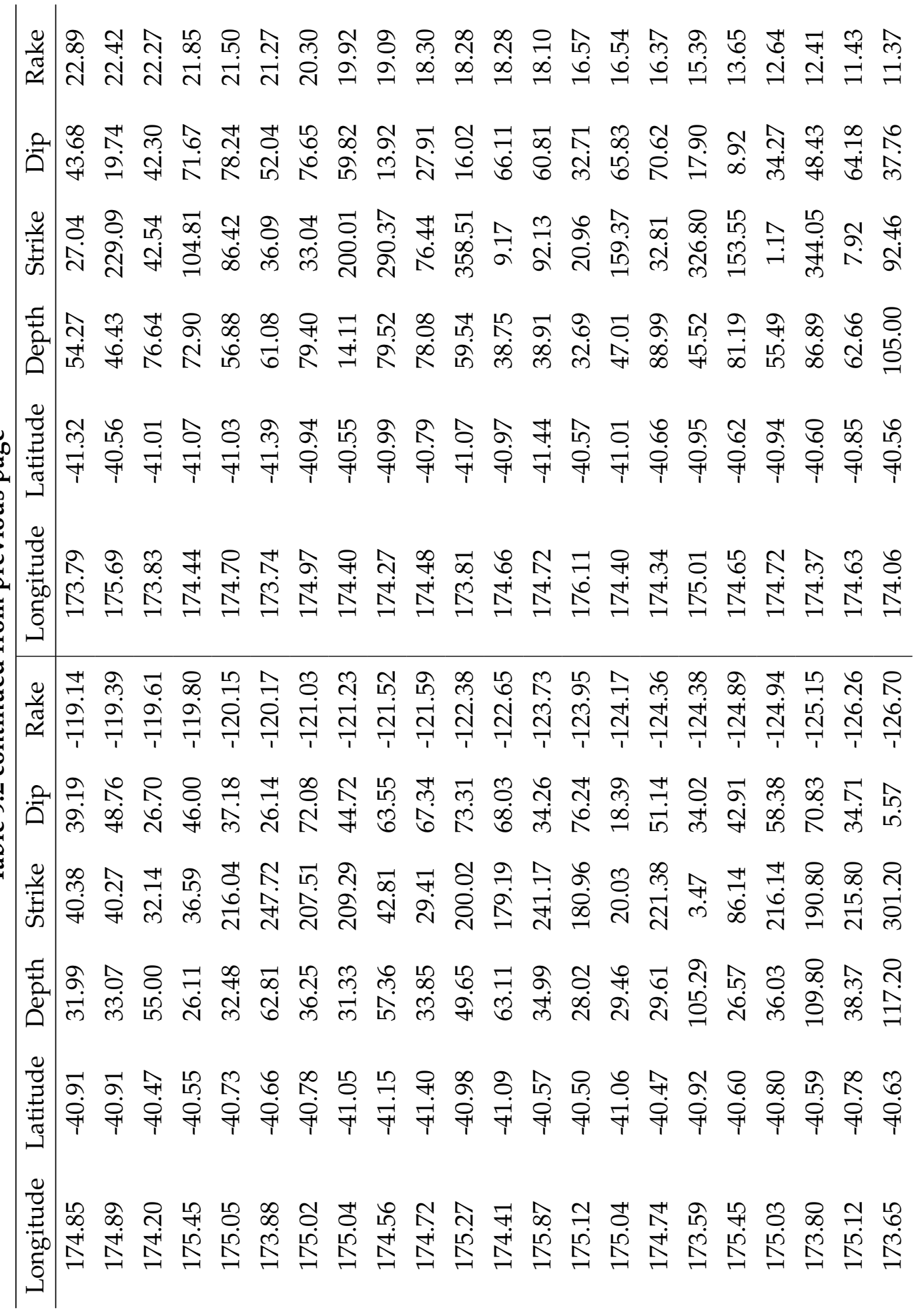




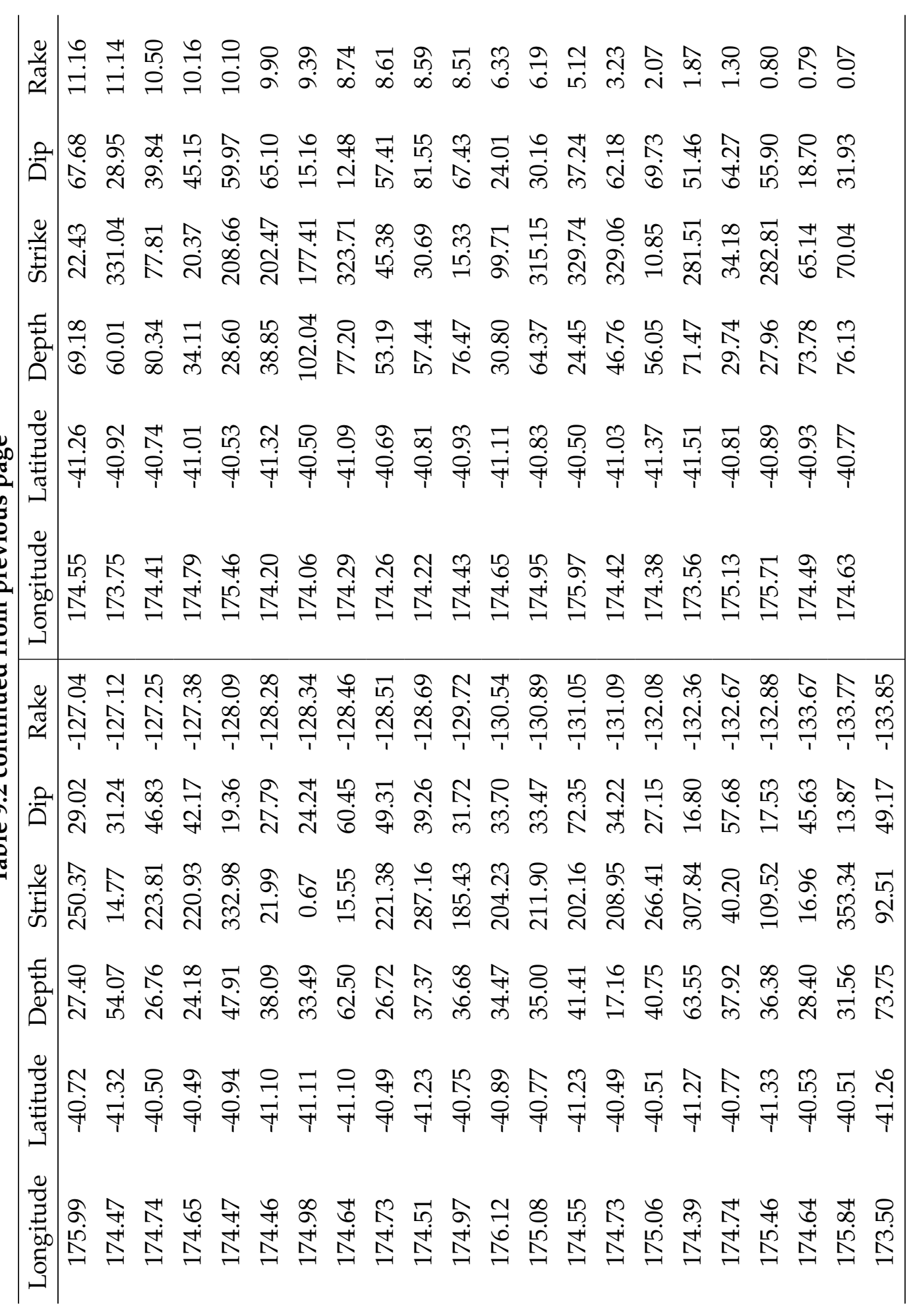


Table 9.3: Results of stress inversion for the down-dip lower plane of the Double Benioff Zone (focal mechanisms with 10 or more polarity picks). Mean and Medium values calculated using the Bayesian method. X10 and X90 indicate the $80 \%$ confidence interval bounds. Map indicated parameters calculated using the Map method, embedded in the Bayesian program (for comparisons only).

\begin{tabular}{cccccc}
\hline Parameter & Mean & Map & Median & X10 & X90 \\
\hline S1 & 43.01 & 41.54 & 42.15 & 17.32 & 69.94 \\
S2 & 138.40 & 135.00 & -42.66 & -71.58 & -10.54 \\
S3 & 93.09 & 100.38 & -90.84 & -147.49 & -1.39 \\
SHmax & 39.95 & 43.20 & 38.92 & 11.10 & 70.27 \\
Nu & 0.38 & 0.40 & 0.38 & 0.20 & 0.56 \\
\hline
\end{tabular}

Table 9.4: Results of stress inversion for the up-dip lower plane of the Double Benioff Zone (focal mechanisms with 10 or more polarity picks). Mean and Medium values calculated using the Bayesian method. X10 and X90 indicate the $80 \%$ confidence interval bounds. Map indicated parameters calculated using the Map method, embedded in the Bayesian program (for comparisons only).

\begin{tabular}{cccccc}
\hline Parameter & Mean & Map & Median & X10 & X90 \\
\hline S1 & 47.87 & 48.46 & 47.62 & 00.85 & 97.27 \\
S2 & 54.07 & 51.92 & 53.17 & 20.09 & 90.63 \\
S3 & 141.38 & 138.46 & -39.40 & -61.56 & -15.13 \\
SHmax & 49.60 & 50.40 & 49.14 & 28.00 & 71.33 \\
Nu & 0.24 & 0.00 & 0.19 & -0.02 & 0.60 \\
\hline
\end{tabular}

Table 9.5: Results of stress inversion for the upper plane of the Double Benioff Zone (focal mechanisms with 10 or more polarity picks). Mean and Medium values calculated using the Bayesian method. X10 and X90 indicate the $80 \%$ confidence interval bounds. Map indicated parameters calculated using the Map method, embedded in the Bayesian program (for comparisons only).

\begin{tabular}{cccccc}
\hline Parameter & Mean & Map & Median & X10 & X90 \\
\hline S1 & 145.65 & 148.85 & -34.31 & -75.38 & 6.62 \\
S2 & 61.17 & 62.31 & 61.29 & 46.99 & 75.24 \\
S3 & 149.71 & 148.85 & -30.26 & -42.07 & -18.70 \\
SHmax & 59.66 & 61.20 & 59.71 & 47.03 & 71.68 \\
Nu & 0.50 & 0.50 & 0.50 & 0.38 & 0.61 \\
\hline
\end{tabular}




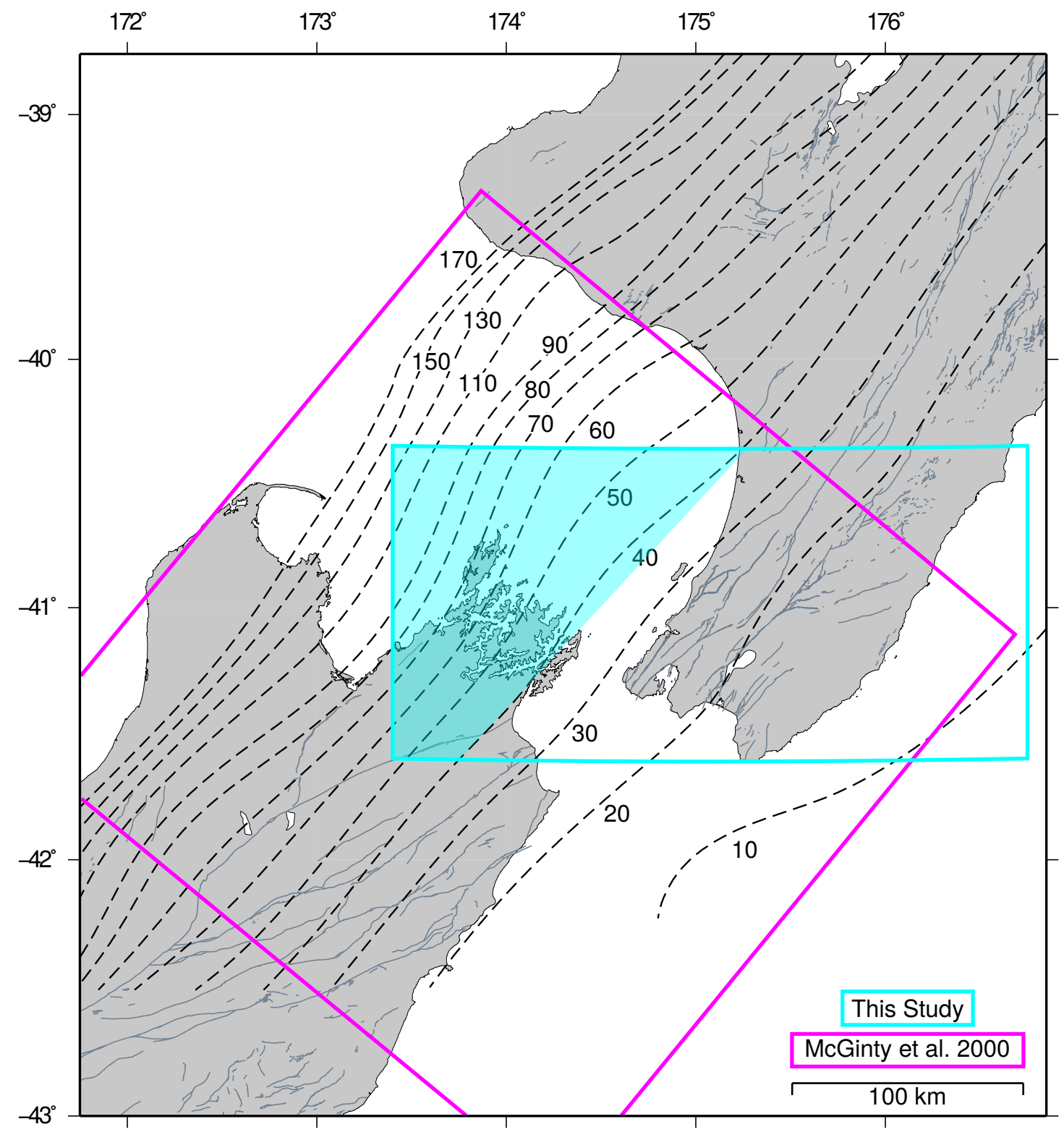

Figure 9.1: A comparison of this study's region of interest (cyan) and McGinty et al. (2000) study area (magenta). This study uses a maximum of 434 and 225 focal mechanisms in the inversion of stresses in the upper and lower bands of seismicity, respectively. Cyan shaded region indicates where bending stresses are observed based on this study. McGinty et al. (2000) used 48 and 12 focal mechanisms in the inversion of stresses in the upper and lower bands of seismicity, respectively, observing no bending stresses. Dashed-lines indicate plate interface depth (Williams et al., 2013). Grey lines show active faults (https://data.gns.cri.nz/af/. 

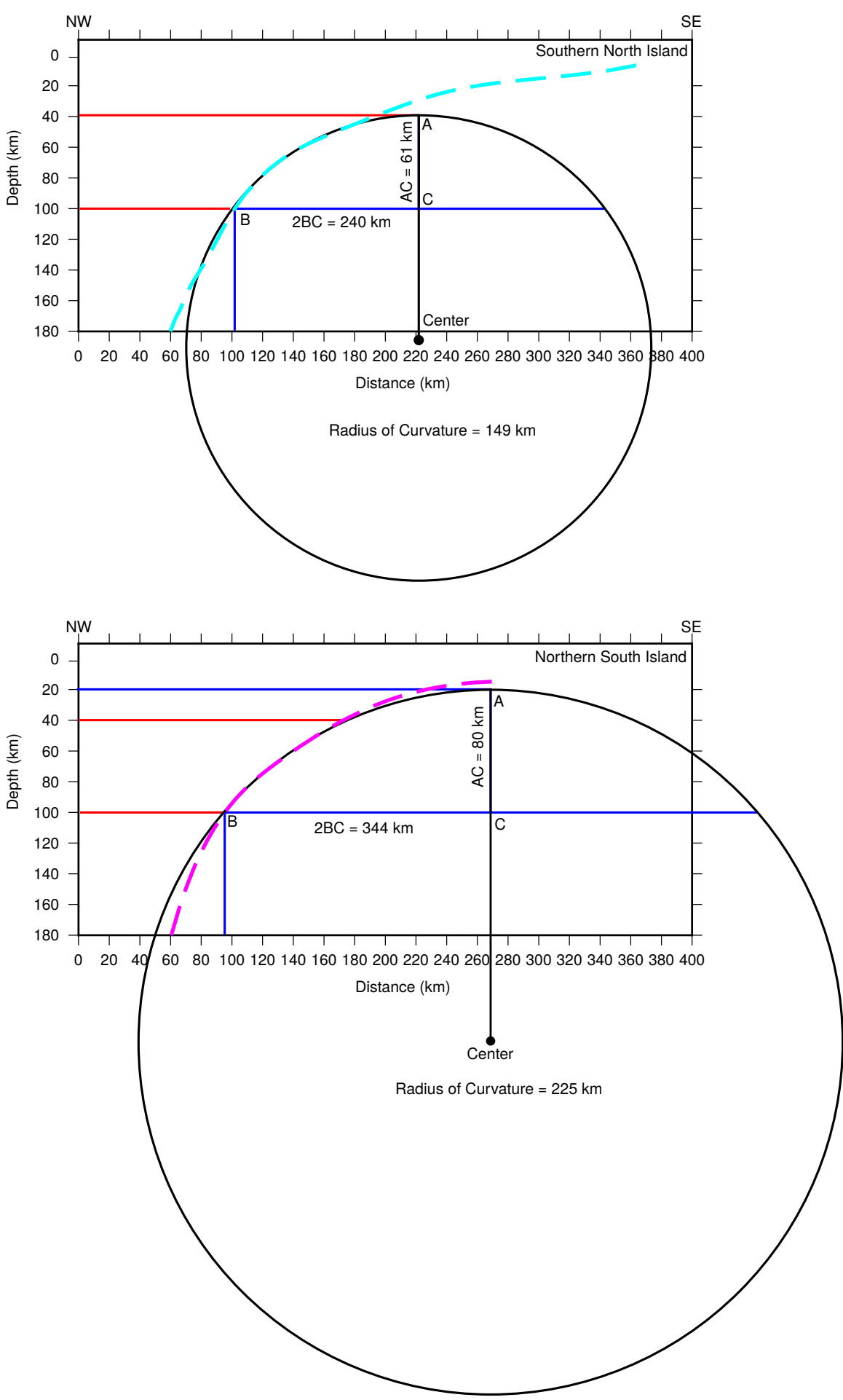

Figure 9.2: A comparison of the radius of curvature for the southern North Island (b, cyan) and the northern South Island (a, magenta), based on plate interface depth (see Figure 4.5, Chapter 4). Calculating radius of curvature $(R)$ between depths of 40 and $100 \mathrm{~km}$ along the plate interface, where we observed bending stresses. $R=(A B / 2)+(2 B C)^{2} /(8 A B)$. Radius of curvature in the southern North Island is $149 \mathrm{~km}$ and $225 \mathrm{~km}$ in the northern South Island. Plate interface depth based on Williams et al. (2013). 


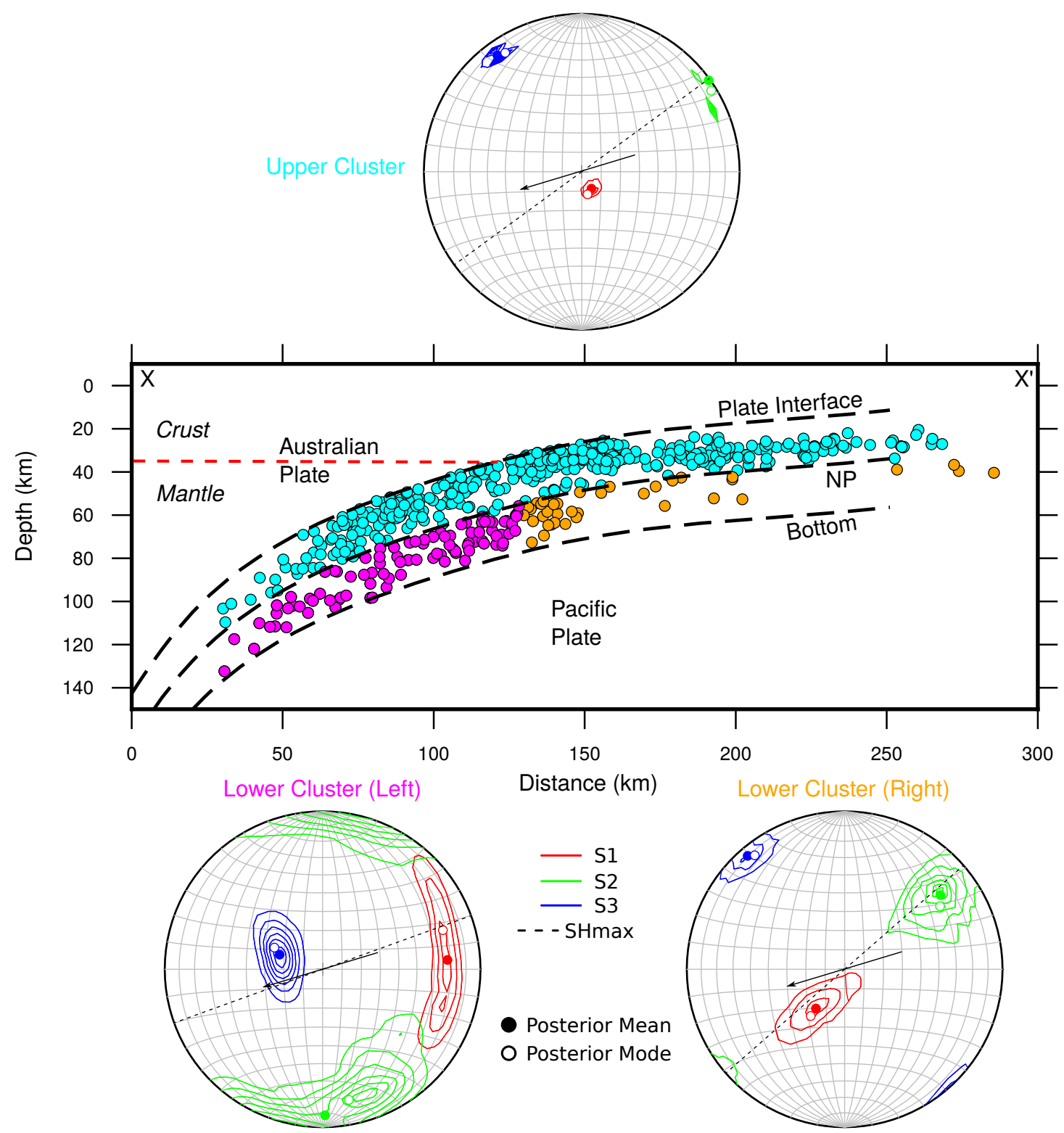

Figure 9.3: Clusters of all focal mechanisms used as inputs into the Bayesian stress inversion method from Arnold and Townend (2007). Red-dashed line indicates approximate of the Moho (Henrys et al., 2013). Upper cluster (434 focal mechanisms) shown by cyan circles, down-dip lower (left) cluster shown by magenta circles (132 focal mechanism) and up-dip lower (right) cluster shown by orange circles (93 focal mechanism), mapped on $X$ to $X^{\prime}$ crosssection from previous figures. Stereonets show azimuth of maximum principle stress (S1), intermediate principle stress (S2), and minimum principle stress (S3), shown as the posterior density functions (PDFs). The best fitting maximum horizontal stress (SHmax) shown as a dashed line. Black arrows indicate plate convergence direction. 
Table 9.6: Results of stress inversion for the down-dip lower plane of the Double Benioff Zone (all focal mechanisms). Mean and Medium values calculated using the Bayesian method. X10 and X90 indicate the $80 \%$ confidence interval bounds. Map indicated parameters calculated using the Map method, embedded in the Bayesian program (for comparisons only).

\begin{tabular}{cccccc}
\hline Parameter & Mean & Map & Median & X10 & X90 \\
\hline S1 & 81.62 & 76.15 & 81.84 & 42.47 & 121.11 \\
S2 & 174.08 & 166.15 & -05.77 & -41.28 & 30.23 \\
S3 & 108.82 & 117.69 & -68.56 & -113.11 & -37.20 \\
SHmax & 70.16 & 48.56 & 66.40 & 24.13 & 121.00 \\
Nu & 0.26 & 0.20 & 0.25 & 0.12 & 0.42 \\
\hline
\end{tabular}

Table 9.7: Results of stress inversion for the up-dip lower plane of the Double Benioff Zone (all focal mechanisms). Mean and Medium values calculated using the Bayesian method. X10 and X90 indicate the $80 \%$ confidence interval bounds. Map indicated parameters calculated using the Map method, embedded in the Bayesian program (for comparisons only).

\begin{tabular}{cccccc}
\hline Parameter & Mean & Map & Median & X10 & X90 \\
\hline S1 & 40.60 & 41.54 & 41.32 & 10.71 & 66.90 \\
S2 & 52.49 & 51.92 & 51.97 & 34.44 & 71.57 \\
S3 & 139.39 & 138.46 & -40.74 & -55.53 & -25.66 \\
SHmax & 48.86 & 50.81 & 48.79 & 35.76 & 61.46 \\
Nu & 0.16 & 0.20 & 0.13 & -0.03 & 0.36 \\
\hline
\end{tabular}

Table 9.8: Results of stress inversion for the upper plane of the Double Benioff Zone (all focal mechanisms). Mean and Medium values calculated using the Bayesian method. X10 and X90 indicate the $80 \%$ confidence interval bounds. Map indicated parameters calculated using the Map method, embedded in the Bayesian program (for comparisons only).

\begin{tabular}{cccccc}
\hline Parameter & Mean & Map & Median & X10 & X90 \\
\hline S1 & 150.03 & 159.23 & -28.68 & -64.17 & 00.79 \\
S2 & 59.55 & 62.31 & 60.17 & 45.14 & 72.96 \\
S3 & 144.06 & 145.38 & -35.95 & -46.08 & -25.95 \\
SHmax & 53.86 & 56.70 & 53.72 & 42.80 & 64.28 \\
Nu & 0.45 & 0.40 & 0.45 & 0.37 & 0.53 \\
\hline
\end{tabular}




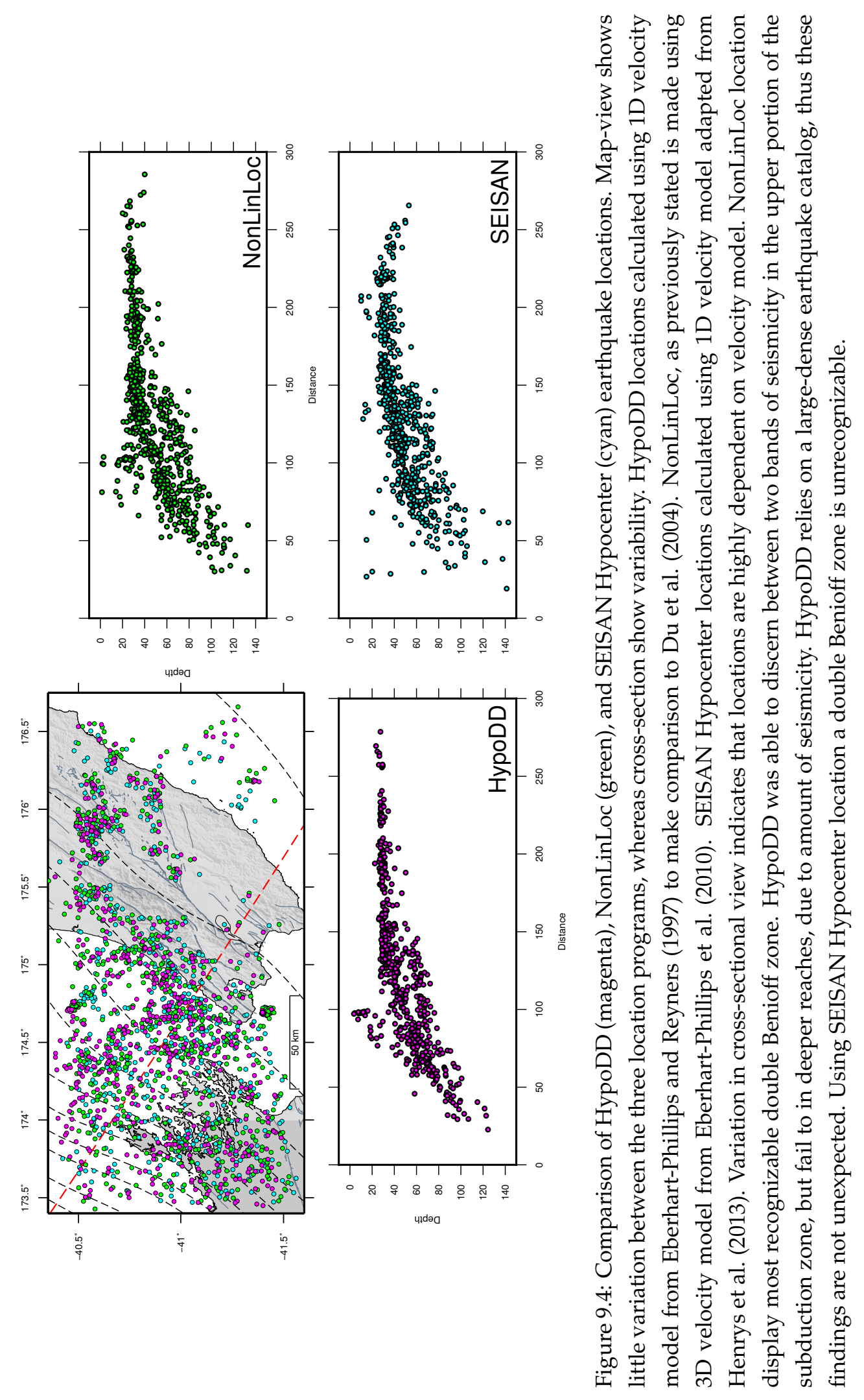




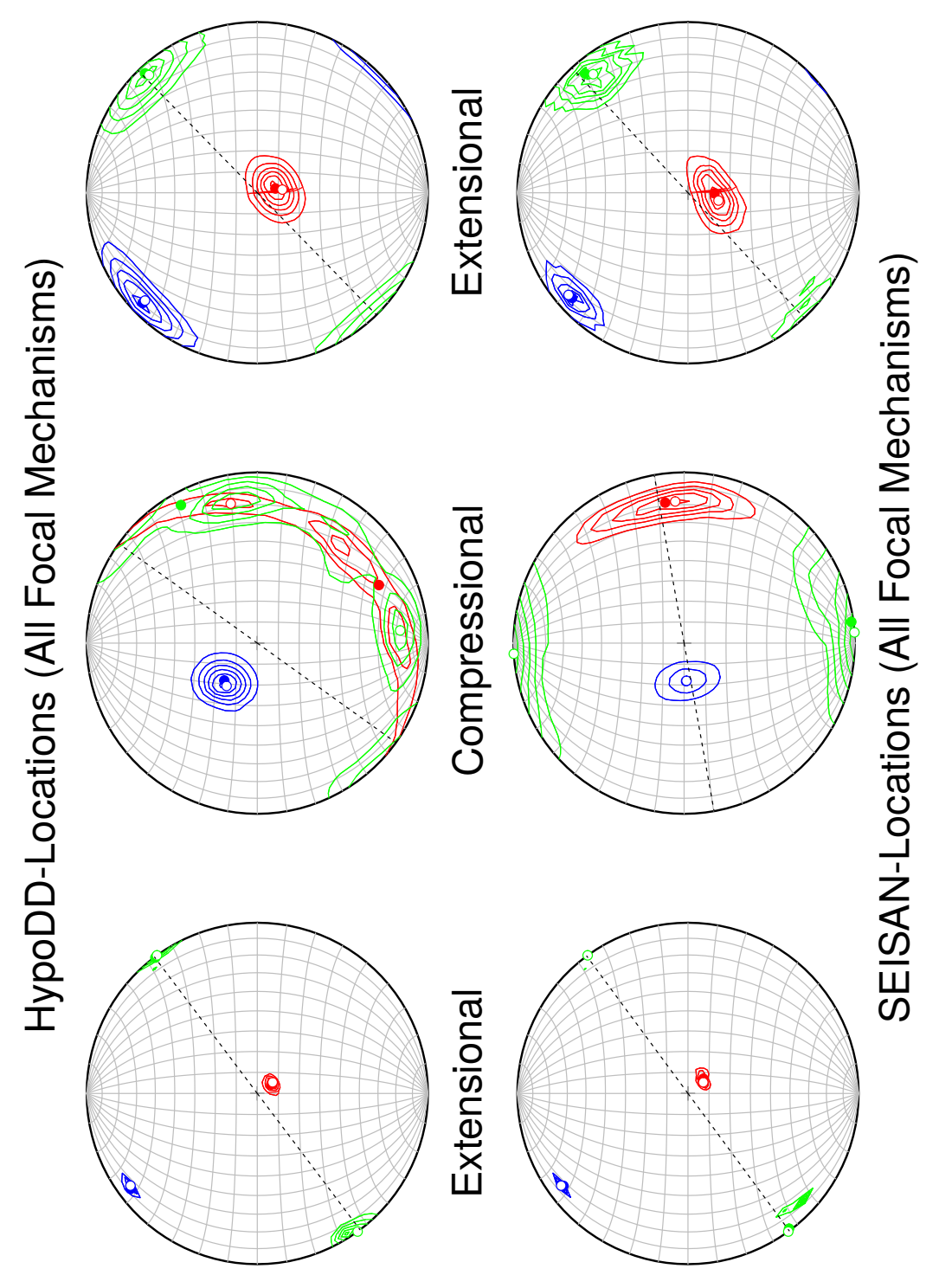

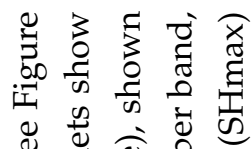

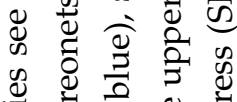

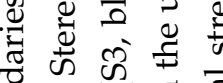

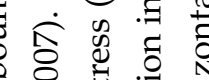

¿े की

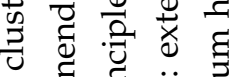

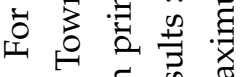

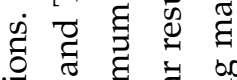

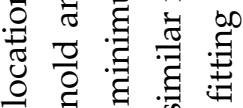

द हैं क्ष

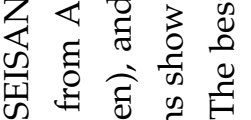

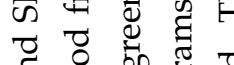

चै ठ․

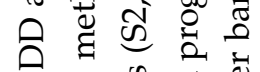

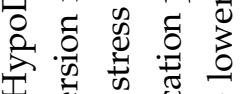

I

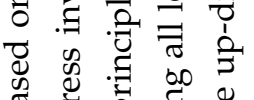

造

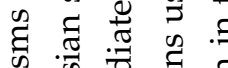

芯芯

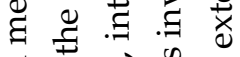

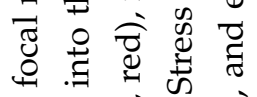

范泀

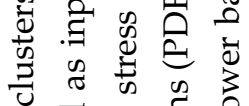

प d

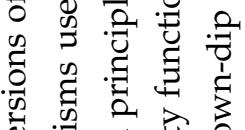

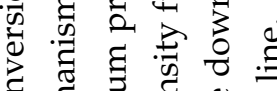

.

离

ம்

Ð

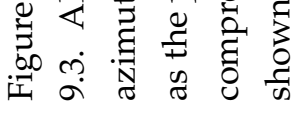



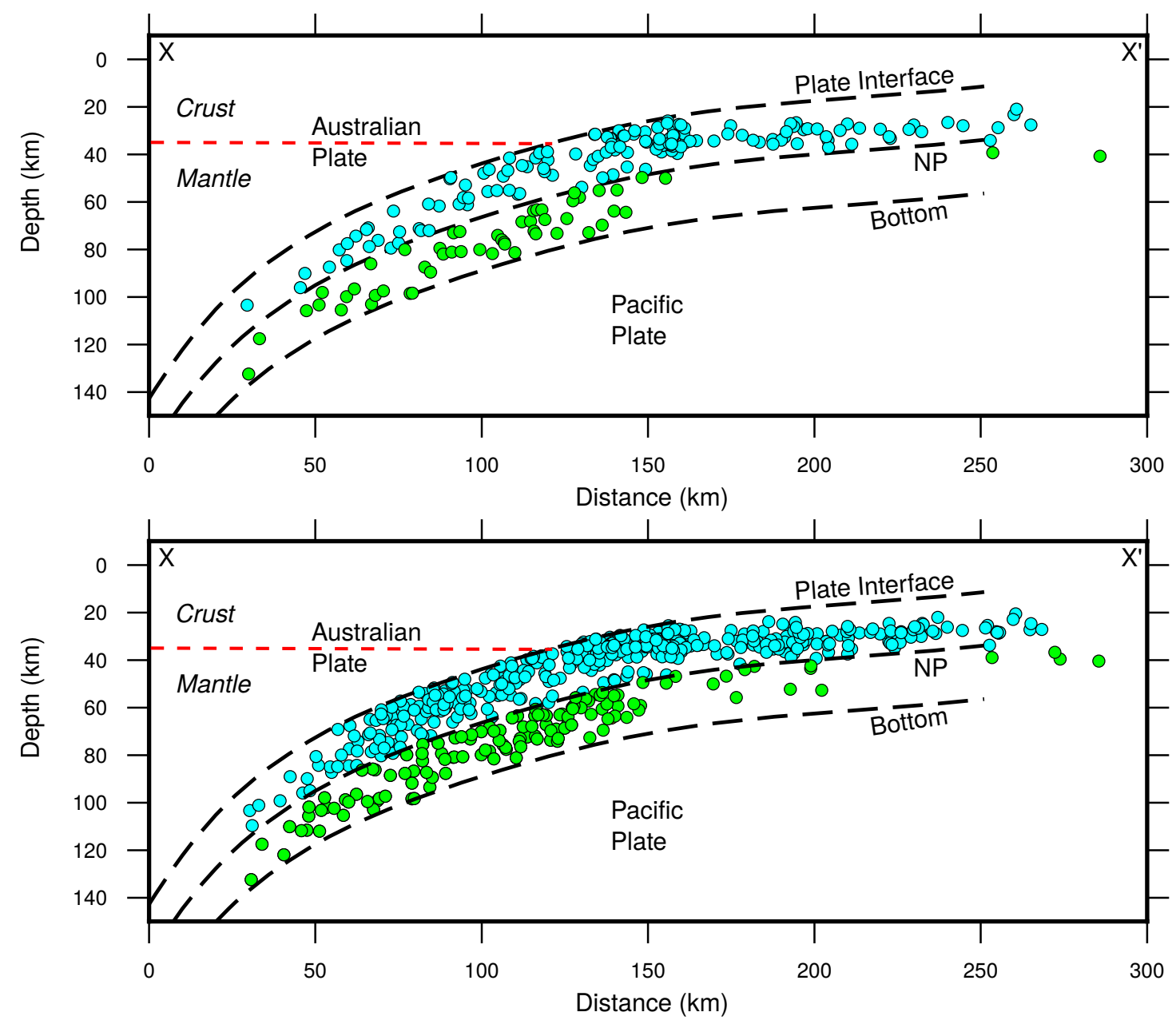

Figure 9.6: Clusters of focal mechanisms based on NonLinLoc locations. Clusters boundaries defined by those in the upper and lower bands of seismicity. Upper crosssections show clusters with 10 or more polarity picks. Lower cross-section consists of focal mechanism regardless of number of polarity picks. 

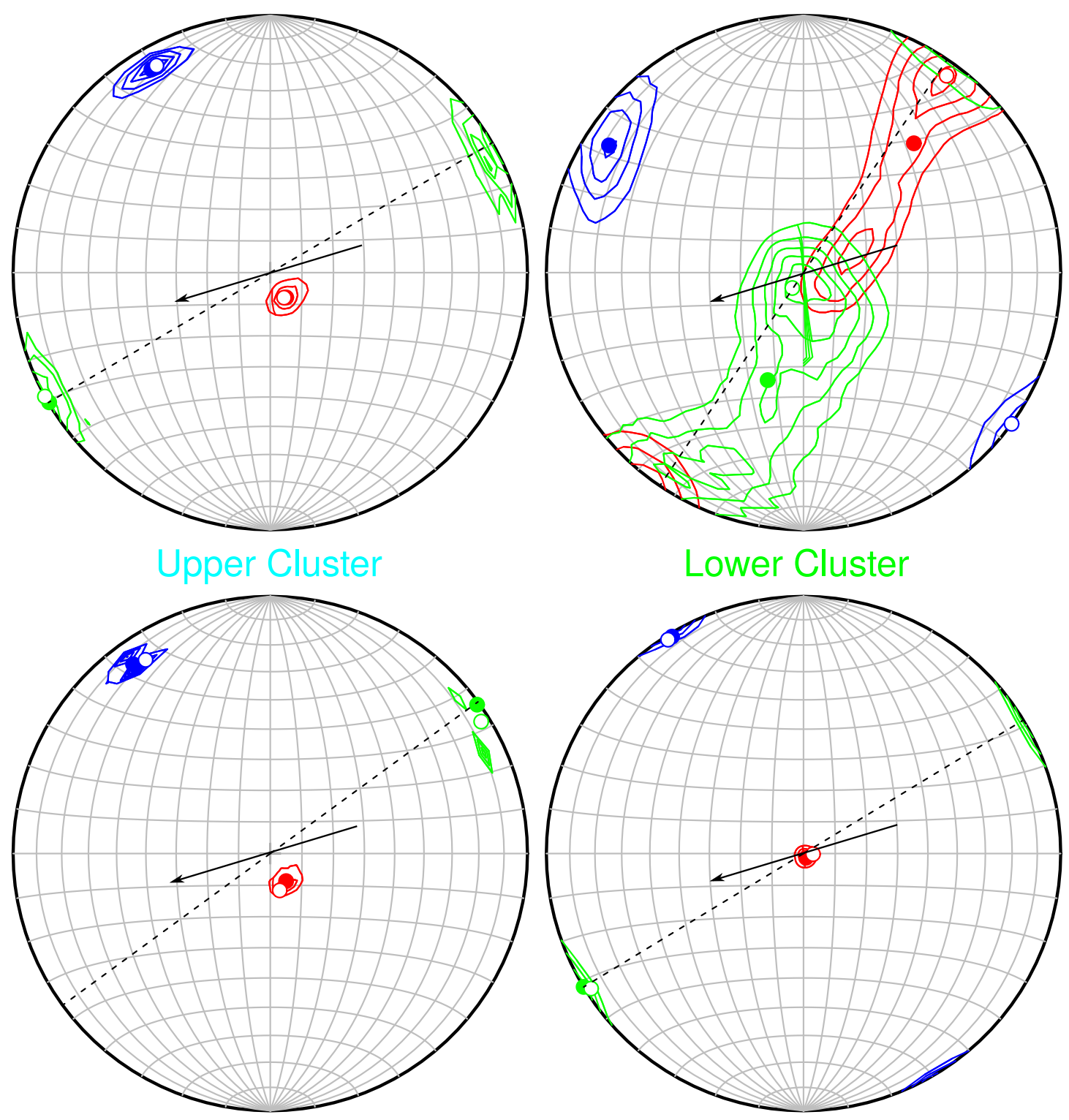

Figure 9.7: Stress inversions of 2 clusters of focal mechanisms. Stereonets show azimuth of maximum principle stress (S1, red), intermediate principle stress (S2, green), and minimum principle stress (S3, blue), shown as the posterior density functions (PDFs). Stress inversions using all location programs show similar results : extension in the upper band and lower band of seismicity. This indicates that bending stress are being overprinted by down-dip tension. 


\section{Chapter 10}

\section{Appendix C: Stress and Structure Controlled Anisotropy Revealed by a High-Density Seismic Transect Across Southern North Island, New Zealand}

This chapter provides appendix material for Chapter 5: Crustal Anisotropy Across Southern North Island, New Zealand Revealed by a High Density Seismic Array. Figures show average unstacked fast azimuth and splitting parameters using splitting results from the all unstacked earthquakes, five random earthquakes, the four closest earthquakes to the SAHKE II array, and one earthquake. In addition are tables that include fast azimuth and delay time statistics. 


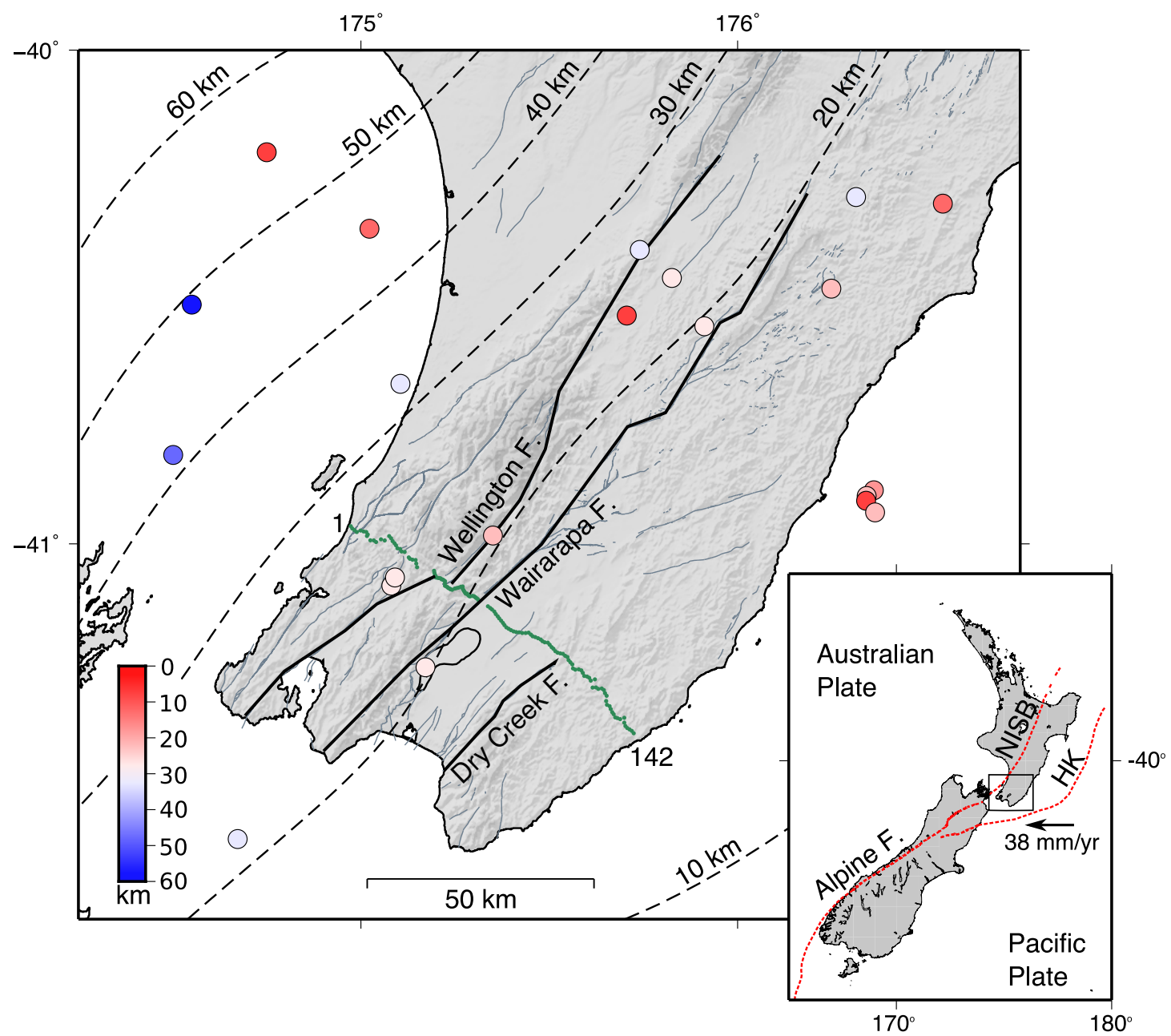

Figure 10.1: Location of 291 high frequency seismic stations (Green circles - appears as Green line). 21 earthquakes (red, white, and blue circles) colored by depth. Dashed-black lines show plate interface depth (Williams et al., 2013). Thick-black lines and grey lines show active faults (e.g., Wellington and Wairarapa faults). Map-inset: New Zealand tectonics showing location of plate boundaries (Red-dashed lines): Alpine Fault, Hikurangi Margin (HK), and North Island Seismic Belt (NISB) (Coffin et al., 2008). Black box indicates location of study area. 


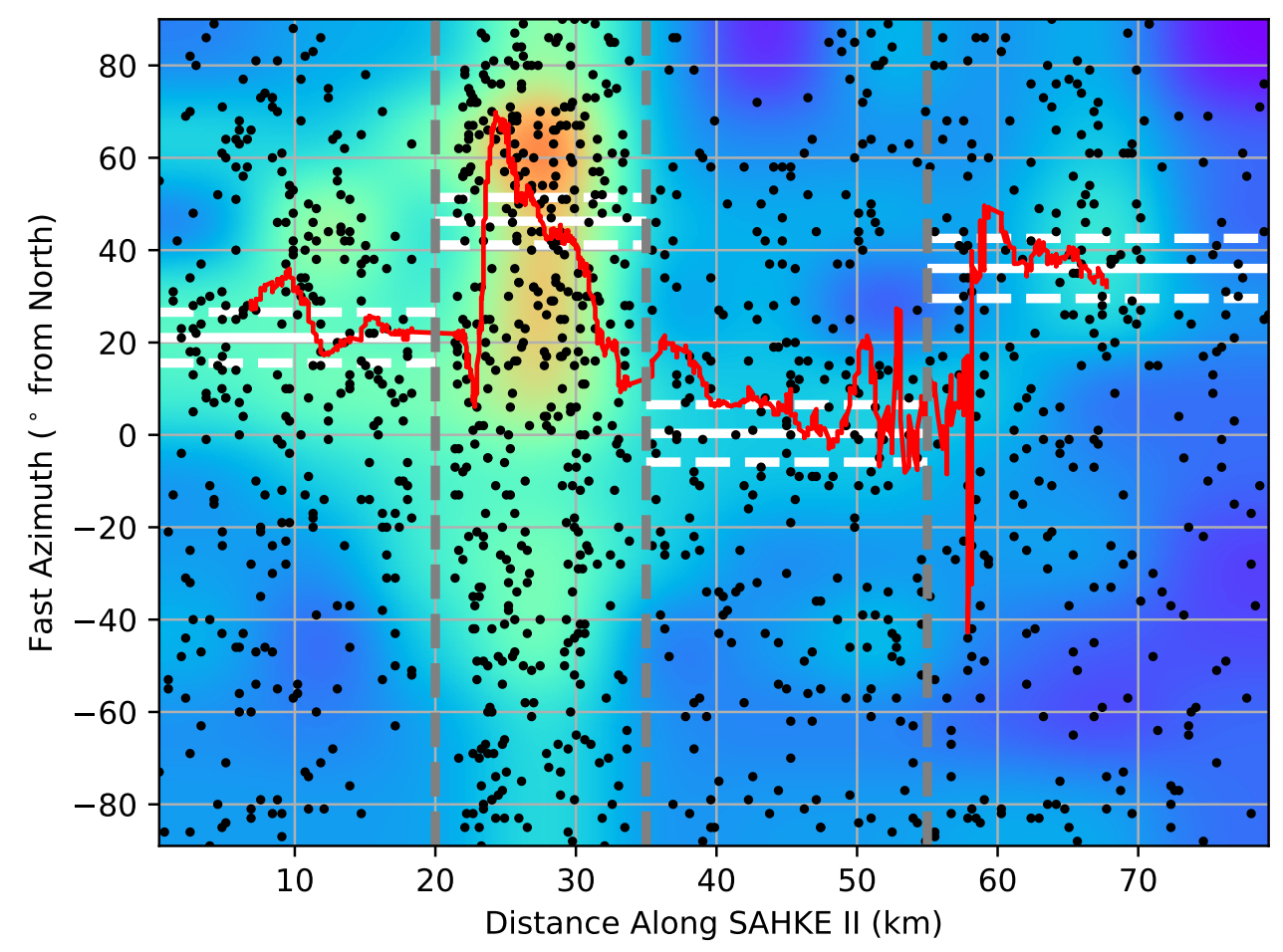

Figure 10.2: Fast azimuth (degrees from North) measurements from all unstacked earthquakes as a function of distance along the SAHKE II array. Distance $0 \mathrm{~km}$ indicates location of westernmost seismic station. Black dot are fast azimuth measurements. Oranges, yellows and greens indicate increase density of measurements. Red-line is the 50-point moving average. Dashed-grey lines separate difference regions of interest (from West-East, see Figure S1) West-coast to the Wellington fault, Wellington fault to the Wairarapa fault, the Wairarapa Basin, and Dry Creek fault to East-coast. Solid-white lines mark the average fast azimuth, dashed-white lines show the $95 \%$ confidence intervals. 


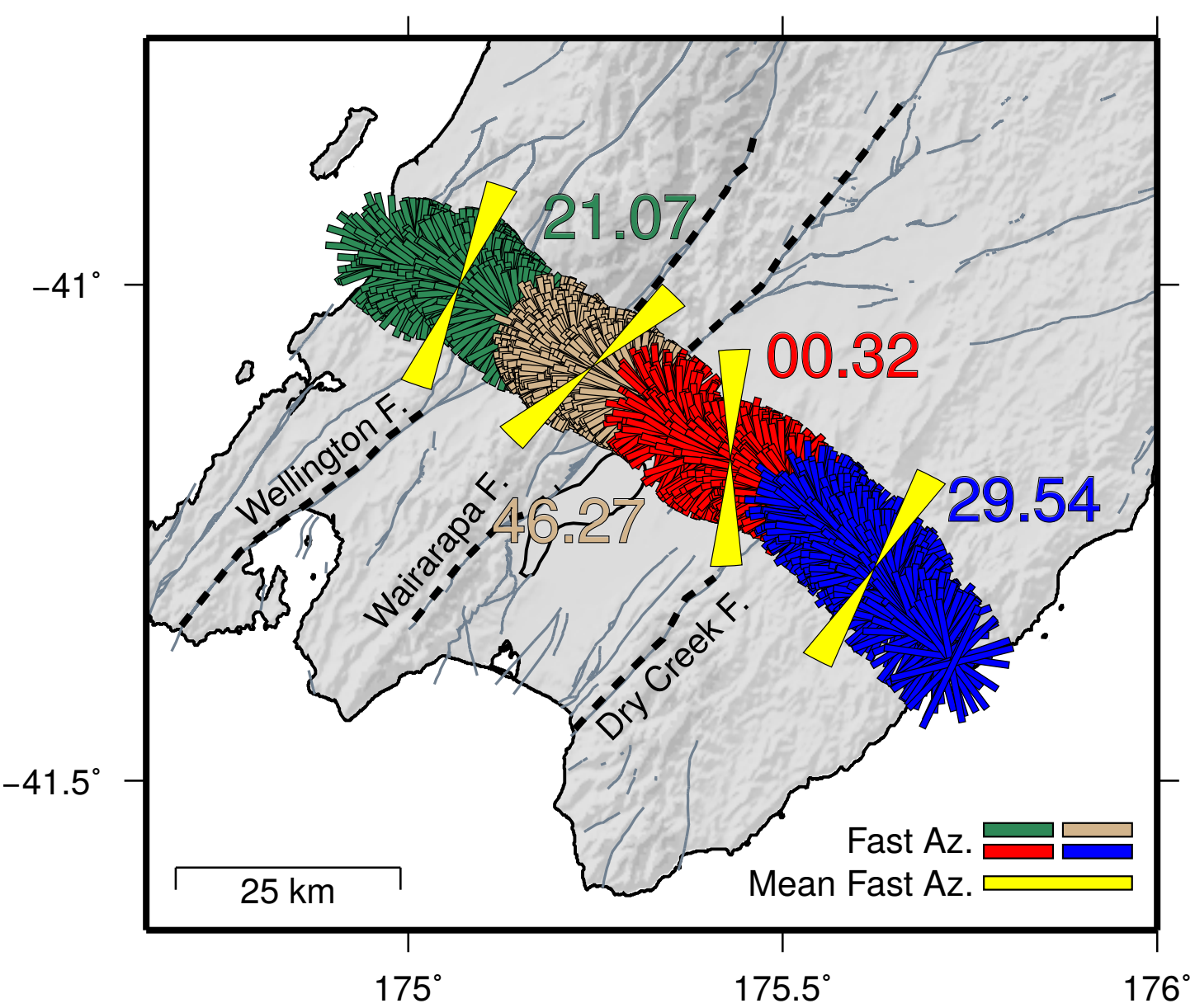

Figure 10.3: Mean fast azimuth for each seismic station. Colors (e.g., green, tan, red, blue) indicate grouping of mean azimuths for averaging. Boundaries defined in previous figures. Colored numbers and yellow wedges indicate the mean fast azimuth and $95 \%$ confidence interval, respectfully. 

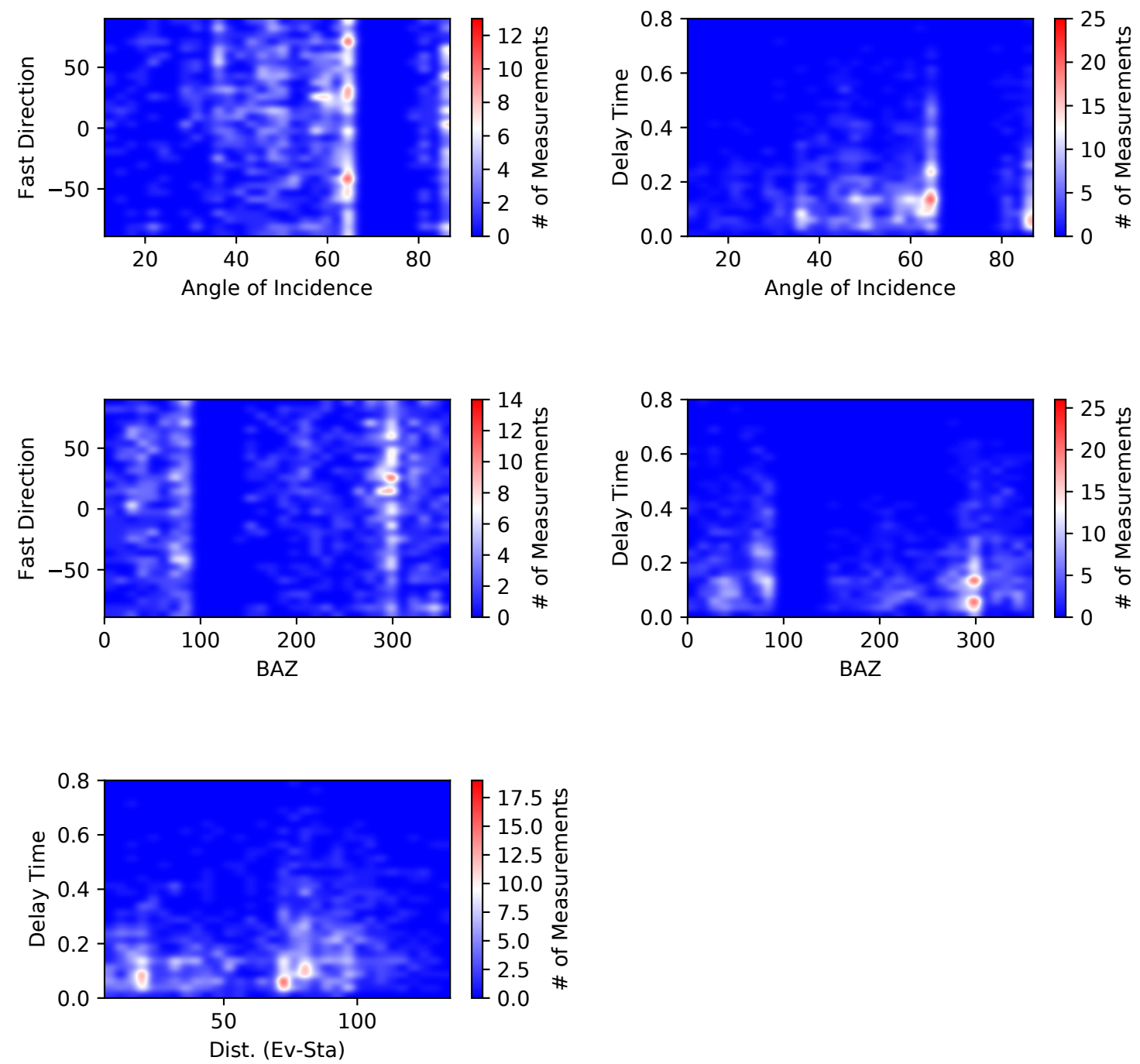

Figure 10.4: Density plots comparing various attributes of all A and B splitting measurements made using MFAST. Measurement attributes compared are: angle of incidence, back azimuth, delay time, distance (earthquake - station), and fast direction azimuth. Hotter colors (reds) indicated a higher occurrence. No one attribute shows a strong dependence on any other, indicating a singular source for the anisotropy measurements calculated. 


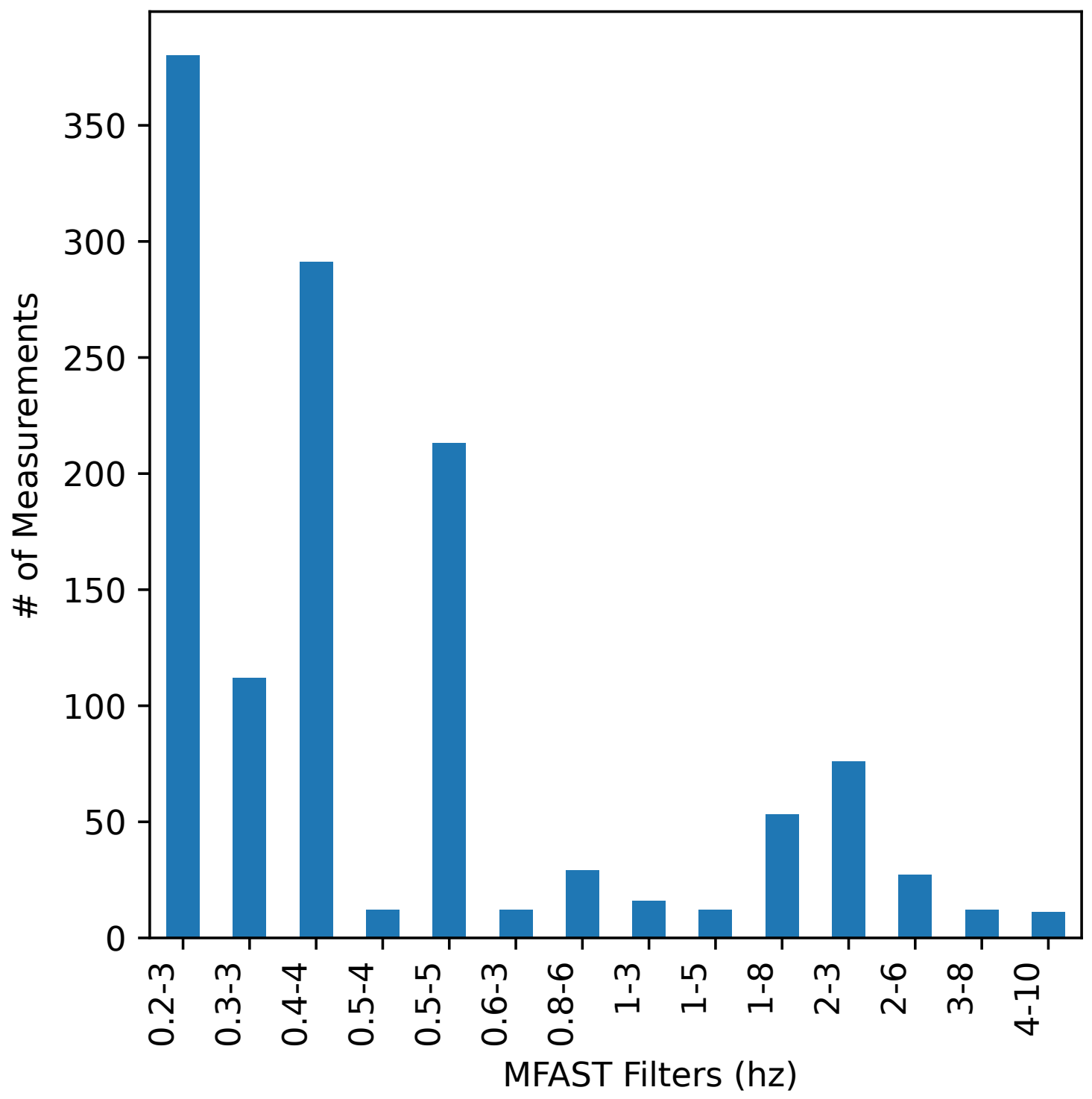

Figure 10.5: MFAST filters used in splitting calculation of all A and B splitting measurements. Lower frequency $(0.2-5 \mathrm{~Hz})$ filters gave more high quality (A \& B quality) measurements. 


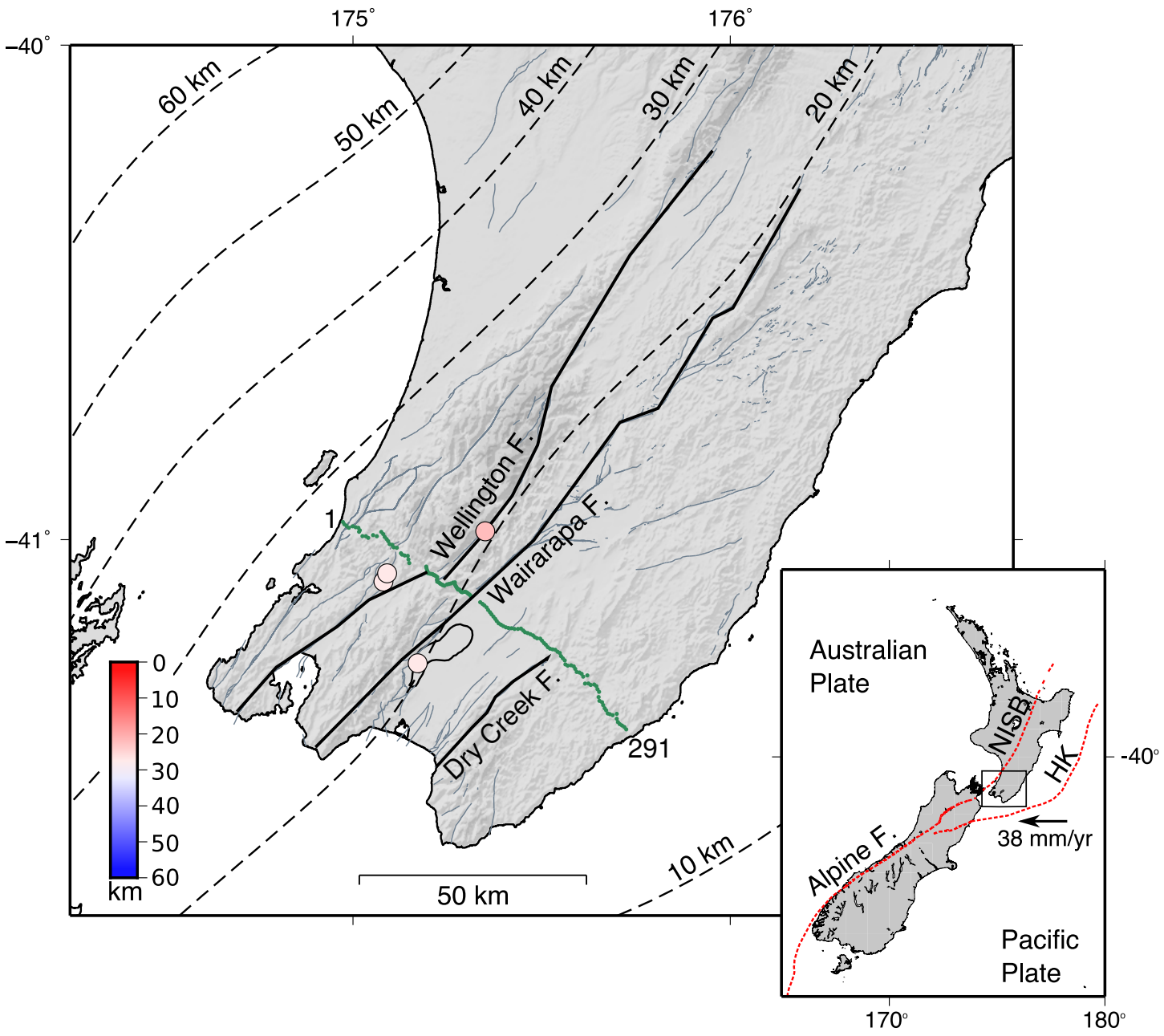

Figure 10.6: Location of 291 high frequency seismic stations (Green circles appears as Green line). The four closest earthquakes, colored by depth, to the SAHKE II array. For all other features see Figure S1. 


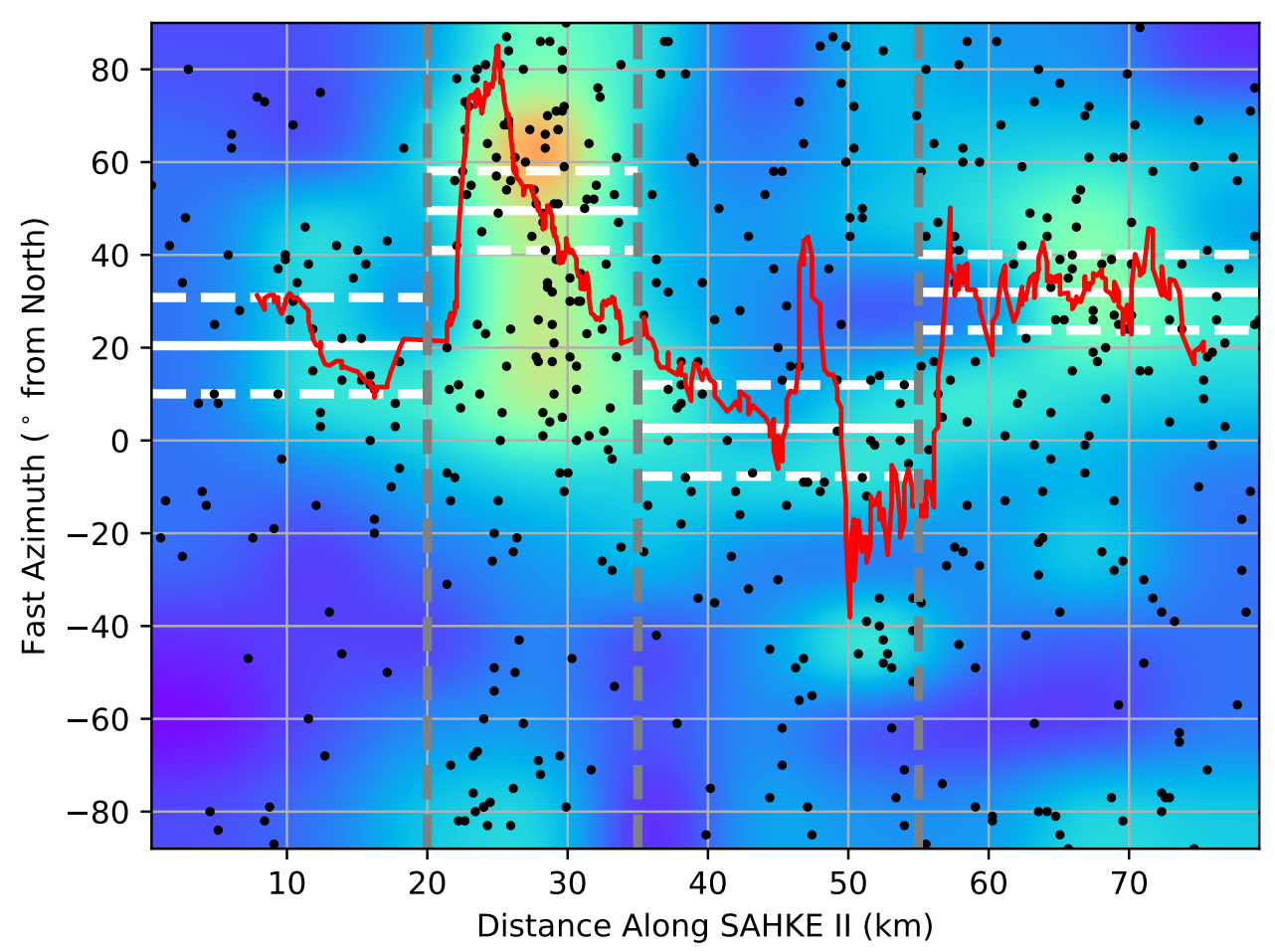

Figure 10.7: Fast azimuth (degrees from North) measurements from the four closest earthquakes to the SAHKE II array as a function of distance along the SAHKE II array. Red line is the 40-point moving average. For all other features see Figure S2. 


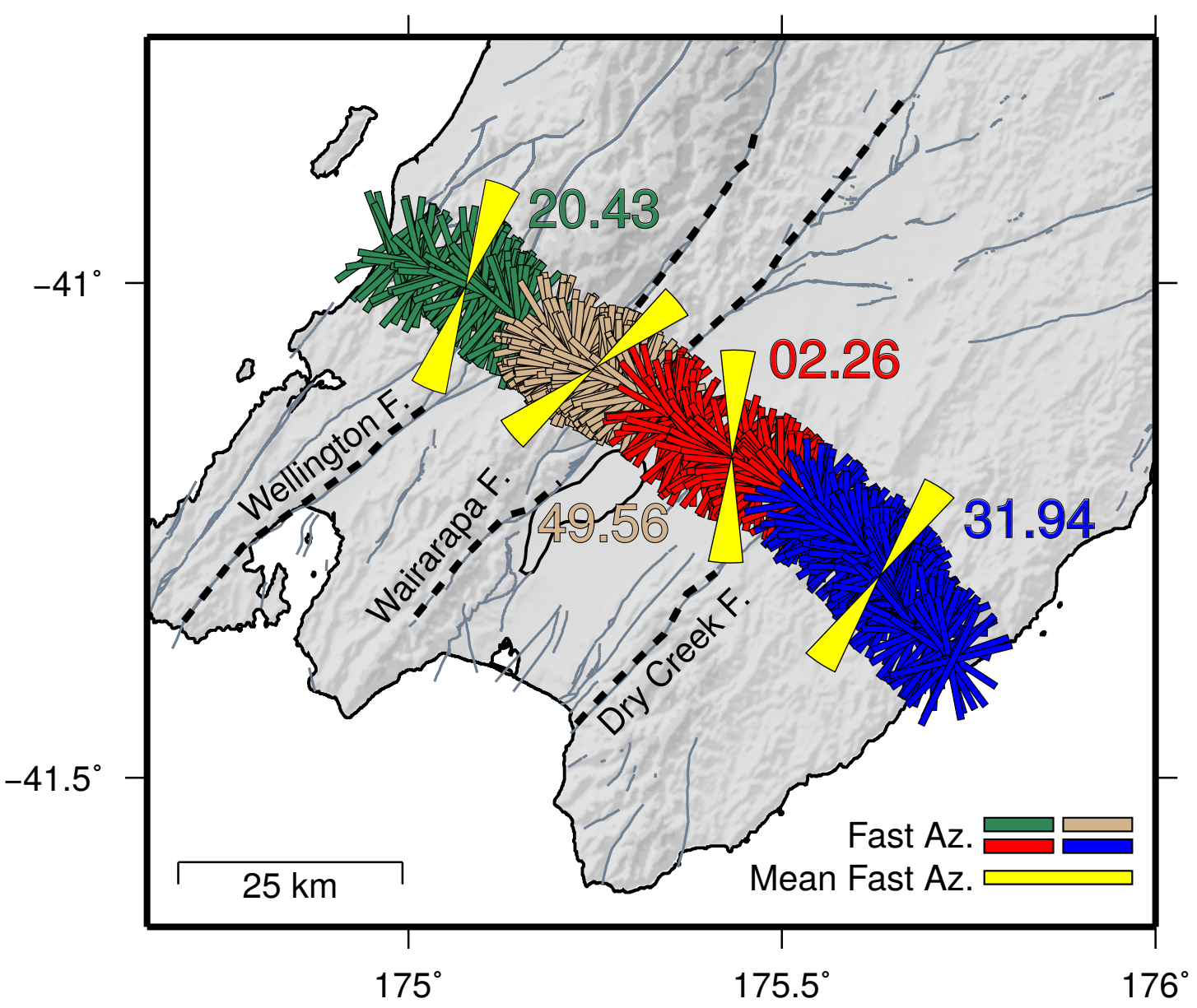

Figure 10.8: Mean fast azimuth for each seismic station using the four closest earthquakes. Colors (e.g., green, tan, red, blue) indicate grouping of mean azimuths for averaging. For all features see Figure S3. 

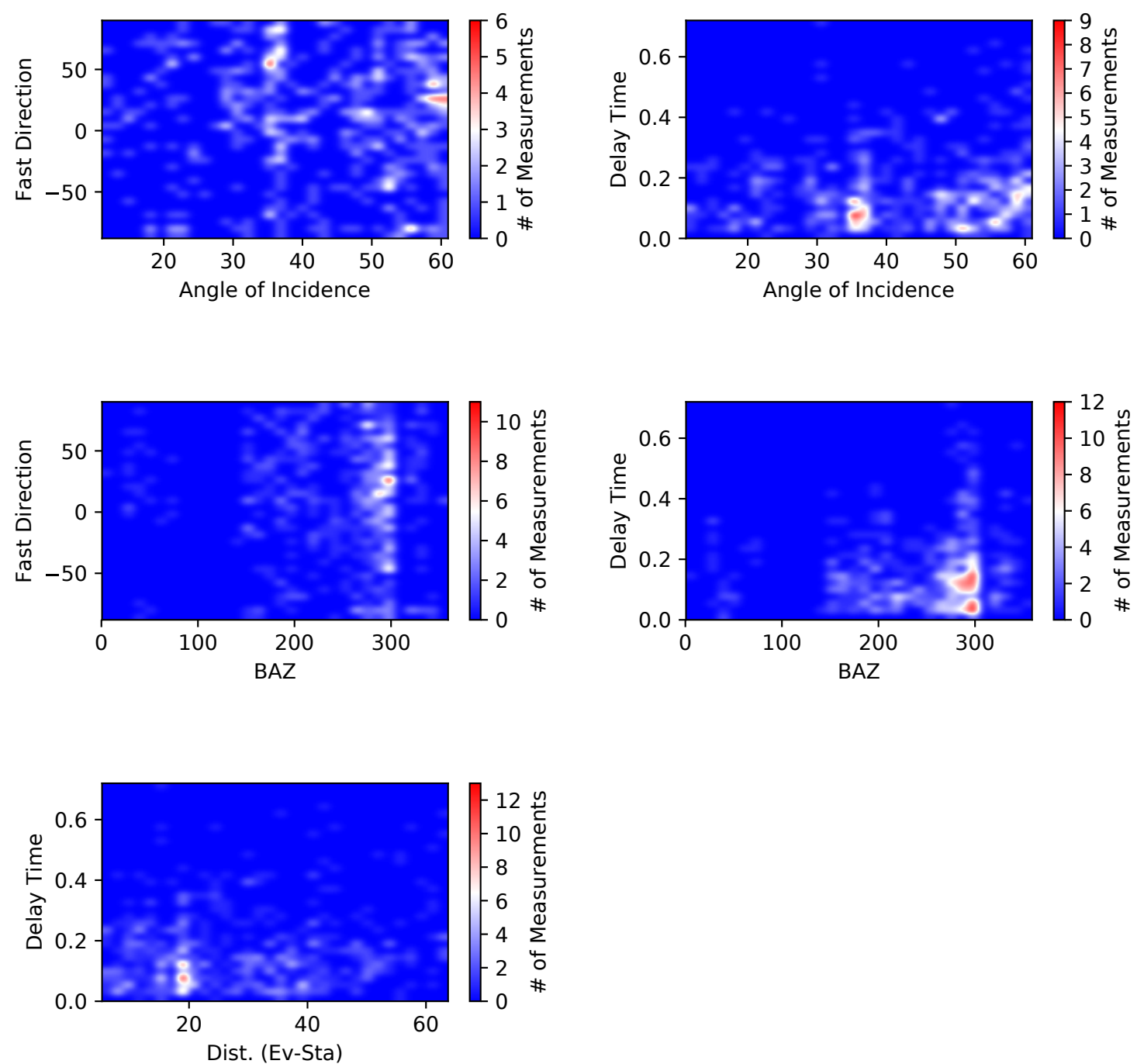

Figure 10.9: Density plots comparing various attributes of the A and B splitting measurements made using MFAST from the four closest earthquakes. Measurement attributes compared are: angle of incidence, back azimuth, delay time, distance (earthquake - station), and fast direction azimuth. No one attribute shows a strong dependence on any other, indicating a singular source for the anisotropy measurements calculated. For all other features see Figure S4. 


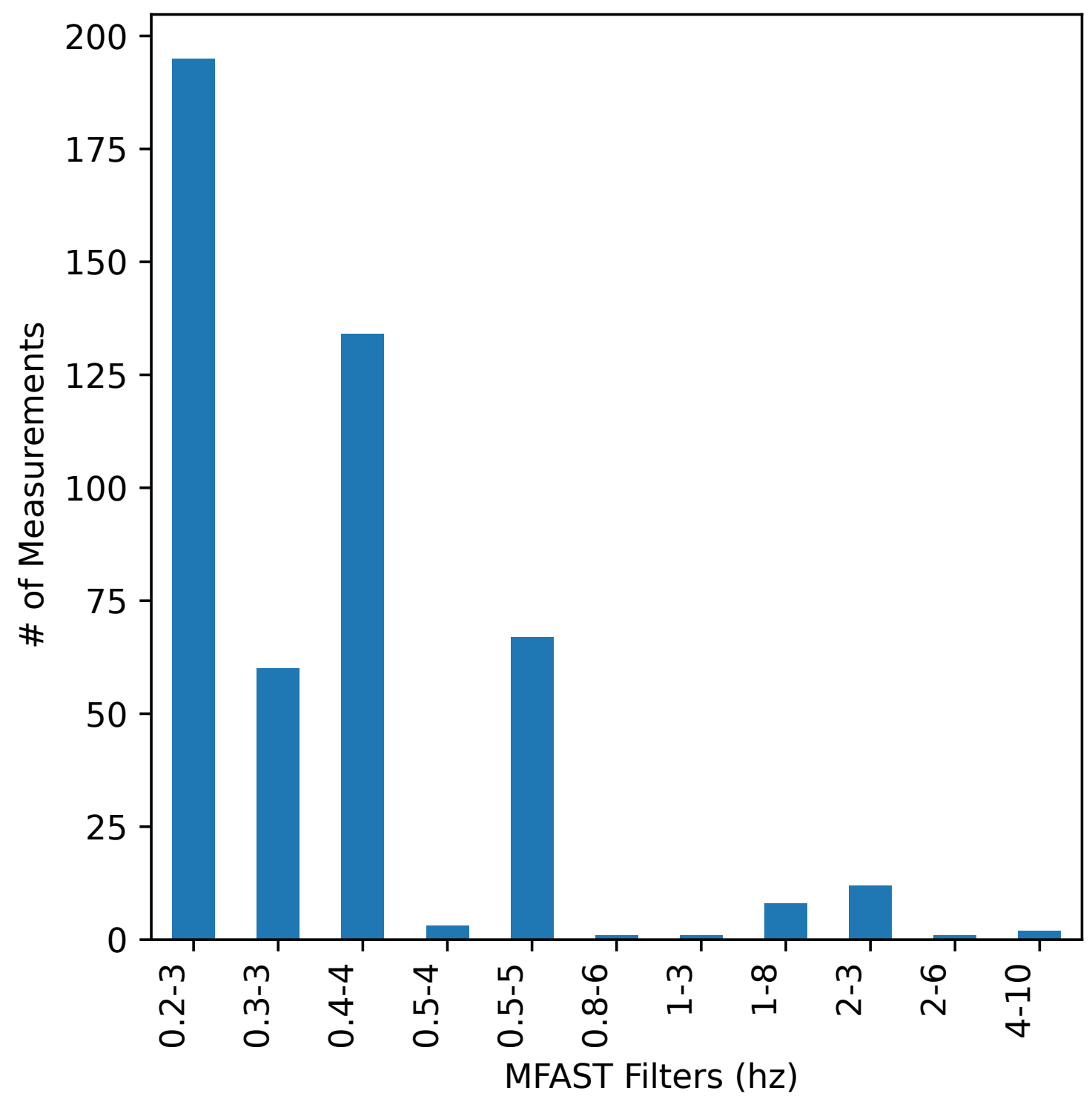

Figure 10.10: MFAST filters used in splitting calculation of the A and B splitting measurements from the four closest earthquakes. Lower frequency (0.2 $5 \mathrm{~Hz}$ ) filters gave more high quality (A \& B quality) measurements. 


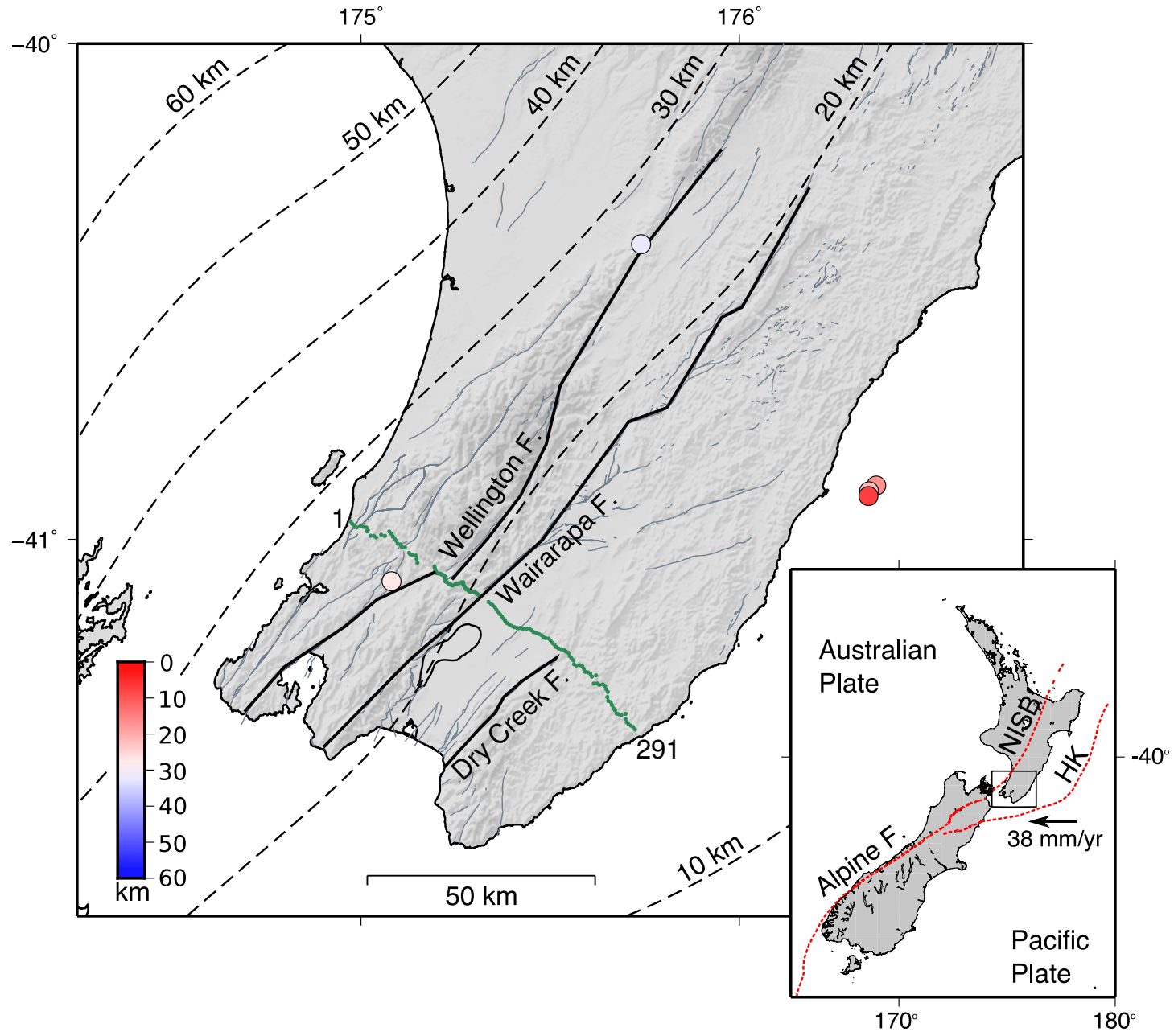

Figure 10.11: Location of 291 high frequency seismic stations (Green circles - appears as Green line) and five randomly chosen earthquakes, colored by depth. For all other features see Figure S1. 


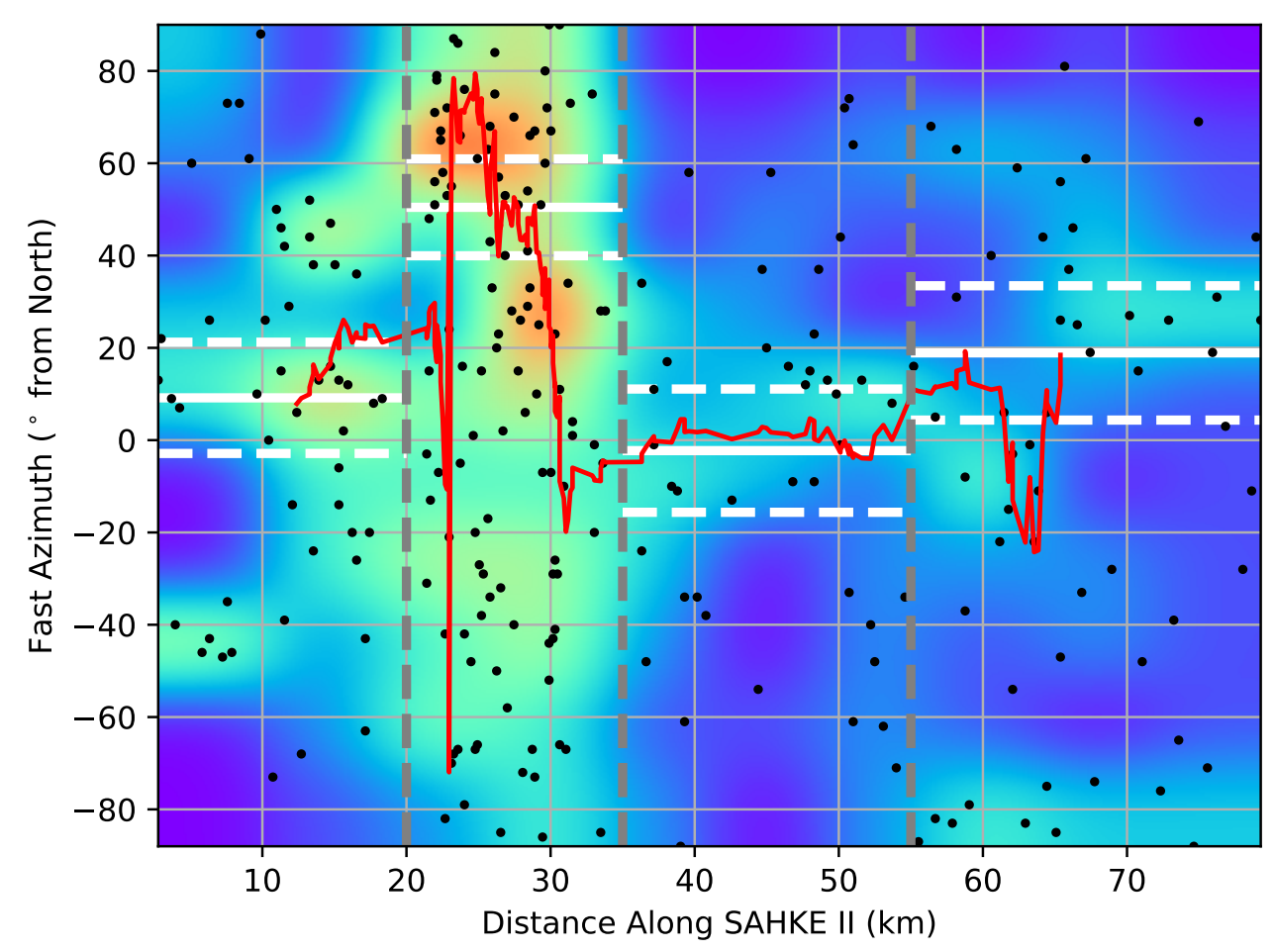

Figure 10.12: Fast azimuth (degrees from North) measurements from the four closest earthquakes to the SAHKE II array as a function of distance along the SAHKE II array. Red line is the 25-point moving average. For all other features see Figure $\mathrm{S} 2$. 


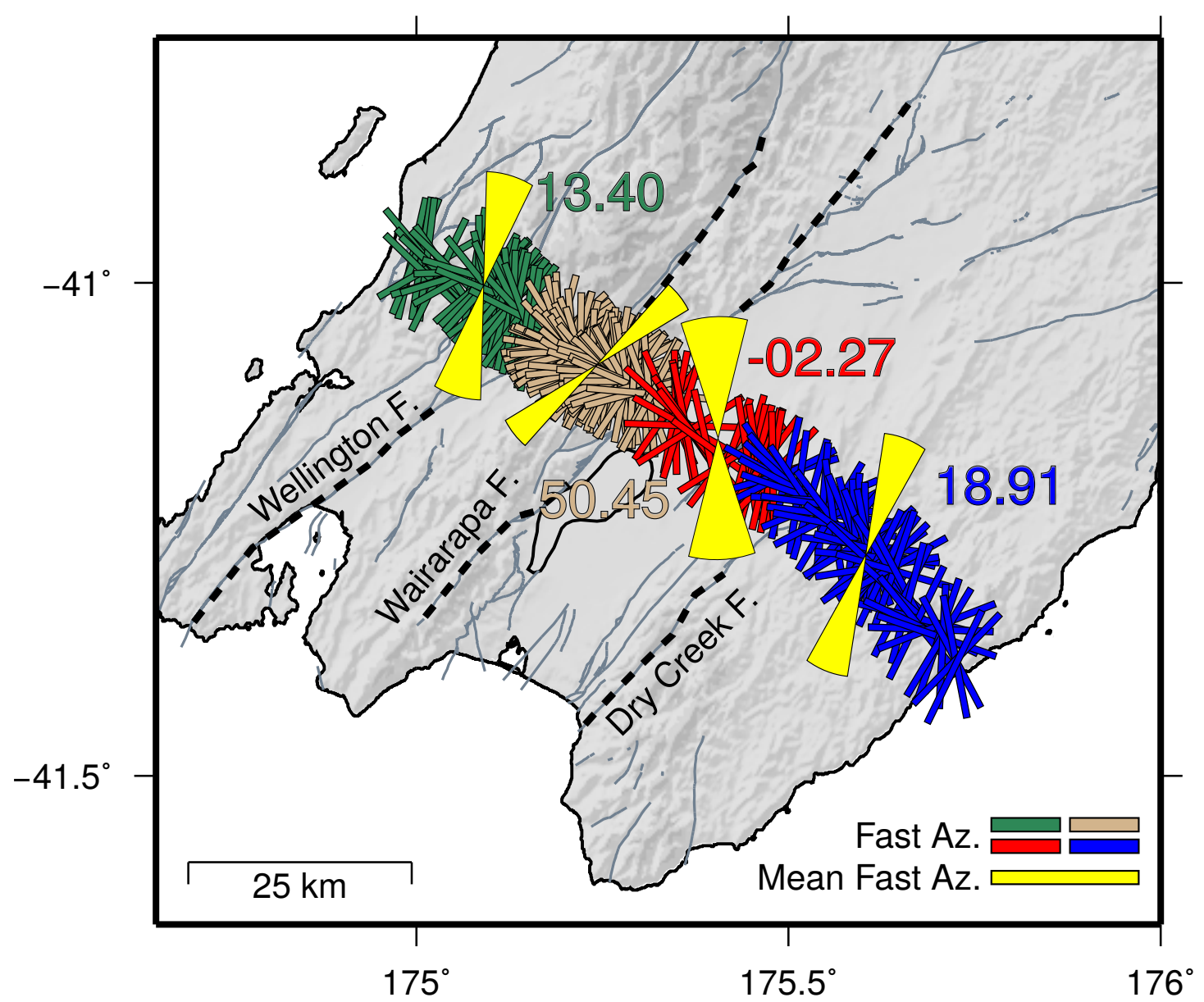

Figure 10.13: Mean fast azimuth for each seismic station using the five randomly chosen earthquakes. Colors (e.g., green, tan, red, blue) indicate grouping of mean azimuths for averaging. For all features see Figure S3. 

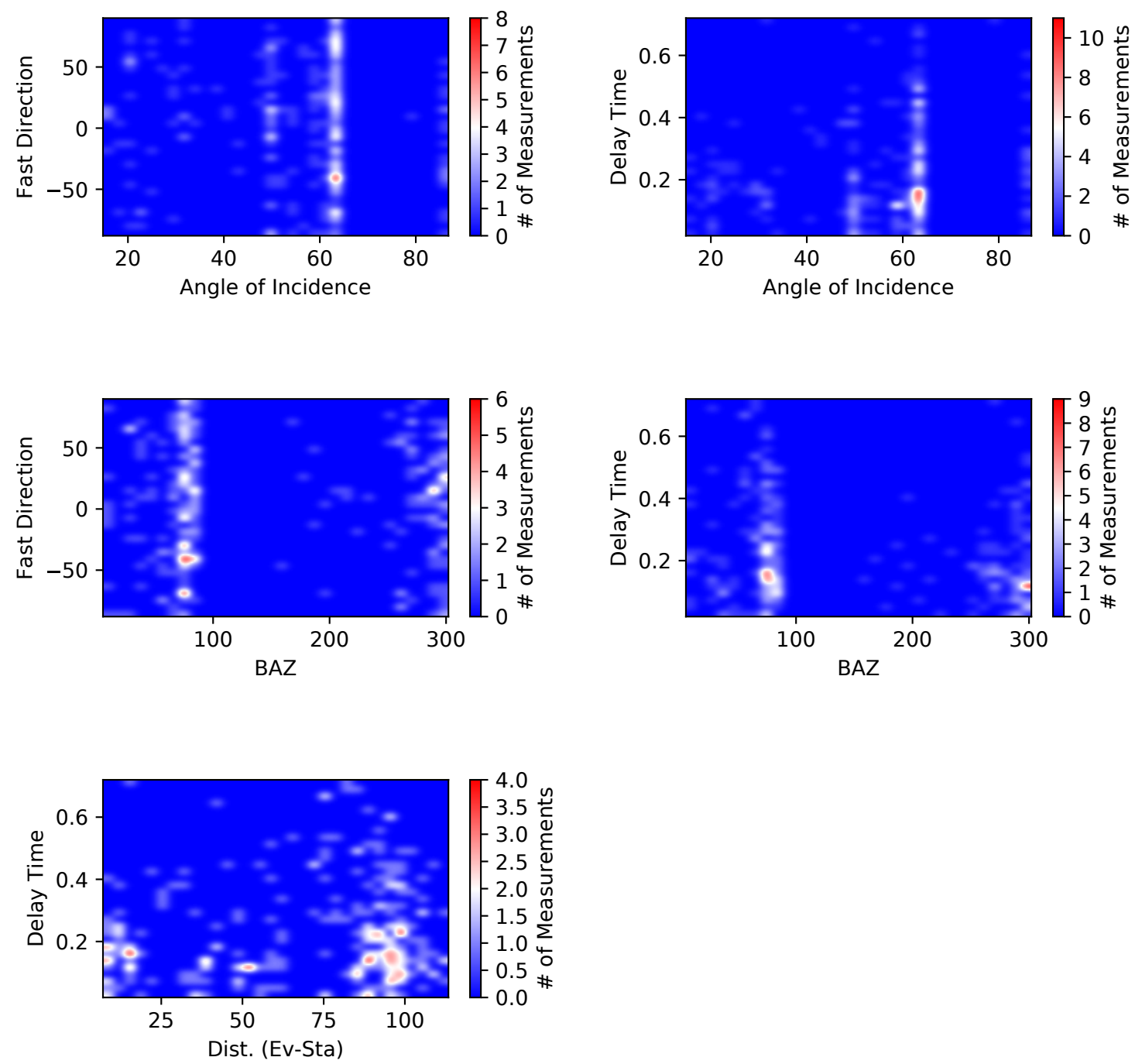

Figure 10.14: Density plots comparing various attributes of the A and B splitting measurements made using MFAST from the five randomly chosen earthquakes. Measurement attributes compared are: angle of incidence, back azimuth, delay time, distance (earthquake - station), and fast direction azimuth. No one attribute shows a strong dependence on any other, indicating a singular source for the anisotropy measurements calculated. For all other features see Figure S4. 


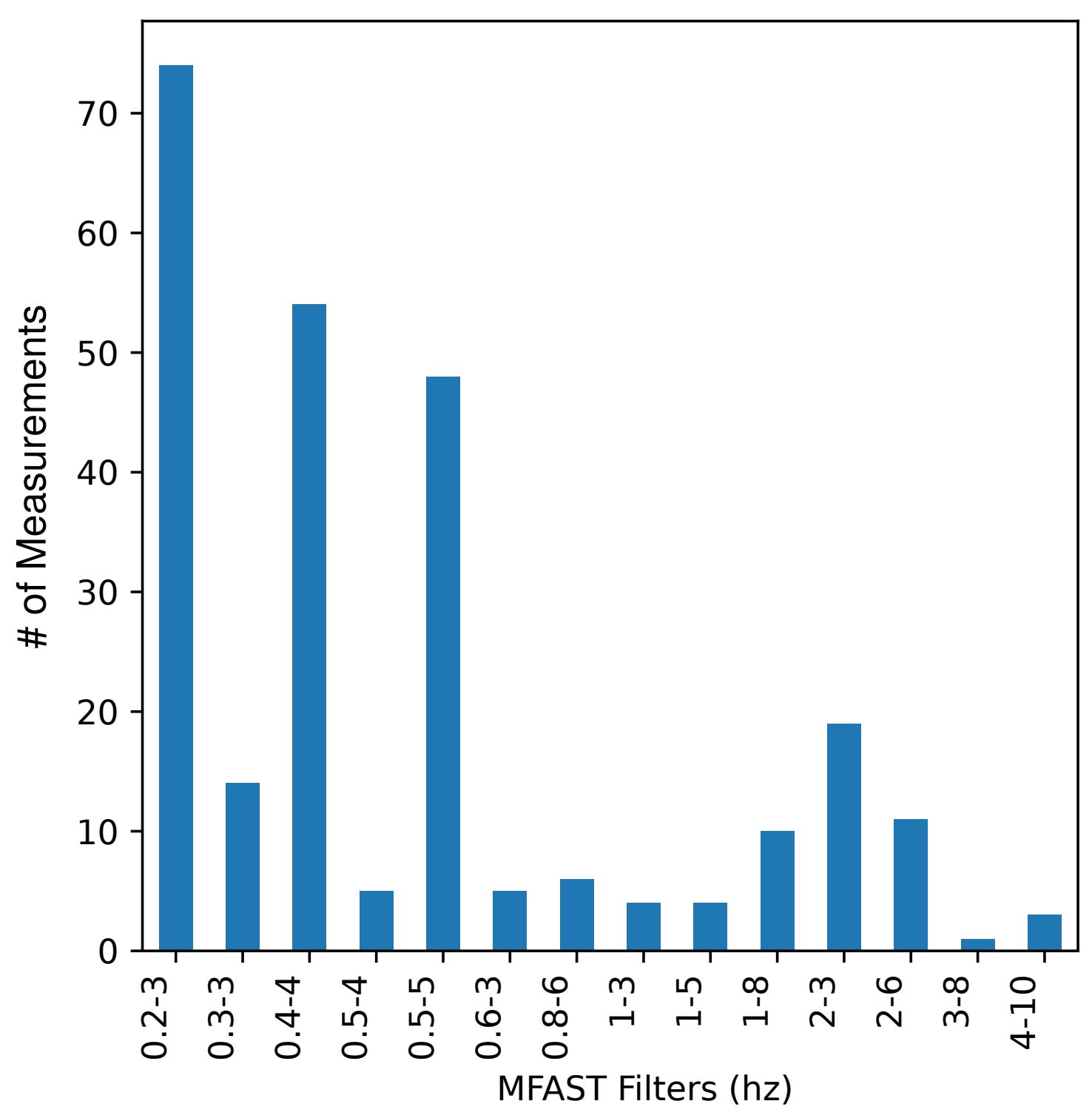

Figure 10.15: MFAST filters used in splitting calculation of the A and B splitting measurements from the five randomly chosen earthquakes. Lower frequency $(0.2-5 \mathrm{~Hz})$ filters gave more high quality (A \& B quality) measurements. 


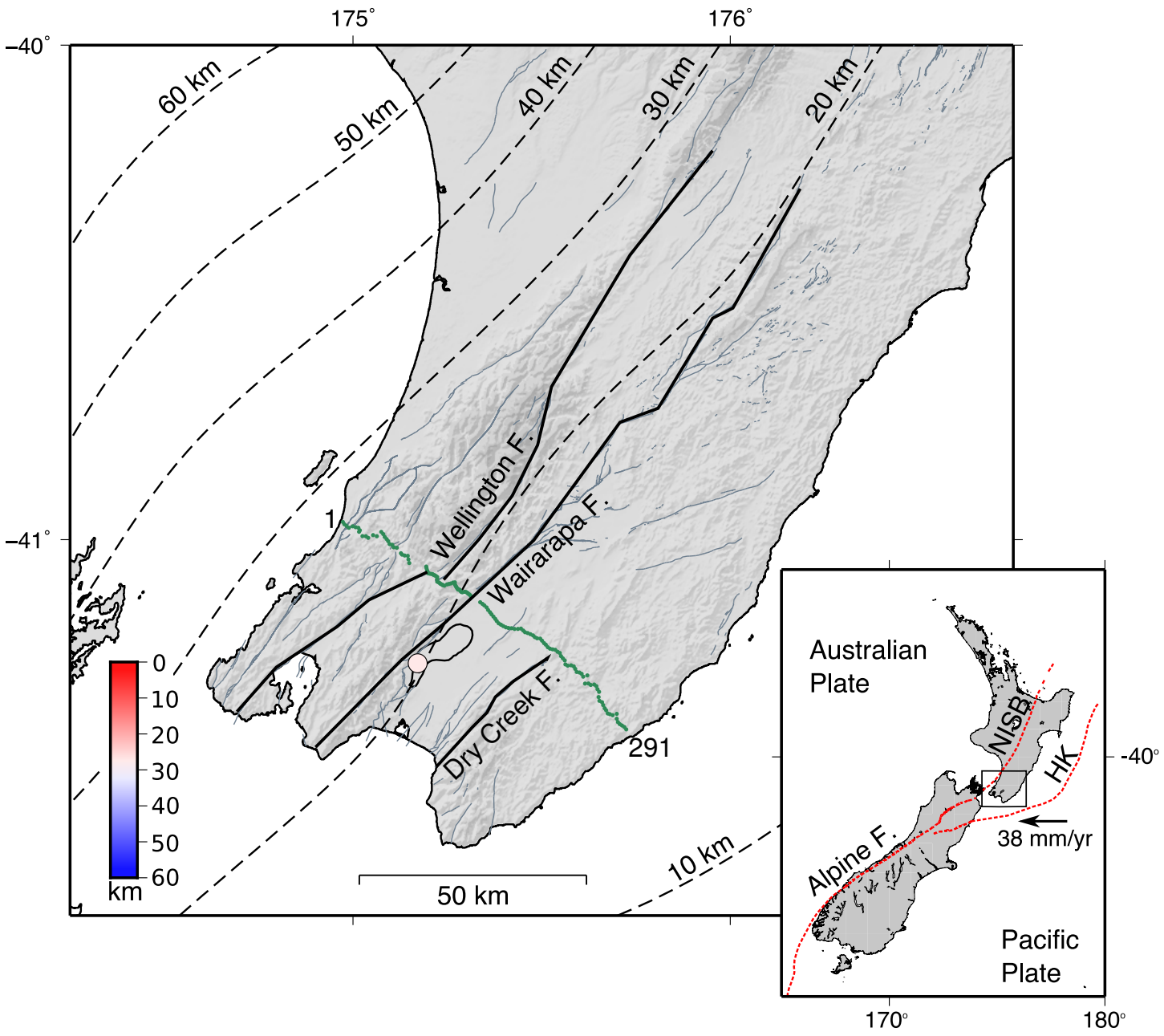

Figure 10.16: Location of 291 high frequency seismic stations (Green circles appears as Green line) and a single earthquake, colored by depth, with lots measurements. For all other features see Figure S1. 


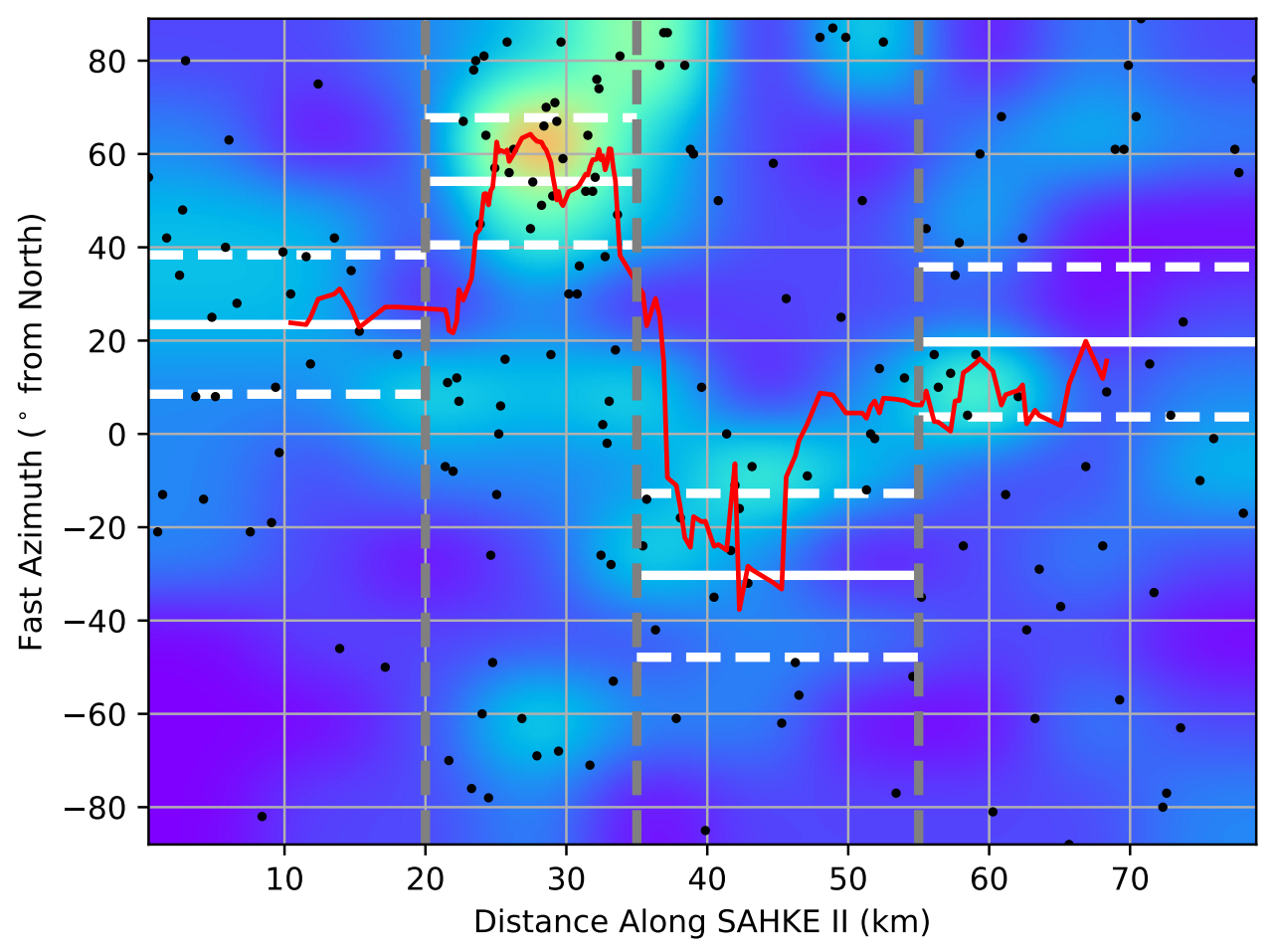

Figure 10.17: Fast azimuth (degrees from North) measurements from a single earthquake source as a function of distance along the SAHKE II array. Red line is the 20-point moving average. For all other features see Figure S2. 


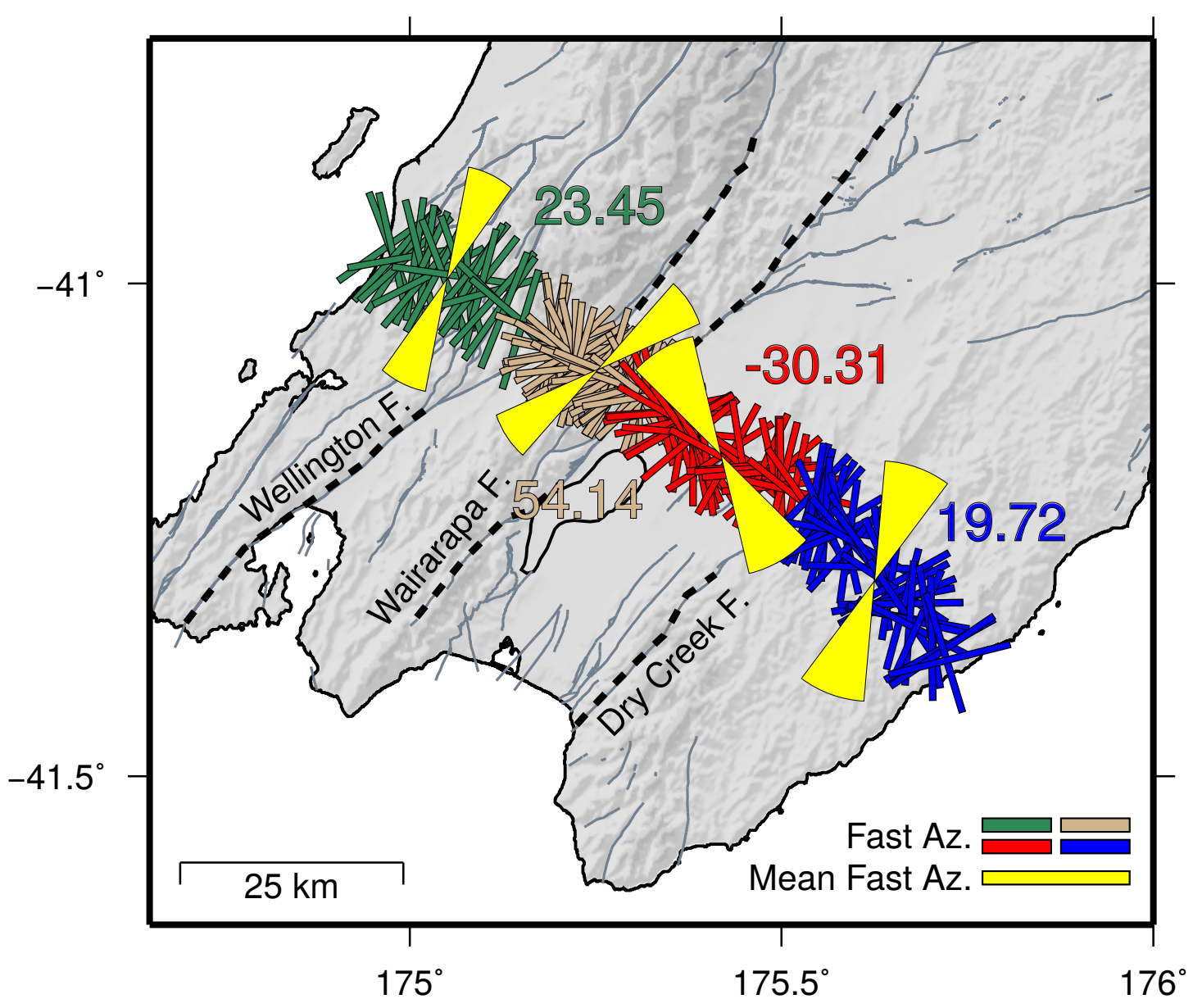

Figure 10.18: Mean fast azimuth for each seismic station using a single earthquake source. Colors (e.g., green, tan, red, blue) indicate grouping of mean azimuths for averaging. For all features see Figure S3. 

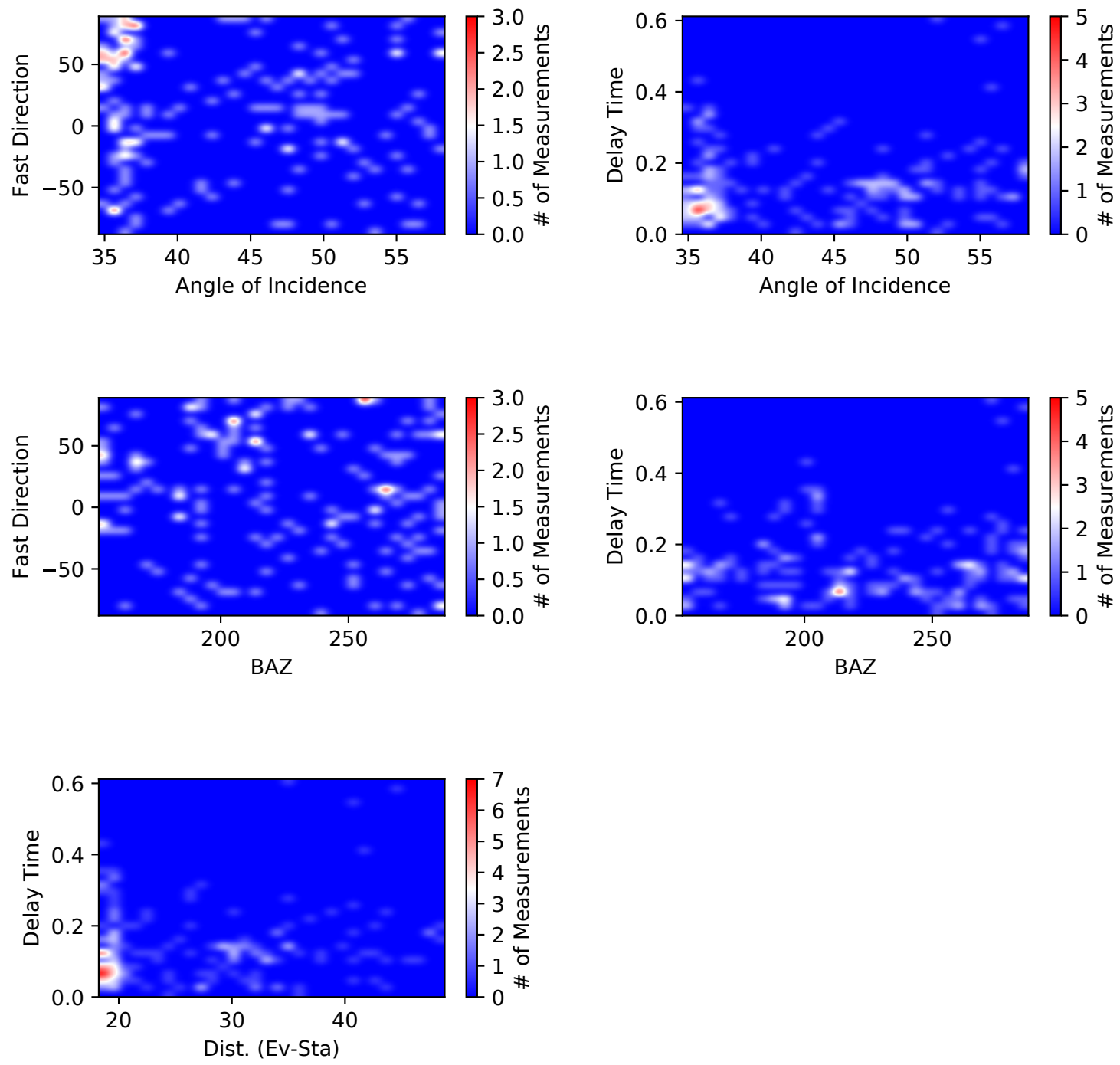

Figure 10.19: Density plots comparing various attributes of the A and B splitting measurements made using MFAST from a single earthquake source. Measurement attributes compared are: angle of incidence, back azimuth, delay time, distance (earthquake - station), and fast direction azimuth. No one attribute shows a strong dependence on any other, indicating a singular source for the anisotropy measurements calculated. For all other features see Figure S4. 


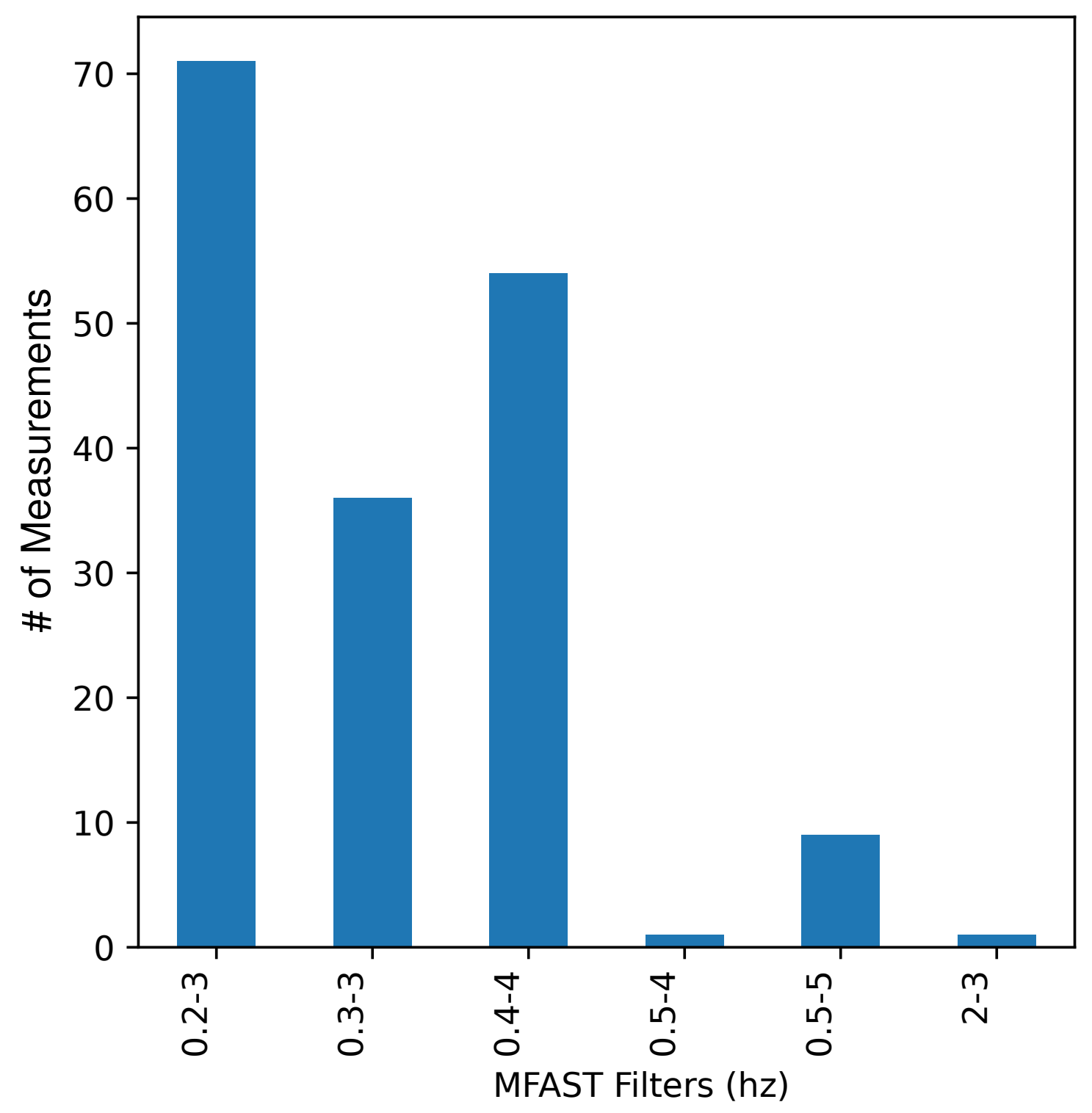

Figure 10.20: MFAST filters used in splitting calculation of the A and B splitting measurements from a single earthquake source. Lower frequency (0.2 - 5 $\mathrm{Hz}$ ) filters gave more high quality (A \& B quality) measurements. 

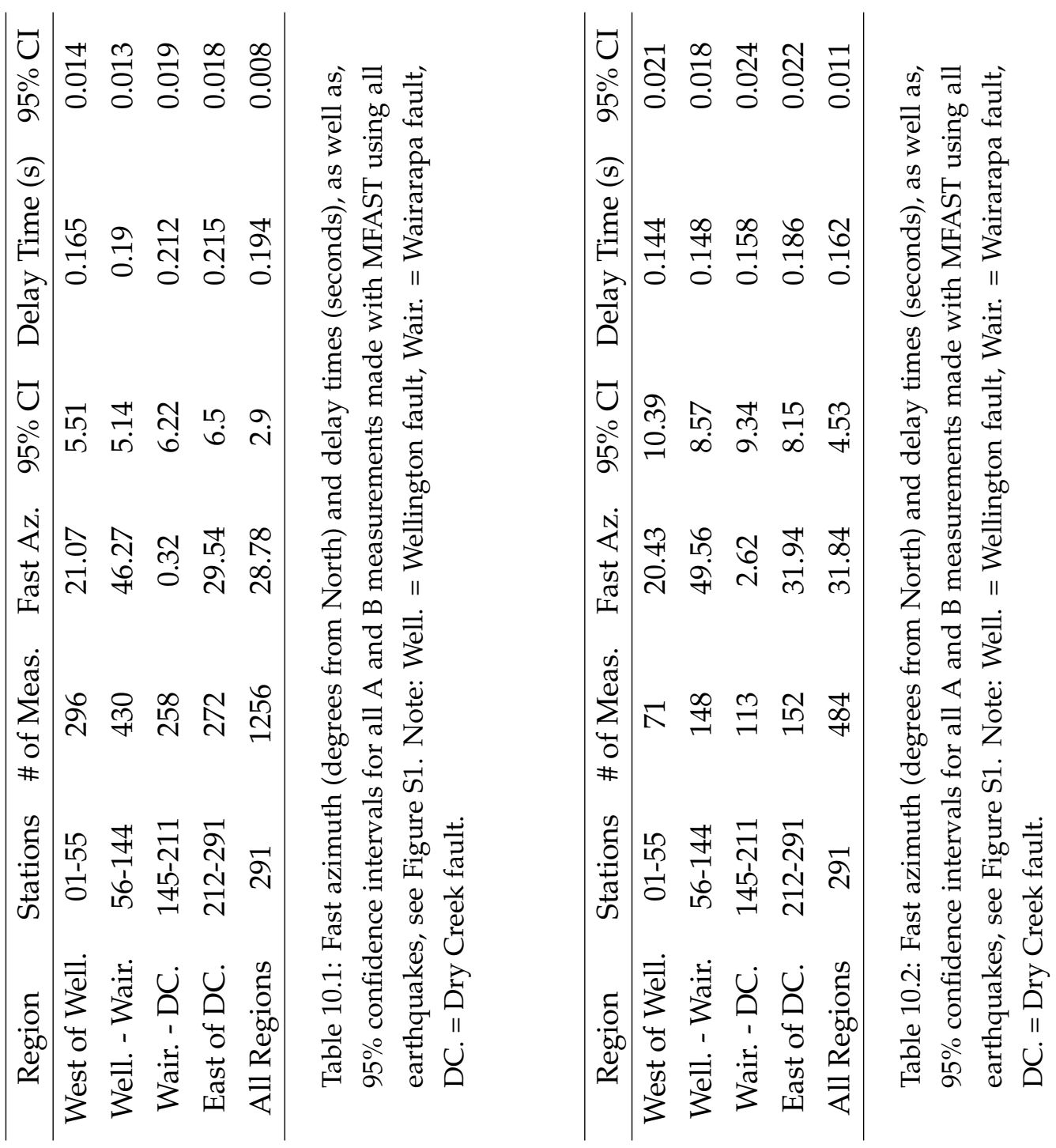

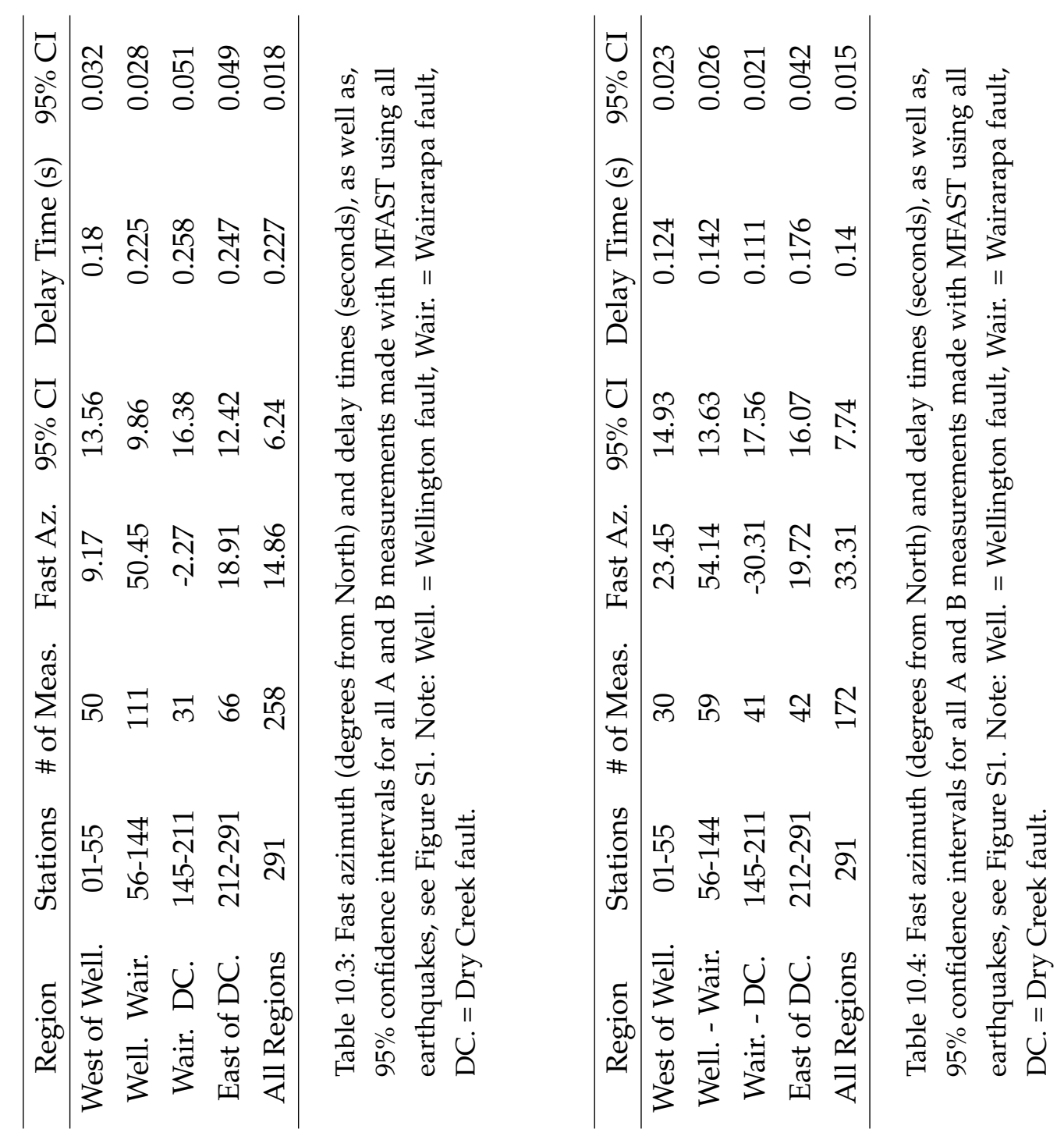


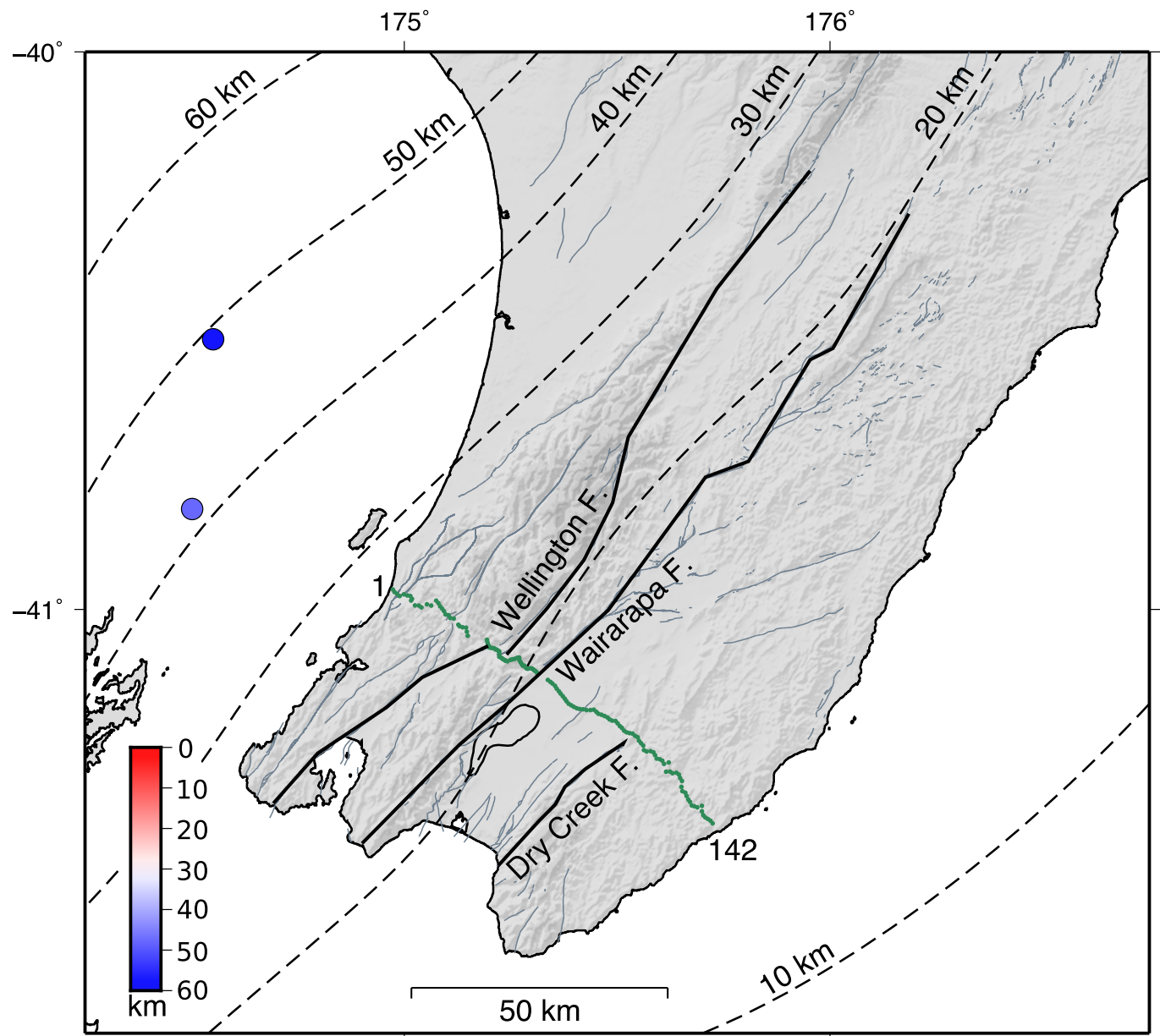

Figure 10.21: Location of 291 high frequency seismic stations (Green circles appears as Green line) and a single earthquake, colored by depth, with lots measurements. For all other features see Figure S1. 


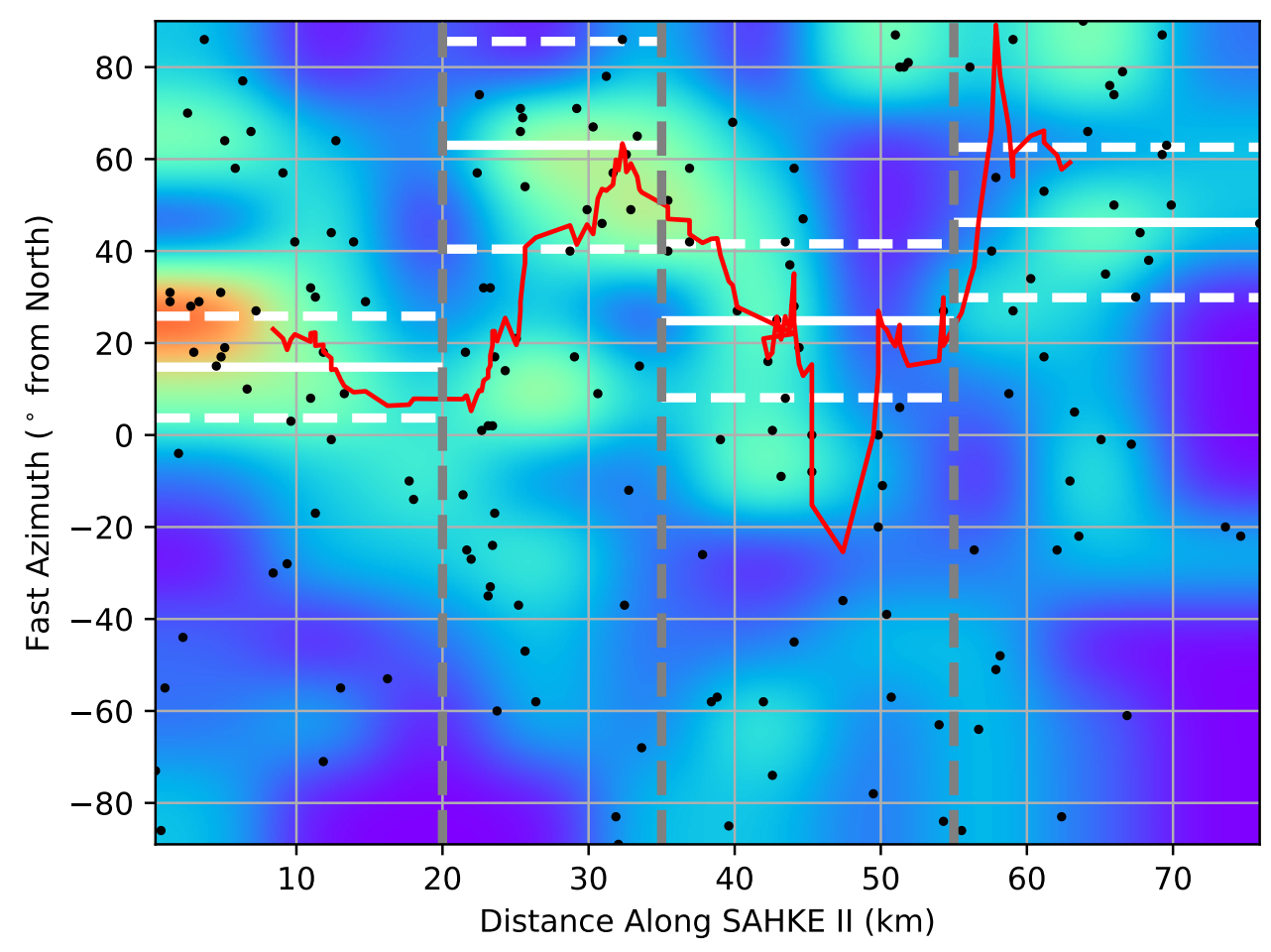

Figure 10.22: Fast azimuth (degrees from North) measurements from 2 deep earthquake source as a function of distance along the SAHKE II array. Red line is the 45-point moving average. For all other features see Figure S2. Possible indication of path affects of shear-wave splitting, but few measurements and large confidence intervals. 

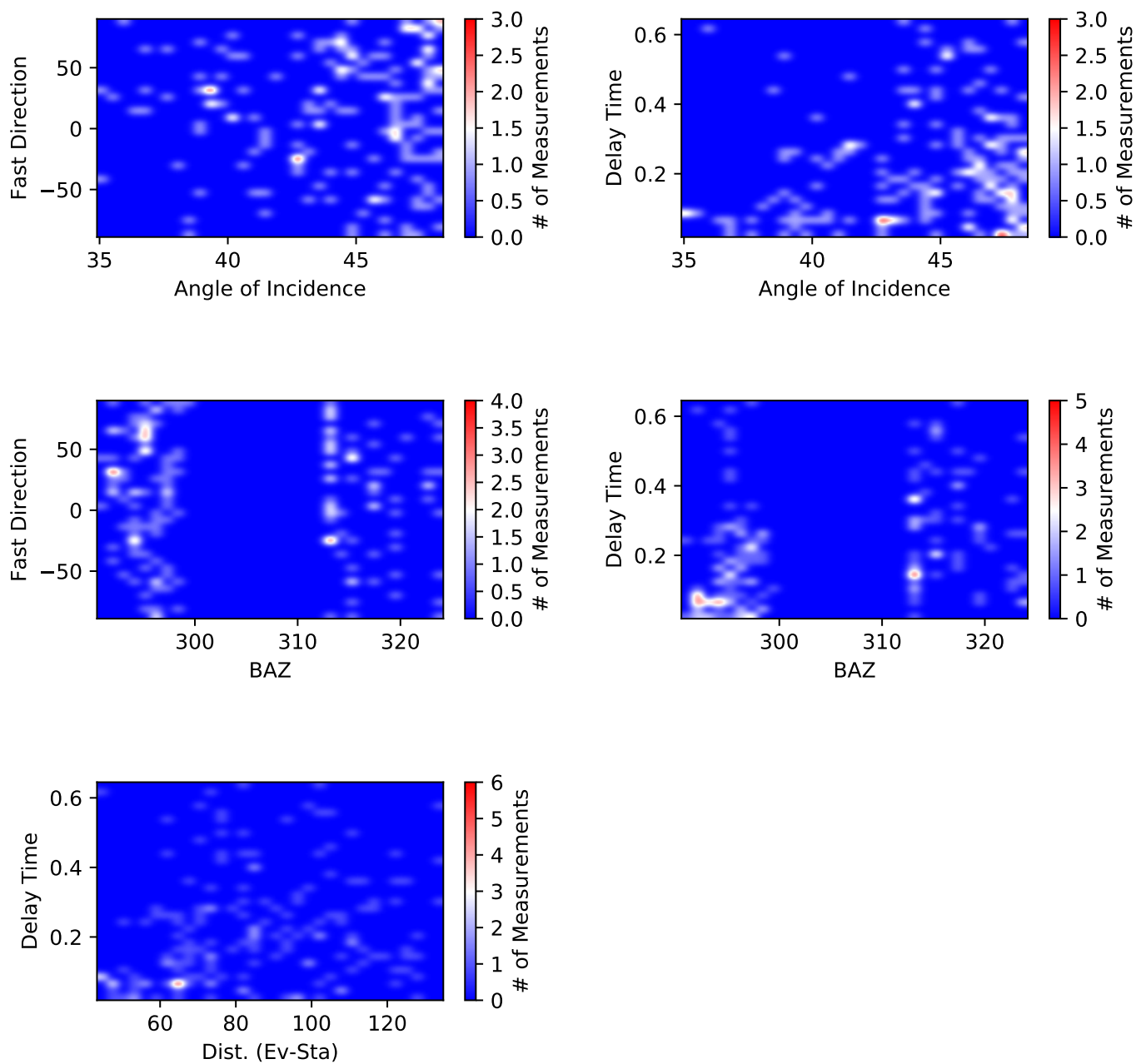

Figure 10.23: Density plots comparing various attributes of the A and B splitting measurements made using MFAST from two deep earthquakes source. Measurement attributes compared are: angle of incidence, back azimuth, delay time, distance (earthquake - station), and fast direction azimuth. No one attribute shows a strong dependence on any other, indicating a singular source for the anisotropy measurements calculated. For all other features see Figure S4. 


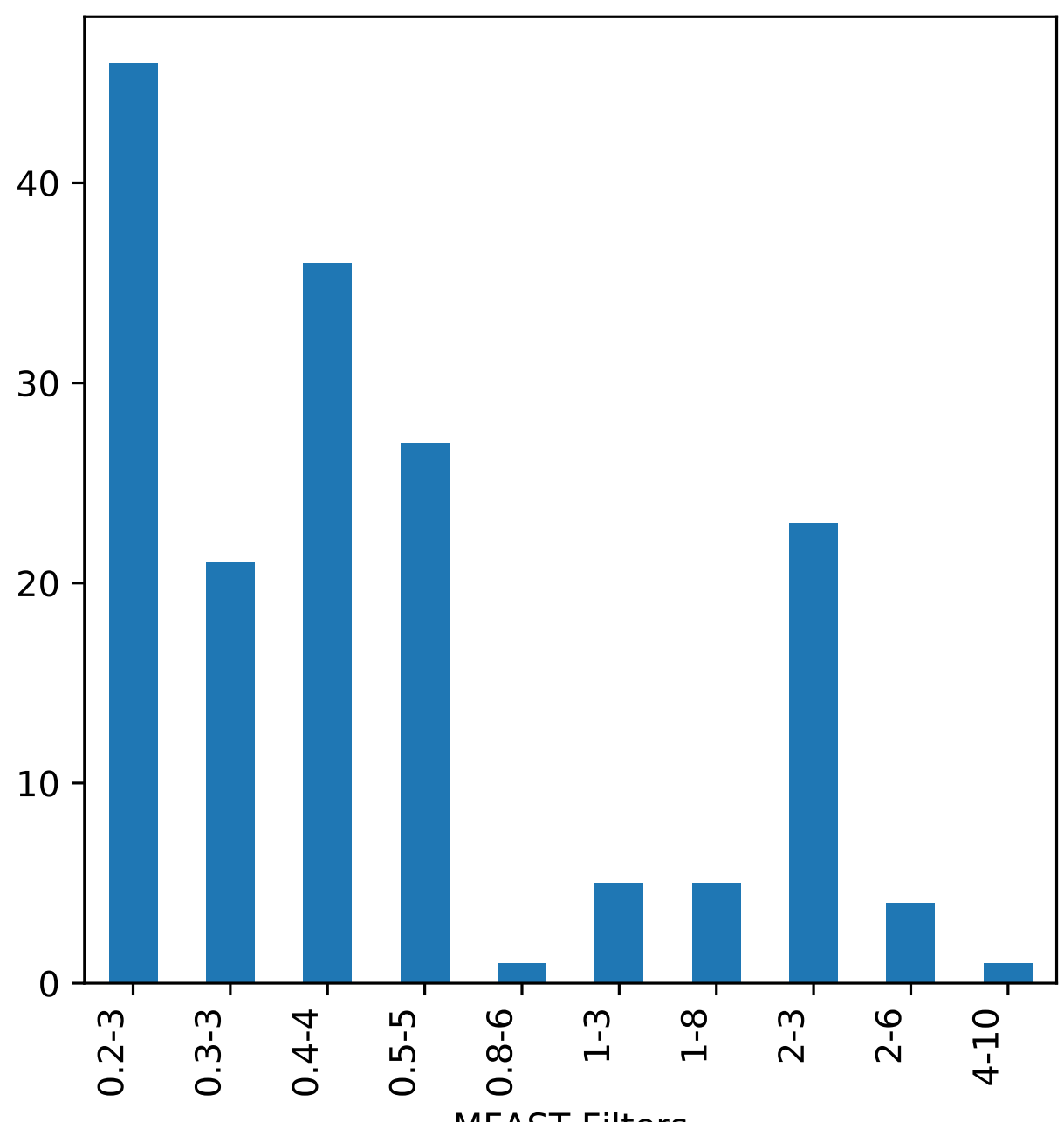

Figure 10.24: MFAST filters used in splitting calculation of the A and B splitting measurements from a single earthquake source. Lower frequency (0.2 - 5 $\mathrm{Hz}$ ) filters gave more high quality (A \& B quality) measurements. 


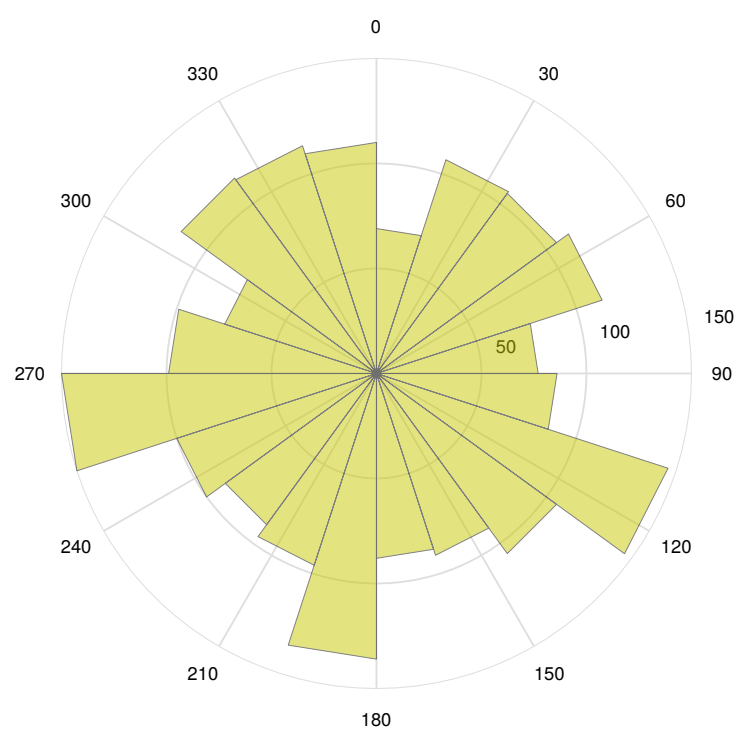

Figure 10.25: Rose diagram of the azimuths of bedding planes throughout the Rakaia Terrane (Begg et al., 2000; Heron).

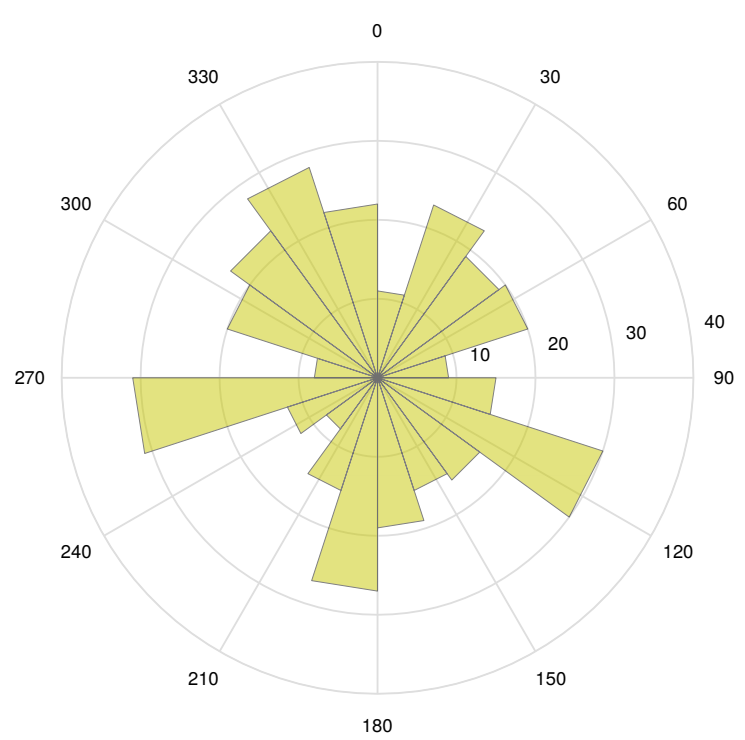

Figure 10.26: Rose diagram of the azimuths of foliation throughout the Rakaia Terrane (Begg et al., 2000; Heron). 


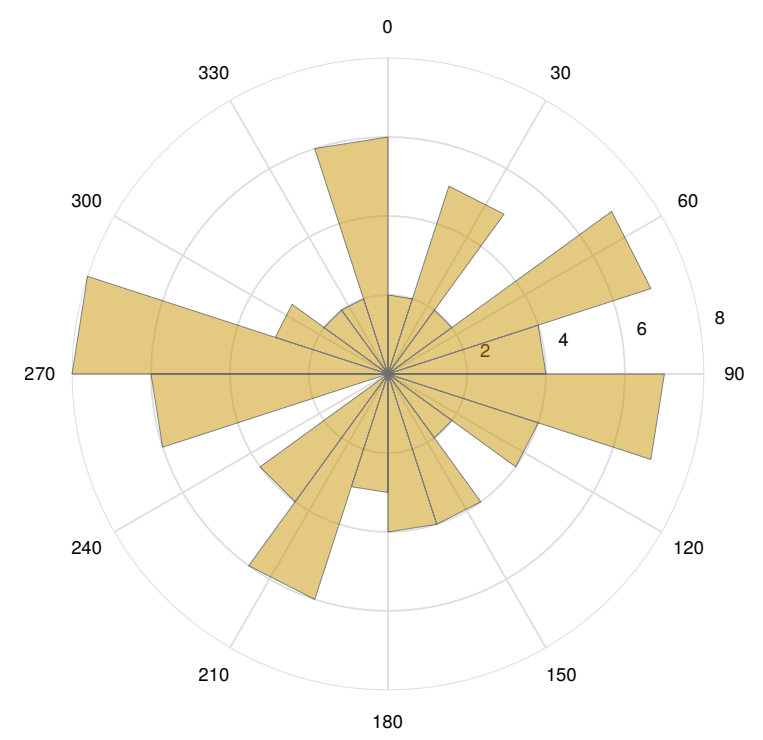

Figure 10.27: Rose diagram of the azimuths of bedding planes of the Rakaia Terrane near the SAHKE II array (Begg et al., 2000; Heron).

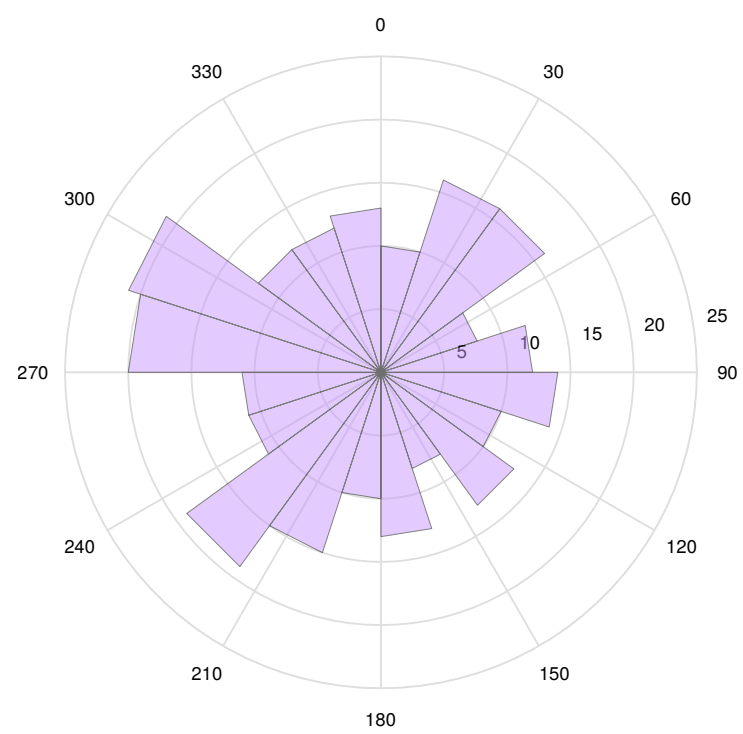

Figure 10.28: Rose diagram of the azimuths of bedding planes throughout the Pahau Terrane (Begg et al., 2000; Heron). 


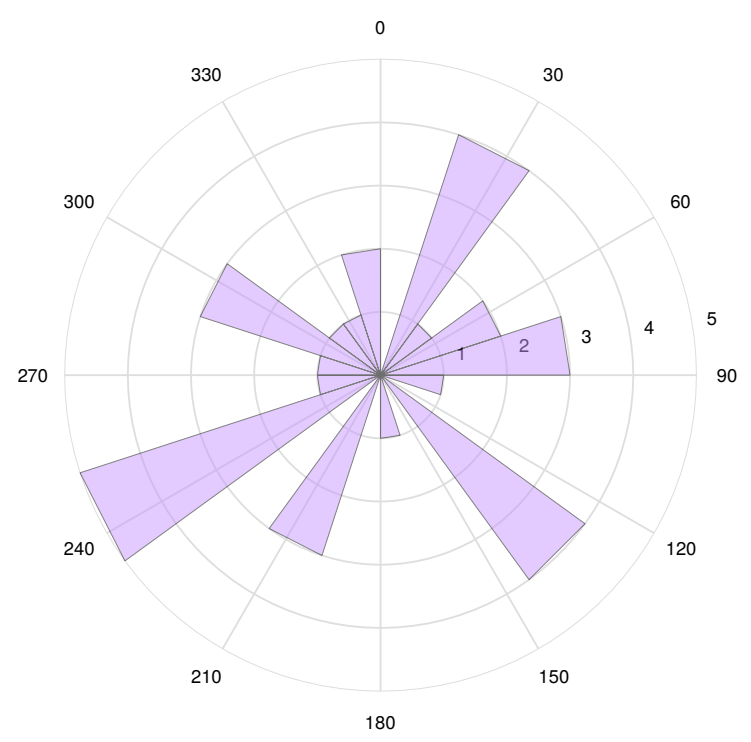

Figure 10.29: Rose diagram of the azimuths of bedding planes of the Pahau Terrane near the SAHKE II array (Begg et al., 2000; Heron). 


\section{Chapter 11}

\section{Appendix D: Preliminary Examination of Long-Term and Short-Term Strain Rates in Central New Zealand}

This chapter provides appendix material for Chapter 6: cGPS Strain Parameters in the Southern North and Northern South Island of New Zealand. Description of Content: Two tables that list the cGPS station velocities for dataset that include and exclude SSEs in both the ITRF2008 and Australian reference frame. A third table gives cGPS velocities averaged over the five days after the $\mathrm{M}_{W} 7.8$ Kairkoura earthquake. 


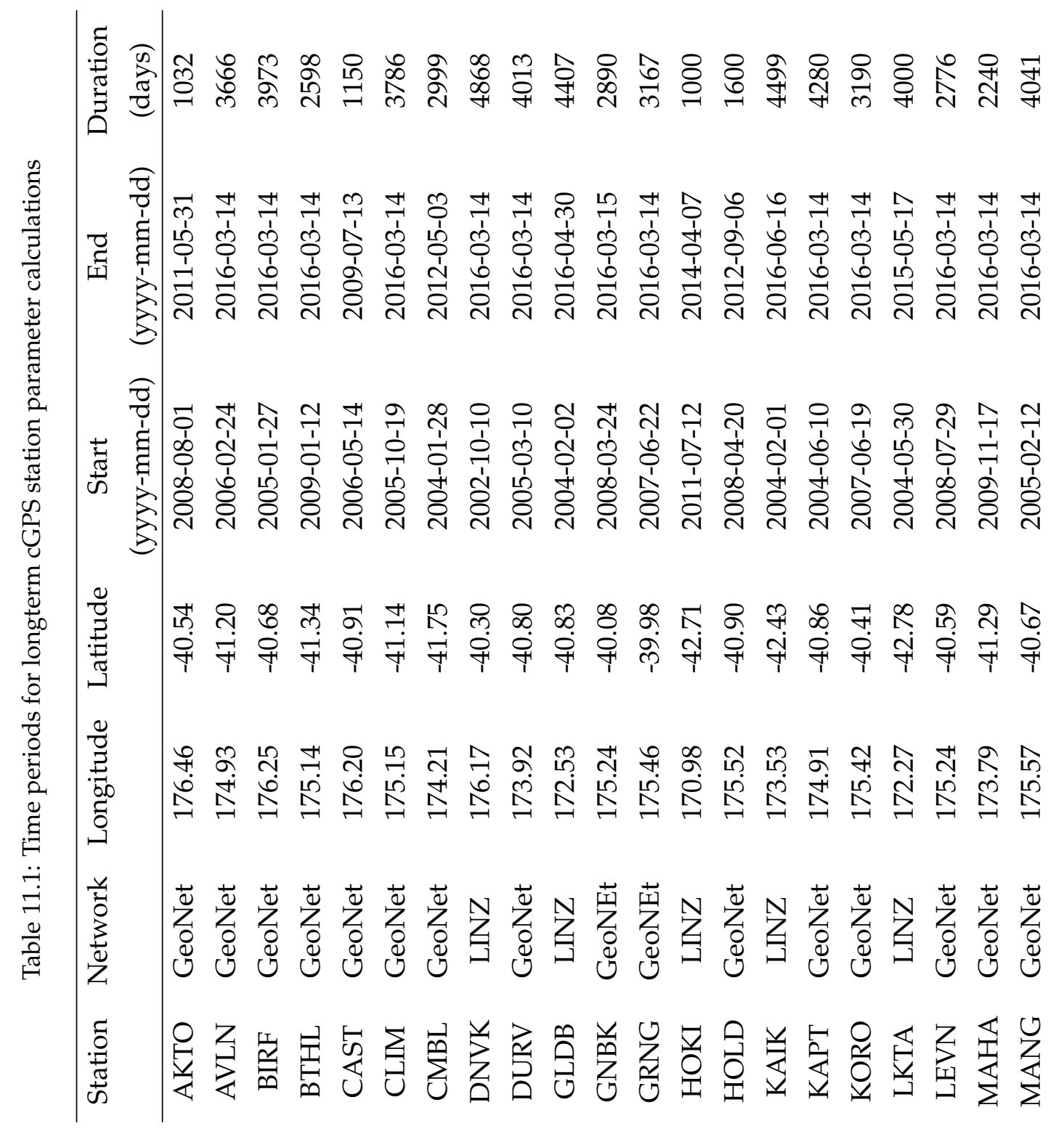




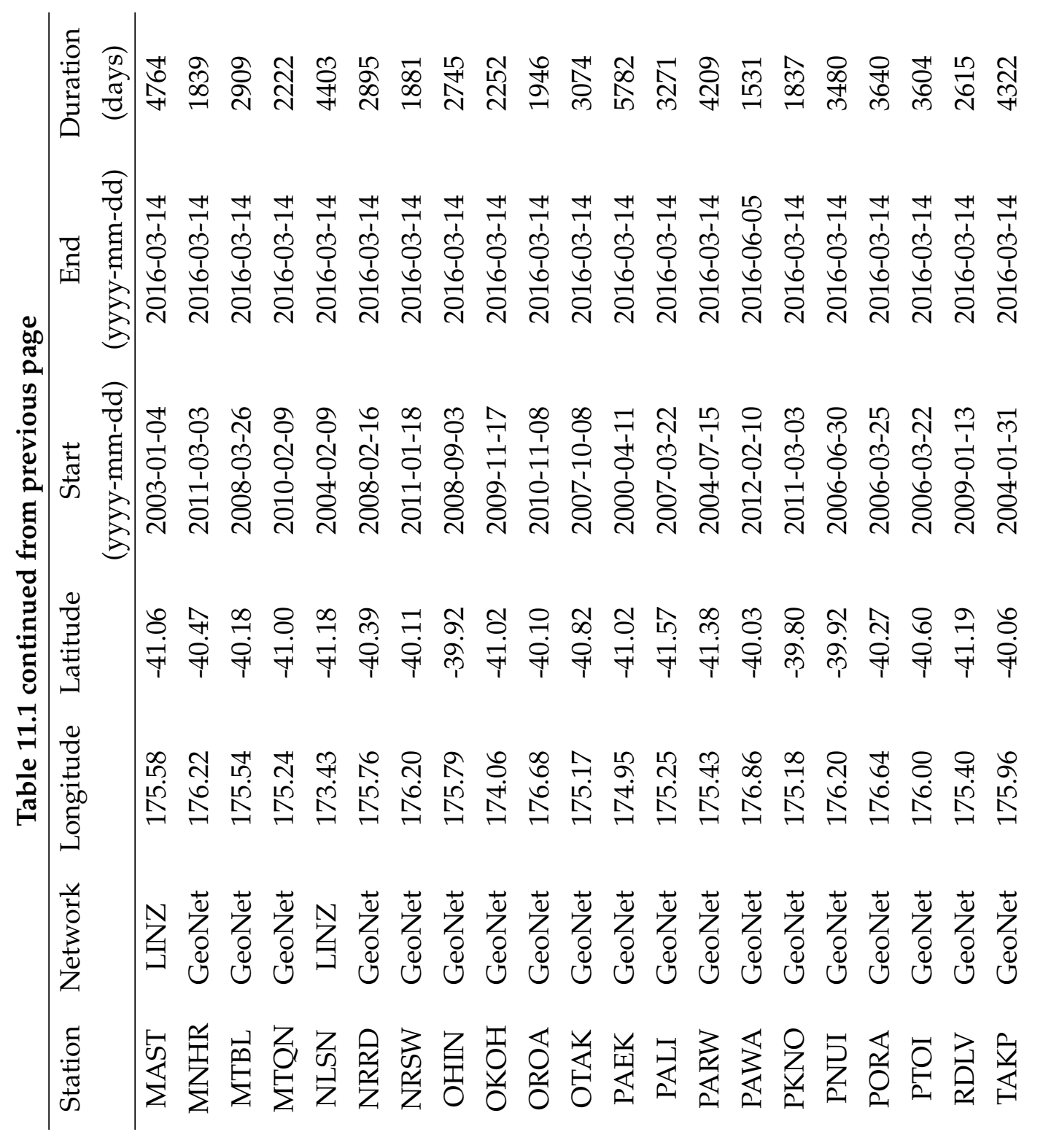




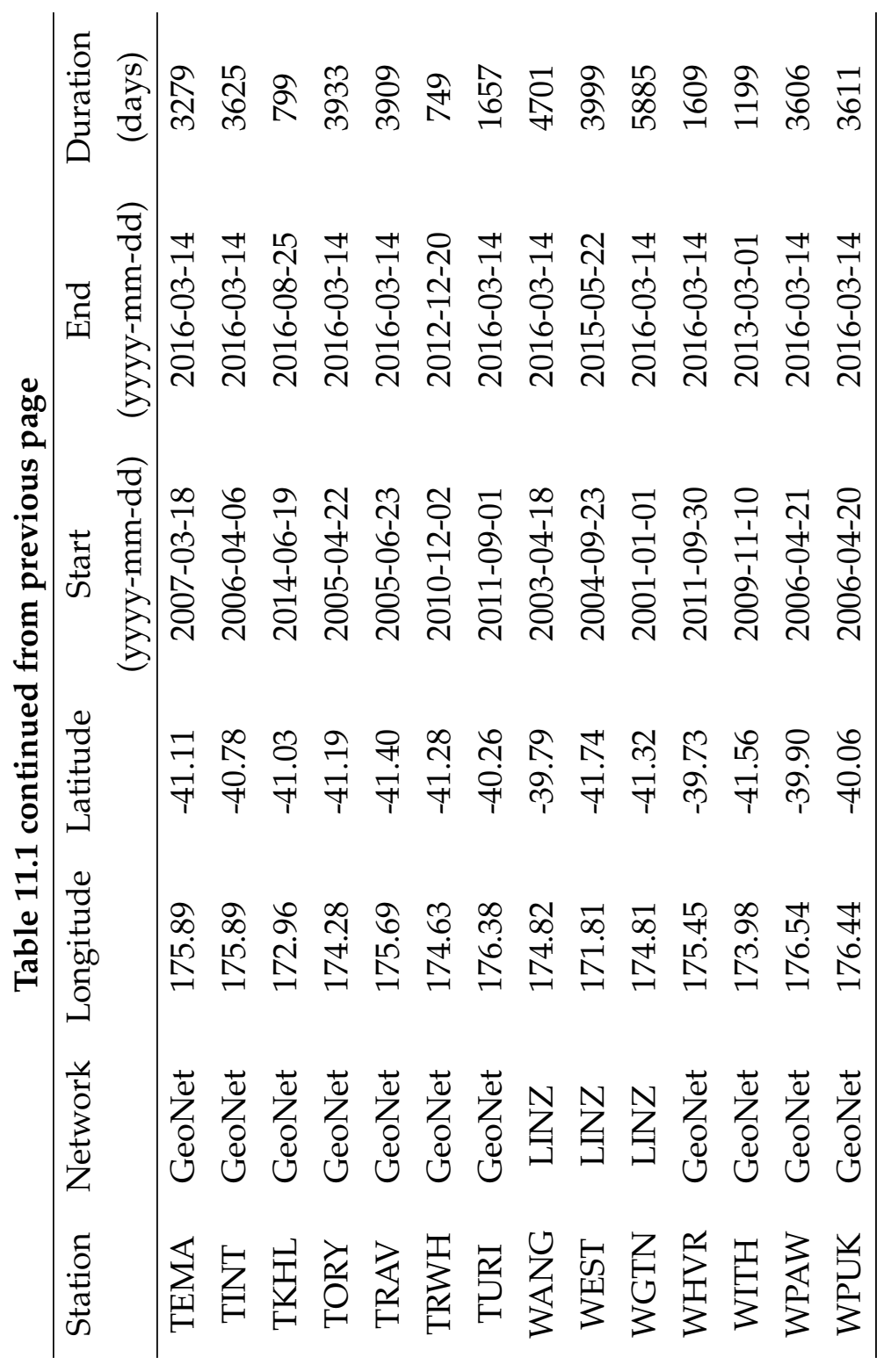




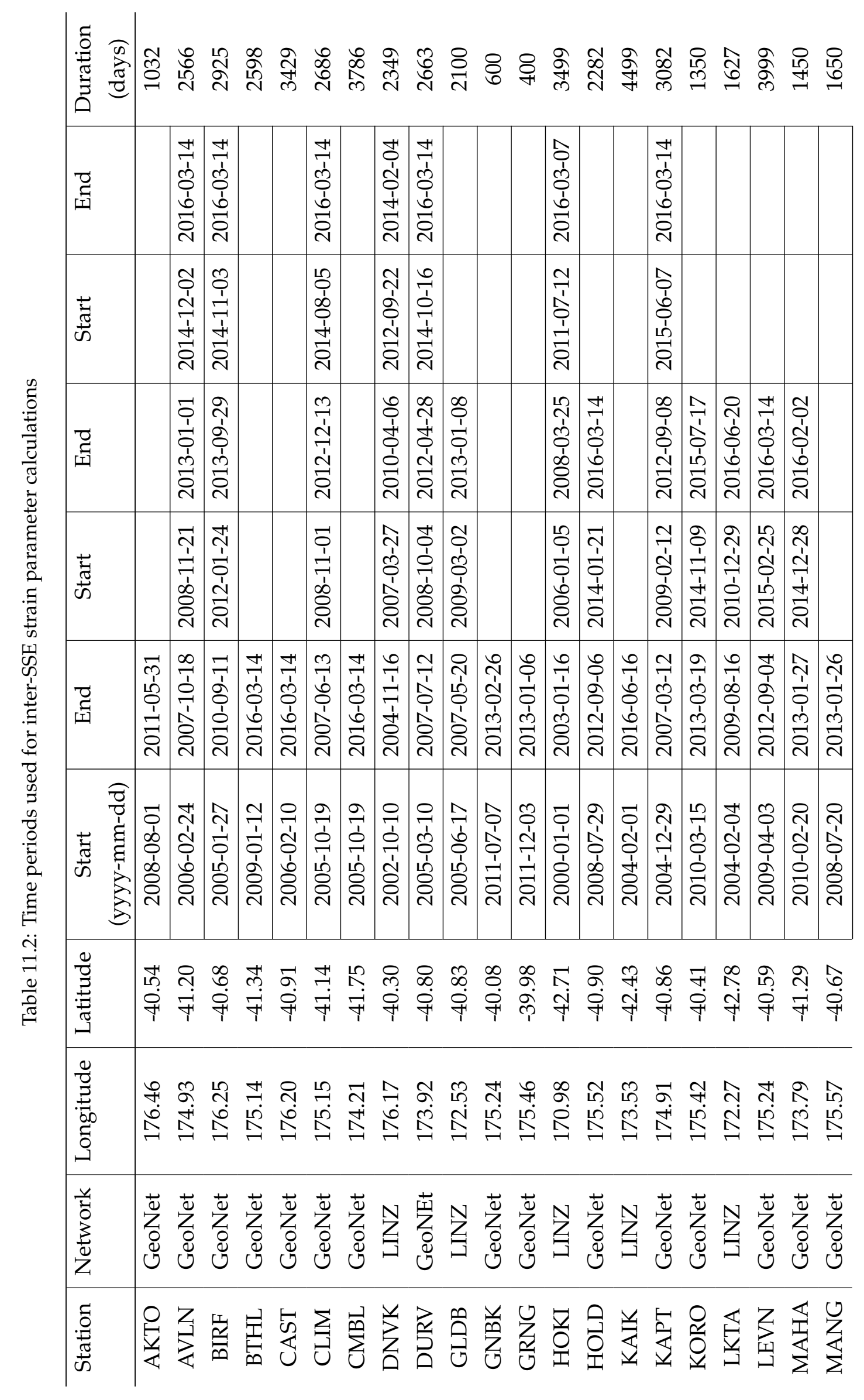




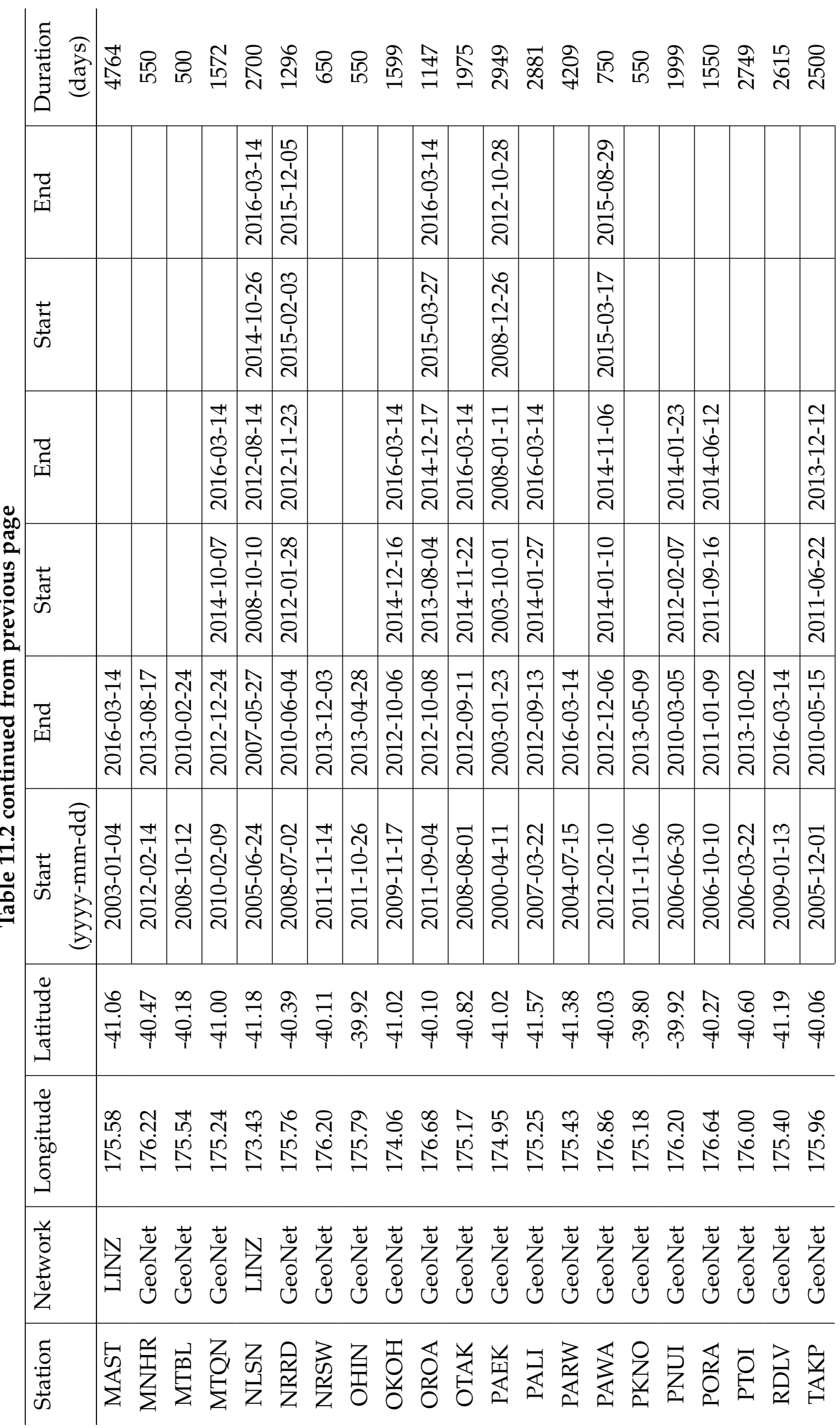




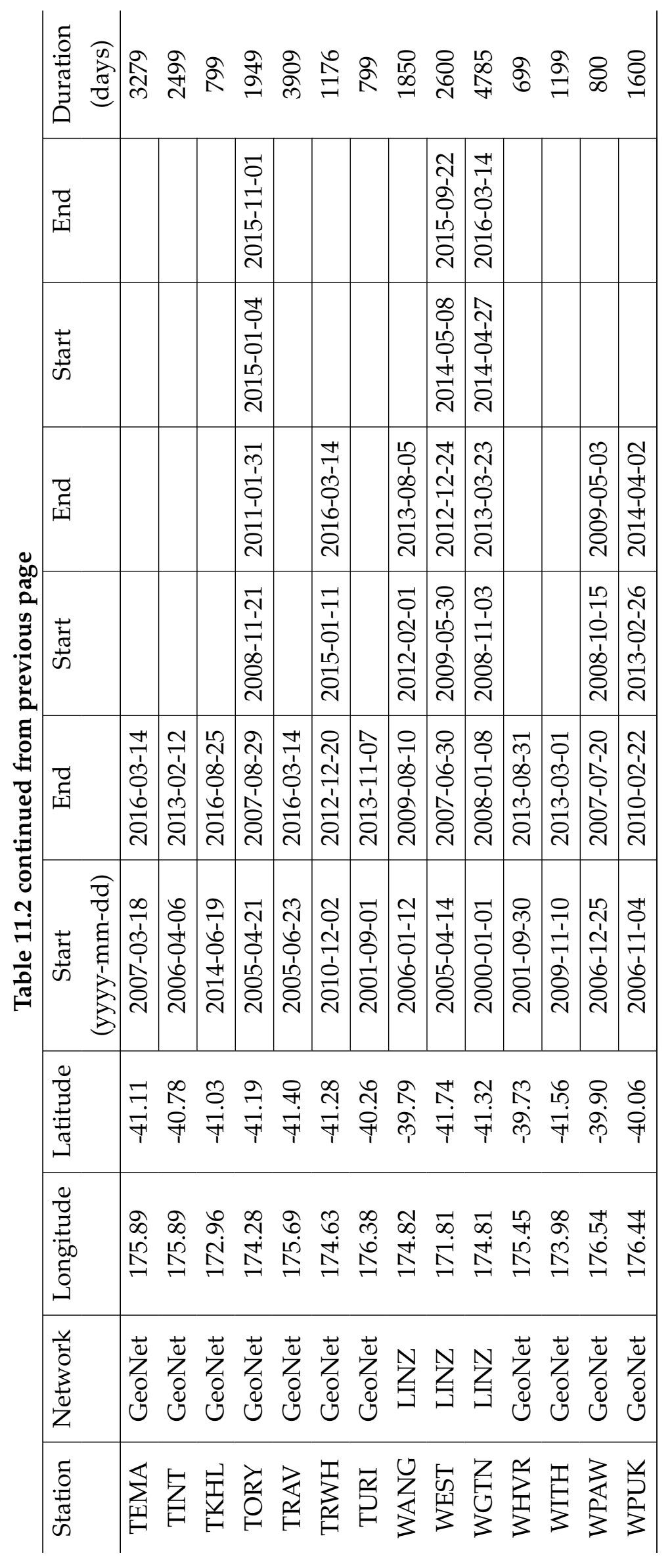


Table 11.3: cGPS station velocities including and excluding SSEs

\begin{tabular}{|c|c|c|c|c|c|c|}
\hline Station & Longitude & Latitude & $\begin{array}{c}\text { SSE: } \\
\mathrm{E}(\mathrm{mm} / \mathrm{yr})\end{array}$ & $\begin{array}{c}\text { SSE: } \\
\mathrm{N}(\mathrm{mm} / \mathrm{yr})\end{array}$ & $\begin{array}{l}\text { Inter SSE: } \\
\mathrm{E}(\mathrm{mm} / \mathrm{yr})\end{array}$ & $\begin{array}{l}\text { Inter SSE: } \\
\mathrm{N}(\mathrm{mm} / \mathrm{yr})\end{array}$ \\
\hline AKTO & 176.46 & -40.54 & -27.01 & 27.27 & -25.11 & 27.27 \\
\hline AVLN & 174.93 & -41.20 & -21.72 & 33.73 & -25.08 & 34.09 \\
\hline BIRF & 176.25 & -40.68 & -25.99 & 29.35 & -28.32 & 29.35 \\
\hline BTHL & 175.14 & -41.34 & -31.17 & 30.99 & -31.17 & 30.99 \\
\hline CAST & 176.20 & -40.91 & -28.07 & 29.49 & -29.13 & 29.24 \\
\hline CLIM & 175.15 & -41.14 & -23.94 & 31.94 & -26.28 & 31.94 \\
\hline CMBL & 174.21 & -41.75 & -24.38 & 32.59 & -24.38 & 32.59 \\
\hline DNVK & 176.17 & -40.30 & -15.44 & 28.73 & -18.14 & 31.54 \\
\hline DURV & 173.92 & -40.80 & -5.29 & 40.81 & -9.71 & 40.81 \\
\hline GLDB & 172.53 & -40.83 & -1.28 & 42.71 & -2.56 & 42.71 \\
\hline GNBK & 175.24 & -40.08 & -3.91 & 34.68 & -10.99 & 34.68 \\
\hline GRNG & 175.46 & -39.98 & -4.31 & 34.05 & -11.32 & 34.05 \\
\hline HOKI & 170.98 & -42.71 & -3.65 & 43.58 & -4.02 & 44.57 \\
\hline HOLD & 175.52 & -40.90 & -24.31 & 30.19 & -23.73 & 30.19 \\
\hline KAIK & 173.53 & -42.43 & -29.24 & 31.65 & -29.24 & 31.65 \\
\hline KAPT & 174.91 & -40.86 & -12.30 & 38.18 & -17.96 & 36.57 \\
\hline KORO & 175.42 & -40.41 & -10.00 & 33.29 & -15.33 & 33.29 \\
\hline LKTA & 172.27 & -42.78 & -22.48 & 32.92 & -22.78 & 32.92 \\
\hline LEVN & 175.24 & -40.59 & -9.82 & 33.65 & -18.10 & 33.65 \\
\hline MAHA & 173.79 & -41.29 & -3.21 & 40.22 & -13.83 & 38.43 \\
\hline MANG & 175.57 & -40.67 & -18.18 & 32.70 & -23.03 & 32.70 \\
\hline MAST & 175.58 & -41.06 & -27.19 & 29.57 & -27.19 & 29.57 \\
\hline MNHR & 176.22 & -40.47 & -19.09 & 27.81 & -23.83 & 29.16 \\
\hline MTBL & 175.54 & -40.18 & -6.57 & 36.83 & -15.11 & 32.16 \\
\hline MTQN & 175.24 & -41.00 & -18.58 & 32.67 & -24.24 & 33.40 \\
\hline NLSN & 173.43 & -41.18 & -4.93 & 40.81 & -8.87 & 41.25 \\
\hline NRRD & 175.76 & -40.39 & -11.86 & 32.23 & -22.01 & 32.41 \\
\hline NRSW & 176.20 & -40.11 & -8.61 & 31.54 & -17.12 & 33.40 \\
\hline OHIN & 175.79 & -39.92 & -3.36 & 34.38 & -13.58 & 30.08 \\
\hline $\mathrm{OKOH}$ & 174.06 & -41.02 & -6.24 & 45.37 & -12.99 & 39.24 \\
\hline OROA & 176.68 & -40.10 & -12.96 & 26.43 & -16.94 & 27.67 \\
\hline OTAK & 175.17 & -40.82 & -14.78 & 35.88 & -21.94 & 34.27 \\
\hline PAEK & 174.95 & -41.02 & -17.45 & 35.66 & -21.61 & 34.86 \\
\hline PALI & 175.25 & -41.57 & -34.82 & 30.70 & -34.20 & 30.70 \\
\hline PARW & 175.43 & -41.38 & -33.62 & 30.73 & -33.62 & 30.73 \\
\hline PAWA & 176.86 & -40.03 & -7.04 & 23.29 & -23.03 & 25.29 \\
\hline PKNO & 175.18 & -39.80 & -2.15 & 38.69 & -8.69 & 37.45 \\
\hline
\end{tabular}


Table 11.3 continued from previous page

\begin{tabular}{ccccccc}
\hline Station & Longitude & Latitude & $\begin{array}{c}\text { SSE: } \\
\mathrm{E}(\mathrm{mm} / \mathrm{yr})\end{array}$ & $\begin{array}{c}\text { SSE: } \\
\mathrm{N}(\mathrm{mm} / \mathrm{yr})\end{array}$ & $\begin{array}{c}\text { Inter SSE: } \\
\mathrm{E}(\mathrm{mm} / \mathrm{yr})\end{array}$ & $\begin{array}{c}\text { Inter SSE: } \\
\mathrm{N}(\mathrm{mm} / \mathrm{yr})\end{array}$ \\
\hline PNUI & 176.20 & -39.92 & -6.21 & 29.93 & -15.00 & 28.91 \\
PORA & 176.64 & -40.27 & -16.46 & 24.71 & -19.89 & 26.75 \\
PTOI & 176.00 & -40.60 & -23.21 & 29.02 & -24.86 & 29.02 \\
RDLV & 175.40 & -41.19 & -29.97 & 29.71 & -29.97 & 29.71 \\
TAKP & 175.96 & -40.06 & -8.61 & 31.24 & -15.99 & 31.97 \\
TEMA & 175.89 & -41.11 & -28.73 & 28.29 & -28.73 & 28.29 \\
TINT & 175.89 & -40.78 & -24.60 & 29.38 & -25.95 & 30.15 \\
TKHL & 172.96 & -41.03 & -4.78 & 42.12 & -4.78 & 42.12 \\
TORY & 174.28 & -41.19 & -11.39 & 39.31 & -15.80 & 39.31 \\
TRAV & 175.69 & -41.40 & -34.02 & 30.04 & -34.02 & 30.04 \\
TRWH & 174.63 & -41.28 & -23.47 & 35.99 & -23.14 & 37.23 \\
TURI & 176.38 & -40.26 & -14.49 & 27.96 & -19.82 & 28.58 \\
WANG & 174.82 & -39.79 & -1.97 & 38.73 & -6.24 & 40.73 \\
WEST & 171.81 & -41.74 & -2.37 & 42.30 & -2.59 & 42.30 \\
WGTN & 174.81 & -41.32 & -23.98 & 33.73 & -24.75 & 33.69 \\
WHVR & 175.45 & -39.73 & -1.50 & 39.24 & -7.70 & 44.60 \\
WITH & 173.98 & -41.56 & -17.52 & 37.12 & -17.52 & 37.60 \\
WPAW & 176.54 & -39.90 & -9.45 & 27.67 & -20.26 & 28.36 \\
WPUK & 176.44 & -40.06 & -11.50 & 28.00 & -18.14 & 31.28 \\
& & & & & &
\end{tabular}

Table 11.4: cGPS station velocities including and excluding SSEs in an Australian plate Reference Frame

\begin{tabular}{ccccccc}
\hline Station & Longitude & Latitude & $\begin{array}{c}\text { SSE } \\
\mathrm{E}(\mathrm{mm} / \mathrm{yr})\end{array}$ & $\begin{array}{c}\text { SSE } \\
\mathrm{N}(\mathrm{mm} / \mathrm{yr})\end{array}$ & $\begin{array}{c}\text { Inter SSE } \\
\mathrm{E}(\mathrm{mm} / \mathrm{yr})\end{array}$ & $\begin{array}{c}\text { Inter SSE } \\
\mathrm{N}(\mathrm{mm} / \mathrm{yr})\end{array}$ \\
\hline AKTO & 176.46 & -40.54 & -26.71 & -12.07 & -24.81 & -12.07 \\
AVLN & 174.93 & -41.20 & -21.45 & -6.78 & -24.81 & -6.42 \\
BIRF & 176.25 & -40.68 & -25.64 & -10.16 & -27.98 & -10.16 \\
BTHL & 175.14 & -41.34 & -30.67 & -9.37 & -30.67 & -9.37 \\
CAST & 176.20 & -40.91 & -27.51 & -10.05 & -28.57 & -10.30 \\
CLIM & 175.15 & -41.14 & -23.63 & -8.41 & -25.97 & -8.41 \\
CMBL & 174.21 & -41.75 & -23.91 & -8.46 & -23.91 & -8.46 \\
DNVK & 176.17 & -40.30 & -15.51 & -10.84 & -18.22 & -8.03 \\
DURV & 173.92 & -40.80 & -5.89 & -0.46 & -10.31 & -0.46 \\
GLDB & 172.53 & -40.83 & -2.51 & 0.41 & -3.79 & 0.41 \\
GNBK & 175.24 & -40.08 & -4.62 & -5.60 & -11.70 & -5.60 \\
GRNG & 175.46 & -39.98 & -5.02 & -6.05 & -12.03 & -6.05 \\
HOKI & 170.98 & -42.71 & -3.83 & 0.18 & -4.19 & 1.17
\end{tabular}


Table 11.4 continued from previous page

\begin{tabular}{|c|c|c|c|c|c|c|}
\hline Station & Longitude & Latitude & $\begin{array}{c}\text { SSE } \\
\mathrm{E}(\mathrm{mm} / \mathrm{yr})\end{array}$ & $\begin{array}{c}\text { SSE } \\
\mathrm{N}(\mathrm{mm} / \mathrm{yr})\end{array}$ & $\begin{array}{c}\text { Inter SSE } \\
\mathrm{E}(\mathrm{mm} / \mathrm{yr})\end{array}$ & $\begin{array}{l}\text { Inter SSE } \\
\mathrm{N}(\mathrm{mm} / \mathrm{yr})\end{array}$ \\
\hline HOLD & 175.52 & -40.90 & -24.08 & -9.88 & -23.49 & -9.88 \\
\hline KAIK & 173.53 & -42.43 & -28.42 & -9.91 & -28.42 & -9.91 \\
\hline KAPT & 174.91 & -40.86 & -12.38 & -2.35 & -18.04 & -3.95 \\
\hline KORO & 175.42 & -40.41 & -10.30 & -6.85 & -15.63 & -6.85 \\
\hline LKTA & 172.27 & -42.78 & -21.94 & -9.56 & -22.23 & -9.56 \\
\hline LEVN & 175.24 & -40.59 & -10.02 & -6.62 & -18.30 & -6.62 \\
\hline MAHA & 173.79 & -41.29 & -3.39 & -1.14 & -14.01 & -2.93 \\
\hline MANG & 175.57 & -40.67 & -18.15 & -7.32 & -23.00 & -7.32 \\
\hline MAST & 175.58 & -41.06 & -26.76 & -10.45 & -26.76 & -10.45 \\
\hline MNHR & 176.22 & -40.47 & -18.97 & -11.71 & -23.71 & -10.36 \\
\hline MTBL & 175.54 & -40.18 & -7.05 & -3.22 & -15.59 & -7.89 \\
\hline MTQN & 175.24 & -41.00 & -18.37 & -7.61 & -24.02 & -6.88 \\
\hline NLSN & 173.43 & -41.18 & -5.38 & -0.82 & -9.32 & -0.38 \\
\hline NRRD & 175.76 & -40.39 & -12.03 & -7.65 & -22.18 & -7.47 \\
\hline NRSW & 176.20 & -40.11 & -8.86 & -8.00 & -17.37 & -6.14 \\
\hline OHIN & 175.79 & -39.92 & -3.98 & -5.47 & -14.20 & -9.78 \\
\hline $\mathrm{OKOH}$ & 174.06 & -41.02 & -6.56 & 4.21 & -13.31 & -1.93 \\
\hline OROA & 176.68 & -40.10 & -13.00 & -12.74 & -16.98 & -11.50 \\
\hline OTAK & 175.17 & -40.82 & -14.79 & -4.45 & -21.94 & -6.06 \\
\hline PAEK & 174.95 & -41.02 & -17.35 & -4.83 & -21.51 & -5.64 \\
\hline PALI & 175.25 & -41.57 & -34.03 & -9.57 & -33.41 & -9.57 \\
\hline PARW & 175.43 & -41.38 & -32.94 & -9.40 & -32.94 & -9.40 \\
\hline PAWA & 176.86 & -40.03 & -7.08 & -15.74 & -23.07 & -13.73 \\
\hline PKNO & 175.18 & -39.80 & -3.16 & -1.63 & -9.70 & -2.87 \\
\hline PNUI & 176.20 & -39.92 & -6.65 & -9.61 & -15.45 & -10.63 \\
\hline PORA & 176.64 & -40.27 & -16.36 & -14.49 & -19.79 & -12.45 \\
\hline PTOI & 176.00 & -40.60 & -23.06 & -10.68 & -24.70 & -10.68 \\
\hline RDLV & 175.40 & -41.19 & -29.49 & -10.44 & -29.49 & -10.44 \\
\hline TAKP & 175.96 & -40.06 & -9.02 & -8.48 & -16.39 & -7.75 \\
\hline TEMA & 175.89 & -41.11 & -28.11 & -11.49 & -28.11 & -11.49 \\
\hline TINT & 175.89 & -40.78 & -24.32 & -10.40 & -25.67 & -9.63 \\
\hline TKHL & 172.96 & -41.03 & -5.61 & 0.14 & -5.61 & 0.14 \\
\hline TORY & 174.28 & -41.19 & -11.43 & -1.69 & -15.85 & -1.69 \\
\hline TRAV & 175.69 & -41.40 & -33.20 & -9.89 & -33.20 & -9.89 \\
\hline TRWH & 174.63 & -41.28 & -23.27 & -4.75 & -22.94 & -3.51 \\
\hline TURI & 176.38 & -40.26 & -14.50 & -11.44 & -19.83 & -10.82 \\
\hline WANG & 174.82 & -39.79 & -3.16 & -1.87 & -7.43 & 0.14 \\
\hline
\end{tabular}


Table 11.4 continued from previous page

\begin{tabular}{ccccccc}
\hline Station & Longitude & Latitude & $\begin{array}{c}\text { SSE } \\
\mathrm{E}(\mathrm{mm} / \mathrm{yr})\end{array}$ & $\begin{array}{c}\text { SSE } \\
\mathrm{N}(\mathrm{mm} / \mathrm{yr})\end{array}$ & $\begin{array}{c}\text { Inter SSE } \\
\mathrm{E}(\mathrm{mm} / \mathrm{yr})\end{array}$ & $\begin{array}{c}\text { Inter SSE } \\
\mathrm{N}(\mathrm{mm} / \mathrm{yr})\end{array}$ \\
\hline WEST & 171.81 & -41.74 & -3.07 & -0.51 & -3.29 & -0.51 \\
WGTN & 174.81 & -41.32 & -23.65 & -6.88 & -24.41 & -6.92 \\
WHVR & 175.45 & -39.73 & -2.46 & -0.88 & -8.67 & 4.49 \\
WITH & 173.98 & -41.56 & -17.34 & -4.10 & -17.34 & -3.63 \\
WPAW & 176.54 & -39.90 & -9.77 & -11.61 & -20.57 & -10.91 \\
WPUK & 176.44 & -40.06 & -11.69 & -11.36 & -18.33 & -8.07
\end{tabular}

Table 11.5: cGPS station co-seismic velocities in response to the KaiKoura $\mathrm{M}_{w} 7.8$ earthquake

\begin{tabular}{|c|c|c|c|c|c|c|}
\hline Station & Longitude & Latitude & Delta E & Delta N & $\mathrm{E}(\mathrm{mm} / \mathrm{yr})$ & $\mathrm{N}(\mathrm{mm} / \mathrm{yr})$ \\
\hline AKTO & 176.46 & -40.54 & 4.470 & 2.310 & 407.89 & 210.79 \\
\hline AVLN & 174.93 & -41.20 & 1.830 & 51.180 & 166.99 & 4670.18 \\
\hline BIRF & 176.25 & -40.68 & -5.140 & 2.480 & -469.03 & 226.30 \\
\hline BTHL & 175.14 & -41.34 & -16.820 & 39.120 & -1534.83 & 3569.70 \\
\hline CAST & 176.20 & -40.91 & -2.440 & 0.660 & -222.65 & 60.23 \\
\hline CLIM & 175.15 & -41.14 & -8.310 & 34.840 & -758.29 & 3179.15 \\
\hline CMBL & 174.21 & -41.75 & 1403.710 & 2397.560 & 128088.54 & 218777.35 \\
\hline DNVK & 176.17 & -40.30 & 0.740 & 4.050 & 67.53 & 369.56 \\
\hline DURV & 173.92 & -40.80 & 16.390 & 57.760 & 1495.59 & 5270.60 \\
\hline GLDB & 172.53 & -40.83 & 33.120 & -16.480 & 3022.20 & -1503.80 \\
\hline GNBK & 175.24 & -40.08 & 4.390 & 17.500 & 400.59 & 1596.88 \\
\hline GRNG & 175.46 & -39.98 & 3.180 & 9.780 & 290.18 & 892.43 \\
\hline HOKI & 170.98 & -42.71 & 31.410 & -5.470 & 2866.16 & -499.14 \\
\hline HOLD & 175.52 & -40.90 & -8.310 & 15.910 & -758.29 & 1451.79 \\
\hline KAIK & 173.53 & -42.43 & 858.510 & 287.420 & 78339.04 & 26227.08 \\
\hline KAPT & 174.91 & -40.86 & 12.340 & 42.590 & 1126.03 & 3886.34 \\
\hline KORO & 175.42 & -40.41 & 2.590 & 15.010 & 236.34 & 1369.66 \\
\hline LKTA & 172.27 & -42.78 & 77.010 & -0.950 & 7027.16 & -86.69 \\
\hline LEVN & 175.24 & -40.59 & 6.000 & 21.500 & 547.50 & 1961.88 \\
\hline MAHA & 173.79 & -41.29 & 39.890 & 166.090 & 3639.96 & 15155.71 \\
\hline MANG & 175.57 & -40.67 & 6.450 & 17.400 & 588.56 & 1587.75 \\
\hline MNHR & 176.22 & -40.47 & -9.980 & 9.230 & -910.68 & 842.24 \\
\hline MTBL & 175.54 & -40.18 & 2.320 & 12.030 & 211.70 & 1097.74 \\
\hline MTQN & 175.24 & -41.00 & -8.080 & 30.860 & -737.30 & 2815.98 \\
\hline NLSN & 173.43 & -41.18 & 45.680 & 15.660 & 4168.30 & 1428.98 \\
\hline NRSW & 176.20 & -40.11 & -11.020 & 15.190 & -1005.58 & 1386.09 \\
\hline OHIN & 175.79 & -39.92 & 3.870 & 9.400 & 353.14 & 857.75 \\
\hline
\end{tabular}


Table 11.5 continued from previous page

\begin{tabular}{ccccccc}
\hline Station & Longitude & Latitude & Delta E & Delta $\mathrm{N}$ & $\mathrm{E}(\mathrm{mm} / \mathrm{yr})$ & $\mathrm{N}(\mathrm{mm} / \mathrm{yr})$ \\
\hline OKOH & 174.06 & -41.02 & 17.400 & 121.140 & 1587.75 & 11054.03 \\
OROA & 176.68 & -40.10 & -3.900 & 2.340 & -355.88 & 213.53 \\
OTAK & 175.17 & -40.82 & 4.690 & 30.690 & 427.96 & 2800.46 \\
PAEK & 174.95 & -41.02 & 7.340 & 46.790 & 669.78 & 4269.59 \\
PALI & 175.25 & -41.57 & -47.710 & 15.580 & -4353.54 & 1421.68 \\
PARW & 175.43 & -41.38 & -30.130 & 13.360 & -2749.36 & 1219.10 \\
PAWA & 176.86 & -40.03 & -2.480 & 5.050 & -226.30 & 460.81 \\
PKNO & 175.18 & -39.80 & 6.620 & 11.940 & 604.08 & 1089.53 \\
PNUI & 176.20 & -39.92 & -3.920 & 7.270 & -357.70 & 663.39 \\
PORA & 176.64 & -40.27 & 1.990 & 4.890 & 181.59 & 446.21 \\
PTOI & 176.00 & -40.60 & -0.700 & 6.060 & -63.88 & 552.98 \\
RDLV & 175.40 & -41.19 & -28.140 & 21.980 & -2567.78 & 2005.68 \\
TAKP & 175.96 & -40.06 & -4.370 & 11.500 & -398.76 & 1049.38 \\
TEMA & 175.89 & -41.11 & -17.320 & 10.620 & -1580.45 & 969.08 \\
TINT & 175.89 & -40.78 & -6.540 & 10.300 & -596.78 & 939.88 \\
TORY & 174.28 & -41.19 & 51.700 & 173.120 & 4717.63 & 15797.20 \\
TRAV & 175.69 & -41.40 & -27.980 & 6.670 & -2553.18 & 608.64 \\
TRWH & 174.63 & -41.28 & 21.040 & 104.760 & 1919.90 & 9559.35 \\
TURI & 176.38 & -40.26 & -5.440 & 6.510 & -496.40 & 594.04 \\
WANG & 174.82 & -39.79 & 5.090 & 16.010 & 464.46 & 1460.91 \\
WEST & 171.81 & -41.74 & 102.920 & -41.720 & 9391.45 & -3806.95 \\
WGTN & 174.81 & -41.32 & 0.230 & 70.140 & 20.99 & 6400.28 \\
WHVR & 175.45 & -39.73 & -0.620 & 9.250 & -56.58 & 844.06 \\
WITH & 173.98 & -41.56 & 259.910 & 879.100 & 23716.79 & 80217.88 \\
WPAW & 176.54 & -39.90 & -3.020 & 5.330 & -275.58 & 486.36 \\
WPUK & 176.44 & -40.06 & -5.320 & 6.130 & -485.45 & 559.36 \\
& & & & & &
\end{tabular}

